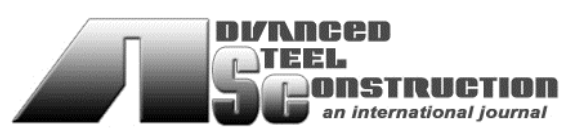

ISSN 1816-112X

Science Citation Index Expanded, Materials Science Citation Index and ISI Alerting

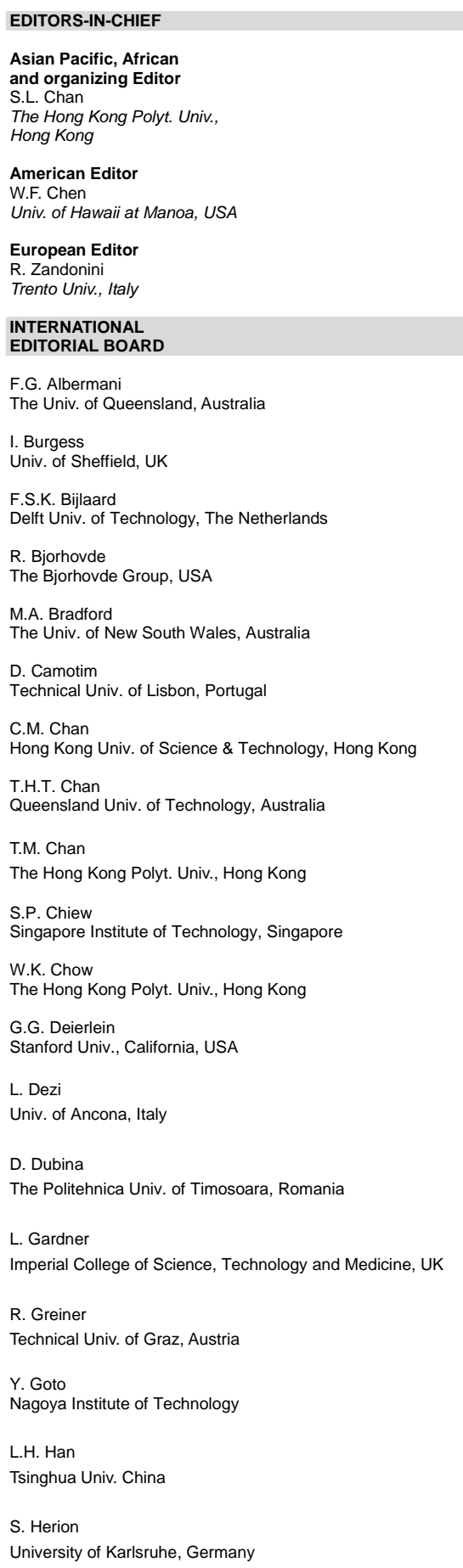

University of Karlsruhe, Germany

\section{Advanced Steel Construction an international journal}

\begin{tabular}{|c|c|}
\hline G.W.M. Ho & P. Schaumann \\
\hline Ove Arup \& Partners Hong Kong Ltd., Hong Kong & Univ. of Hannover, Germany \\
\hline B.A. Izzuddin & Y.J. Shi \\
\hline $\begin{array}{l}\text { Imperial College of Science, Technology and } \\
\text { Medicine, UK }\end{array}$ & Tsinghua Univ., China \\
\hline $\begin{array}{l}\text { J.P. Jaspart } \\
\text { Univ. of Liege, Belgium }\end{array}$ & $\begin{array}{l}\text { G.P. Shu } \\
\text { Southeast Univ. China }\end{array}$ \\
\hline $\begin{array}{l}\text { S. A. Jayachandran } \\
\text { IIT Madras, Chennai, India }\end{array}$ & $\begin{array}{l}\text { L. Simões da Silva } \\
\text { Department of Civil Engineering, University of } \\
\text { Coimbra, Portugal }\end{array}$ \\
\hline S.E. Kim & J.G. Teng \\
\hline Sejong Univ., South Korea & The Hong Kong Polyt. Univ., Hong Kong \\
\hline S. Kitipornchai & G.S. Tong \\
\hline The Univ., of Queensland, Australia & Zhejiang Univ., China \\
\hline D. Lam & K.C. Tsai \\
\hline Univ. of Bradford, UK & National Taiwan Univ., Taiwan \\
\hline G.Q. Li & C.M. Uang \\
\hline Tongji Univ., China & Univ. of California, USA \\
\hline J.Y.R. Liew & B. Uy \\
\hline National Univ. of Singapore, Singapore & The University of New South Wales, Australia \\
\hline Y.P. Liu & M. Veljkovic \\
\hline The Hong Kong Polyt. Univ., Hong Kong & Univ. of Lulea, Sweden \\
\hline $\begin{array}{l}\text { S.W. Liu } \\
\text { NIDA EUROPE Ltd., UK }\end{array}$ & $\begin{array}{l}\text { F. Wald } \\
\text { Czech Technical Univ. in Prague, Czech }\end{array}$ \\
\hline $\begin{array}{l}\text { E.M. Lui } \\
\text { Syracuse Univ., USA }\end{array}$ & $\begin{array}{l}\text { Y.C. Wang } \\
\text { The Univ. of Manchester, UK }\end{array}$ \\
\hline Y.L. Mo & Y.L. Xu \\
\hline Univ. of Houston, USA & The Hong Kong Polyt. Univ., Hong Kong \\
\hline J.P. Muzeau & D. White \\
\hline CUST, Clermont Ferrand, France & Georgia Institute of Technology, USA \\
\hline $\begin{array}{l}\text { D.A. Nethercot } \\
\text { Imperial College of Science, Technology and } \\
\text { Medicine, UK }\end{array}$ & $\begin{array}{l}\text { E. Yamaguchi } \\
\text { Kyushu Institute of Technology, Japan }\end{array}$ \\
\hline $\begin{array}{l}\text { Y.Q. Ni } \\
\text { The Hong Kong Polyt. Univ., Hong Kong }\end{array}$ & $\begin{array}{l}\text { Y.B. Yang } \\
\text { National Taiwan Univ., Taiwan }\end{array}$ \\
\hline $\begin{array}{l}\text { D.J. Oehlers } \\
\text { The Univ. of Adelaide, Australia }\end{array}$ & $\begin{array}{l}\text { Y.Y. Yang } \\
\text { China Academy of Building Research, Beijing, China } \\
\text { B. Young }\end{array}$ \\
\hline $\begin{array}{l}\text { J.L. Peng } \\
\text { Yunlin Uni. of Science \& Technology, Taiwan }\end{array}$ & $\begin{array}{l}\text { The Univ. of Hong Kong, Hong Kong } \\
\text { X.L. Zhao }\end{array}$ \\
\hline K. Rasmussen & Monash Univ., Australia \\
\hline $\begin{array}{l}\text { The Univ. of Sydney, Australia } \\
\text { J.M. Rotter }\end{array}$ & $\begin{array}{l}\text { X H Zhou, } \\
\text { Chongqing University, China }\end{array}$ \\
\hline The Univ. of Edinburgh, UK & $\begin{array}{l}\text { Z.H. Zhou } \\
\text { Alpha Consultant Ltd., Hong Kong }\end{array}$ \\
\hline $\begin{array}{l}\text { C. Scawthorn } \\
\text { Scawthorn Porter Associates, USA }\end{array}$ & \begin{tabular}{|l} 
R.D. Ziemian \\
Bucknell University, USA
\end{tabular} \\
\hline
\end{tabular}

Cover: 1000ton+ temporary steel platform in support of heavy-duty mobile cranes, designed by second-order direct analysis without effective length

e-copy of IJASC is free to download at "www.ascjournal.com" in internet and mobile apps. 



\section{General Information}

\section{Advanced Steel Construction, an international journal}

\section{Aims and scope}

The International Journal of Advanced Steel Construction provides a platform for the publication and rapid dissemination of original and up-to-date research and technological developments in steel construction, design and analysis. Scope of research papers published in this journal includes but is not limited to theoretical and experimental research on elements, assemblages, systems, material, design philosophy and codification, standards, fabrication, projects of innovative nature and computer techniques. The journal is specifically tailored to channel the exchange of technological know-how between researchers and practitioners. Contributions from all aspects related to the recent developments of advanced steel construction are welcome.

Instructions to authors

Submission of the manuscript. Authors may submit on-line at www.hkisc.org

Asian Pacific , African and organizing editor : Professor S.L. Chan, Email: ceslchan@polyu.edu.hk

American editor :

European editor:

Professor W.F. Chen, Email: waifah@hawaii.edu

Professor R. Zandonini, Email: riccardo_zandonini@ing.unitn.it

All manuscripts submitted to the journal are recommended to accompany with a list of four potential reviewers suggested by the author(s). This list should include the complete name, address, telephone and fax numbers, email address, and at least five keywords that identify the expertise of each reviewer. This scheme will improve the process of review.

Style of manuscript

General. Author(s) should provide full postal and email addresses and fax number for correspondence. The manuscript including abstract, keywords, references, figures and tables should be in English with pages numbered and typed with double line spacing on single side of A4 or letter-sized paper. The front page of the article should contain:

a) a short title (reflecting the content of the paper);

b) all the name(s) and postal and email addresses of author(s) specifying the author to whom correspondence and proofs should be sent;

c) an abstract of 100-200 words; and

d) 5 to 8 keywords.

The paper must contain an introduction and a conclusion. The length of paper should not exceed 25 journal pages (approximately 15,000 words equivalents).

Tables and figures. Tables and figures including photographs should be typed, numbered consecutively in Arabic numerals and with short titles. They should be referred in the text as Figure 1, Table 2, etc. Originally drawn figures and photographs should be provided in a form suitable for photographic reproduction and reduction in the journal.

Mathematical expressions and units. The Systeme Internationale $(\mathrm{SI})$ should be followed whenever possible. The numbers identifying the displayed mathematical expression should be referred to in the text as Eq. 1, Eq. 2.

References. References to published literature should be referred in the text, in the order of citation with Arabic numerals, by the last name(s) of the author(s) (e.g. Zandonini and Zanon [3]) or if more than three authors (e.g. Zandonini et al. [4]). References should be in English with occasional allowance of 1-2 exceptional references in local languages and reflect the current state-of-technology. Journal titles should be abbreviated in the style of the Word List of Scientific Periodicals. References should be cited in the following style $[1,2,3]$.

Journal: [1] Chen, W.F. and Kishi, N., "Semi-rigid Steel Beam-to-column Connections, Data Base and Modelling", Journal of Structural Engineering, ASCE, 1989, Vol. 115, No. 1, pp. 105-119.

Book: [2] Chan, S.L. and Chui, P.P.T., "Non-linear Static and Cyclic Analysis of Semi-rigid Steel Frames", Elsevier Science, 2000

Proceedings: [3] Zandonini, R. and Zanon, P., "Experimental Analysis of Steel Beams with Semi-rigid Joints", Proceedings of International Conference on Advances in Steel Structures, Hong Kong, 1996, Vol. 1, pp. 356-364.

Proofs. Proof will be sent to the corresponding author to correct any typesetting errors. Alternations to the original manuscript at this stage will not be accepted. Proofs should be returned within 48 hours of receipt on-line.

Copyright. Submission of an article to "Advanced Steel Construction" implies that it presents the original and unpublished work, and not under consideration for publication nor published elsewhere. On acceptance of a manuscript submitted, the copyright thereof is transferred to the publisher by the Transfer of Copyright Agreement and upon the acceptance of publication for the papers, the corresponding author must sign the form for Transfer of Copyright.

Permission. Quoting from this journal is granted provided that the customary acknowledgement is given to the source.

Page charge and Reprints. There will be no page charges if the length of paper is within the limit of 25 journal pages. A total of 30 free offprints will be supplied free of charge to the corresponding author. Purchasing orders for additional offprints can be made on order forms which will be sent to the authors. These instructions can be obtained at the Hong Kong Institute of Steel Construction, Journal website: http://www.hkisc.org

The International Journal of Advanced Steel Construction is published quarterly by learnt society, The Hong Kong Institute of Steel Construction, c/o Department of Civil \& Environmental Engineering, The Hong Kong Polytechnic University, Hung Hom, Kowloon, Hong Kong.

Disclaimer. No responsibility is assumed for any injury and / or damage to persons or property as a matter of products liability, negligence or otherwise, or from any use or operation of any methods, products, instructions or ideas contained in the material herein.

Subscription inquiries and change of address. Address all subscription inquiries and correspondence to Member Records, IJASC. Notify an address change as soon as possible. All communications should include both old and new addresses with zip codes and be accompanied by a mailing label from a recent issue. Allow six weeks for all changes to become effective.

The Hong Kong Institute of Steel Construction

HKISC

c/o Department of Civil and Environmental Engineering,

The Hong Kong Polytechnic University,

Hunghom, Kowloon, Hong Kong, China.

Tel: 852- 27666047 Fax: 852- 23346389

Email: ces/chan@polyu.edu.hk Website: http://www.hkisc.org/

ISSN 1816-112X

Science Citation Index Expanded, Materials Science Citation Index and ISI Alerting

Copyright $\odot 2016$ by:

The Hong Kong Institute of Steel Construction. 



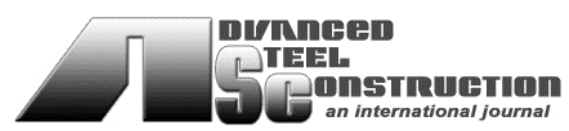

ISSN 1816-112X

Science Citation Index Expanded, Materials Science Citation Index and ISI Alerting

\section{EDITORS-IN-CHIEF}

\section{Asian Pacific, African} and organizing Editor

S.L. Chan

The Hong Kong Polyt. Univ., Hong Kong

Email: ces/chan@polyu.edu.hk

\section{American Editor}

W.F. Chen

Univ. of Hawaii at Manoa, USA

Email: waifah@hawaii.edu

\section{European Editor}

R. Zandonini

Trento Univ., Italy

Email: riccardo.zandonini@ing.unitn.it

\section{Advanced Steel Construction an international journal}

VOLUME 12 NUMBER 4 DECEMBER 2016

Technical Papers

Safety Analysis of Steel Box Girder Bridges with Pitting

Corrosion

Yasser Sharifi and Jeom Kee Paik

Reflector Wind Load Characteristics of the Large All-Movable Antenna and Its Effect on Reflector Surface Precision

Yan Liu, Hong-liang Qian and Feng Fan

Performance of Steel-Reinforced Square Concrete-Filled Steel Hollow Section (SRSCFSHS) Columns under Uniaxial

Compression

Jing-ming Cai, Jin-long Pan and Yu-fei Wu

Tubular Steel Poles under Lateral Load Patterns

Edgar Tapia-Hernández

A Performance Study of Beam Column Connections of Self-Centering Steel Frame with U-Shaped Steel Dampers Yanxia Zhang, Zhenxing Li, Wenzhan Zhao, Rui Li and Jiarui Li

Generalised Element Load Method with Whole Domain Accuracy 466 for Reliable Structural Design

Chi-Kin Iu

Experimental Study and Finite Element Modelling of Push-out 487 Tests on a New Shear Connector of I-shape

Messaoud Titoum, Aida Mazoz, Abdelkader Benanane and Djamel Ouinas

Announcement by IJASC :

Announcement for ICTWS'18 



\title{
SAFETY ANALYSIS OF STEEL BOX GIRDER BRIDGES WITH PITTING CORROSION
}

\author{
Yasser Sharifi ${ }^{1, *}$ and Jeom Kee Paik ${ }^{2}$ \\ ${ }^{I}$ Department of Civil Engineering, Vali-e-Asr University of Rafsanjan, Rafsanjan, Iran \\ ${ }^{2}$ LRET Research Centre of Excellence, Pusan National University, Busan, Korea \\ *(Corresponding author: E-mail: yasser_sharifi@yahoo.comory.sharifi@vru.ac.ir or)
}

Received: 18 February 2015; Revised: 10 December 2015; Accepted: 5 January 2016

\begin{abstract}
Steel bridges corrode due to environmental exposure. The consequence is a reduction in both the load-carrying capacity and safety of a bridge. Therefore, it is needed to evaluate procedures for an exact prediction of the load-carrying capacity and reliability of bridges, in order to make reasonable decisions about repair, rehabilitation and renewal. The aim of this study is to develop and demonstrate a procedure for the assessment of steel box girder bridge ultimate strength reliability that takes the degradation of plate members due to pit corrosion into account. The present paper treats the effect of pitting corrosion on the load-carrying capacity and reliability of steel box girder bridges and the results are compared with the uniform corrosion effect. The procedure and results of this study can be used for the better prediction of the service life of deteriorating steel box girder bridges and the development of optimal reliability-based maintenance strategies.
\end{abstract}

Keywords: Bridges, pitting corrosion, reliability analysis, probabilistic model, steel box girders

DOI:10.18057/IJASC.2016.12.4.1

\section{INTRODUCTION}

Bridges are important to everyone. The majority of steel bridges in the United States were constructed after World War II from 1950 to 1980. Therefore, bridges are aging and their probabilities of failure are increasing. Bridge elements deteriorate with time due to corrosion, wear, fatigue and other forms of material degradation. Moreover, lately, the legal load on bridges has increased and the problem is that the majority of the old bridges fail to satisfy this requirement. In addition, the maintenances cost of a bridge is of great importance. Deficient bridges are either repaired, or replaced. The efficient maintenance, repair and rehabilitation of existing bridges require the development of a methodology that allows for the accurate evaluation of load-carrying capacity and the prediction of remaining life. Corrosion is one of the most important causes of deterioration in steel bridges (Cheung and Li [1]; Czarnecki and Nowak [2]; Melchers [3]; Melchers and Jeffrey [4]; Sharifi [5]; Sharifi and Paik [6-8]; Sharifi and Tohidi [9,10]; Tohidi and Sharifi [11-14]).

Many of the factors that determine the performance of deteriorating structures are characterized by a high degree of uncertainty. Probability and statistics provide a framework for dealing with such uncertainty. As the methods and concepts of structural reliability developed over the last few decades, they have become increasingly better understood and approved by engineers. At present, reliability can be considered as a rational evaluation criterion for bridge performance. The reliability methods allow for consideration of uncertainties associated with material properties, geometry and dimensions, loads, and environmental conditions, and they can be used for a better estimation of the failure probability (Melchers [3]; Melchers and Jeffrey [4]; Sarveswaran and Roberts [15]; Sommer et al. [16]).

Probabilistic models make it possible to establish a reliability time profile for a bridge. The engineer then has to decide the point at which the structure becomes unsafe. To do so, he or she 
must first establish a reliability index that can be used as the acceptable level below which the structure is considered to be unsafe. Maybe system models are accurate for reliability analysis of the strength failure of bridges (Sarveswaran and Roberts [15]). However, because the rehabilitation and repair of the bending or shear failure of a steel bridge are not usually required because of structure collapse, but rather because of local limit state failure, element-level reliability analysis may be more suitable than system-level reliability analysis in cases of the ultimate strength of steel or concrete bridges. Since the flexural failure is one of the most important of failure mode for steel girder bridges, the ultimate moment resistance has been considered in this paper. Time-dependent reliability analyses such as those by Mori and Ellingwood [17], Thoft-Christensen [18], Enright and Frangopol [19] and others can be used as decision-making tools, or provide additional information on which to base inspection, maintenance and repair strategies.

The results of this study will be useful for practicing engineers who need to employ reliability analysis in practical applications. The example presented herein demonstrates the procedures that are required to calculate the latest time to repair intervention for a number of deteriorating steel box beams that support a bridge. The viewpoint adopted is that of the practicing engineer. Employing a bridge-specific deterioration model, this study highlights the problems associated with determining the latest such intervention for a sample bridge substructure. The experience gained and the difficulties faced by practicing engineers when using this method of analysis are also discussed.

\section{CORROSION MECHANICS}

Deterioration due to corrosion is considered in this study. To predict likely corrosion damage tolerance a priori, it is necessary to estimate the corrosion rate for each type of structural member. Theoretical predictions of these corrosion rates have been attempted, but they represent a difficult task. An easier alternative is to base the rate prediction on the statistical analysis of past data for comparable situations. There are four corrosion-related questions that ideally need to be answered for the structural components in a space:

1. Where is corrosion likely to occur?

2. When will it start?

3. What is its likely extent?

4. What are the likely corrosion rates?

The first question can usually be answered through some form of historical data, e.g., the results of previous surveys. Similarly, the information required to answer the second question can be gleaned from prior surveys of the given structure. Assumptions as to the start of the corrosion can of course be made, depending on the use of a protection system, the characteristics of the coating and the anode residence time. The extent of the corrosion will presumably increase with time, although our ability to predict corrosion progress remains very limited. Thus, the only real alternative for answering the third question is to pessimistically assumes a greater corrosion extent than is really likely, which is how nominal design corrosion values are usually arrived at (Paik et al. [20]). A potential damage due to corrosion is an important consideration in the design of steel bridges. The corrosion effects can vary from nonstructural maintenance problems to a local failure or an overall collapse. Four major categories of corrosion effects are identified: loss of section, creation of stress concentration, introduction of unintended fixity and introduction of unintended movement (Czarnecki and Nowak [2]). The most common is loss of material. The loss of material can be either uniform, when corrosion affects large areas of a bridge component, or localized in a form of pits. Likewise, the loss of section of some components may have little or even no effect on the overall capacity of a bridge, whereas deterioration of other members can have a significant effect. Therefore, it is very important to make a distinction between a localized corrosion, related to the 
behavior of a member and deterioration of a component that affects the structural performance of the whole bridge. The loss of material can result in a smaller net cross-section and it may lead to a reduction of fracture and buckling resistances of a member (Kayser [21]). This study addresses the most common types of corrosion that cause a reduction in strength, and develops a probabilistic rate model.

\subsection{Corrosion Damage Idealization}

(a)

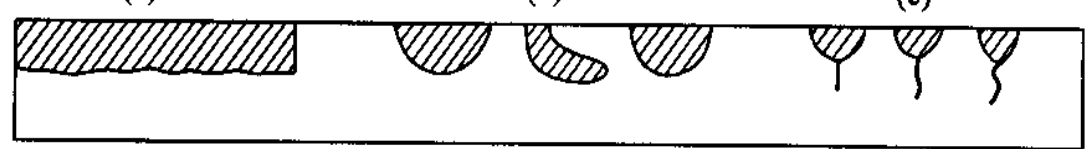

Figure. 1. Typical Modes of Corrosion Damage: (A) General (Uniform) Corrosion; (B) Localized Corrosion; (C) Fatigue Cracks Arising from Localized Corrosion

Figure 1 shows some of the more common types of corrosion-related damage that affect the strength of steel structures to a greater extent than other types. General corrosion (also called uniform corrosion) uniformly reduces the thickness of structural members, as shown in Figure 1(a), whereas localized corrosion (e.g., pitting or grooving) causes degradation in local regions, as shown in Figure 1(b). Fatigue cracks may sometimes arise from localized corrosion, as shown in Figure 1(c). In the present study, two types of corrosion damage idealization are considered, namely, general and pit corrosion. For the former, it is assumed that the thickness of the entire plate is uniformly reduced by the corrosion. The latter, in contrast, is assumed to reduce the plate thickness in localized regions. To assess the scale of breakdown due to pit corrosion, a parameter denoted DOP (degree of pit corrosion intensity) is often used, where DOP is defined as the ratio percentage of the corroded surface area to the original plate surface area, namely (Paik et al. [22, 23]),

$D O P=\frac{1}{a b} \sum_{i=1}^{n} A_{p i} \times 100(\%)$,

where $n$ is the number of pits, $A_{p i}$ is the surface area of the $i t h$ pit, $a$ is the plate length, and $b$ is the plate breadth.

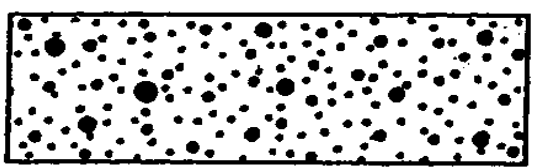

(a) $10 \% \mathrm{DOP}$

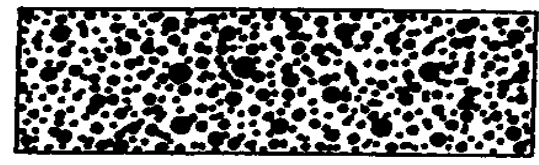

(c) $30 \%$ DOP

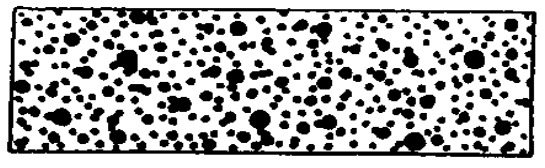

(b) $20 \%$ DOP

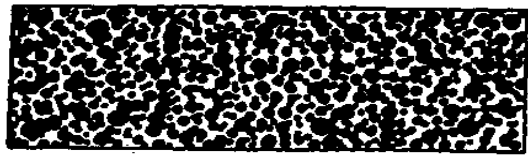

(d) $50 \%$ DOP

Figure. 2. Pitting Intensity Diagrams (Paik et al. $[22,23])(D O P=$ Degree of Pit Corrosion Intensity as a Ratio of the Pitted Surface Area to the Original Plate Surface Area):

(A) $10 \%$ DOP; (B) $20 \%$ DOP; (C) $30 \%$ DOP; (D) $50 \%$ DOP 


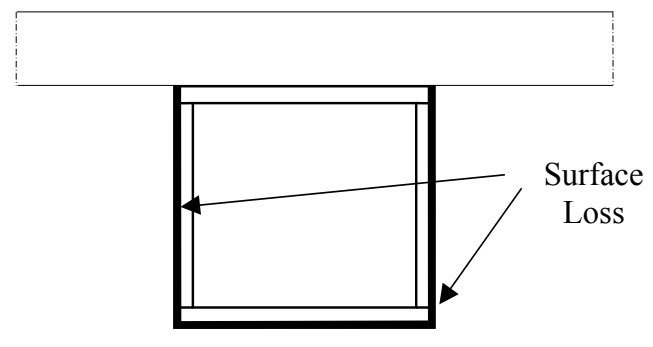

Figure 3. Model of Corroded Non-Composite Steel Box Girder Cross-Section

Figure 2 shows samples of pit corrosion damage distribution in plates (Paik et al. [22, 23]). Although the distribution of the pit corrosion on the plates is scattered, it can be seen that the shape of the corrosion is typically circular (Paik et al. [22, 23]; Nakai [24]). The maximum diameter of localized corrosion may be in the range of $25-80 \mathrm{~mm}$ for the marine immersion corrosion of steel (Daidola et al. [25]), with the lower values more likely.

Our investigation of the box girder section assumes that all sides of the girder will corrode uniformly and in a localized manner, except for the upper plate, which is protected from corrosion attack by the concrete deck. It is also assumed that the interior of the box girder is protected from environmental exposure and corrosion attack, as can be seen from Figure 3. Figure 3 shows that general corrosion uniformly decreases the plate thickness of both sides and the bottom flange of the box girder section. In the same way, it is also assumed that pitting corrosion, which is uniformly distributed, affects the strength of the following plates by the different degrees of intensity shown in Figure 4. Finally, it is assumed that the pit diameter varies from 10 to $80 \mathrm{~mm}$, and the distance between the adjacent pits centers is constant. The depth of pit corrosion will of course vary by time.

\subsection{Probabilistic Corrosion Rate Modeling}

In reliability analysis based on the ultimate steel box girder strength of corroded bridges, a probabilistic corrosion rate estimation model needs to be established in advance. Kayser and Nowak [26] collected data on corrosion performance of actual steel bridges.

There is considerable variability in corrosion losses, it is therefore appropriate to consider these quantities as random variables with parameters that change with time. A distinguishing feature of the models developed recently for general corrosion loss and for maximum pit depth under marine immersion conditions is that they are based on fundamental concepts, both in corrosion science and in marine bacteriology. Both these fields are important because it has been recognized that the corrosion process changes from being controlled by the rate of metal oxidation by oxygen in the early period of exposure to being controlled by the rate of metabolism of anaerobic bacteria under longer-term exposures. The models have been calibrated in terms of their parameters using data available in the literature. The models, both for corrosion loss and pit depth, are shown in Figure 5 together with the parameters used to describe them. These parameters are summarized in Table 1. Note that the initial corrosion rate parameter $r_{0}$ does not appear for pitting since pitting of considerable depth (around $100 \mathrm{~mm}$ ) occurs usually within days of exposure (Melchers [3]; Melchers and Jeffrey [4]) (for further information, refer to (Melchers and Jeffrey [4])). 


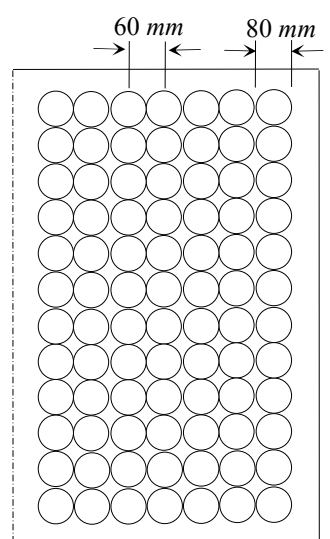

a) $\mathrm{DOP}=75.40 \%$

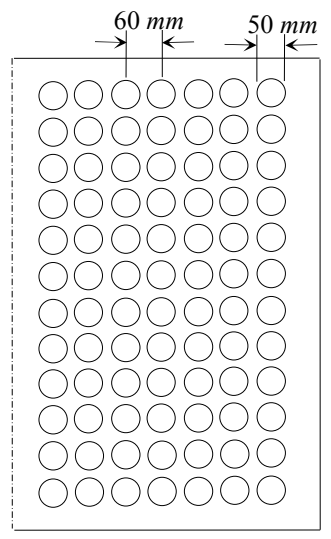

d) $\mathrm{DOP}=29.45 \%$

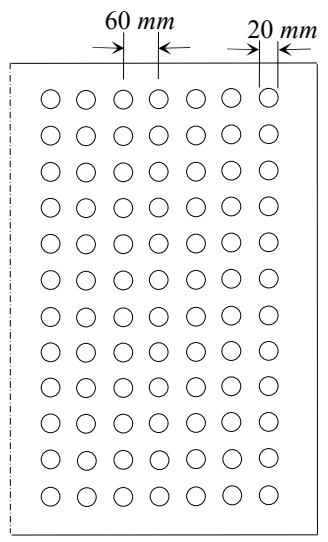

g) $\mathrm{DOP}=4.71 \%$

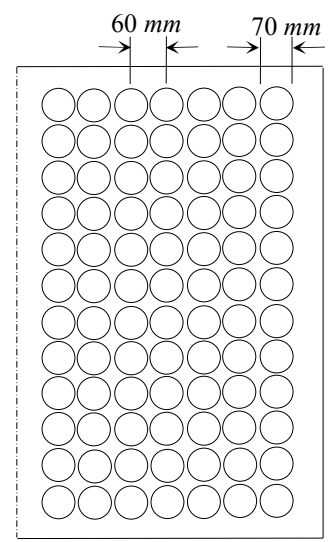

b) $\mathrm{DOP}=57.73 \%$

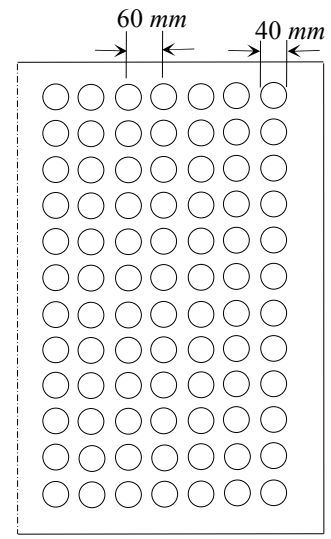

e) $\mathrm{DOP}=18.85 \%$

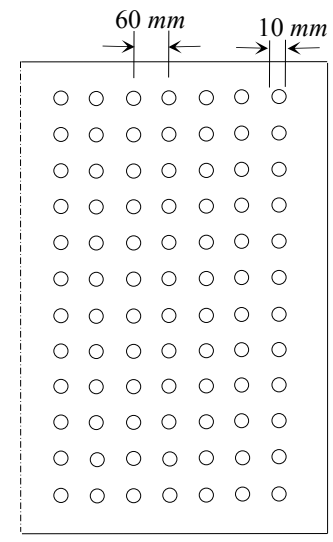

h) $\mathrm{DOP}=1.18 \%$

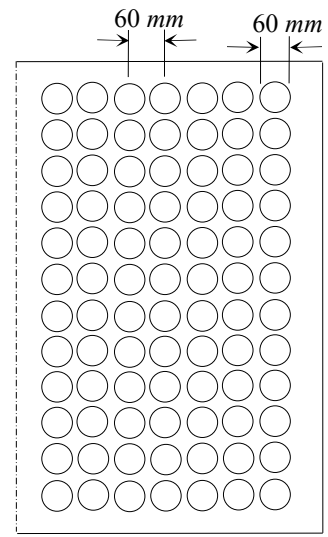

c) $\mathrm{DOP}=42.41 \%$



f) $\mathrm{DOP}=10.60 \%$

Figure 4. Typical Models of Pit Distribution

\subsection{Probabilistic Corrosion Rate Modeling}

In reliability analysis based on the ultimate steel box girder strength of corroded bridges, a probabilistic corrosion rate estimation model needs to be established in advance. Kayser and Nowak [26] collected data on corrosion performance of actual steel bridges. 
There is considerable variability in corrosion losses, it is therefore appropriate to consider these quantities as random variables with parameters that change with time. A distinguishing feature of the models developed recently for general corrosion loss and for maximum pit depth under marine immersion conditions is that they are based on fundamental concepts, both in corrosion science and in marine bacteriology. Both these fields are important because it has been recognized that the corrosion process changes from being controlled by the rate of metal oxidation by oxygen in the early period of exposure to being controlled by the rate of metabolism of anaerobic bacteria under longer-term exposures. The models have been calibrated in terms of their parameters using data available in the literature. The models, both for corrosion loss and pit depth, are shown in Figure 5 together with the parameters used to describe them. These parameters are summarized in Table 1. Note that the initial corrosion rate parameter $r_{0}$ does not appear for pitting since pitting of considerable depth (around $100 \mathrm{~mm}$ ) occurs usually within days of exposure (Melchers [3]; Melchers and Jeffrey [4]) (for further information, refer to (Melchers and Jeffrey [4])).
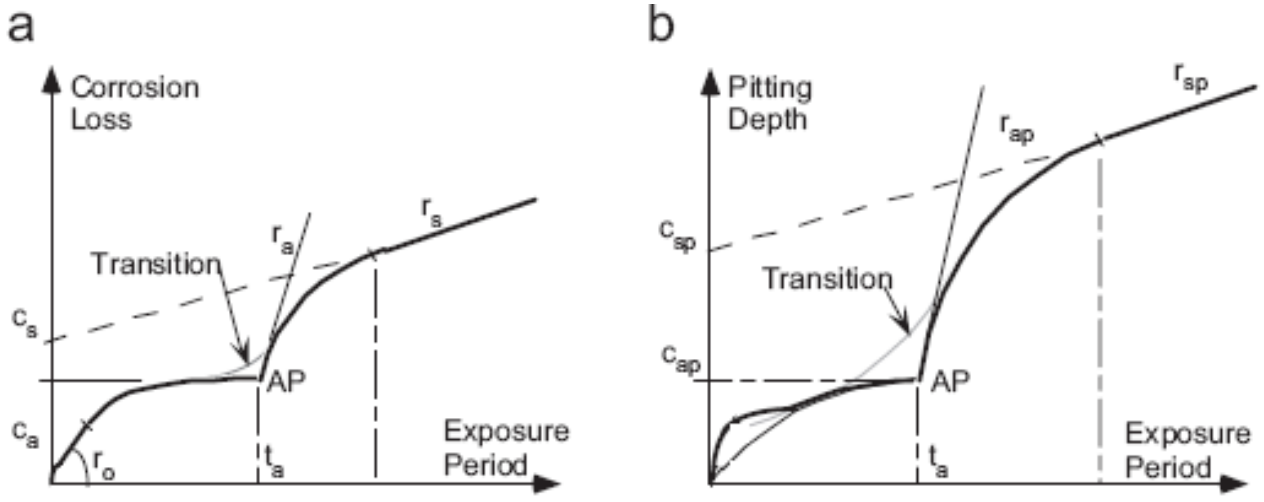

Figure 5. Model for the Mean Value Function for (A) General Corrosion Loss (in mm) and (B) Pit Depth (in mm) Versus Exposure Time (in year) (Melchers [3]; Melchers and Jeffrey [4])

Table 1. Calibration of Model Parameters for General and For Pitting Corrosion under Immersion Conditions In Unpolluted Low Velocity Shallow Waters As a Function of Annual Average Seawater Temperature $T$ (Melchers and Jeffrey [4])

\begin{tabular}{lllll}
\hline Model parameter & General corrosion & At $10^{\circ} \mathrm{C}$ & Pitting corrosion & At $10^{\circ} \mathrm{C}$ \\
\hline$r_{0}(\mathrm{~mm} /$ year $)$ & $r_{0}=0.076 \exp (0.054 T)$ & 0.13 & - & \\
$c_{\mathrm{a}}(\mathrm{mm})$ & $c_{\mathrm{a}}=0.32 \exp (-0.038 T)$ & 0.22 & $c_{\mathrm{ap}}=0.99 \exp (-0.052 T)$ & 0.59 \\
$t_{\mathrm{a}}($ year $)$ & $t_{\mathrm{a}}=6.61 \exp (-0.088 T)$ & 2.75 & $t_{\mathrm{s}}=6.61 \exp (-0.088 T)$ & 2.75 \\
$r_{\mathrm{a}}(\mathrm{mm} /$ year $)$ & $r_{\mathrm{a}}=0.066 \exp (0.061 T)$ & 0.12 & $r_{\mathrm{ap}}=0.596 \exp (0.0526 T)$ & 1.01 \\
$c_{\mathrm{s}}(\mathrm{mm})$ & $c_{\mathrm{s}}=0.141-0.00133 T$ & 0.13 & $c_{\mathrm{sp}}=0.641 \exp (0.00613 T)$ & 0.68 \\
$r_{\mathrm{s}}(\mathrm{mm} /$ year $)$ & $r_{\mathrm{s}}=0.039 \exp (0.0254 T)$ & 0.05 & $r_{\mathrm{sp}}=0.353 \exp (-0.0436 T)$ & 0.23 \\
\hline
\end{tabular}

\section{BOX GIRDER ULTIMATE STRENGTH MODELING}

To identify a performance function it is needed to estimate an appropriate resistance formula. This study employed the analytical approach suggested by Paik and Mansour [27] to calculate the ultimate strength of a box under bending conditions. It is often observed in nonlinear finite element calculations that a box will reach its ultimate limit if both the collapse of the compression flange and the yielding of the tension flange occur. The side shell in the vicinity of the compression and tension flanges will also often fail, although the material around the final neutral axis will remain essentially in an elastic state. 


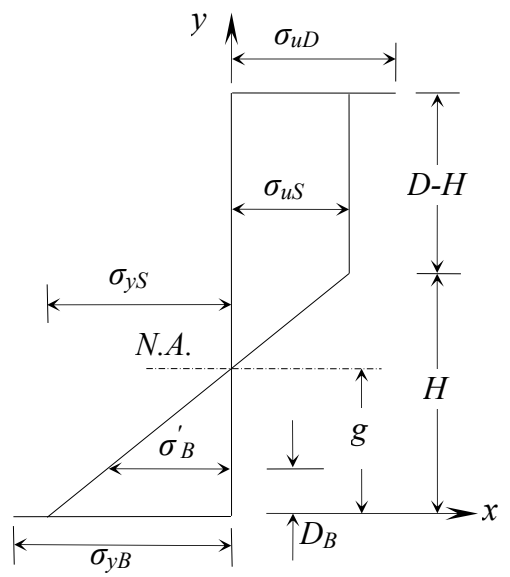

Figure 6. Longitudinal Stress Distribution over the Box Cross-section at the Overall Collapse State suggested by Paik and Mansour [27]

Based on these observations, Paik and Mansour [28] assumed a credible distribution of the longitudinal stresses in the box section at the overall collapse state shown in Figure 6. On the basis of this distribution, they then derived an explicit analytical formula for the corresponding resistive moment. The accuracy of the formula was then verified by comparison with both experimental and numerical results. The resulting expressions for the ultimate bending strength of a double-bottomed box are given by the following Paik and Mansour [28].

$$
\begin{aligned}
M_{u}= & -A_{D} \sigma_{u D}(D-g)-\frac{A_{S}}{D}(D-H)(D+H-2 g) \sigma_{u S} \\
& -A_{B} g \sigma_{y B}+\frac{A_{B}^{\prime}}{H}\left(g-D_{B}\right)\left[D_{B} \sigma_{u S}-\left(H-D_{B}\right) \sigma_{y S}\right], \\
& -\frac{A_{S} H}{3 D}\left[(2 H-3 g) \sigma_{u S}-(H-3 g) \sigma_{y S}\right]
\end{aligned}
$$

where

$$
\begin{aligned}
H= & \frac{1}{2}\left\{\left(\frac{A_{D} \sigma_{u D}+2 A_{S} \sigma_{u S}-A_{B} \sigma_{y B}-A_{B}^{\prime} \sigma_{y s}}{A_{S}\left(\sigma_{u S}+\sigma_{y s}\right)}\right) D\right. \\
& \left.+\left[\left(\frac{A_{D} \sigma_{u D}+2 A_{S} \sigma_{u S}-A_{B} \sigma_{y B}-A_{B}^{\prime} \sigma_{y s}}{A_{S}\left(\sigma_{u S}+\sigma_{y s}\right)}\right)^{2} D^{2}+\frac{4 A_{B}^{\prime} D_{B}}{A_{S}} D\right]^{1 / 2}\right\}, \\
g= & \frac{\sigma_{y s}}{\sigma_{u s}+\sigma_{y s}} H .
\end{aligned}
$$

For a single box girder, the formula can be simplified to

$$
\begin{aligned}
M_{u}= & -A_{D} \sigma_{u D}(D-g)-\frac{A_{S}}{D}(D-H)(D+H-2 g) \sigma_{u S} \\
& -A_{B} g \sigma_{y B}-\frac{A_{S} H}{3 D}\left[(2 H-3 g) \sigma_{u S}-(H-3 g) \sigma_{y S}\right],
\end{aligned}
$$


where

$$
\begin{aligned}
& H=\left(\frac{A_{D} \sigma_{u D}+2 A_{S} \sigma_{u S}-A_{B} \sigma_{y B}}{A_{S}\left(\sigma_{u S}+\sigma_{y s}\right)}\right) D \\
& g=\frac{\sigma_{y s}}{\sigma_{u s}+\sigma_{y s}} H .
\end{aligned}
$$

To calculate the ultimate moment capacity of the box using equation 2 or 3 , the ultimate strength of the compression flange and the side structure in the vicinity of the compression flange, both of which are either stiffened panels or lacking in stiffeners, must be known. Theoretically, the idealized failure modes of a stiffened panel under compressive loads can be categorized into six classes (Paik and Thayamballi [29]):

- Mode I: Overall collapse of plating and stiffeners as a unit

- Mode II: Biaxial compressive collapse without failure of support members

- Mode III: Beam - column type collapse

- Mode IV: Local buckling of the stiffener web (after failure of the plating between the stiffeners)

- Mode V: Tripping of the stiffener

- Mode VI: Gross yielding

The collapse of a stiffened panel may be said to occur at the lowest value of the ultimate load calculated from one of these six collapse patterns. As an alternative, a number of simplified formulas for predicting the ultimate compressive strength of stiffened panels are available in the literature (Paik and Thayamballi [28]), but the realistic calculation of ultimate strength considering all possible modes and their interactions remains a relatively complicated task. In this regard, Paik and Thayamballi [29] derived an empirical formula to predict the ultimate compressive strength of stiffened panels on the basis of data from a total of 130 collapse tests on stiffened plates with usual levels of initial imperfection. The formula is expressed as a function of plate slenderness ratio $\beta^{\prime}$ and column (stiffener) slenderness ratio $\lambda^{\prime}$ (for further information, refer to Paik and Thayamballi [29]):

$$
\sigma_{u} / \sigma_{y}=\left[0.995+0.936 \lambda^{\prime 2}+0.17 \beta^{\prime 2}+0.188 \lambda^{\prime 2} \beta^{\prime 2}-0.067 \lambda^{\prime 4}\right]^{-0.5} .
$$

It should be noted that the foregoing formula implicitly includes the effects of initial imperfections at a moderately large level. In addition, the ultimate strength of an imperfect unstiffened plate under compression stress may be predicted as a function of the plate slenderness ratio, as follows (Paik et al. [30]).

$$
\sigma_{u} / \sigma_{y}=\left\{\begin{array}{lll}
-0.032 \beta^{\prime 4}+0.002 \beta^{\prime 2}+1.0 & \text { for } & \beta^{\prime} \leq 1.5 \\
1.274 / \beta^{\prime} & \text { for } & 1.5<\beta^{\prime} \leq 3.0 . \\
1.248 / \beta^{\prime 2}+0.283 & \text { for } & \beta^{\prime}>3.0
\end{array}\right.
$$

For convenience, the illustrative calculations presented in this study employ equation 5 to predict the ultimate compressive strength of the representative unstiffened plate at the compressive flange or side structure of the box. 


\section{EFFECTS OF PIT CORROSION ON PLATE ULTIMATE STRENGTH}

Corrosion wastage can reduce the ultimate strength of bridge plates. As previously mentioned, two types of corrosion damage are usually considered, namely, general (or uniform) and localized corrosion. The former reduces plate thickness uniformly, whereas the latter, such as pitting, appears non-uniformly in select regions, such as the side plates in box girder bridges. The ultimate strength of a steel member with general corrosion can be easily predicted, i.e., by excluding the plate thickness loss that results from corrosion. It is proposed here, in contrast, that the ultimate strength prediction of a structural member with pit corrosion be made using a strength knock-down factor approach. A series of experimental and numerical studies on steel-plated structures (Paik and Thayamballi [29]), however, led to the realization that the plate ultimate strength reduction characteristics that are due to general corrosion are quite different from those that are due to pit corrosion. So-called equivalent plate thickness reduction approaches, which represent a pitted plate with an equivalent plate, are sufficient for the accurate prediction of the plate's strength.

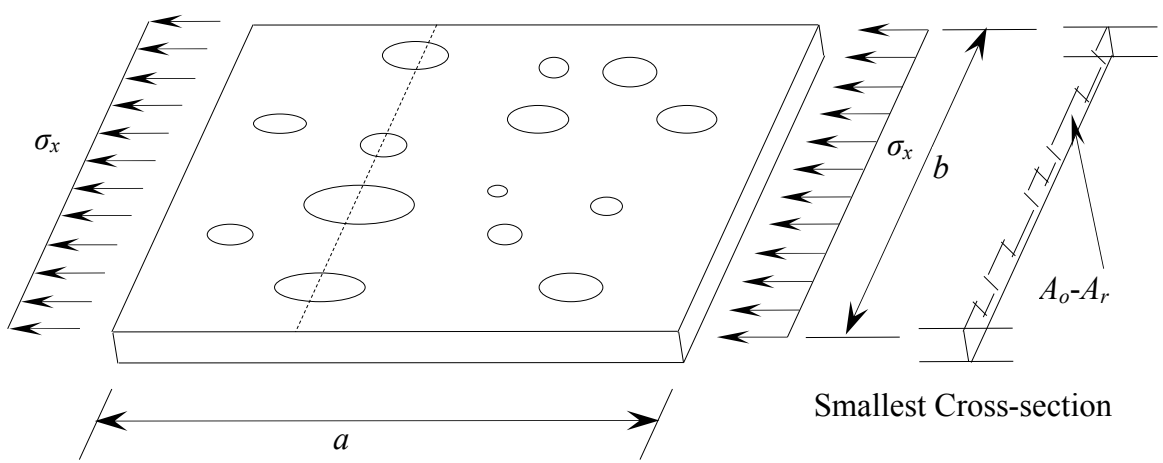

Figure 7. Schematic of Localized Pit Corrosion and Definition of the Smallest Cross-sectional Area $\left(A_{0}=\right.$ cross-sectional area of the intact plate)

Experimental and numerical studies (Paik and Thayamballi [29]) demonstrate that the ultimate strength of a plate with pit corrosion can be estimated with a strength knock-down factor that can be calculated using the following formulation for axial compressive loading.

$R_{x r}=\frac{\sigma_{x u}}{\sigma_{\text {хио }}}=\left(\frac{A_{0}-A_{r}}{A_{0}}\right)^{0.73}$,

\section{LOAD MODELING}

Two load components are considered: dead load and live load (truck traffic).

\subsection{Dead Load Model}

Dead load is treated as the normal random variable. The basic statistical parameters are a bias factor, $\lambda$, which is the ratio of the mean to nominal value, and coefficient of variation $V$. Dead load includes the weight of the girders, deck slab, wearing surface, barriers, diaphragms and sidewalk, where applicable. Bias factor $\lambda=1.03$ and $V=0.08$ for factory-made components (girders, diaphragms), $\lambda=1.05$ and $V=0.10$ for cast-in-place components (deck, barriers, sidewalk), and the 
asphalt wearing surface is taken to have a mean value of $75 \mathrm{~mm}$, with $V=0.25$ (Nowak and Collins [31]; Nowak [32]; Nowak [33]; Nowak and Szerszen [34]; Nowak and Szerszen [35]).

\subsection{Live Load Model}

The live load on a bridge is the result of vehicular traffic. It can be considered as the sum of the static and dynamic components. The latter can be represented by an equivalent static load that is defined as the dynamic load factor. The live load effects depend on a number of parameters, including the span length, axle load, axle configuration, gross vehicle weight, position of the vehicle on the bridge (transversely and longitudinally), traffic volume, number of vehicles on the bridge (multiple presence), girder spacing and mechanical properties of the structural members (Nowak and Collins [31]; Nowak [32]; Nowak [33]; Nowak and Szerszen [34]; Nowak and Szerszen [35]). This study employed the load model developed by AASHTO (AASHTO LRFD [36]) (Figure 8).

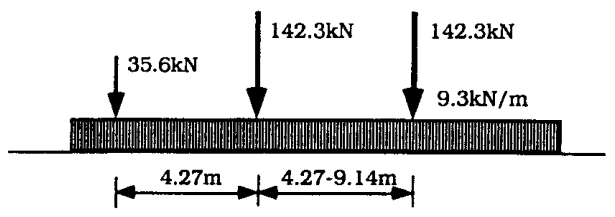

Figure 8. Proposed Nominal Live Loading (AASHTO LRFD [36])

It is assumed that the bias factor, $\lambda$, for the live load distribution factors specified in the design code is between 1.10 and 1.20, and that the coefficient of variation, $V$, is 0.18 (Barker and Puckett [37]). This study adopted a bias factor of 1.15 and a coefficient of variation of 0.18 . The dynamic load factor is defined as the ratio of the dynamic load to the static live load. Field measurements show that the dynamic load factor decreases for heavier. Here, the dynamic load factor $(I M)$ is selected on the basis of the AASHTO specifications. The design live load in AASHTO (AASHTO LRFD [33]) is specified as the effect of the design truck shown in Figure 8 superimposed with a uniformly distributed load of $9.3 \mathrm{kN} / \mathrm{m}$. The live load distribution for interior and exterior girders can be estimated using the AASHTO specifications (for further information, see (Barker and Puckett [37])).

\section{UNCERTAINTY ASSESSMENT AND RELIABILITY CALCULATION}

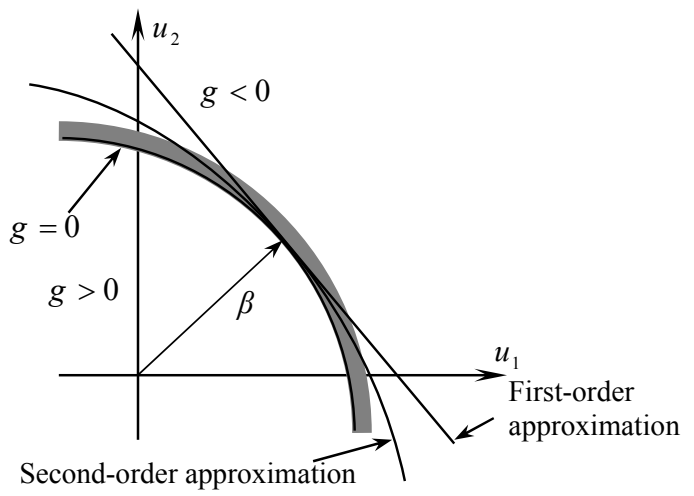

Figure 9. First- and Second-order Reliability Methods 
The aim here is to calculate the probability of failure, and hence its complement, reliability, that is related to the ultimate strength of a box girder bridge acted upon by an extreme total bending moment during its lifetime. Box girder strength declines over time because of corrosion. Thus, the reliability measure also reduces with time. As the theory of reliability analysis is discussed in many studies [e.g., (Nowak and Collins [31]; Mansour [38]; Achintya and Mahadevan [39]; Lemarie [40])], only a very brief description is given here. The probability of failure can generally be calculated as follows.

$P_{F}=\int_{f(X) \leq 0} p_{x}(X) d x$

where $p(X)$ is the joint probability density function of the random variables, $X=\left(x_{1}, x_{2}, \ldots, x_{\mathrm{n}}\right)$, which are associated with loading, material properties, geometrical characteristics, etc., and $f(X)$ is the limit state function, defined such that negative values imply failure. Reliability analysis can be performed through numerical integration, the simulation technique or approximate methods. Because $f(X)$ is usually a complicated nonlinear function, it is not easy to perform the integration of equation (7) directly. Although the simulation technique may be time-consuming because of the small probabilities involved in the analysis, it has become popular in recent years due to the development of such variance reduction techniques as importance sampling (Sarveswaran and Roberts [15]). Therefore, the equation is normally solved through simulation techniques or approximate procedures Nowak and Collins [31]; Mansour [38]; Achintya and Mahadevan [39]; Lemarie [40]).

In the approximation methods (Figure 9), the limit state surface is usually approximated at the design point by either a tangent hyper plane or hyper parabola, which simplifies the mathematics related to the calculation of failure probability. The first type of approximation results in the use of a so called first-order reliability method (FORM), and the second type is central to the so called second-order reliability method (SORM). Such methods facilitate the rapid calculation of the probability of failure by widely available standard software packages. The reliability analysis in this study was performed using FORM analysis.

The result of such a standard reliability calculation is a reliability index, $\beta$, which is related to the probability of failure by

$P_{F}=\phi(-\beta)$,

where $\phi$ is the standard normal distribution function.

In our case, the failure condition associated with box-girder collapse can be written as (limit state function):

$f(x)=Z_{1} M_{u}-M_{D}-M_{L} \leq 0$,

where

$M_{u}=$ the random variable representing ultimate strength,

$M_{D}=$ the random variable representing the dead load and

$M_{L}=$ the random variable representing the live load

$Z_{1}=$ a variable modeling the uncertainty in estimating the moment capacity.

The aforementioned failure condition uses the limit state function for box girder collapse as a function of four variables. However, recall that variable $M_{u}$ is actually estimated by an analytical 
procedure that involves the individual thicknesses, yield strength and moduli of elasticity, namely, $t$, $\sigma_{y}$ and $E$, such that

$M_{u}=M_{u}\left(t, \sigma_{y}, E\right)$.

It seems that there are six types of random variables to be characterized.

\section{APPLICATION EXAMPLE}

To demonstrate the application of the proposed procedure, a hypothetical steel box girder bridge is selected from an extensive parametric study aimed at the design of box girder bridge components.

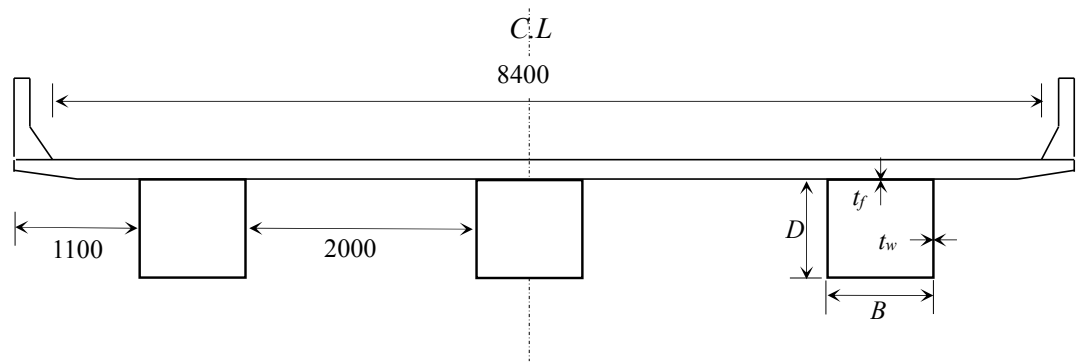

Figure 10. Typical Cross-Section of Box Girder Bridge (dimensions in mm)

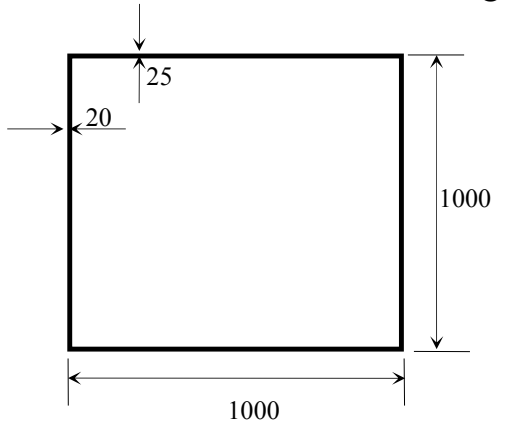

Figure 11. Dimensions (in mm) of Cross-Section of Box Girder

Table 2. Values Used in Calculations (lognormal distributions)

\begin{tabular}{lcc}
\hline Parameters & $\begin{array}{c}\text { Mean } \\
\mu\end{array}$ & $\begin{array}{c}\text { Standard } \\
\text { deviation } \\
\sigma\end{array}$ \\
\hline Modulus of elasticity for steel, $E$ & $2.1 \times 10^{5} \mathrm{~N} / \mathrm{mm}^{2}$ & $2.1 \times 10^{4} \mathrm{~N} / \mathrm{mm}^{2}$ \\
\hline Yield stress in steel, $\sigma_{y}$ & $350 \mathrm{~N} / \mathrm{mm}^{2}$ & $35 \mathrm{~N} / \mathrm{mm}^{2}$ \\
\hline Model uncertainty variable, $Z_{1}$ & 1.0 & 0.1 \\
\hline
\end{tabular}

It is assumed that the bridge is not protected against corrosion. It has a simple span of $20 \mathrm{~m}$ and two lanes with traffic flowing in the same direction. The cross-section is shown in Figs. 10 and 11. The material parameters are assumed to be log-normally distributed, and the mean values and standard deviations are shown in Table 2. The thicknesses of the deck and asphalt are $250 \mathrm{~mm}$ and $75 \mathrm{~mm}$, respectively. The lifetime, $T$, chosen is 75 years. Deterministic analysis showed that, for each girder, 
prior to any corrosion, the nominal moment capacity is $M_{n}=9725 \mathrm{kN}-\mathrm{m}$. In the probabilistic analysis, $M_{n}$ is calculated using the statistical parameters shown in Table 2.

\subsection{Dead Load}

The mean value of the design dead load bending moment of the steel box girder is calculated, with the results shown in Table 3 for interior and exterior girders. To calculate the dead load for each girder, the dead load components for asphalt and the other components are first calculated separately, after which the equivalent dead load for each girder is calculated by estimating the mean and standard deviation of the components, as shown in Table 3.

Table 3. Dead Load for Girders (normal distributions)

\begin{tabular}{lcc}
\hline Parameters & $\begin{array}{c}\text { Mean } \\
\mu\end{array}$ & $\begin{array}{c}\text { Standard } \\
\text { deviation } \\
\sigma\end{array}$ \\
\hline $\begin{array}{l}\text { Midspan dead load moment for interior } \\
\text { girder, } M_{D I}\end{array}$ & $15.50 \times 10^{8} \mathrm{~N}-\mathrm{mm}$ & $1.44 \times 10^{8} \mathrm{~N}-\mathrm{mm}$ \\
\hline $\begin{array}{l}\text { Midspan dead load moment for exterior } \\
\text { girder, } M_{D E}\end{array}$ & $19.46 \times 10^{8} \mathrm{~N}-\mathrm{mm}$ & $1.81 \times 10^{8} \mathrm{~N}-\mathrm{mm}$ \\
\hline
\end{tabular}

\subsection{Live Load}

Based on the specifications provided in Section 5.2, the mean and standard deviation of the live load for each girder are calculated and shown in Table 4.

Table 4. Live Load for Girders (lognormal distributions)

\begin{tabular}{lcc}
\hline Parameters & $\begin{array}{c}\text { Mean } \\
\mu\end{array}$ & $\begin{array}{c}\text { Standard } \\
\text { deviation } \\
\sigma\end{array}$ \\
\hline $\begin{array}{l}\text { Midspan live load moment for interior } \\
\text { girder, } M_{L I}\end{array}$ & $18.58 \times 10^{8} \mathrm{~N}-\mathrm{mm}$ & $3.34 \times 10^{8} \mathrm{~N}-\mathrm{mm}$ \\
\hline $\begin{array}{l}\text { Midspan live load moment for exterior } \\
\text { girder, } M_{L E}\end{array}$ & $22.92 \times 10^{8} \mathrm{~N}-\mathrm{mm}$ & $4.13 \times 10^{8} \mathrm{~N}-\mathrm{mm}$ \\
\hline
\end{tabular}

\subsection{Results}

Probabilistic analysis was carried out to calculate the ultimate strength, reliability and probability of failure of the corroded box girders as the bridge ages. Figure 12 shows the trends of variation in the ultimate moment strength versus time. It can be seen that the ultimate bending strength of the corroded box girders is reduced with an increase in the age of the bridge. In addition, as expected, the ultimate moment decreases with an increase in the DOP at the same time. 


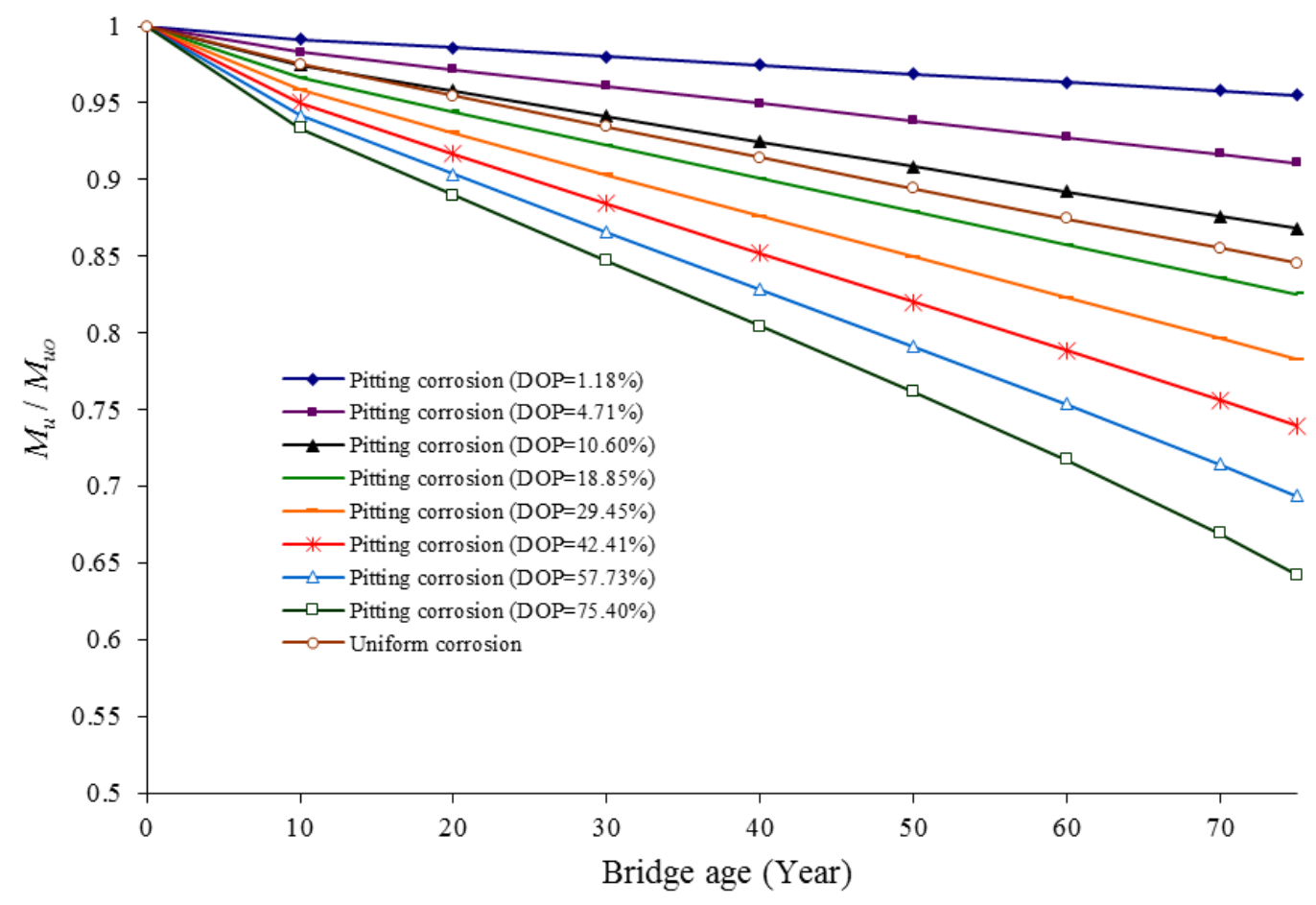

Figure 12. Variation of Box Ultimate Strength Mean Values with Age

Reliability analysis is performed based on FORM analysis. The reliability indices for two girders (interior and exterior) of a highway bridge that is assumed to be uniformly corroded and localized with different DOP are demonstrated using reliability software, with the results shown in Figs. 13 and 14 .

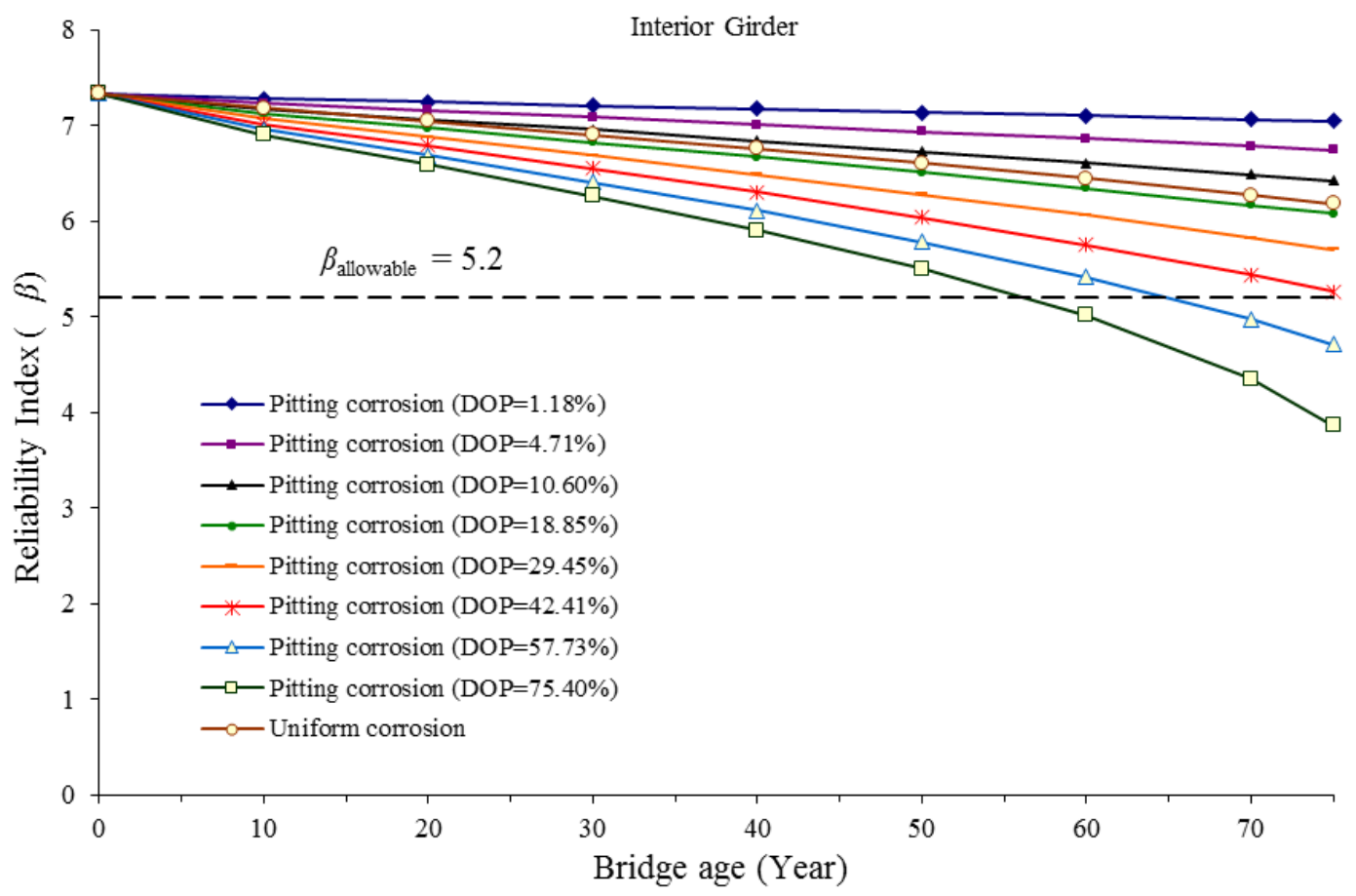

Figure 13. Variation in Reliability Index with Age for Interior Girder 


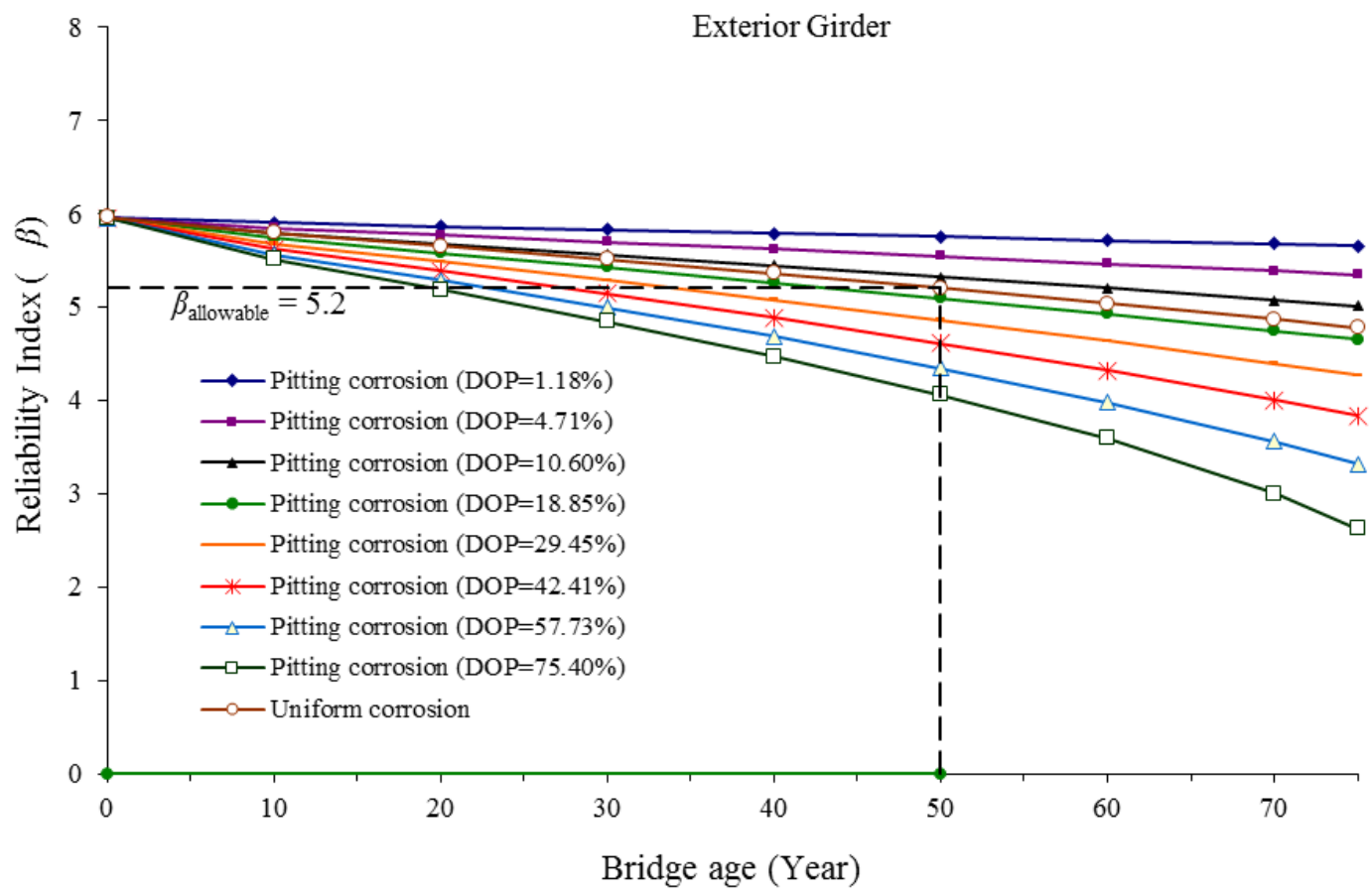

Figure 14. Variation in Reliability Index with Age for Exterior Girder

The corresponding probabilities of failure for the two girders (interior and exterior) for different pitting corrosion intensities (DOP) and uniform corrosion are also presented in Figs. 15 and 16.

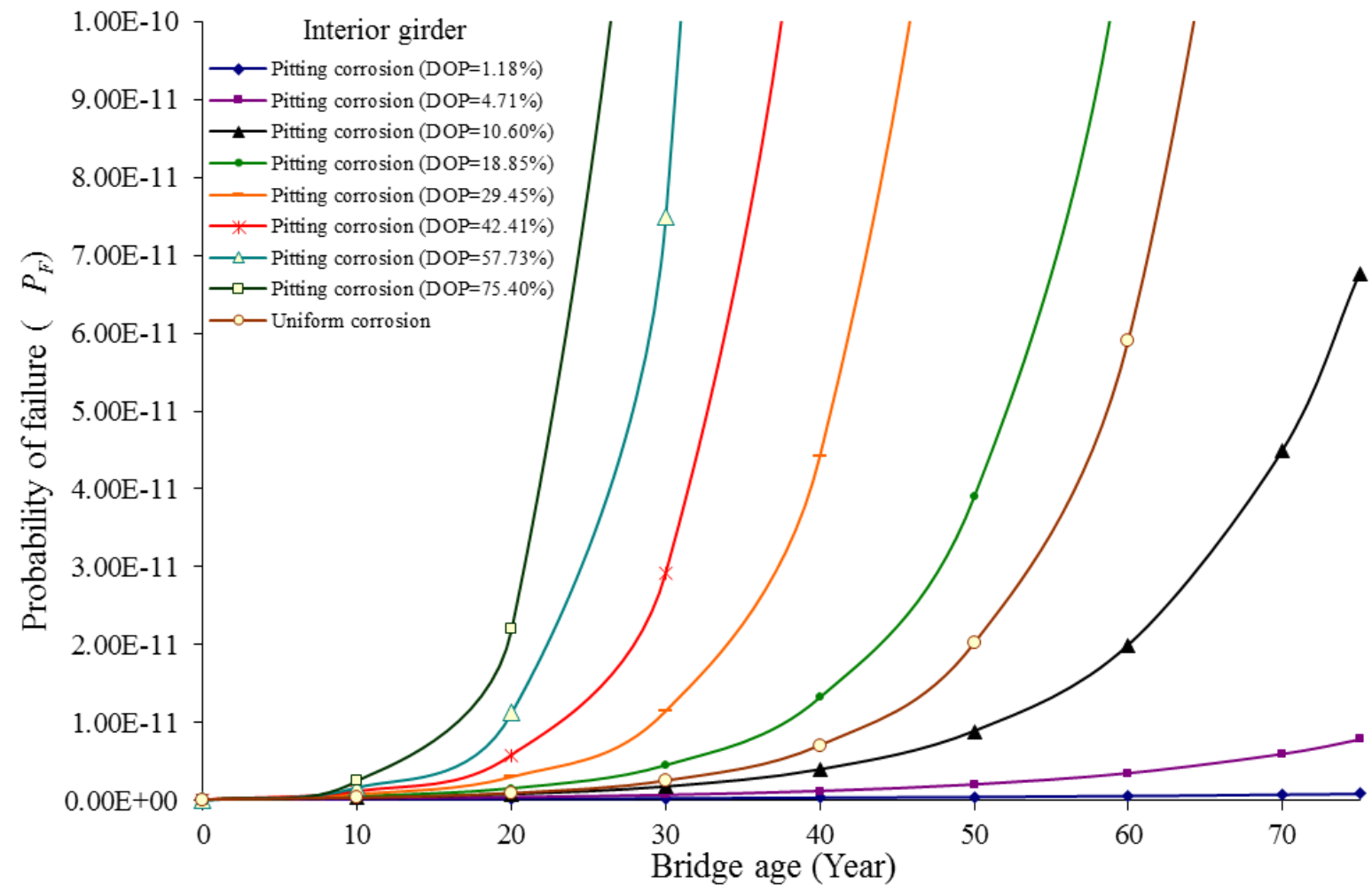

Figure 15. Variation in Probability of Failure with Age for Interior Girder 


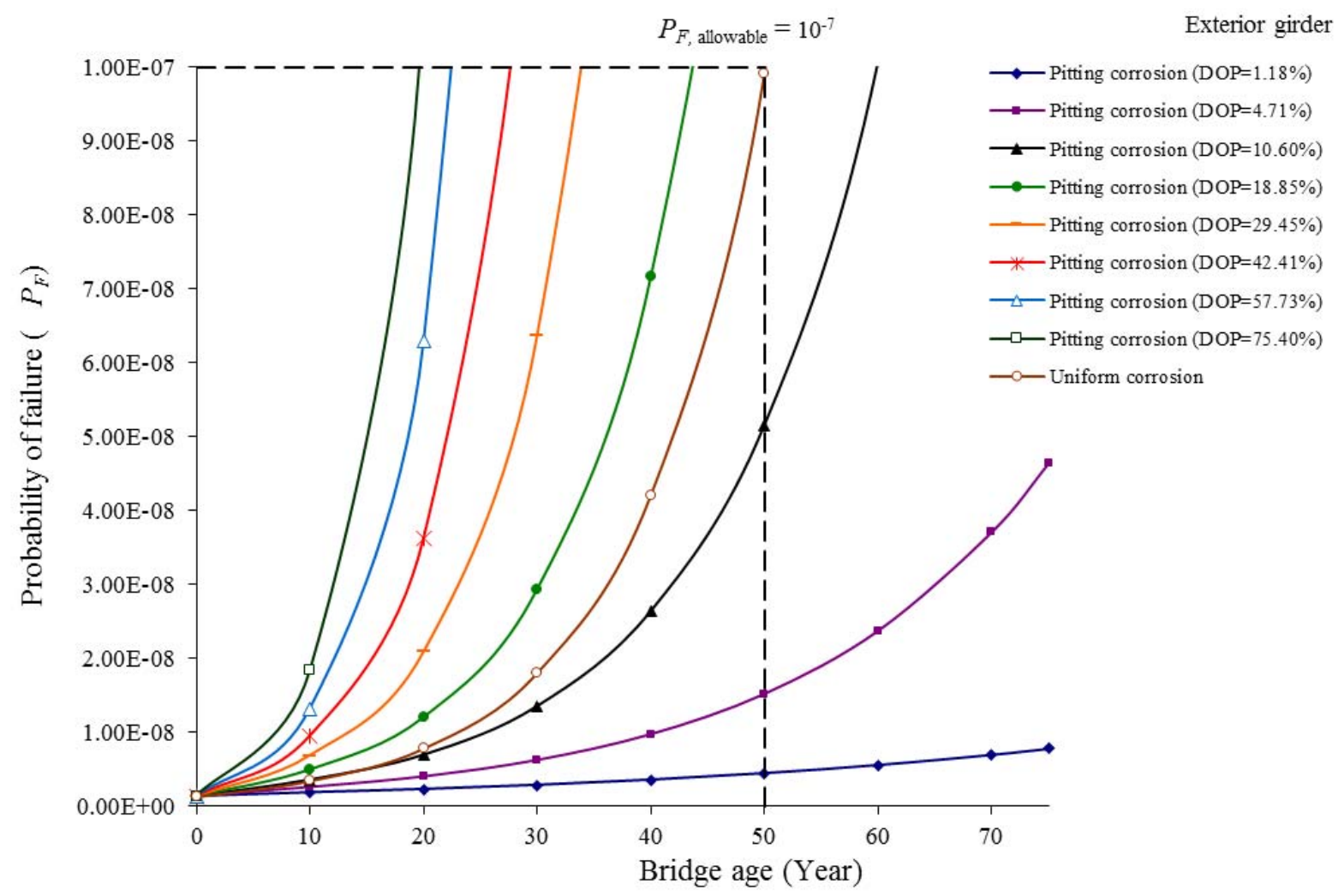

Figure 16. Variation in Probability of Failure with Age for Exterior Girder

This study considers the effects of pitting and uniform corrosion on the load-carrying capacity and reliability of a corroded steel box girder. The results of the FORM analysis method plotted in Figs. 13-16. These figures also give the minimum reliability index or maximum probability of failure for assessment of the ultimate strength reliability of corroded steel box girder bridges.

\section{ACCEPTANCE LEVEL OF RELIABILITY}

\subsection{Approaches to Establishing Acceptance Level}

To determine the latest time for the repair intervention of girders, it is first necessary to establish an acceptance level of reliability below which they may be considered unsafe. Not only the accuracy of resistance and load modeling has an influence on reliability but also there are several factors which cannot be modeled in structural reliability analysis. Practicing engineers generally prefer to quantify the reliability level that is implicit in current bridge codes and standards, which have a proven safety record, using probabilistic analysis and then employ this level as the acceptance level of reliability. This method is known as "calibration to existing codes and standards," and is widely used to establish target reliability levels for design situations. The calibration procedure is discussed in many textbooks, e.g., Melchers [41]. It has also been applied to the quantification of the reliability levels implicit in bridge design and assessment codes (Nowak and Lind [42]; Flint et al. [43]; Chryssanthopoulos and Micic [44]). It is also recommended that acceptance levels be based on the consequences of failure and the nature of the failure mode. Therefore, the allowable reliabilities shown in Table 5, which are based on the type of failure has been used in this study. 
Table 5. Target (or acceptance) Reliability Levels (Chryssanthopoulos and Micic [44])

\begin{tabular}{lccc}
\hline $\begin{array}{l}\text { Failure } \\
\text { consequences }\end{array}$ & $\begin{array}{c}\text { Ductile failure } \\
\text { with reserve } \\
\text { strength }\end{array}$ & $\begin{array}{c}\text { Ductile failure } \\
\text { without reserve } \\
\text { strength }\end{array}$ & Brittle failure \\
\hline Not serious & $3.09\left(10^{-3}\right)$ & $3.71\left(10^{-4}\right)$ & $4.26\left(10^{-5}\right)$ \\
\hline Serious & $3.71\left(10^{-4}\right)$ & $4.26\left(10^{-5}\right)$ & $4.75\left(10^{-6}\right)$ \\
\hline Very serious & $4.26\left(10^{-5}\right)$ & $4.75\left(10^{-6}\right)$ & $5.20\left(10^{-7}\right)$ \\
\hline
\end{tabular}

Corresponding failure probabilities are given in parentheses

\subsection{Determination of Latest Time to Intervention}

The foregoing approaches were taken into account in selecting the time for repair intervention. Applying the allowable reliability index, for example 5.2 (brittle failure and very serious) or corresponding probability of failure $10^{-7}$, and employing reliability analysis results, the earliest time for the repair of exterior girders in a marine environment is around 50 years in case of uniform corrosion (see Figs. 14 and 16). By using the abovementioned procedure it can be found that there is no failure for interior girders during their life time, 75 years, (see Figs. 13 and 15). In other words, if such a bridge is constructed now (in 2010), then its exterior girders should be repaired in fifty years' time (in 2060). If it is already in existence and is older than fifty years, then it is unsafe to use the assumptions and procedures reported here.

\section{CONCLUDING REMARKS}

This study has developed a probability-based procedure for selection of the critical time at which bridge girders should be repaired during their service life. Two types of corrosion are considered, namely, uniform corrosion and pitting corrosion with different degrees of intensity. Reliability indices are calculated using available load and resistance models. A probabilistic ultimate strength model is developed by employing the simple analytical formulation derived by Paik and Mansour [27]. Bridge girders are subject to a loss in capacity over time due to corrosion. The live load can be distributed to girders using the guidance formula for the highway bridge design. Time-dependent reliability indices can serve as the basis for selecting the latest time to repair or renew individual girders, with the critical components identified as those associated with the lowest reliability indices.

From the developments and illustrations presented herein, the following conclusions can be drawn.

1. The results show that by calculating the DOP of a corroded bridge girder, it can be estimated its time-variant reliability profiles, and hence it can be predicted the repair or renewal time.

2. As expected, the ultimate strength of corroded box girders may decrease with time, and in a certain time it will decrease with an increase in DOP.

3. The ultimate limit analytical formula (Paik and Mansour [27]) described in this study, and applied to the prediction of the ultimate strength of box girders, is useful for evaluating the time-variant steel box girder strength reliability of corroded bridges.

4. The procedures developed herein will be useful in assessing the ultimate strength reliability of aging steel box girder bridges by taking into account the degradation of plate members due to corrosion. This procedure is not only applicable to practicing engineers, but is also presented as a scientific method for estimating the longevity of bridges. 


\section{NOTATIONS}

The following symbols are used in this paper.

$A_{B}, A_{B}^{\prime}, A_{D}=$ sectional area of outer bottom, inner or upper

$A_{S}=$ half of the sectional area of the side structure, including any longitudinal stiffeners

$E=$ Young's modulus

$f(x)=$ ultimate limit state function

$g=$ height of the neutral axis

$P_{F}=$ probability of failure

$M_{u}, M_{u o}=$ random variable representing the ultimate strength of a corroded or uncorroded box girder

$\sigma_{x i}=$ standard deviation of random variable $x_{i}$

$t=$ plate thickness of a member and time in years

$\beta^{\prime}=\frac{b}{t} \sqrt{\frac{\sigma_{y}}{E}}=$ slenderness ratio of plating between longitudinal stiffeners

$\lambda^{\prime}=\frac{l}{\pi r} \sqrt{\frac{\sigma_{y}}{E}}=$ slenderness ratio of a stiffener together with fully effective plating

$l=$ length of the stiffened panel between the transverse support frames

$r=$ radius of gyration of stiffener

$\beta=$ reliability index

$\lambda=$ bias factor

$\mu_{x}=$ mean value of random variable $x_{i}$

$\sigma_{u}=$ ultimate compressive strength of a plate

$\sigma_{u D}, \sigma_{u S}=$ ultimate compressive strength of a representative plate at the upper or side shell

$\sigma_{y}=$ mean yield strength of the material

$\sigma_{y B}, \sigma_{y S}=$ mean yield strength of the bottom or side shell

$\phi=$ standard normal distribution function

$M_{D}=$ dead-load moment

$M_{L}=$ live-load moment

$M_{n}=$ nominal bending moment strength

$T=$ lifetime of bridge

$I M=$ dynamic live load

DOP $=$ degree of pit corrosion intensity as a ratio of the pitted surface area to the original plate surface area

$n=$ number of pits

$A_{p i}=$ surface area of the $i t h$ pit

$a=$ plate length

$b=$ plate breadth

$d_{r}=$ diameter of the pit

$R_{x r}=$ a factor of ultimate compressive strength reduction due to pit corrosion

$\sigma_{x u}=$ ultimate compressive strength for a member with pit corrosion

$\sigma_{\text {хио }}=$ ultimate compressive strength for an intact (uncorroded) member

$A_{0}=$ original cross-sectional area of the intact member

$A_{r}=$ cross-sectional area involved in pit corrosion at the smallest cross-section (see Fig. 7) 


\section{ACKNOWLEDGEMENTS}

This work was undertaken for the two-year project by the Pusan National University Research Grant.

\section{REFERENCES}

[1] Cheung, M.S. and Li, W.C. "Serviceability Reliability of Corroded Steel Bridges", Canadian Journal of Civil Engineering, 2001, Vol. 28, No. 3, pp. 419-424.

[2] Czarnecki, A.A. and Nowak, A.S. "Time-variant Reliability Profiles for Steel Girder Bridges", Structural Safety, 2008, Vol. 30, No. 1, pp. 49-64.

[3] Melchers, R.E. "The Effect of Corrosion on the Structural Reliability of Steel Offshore Structures", Corrosion Science, 2005, Vol. 47, No. 10, pp. 2391-410.

[4] Melchers, R.E. and Jeffrey, R.J. "Probabilistic Models for Steel Corrosion Loss and Pitting of Marine Infrastructure”, Reliability Engineering and System Safety, 2008, vol. 93, No. 3, pp. 423-432.

[5] Sharifi, Y. "Reliability of Deteriorating Steel Box-girder Bridges under Pitting Corrosion", Advanced Steel Construction, 2011, Vol. 7, No. 3, pp. 220-238.

[6] Sharifi, Y. and Paik, J.K. "Ultimate Strength Reliability Analysis of Corroded Steel-box Girder Bridges", Thin-Walled Structures, 2011, Vol. 49, No. 1, pp. 157-166.

[7] Sharifi, Y. and Paik, J.K. "Environmental Effects on Ultimate Strength Reliability of Corroded Steel Box Girder Bridges", Structural Longevity, 2010, Vol. 18, No. 1, pp. 1-20.

[8] Sharifi, Y. and Paik, J.K. "Maintenance and Repair Scheme for Corroded Stiffened Steel Box Girder Bridges based on Ultimate Strength Reliability and Risk Assessments", Engineering Structures and Technologies, 2014, Vol. 6, No. 3, pp. 43-53.

[9] Sharifi, Y. and Tohidi, S. "Lateral-torsional Buckling Capacity Assessment of Web Opening Steel Girders by Artificial Neural Networks-elastic Investigation”, Frontiers of Structural and Civil Engineering, 2014, Vol. 8, No. 2, 167-177.

[10] Sharifi, Y. and Tohidi, S. "Ultimate Capacity Assessment of Web Plate Beams with Pitting Corrosion Subjected to Patch Loading by Artificial Neural Networks", Advanced Steel Construction 2014, Vol. 10, No. 3, pp. 325-350.

[11] Tohidi, S. and Sharifi, Y. "Restrained Distortional Buckling Capacity of Half-through Bridge Girders”, The IES Journal Part A: Civil \& Structural Engineering, 2014, Vol. 7, No. 3, 163-173.

[12] Tohidi, S. and Sharifi, Y. "Inelastic Lateral-torsional Buckling Capacity of Corroded Web Opening Steel Beams using Artificial Neural Networks", The IES Journal Part A: Civil \& Structural Engineering, 2015, Vol. 8, No. 1, pp. 24-40.

[13] Tohidi, S. and Sharifi, Y. "Neural Networks for Inelastic Distortional Buckling Capacity Assessment of Steel I-beams", Thin-walled Structures, 2015, Vol. 94, pp. 359-371.

[14] Tohidi, S. and Sharifi, Y., "Empirical Modeling of Distortional Buckling Strength of Half-through Bridge Girders via Stepwise Regression Method", Advances in Structural Engineering, 2015, Vol. 18, No. 9, pp. 1383-1397.

[15] Sarveswaran, V. and Roberts, M.B., "Reliability Analysis of Deteriorating Structures-The Experience and Needs of Practicing Engineers", Structural Safety, 1999, Vol. 21, No. 4, pp. 357-372.

[16] Sommer, A.M., Nowak, A.S. and Thoft-Christensen, P. "Probability-based Bridge Inspection Strategy", Journal of Structural Engineering, 1993, Vol. 119, No. 12, pp. 3520-3536.

[17] Mori, Y. and Ellingwood, B.R. "Maintenance Reliability of Concrete Structures I: Role of Inspection and Repair", Journal of Structural Engineering, 1994, Vol. 120, No. 8, pp. 824-45.

[18] Thoft-Christensen, P., "Advanced Bridge Management Systems", Structural Engineering Review, 1992, Vol. 7, No. 3, pp. 151-63. 
[19] Enright, M.P. and Frangopol, D.M., "Service-life Prediction of Deteriorating Concrete Bridges", Journal of Structural Engineering, 1998, Vol. 124, No. 3, pp. 309-17.

[20] Paik, J.K., Kim, S.K. and Lee, S.K., "Probabilistic Corrosion Rate Estimation Model for Longitudinal Strength Members of Bulk Carriers", Ocean Engineering, 1998, Vol. 25, No. 10, pp. 837-860.

[21] Kayser, J.R., "The Effects of Corrosion on the Reliability of Steel Girder Bridges", PhD Thesis, University of Michigan, Ann Arbor, Mich., USA, 1988.

[22] Paik, J.K., Lee, J.M. and Ko, M.J., "Ultimate Compressive Strength of Plate Elements with Pit Corrosion Wastage”, J. Eng Marit Environ., 2003, Vol. 217, No. M4, pp. 185-200.

[23] Paik, J.K., Lee, J.M. and Ko, M.J., "Ultimate Shear Strength of Plate Elements with Pit Corrosion Wastage", Thin-Walled Structures, 2004, Vol. 42, No. 8, pp. 1161-76.

[24] Nakai, T., Matsushita, H. and Yamamoto, N., "Effect of Pitting Corrosion on the Ultimate Strength of Steel Plates subjected to in-plane Compression and Bending", Journal of Marine Science and Technology, 2006, Vol. 11, No. 1, pp. 52-64.

[25] Daidola, J.C., Parente, J., Orisamolu, I.R. and Ma, K.T., "Residual Strength Assessment of Pitted Plate Panels", SSC-394, Ship Structure Committee, Washington, DC, 1997.

[26] Kayser, J.R. and Nowak, A.S., "Reliability of Corroded Steel Girder Bridges", Structural Safety, 1989, Vol. 6, No. 1, pp. 53-63.

[27] Paik, J.K. and Mansour, A.E., "A Simple Formulation for Predicting the Ultimate Strength of Ships”, J. Mar. Sci. Technol., 1995, Vol. 1, No. 1, pp. 52-62.

[28] Paik, J.K. and Thayamballi, A.K., "Ultimate Limit State Design of Steel-Plated Structures", John Wiley \& Sons, Ltd., Hoboken, New Jersey, USA, 2003.

[29] Paik, J.K. and Thayamballi, A.K., "An Empirical Formulation for Predicting the Ultimate Compressive Strength of Stiffened Panels", Proc. $7^{\text {th }}$ International Offshore and Polar Engineering Conference, IV, Honolulu, pp. 328-338, 1997.

[30] Paik, J.K., Thayamballi, A.K. and Lee, J.M., "Effect of Initial Deflection Shape on the Ultimate Strength Behavior of Welded Steel Plates under Biaxial Compressive Loads", Journal of Ship Research, 2004, Vol. 48, No. 1, pp. 45-60.

[31] Nowak, A.S. and Collins, K.R., "Reliability of Structures", McGraw-Hill, Thomas Casson, Boston, USA, 2000.

[32] Nowak, A.S., "Live Load Model for Highway Bridges”, Structural Safety, 1993, Vol. 13, No. 1-2, pp. 53-66.

[33] Nowak, A.S., "Calibration of LRFD Bridge Code”, Journal of Structural Engineering, 1995, Vol. 121, No. 8, pp. 1245-1251.

[34] Nowak, A.S. and Szerszen, M.M., "Bridge Load and Resistance Models", Engineering Structures, 1998, Vol. 20, No. 11, pp. 985-990.

[35] Nowak, A.S. and Szerszen, M.M., "Structural Reliability as Applied to Highway Bridges", Prog. Struct. Engng. Mater., 2000, Vol. 2, No. 2, pp. 218-224.

[36] AASHTO LRFD "Bridge Design Specifications, American Association of State Highway and Transportation Officials", Washington, D.C., 2004.

[37] Barker, R.M. and Puckett, J.A., "Design of Highway Bridges and LRFD Approach", John Wiley \& Sons, Inc., Hoboken, New Jersey, USA, 2007.

[38] Mansour, A.E., "An Introduction to Structural Reliability Theory", Ship Structure Committee, Report No. SSC-351, 1990.

[39] Achintya, H. and Mahadevan, S., "Probability, Reliability and Statistical Methods in Engineering Design", John Wiley \& Sons, Inc., Hoboken, New Jersey, USA, 2000.

[40] Lemarie, M., "Structural Reliability", John Wiley \& Sons, Inc., Hoboken, New Jersey, USA, 2009.

[41] Melchers, R.E., "Structural Reliability Analysis and Prediction', Wiley, Chichester, UK, 1999.

[42] Nowak, A.S. and Lind, N.C., "Practical Bridge Code Calibration', J Strut Div, 1979, Vol. 105, No. 12, pp. 497-510. 
[43] Flint, A.R., Smith, B.W., Baker, M.J. and Manners, W., "The Derivation of Safety Factors for Design of Highway Bridges", In: Proc. Conf. on the New Code for the Design of Steel Bridges, Cardiff, March, 1980.

[44] Chryssanthopoulos, M.K. and Micic, T.V., "Reliability Evaluation of Short Span Bridges", In: Proc. of the International Symposium on the Safety of Bridges, ICE/HA, London, July, 1996. 



\title{
REFLECTOR WIND LOAD CHARACTERISTICS OF THE LARGE ALL-MOVABLE ANTENNA AND ITS EFFECT ON REFLECTOR SURFACE PRECISION
}

\author{
Yan Liu ${ }^{1, *}$, Hong-liang Qian ${ }^{2}$ and Feng Fan ${ }^{2}$ \\ 1 School of Civil Engineering, Chang'an University, Xi'an 710061, P.R. China \\ ${ }^{2}$ School of Civil Engineering, Harbin Institute of Technology, Harbin 150090, P.R. China \\ *(Corresponding author: E-mail: actor_liu@126.com)
}

Received: 23 August 2015; Revised: 19 January 2016; Accepted: 20 February 2016

\begin{abstract}
The wind load could cause the deformation of the reflector surface, seriously affect the resolution and the sensitivity of the antenna and degrade its performance. So the analysis of the wind characteristics of the reflector surface is particularly important. For one thing, the wind loads acting on an open parabolic reflector, as a commonly used type of reflector $(F / D=0.3)$, are obtained by the wind tunnel test and CFD technique and wind characters of the parabolic reflector are revealed. Wind-induced dynamic behaviors under different upwind profiles are also analyzed by the finite element method (FEM). After that based on the numerical simulation, a large number of different kinds of reflectors are researched and analyzed and the results for different diameters, focal length to diameter ratios are acquired to provide sufficient information for wind force proofing design of the antenna structures. Finally, taking the established $110 \mathrm{~m}$ antenna structure as the example and based on the instantaneous pressures derived from the wind tunnel tests, the mechanic performances of the structure at the survival wind speed and working speed are respectively investigated, and consequently the reliability of its mechanic performance is evaluated. The surface RMS of structural responses under various wind loads conditions and internal mechanisms are finally discussed to provide valuable data for the deformation control of the actuators in further work.
\end{abstract}

Keywords: Antenna structure, wind tunnel test, numerical simulation, wind-induced vibration response, wind force proofing design

DOI:10.18057/IJASC.2016.12.4.2

\section{INTRODUCTION}

As a multi-functional, automatic, high-integrated electronic mechanical equipment, the radio telescope structure is subjected to random wind load in the operation of variable-position rotation, which causes the surface deviation of deformed reflector from the theoretical designed reflector. This error has an important influence on the surface accuracy of the reflector [1-3].

For the calculation of wind load, the wind pressure distribution on the reflector surface is required. The influence factors on the distribution are complex and diverse, not only by the wind turbulence in the wind, but also by the wind angle, pitch angle of the antenna structure, the geometrical characteristics of the reflector surface and so on. From the view of the present situation of the domestic application, Miyun 50m antenna in Beijing, Shanghai $65 \mathrm{~m}$ antenna and $110 \mathrm{~m}$ to be built in Xinjiang all belongs to the same category of the all-movable radio telescope which has a focal length to diameter ratio of 0.3 , a circular aperture and parabolic reflector. This situation reflects that the geometric characteristics of the reflector are very common. From the research status of wind force proofing design for the antenna structures, foreign scholars have carried out the wind tunnel test at 4 upwind attitudes for the focal length to diameter ratios 0.5 and 0.25 respectively and acquired the average wind pressure distribution. It can be seen in this achievement the analysis cases for different upwind attitudes are scarce. In domestic the wind tunnel tests study for the focal length to diameter ratio 0.3 with 12 upwind attitudes have been carried out to give the overall drag coefficient of reflector but the average wind pressure distribution of the surface is not given. According to the Load Code for the Design of Building Structures, facing the results achieved, 
although the spherical shell in the geometrical shape is the most close to the parabolic surface, there are still some differences between the two above. Simultaneously the results of the spherical shell derive from the enclosed structure yet the reflector of the antenna in wind field belongs to an open type structure. So the circling flow characteristics around for the two types of structures are quite different.

It can be seen that the research results of this kind of structure are not comprehensive. The comprehension for its wind load and wind induced vibration response characteristics is very poor. It is necessary to carry out a large number of wind tunnel tests and numerical simulations for the reflector structure and provide the meaningful references for the wind load proofing design of the antenna structure and the valuable data for the deformation control of the actuators caused by the wind load.

\section{CFD NUMERICAL SIMULATIONS}

In this work the research objects are different radio telescopes so in the numerical simulation the grid division strategy is significant to solve the FEM [4-7]. The problems need to be done reflect in that the reflector has an open parabolic surface, it is difficult to deal with the grid division around the surface area and not easy to form a high quality grid. So it is intended to make a hybrid mesh for the computational domain. Meanwhile it is necessary to increase the grid around the upper and lower surface, adjust the gradient ratio of the grid and the $y^{+}$value near the surface boundary to further improve the mesh quality and calculation accuracy.

Where, $y^{+}$is introduced to represent the distance from the centroid of the near wall mesh to the wall surface. This dimensionless quantity is related with speed, viscosity and shear stress of the fluid. The specific division is illustrated in section 2.3.

\subsection{Computational Domain Settings}

In the numerical simulation of wind pressure distribution the computational domain is closed by setting several wall surfaces to guarantee the blocking probability is less than $5 \%$. So it is necessary to determine the appropriate computational domain. Computational domain comprises upper reaches $L_{1}$, lower reaches $L_{2}$, windward width $B$, and height $H$. The computational domain is shown in Figure 1 [8-9] and each parameter set is list in Table 1.

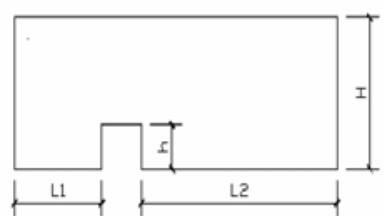

a) Longitudinal section of computational domain

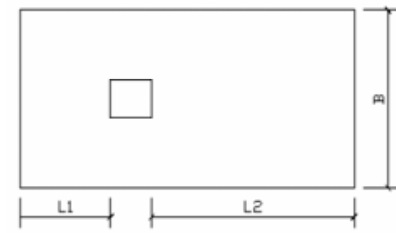

b) Horizontal plane of computational domain Figure 1. Configuration Items of the Computational Domain

Table 1. Computational Field Setting

\begin{tabular}{ccc}
\hline Model size & \multicolumn{1}{c}{$l \times b \times h$} \\
\hline Computational domain & $L_{1}=5 l, L_{2}=15 l, \quad H=8 h, \quad B=10 b$ \\
\hline
\end{tabular}




\subsection{Turbulence Model and Boundary Conditions}

According to the references the complete Reynolds stress model has a relatively high accuracy for solving the flow around a bluff body and its use range is wide. So in this work the RSM turbulence model is used to solve the constant pressure field around a constant flow of the reflector structure. The boundary conditions of the model are set in Table 2 .

\section{$2.3 \quad$ Meshing}

Meshing has a direct influence on the results of numerical simulation and is mainly embodied with the gird size and the grid type. Based on many times in meshing for the flow field around the reflector structure, finally the grid type and grid quantity adopted for each part of the flow field are shown in Table 3 and Figure 2.

1) The outside domain uses the structural hexahedral mesh which could provide a fine grid size, decrease the grid quantity and guarantee the grid quality. While the inside domain uses unstructured tetrahedral grid which could achieve effective meshing to the flow field around the reflector structure.

Table 2. Boundary Condition Setting in CFD

Shear flow is considered: wind profile $V_{z}=V_{10}(z / 10)^{\alpha}$, geomorphic type

B $\alpha=0.15, V_{10}=33.5 \mathrm{~m} / \mathrm{s}$ according to the basic wind pressure.

The governing equations of the incompressible turbulent wind flow around buildings are presented by the RANS equations as follows.

$$
\frac{\partial u_{i}}{\partial x_{i}}=0, \frac{\partial}{\partial x_{j}}\left(\rho u_{j} u_{i}\right)=-\frac{\partial p}{\partial x_{i}}+\frac{\partial}{\partial x_{j}}\left[\mu\left(\frac{\partial u_{i}}{\partial x_{j}}+\frac{\partial u_{j}}{\partial x_{i}}\right)-\rho \overline{u_{i}^{\prime} u_{j}^{\prime}}\right] \text {. }
$$

Inlet boundary Turbulence properties are defined by means of kinetic energy and condition

$$
\text { turbulent dissipation rate. } k=1.5\left(V_{Z} \cdot I\right)^{2}, \quad \varepsilon=\frac{1}{l} 0.09^{\frac{3}{4}} k^{\frac{3}{2}} \text {. Where } l
$$

represents turbulent characteristic scale, and I represents turbulent intensity.

Turbulent intensity of the incoming flow: Refers to data of the second geomorphic type in Australia Code [10-11].

Reference coordinate system: $Y$ axis represents the length direction of the computational domain and $Z$ represents the height direction of the structure.

Outlet $\quad$ Fully developed flow boundary condition is adopted and the normal boundary gradient of any physical quantity $\psi$ in the flow field is zero.

condition

Wall condition

Top and both sides computational domain: free slip wall condition. Reflector surface and ground: no slip wall condition.

2) Because the parabolic reflector has a gradient of spatial curvature and the thickness of the model is only $100 \mathrm{~mm}$. The near wall region adopts the prismatic boundary layer grid to realize the precise control to the meshing and meet the requirements of the minimal wall distance [12-15]. The distance can be characterized by the dimensionless value $y^{+}$which could be expressed in formula (1). The closest grid point near the wall surface is adopted to be $0.025 \mathrm{D}$, with corresponding wall unit $\mathrm{y}^{+}$ranging from about $8 \sim 30$. The determination of $\mathrm{y}^{+}$is controlled and realized by mesh division. 
$y^{+}=\frac{\rho u_{\tau} y}{\mu}$

Where $u_{\tau}$ represents the frictional velocity, $y$ represents the normal distance from the nodes in the first row to the wall surface. $\rho$ represents the air density, and $\mu$ represents the kinematic coefficient of viscosity.

Table 3. Mesh Division for Calculation Area in the Flow Field

\begin{tabular}{cccc}
\hline \multirow{2}{*}{ Model } & Computational domain & Mesh type & Mesh \\
& Outside domain & Structured hexahedral mesh & 1000,000 \\
Parabolic & Inside domain & Unstructured tetrahedral mesh & 500,000 \\
reflector & Near wall region & Prismatic boundary layer mesh & 150,000 \\
\hline
\end{tabular}

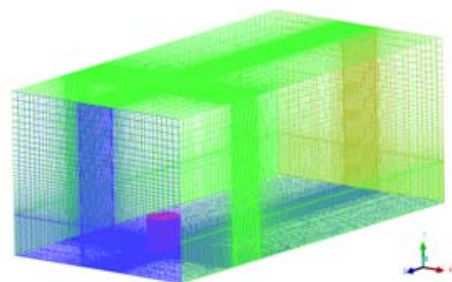

a) Outer calculation domain

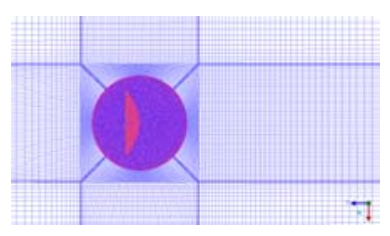

b) Inner calculation domain

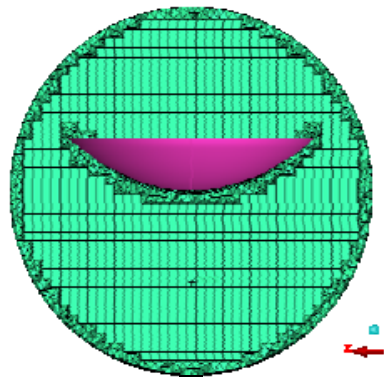

c) Domain of near the wall

Figure 2. Mesh of the Numerical Domain

\section{$2.4 \quad$ Analysis Cases}

The wind direction is defined as shown in Figure 3. According to the symmetry of the model, the wind angle for test is selected about every $30^{\circ}$ in the range of $0^{\circ}$ to $180^{\circ}$. In the pitching rotation the angles of $5^{\circ}, 30^{\circ}, 60^{\circ}$ and $90^{\circ}$ are selected for test. Based on the above parameters there are 22 analysis cases in total (For the pitch angle of $90^{\circ}$, any wind direction is polar symmetrical about the central axis of the reflector so a kind of wind angle is enough).

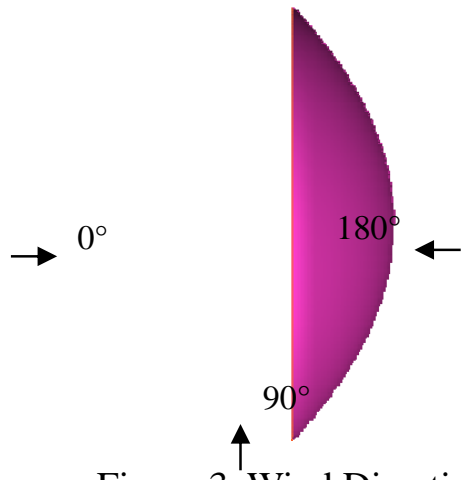

Figure 3. Wind Direction Angle 


\subsection{CFD Simulation Results}

The numerical simulations are carried out by the software Fluent and the average wind pressure distribution on the reflector surface is described in the form of contour by the software Tecplot, shown in Figure 4 to Figure 7. From the figures, under the pitch angle of $5^{\circ}$ for the model, when the wind angle is less than $90^{\circ}$ the reflector surface is completely under the positive pressure and with the increase of the wind angle, the partial pressure coefficient of the edge region increases. When the wind angle is $90^{\circ}$ for the same pitch angle, the negative pressure begins to appear on the reflector surface as the wind suction and the wind pressure distribution along the wind direction is basically symmetrical. The negative pressure area of the reflector surface gradually expands with the increase of the wind angle till the wind angle runs up to $180^{\circ}$, the reflector surface is completely under the negative pressure. When the pitch angle of the model is $30^{\circ}$ or $60^{\circ}$, the wind pressure distribution of the reflector surface is similar to that of the $5^{\circ}$ pitch angle model. In addition, under the same direction with the increase of the pitch angle, the local positive pressure coefficient increases and the distribution area expands. Especially for the pitch angle of $60^{\circ}$ under the wind angle of $60^{\circ}$, the maximum positive pressure coefficient reaches 1.9. The wind pressure distribution on the reflector surface not only has a good symmetry but also shows the maximum negative pressure in the front edge of the windward side for the pitch angle of $90^{\circ}$ under the wind angle of $0^{\circ}$. Meanwhile the absolute value of the negative pressure coefficient gradually decreases and turns to the positive pressure along the flow direction. In the lower reaches the positive pressure begins to increases and the positive pressure area is greater than that of the negative area in general.

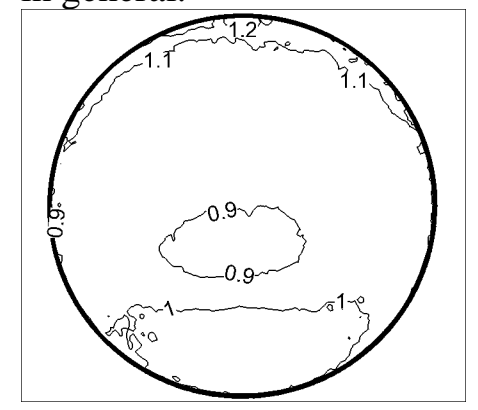

a) $0^{\circ}$

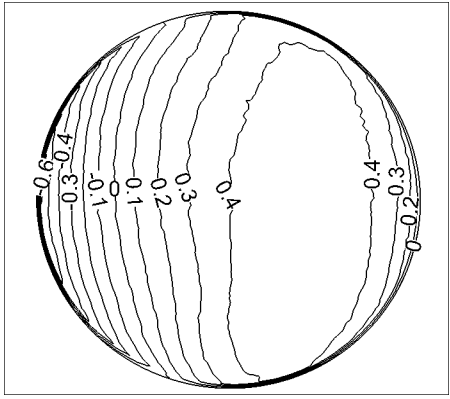

d) $90^{\circ}$

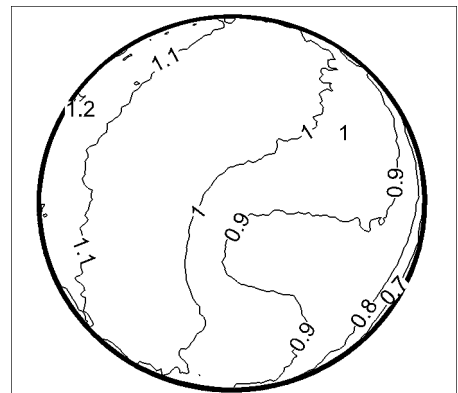

b) $30^{\circ}$

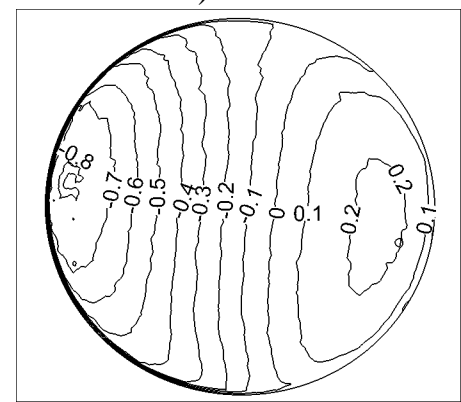

e) $120^{\circ}$

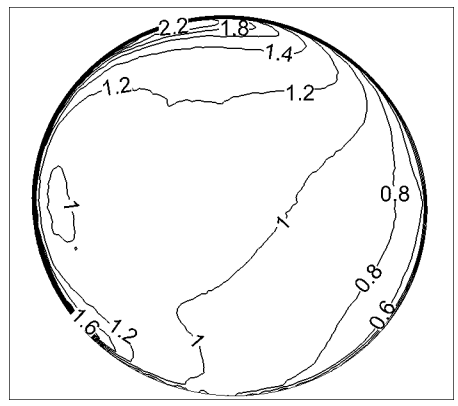

c) $60^{\circ}$

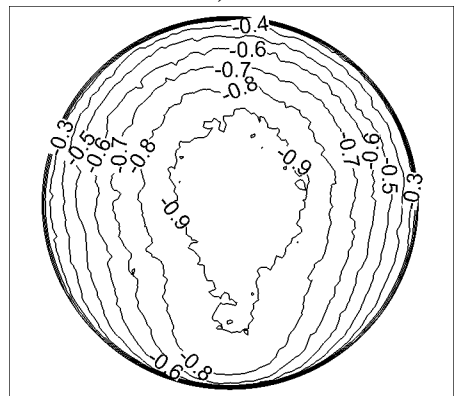

f) $180^{\circ}$

Figure 4. Mean Wind Pressure Coefficients of Reflector under Different Wind Angles for $5^{\circ}$ Pitch Angle 


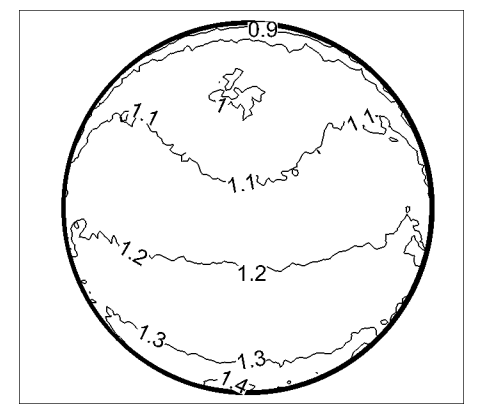

a) $0^{\circ}$

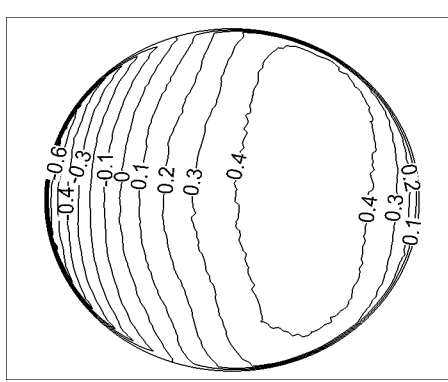

d) $90^{\circ}$

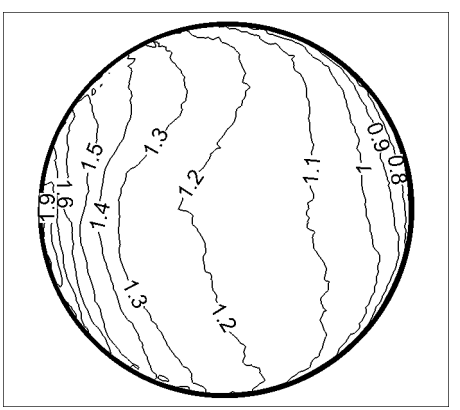

b) $30^{\circ}$

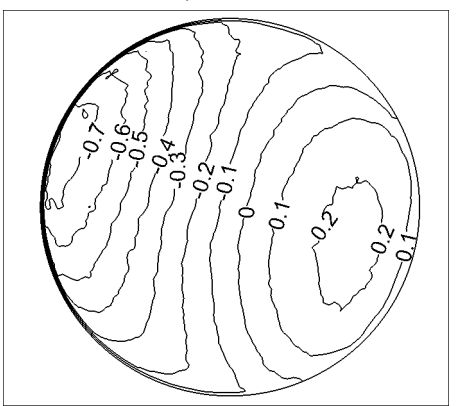

e) $120^{\circ}$

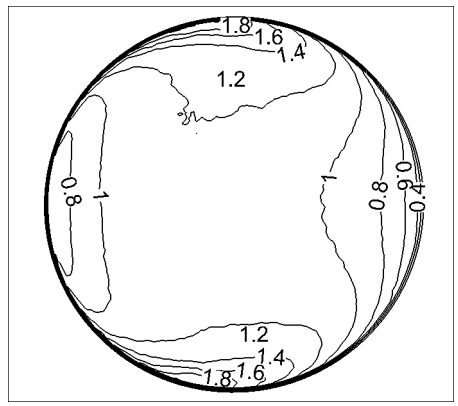

c) $60^{\circ}$

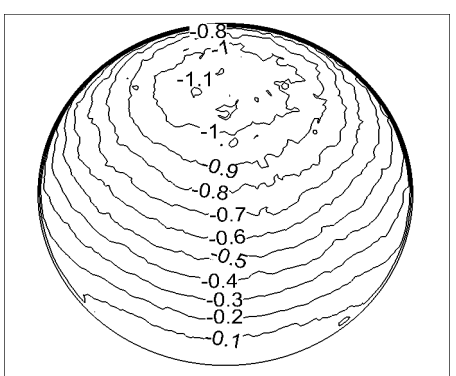

f) $180^{\circ}$

Figure 5. Mean Wind Pressure Coefficients of Reflector under Different Wind Angles for $30^{\circ}$ Pitch Angle

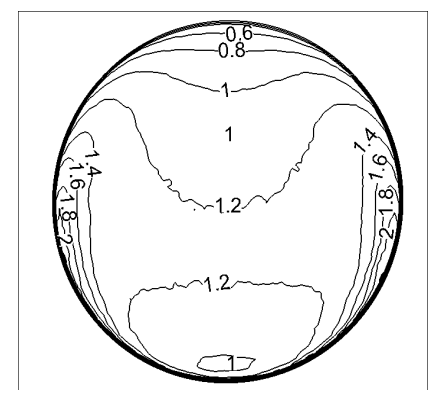

a) $0^{\circ}$

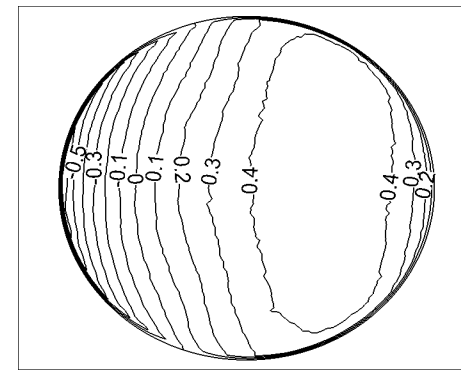

d) $90^{\circ}$

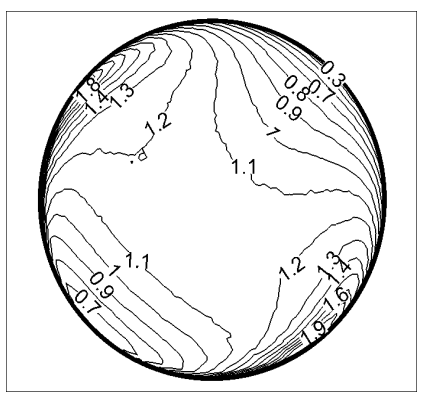

b) $30^{\circ}$

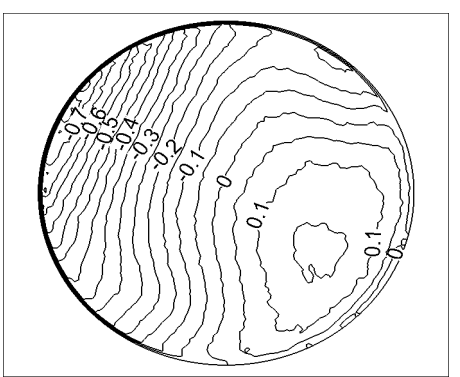

e) $120^{\circ}$

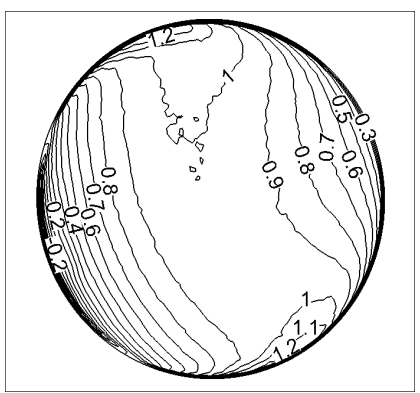

c) $60^{\circ}$

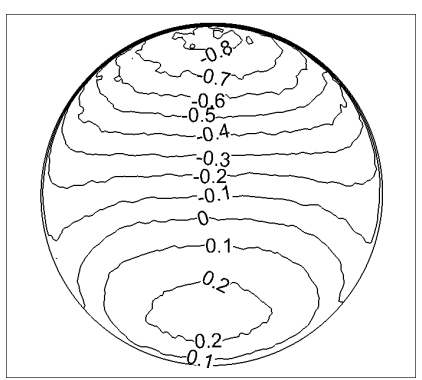

f) $180^{\circ}$

Figure 6. Mean Wind Pressure Coefficients of Reflector under Different Wind Angles for $60^{\circ}$ Pitch Angle 


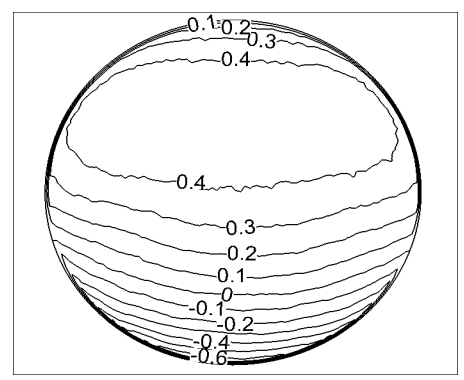

Figure 7. Mean Wind Pressure Coefficients of Reflector for $90^{\circ}$ Pitch Angle

\section{WIND TUNNEL TEST}

In order to verify CFD numerical simulation validity for parabolic reflector structure, scale model test for the $110 \mathrm{~m}(F / D=0.3)$ reflector structure is carried out in the wind tunnel. The test cases concur with the simulation cases and the test is the manometric test of rigid models. By comparison between the test and simulation, the wind pressure characteristics of the parabolic reflector structure are described furtherly and the internal mechanism is revealed.

\subsection{Wind Tunnel Facility and Measurement System}

The manometric test is carried out in the State Key Laboratory for Wind Tunnel and Water flume in Harbin Institute of Technology. The wind tunnel has a double closed test section with the single reflow (shown in Figure 8). The laboratory is a comprehensive experiment platform which integrates the wind field simulation of the near ground surfaces, the deep ocean wave simulation and the rainfall simulation. The small section is $4 \mathrm{~m}$ in width, $3 \mathrm{~m}$ in height and $25 \mathrm{~m}$ in length and the testing wind speed is $3 \mathrm{~m} / \mathrm{s} \sim 50 \mathrm{~m} / \mathrm{s}$. The big section is $6 \mathrm{~m}$ in width, $3.6 \mathrm{~m}$ in height and $50 \mathrm{~m}$ in length and the testing wind speed is $3 \mathrm{~m} / \mathrm{s} \sim 27 \mathrm{~m} / \mathrm{s}$. This work is carried out in the small testing section.

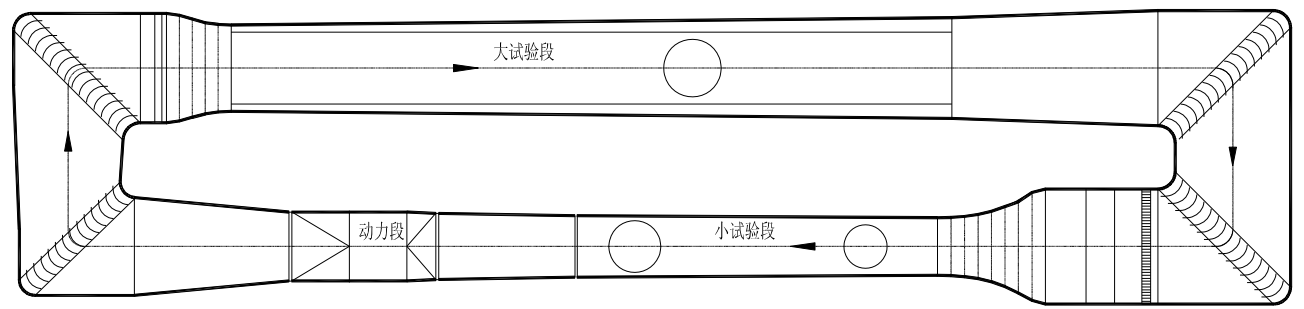

Figure 8. Outline Drawing of Wind Tunnel in HIT

Manometry system uses the electronic pressure scanning valve system produced by Scanivalve scanning company in the USA for scanning and measurement. Finally, the data is recorded and processed by the signal acquisition and data processing software realized in the PC, shown in the Figure 9. 

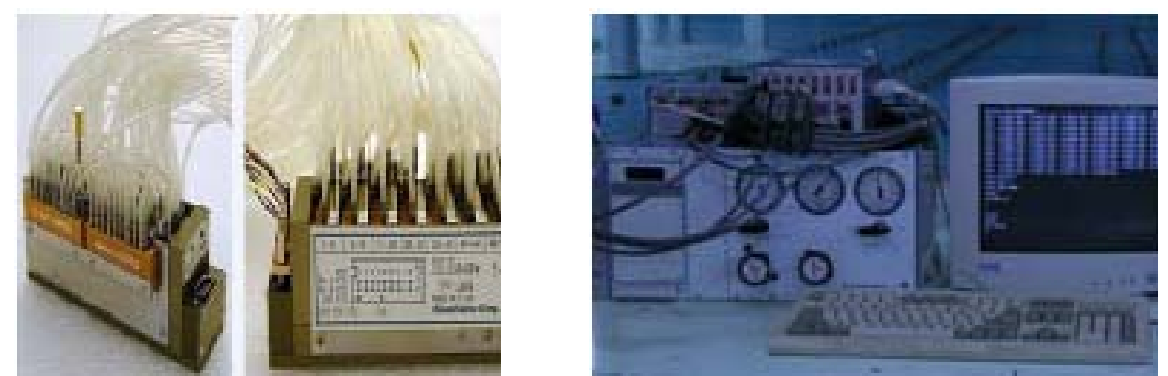

Figure 9. Electronic Pressure Scanner System for DSM3400

\subsection{Simulation of the Atmospheric Boundary Layer}

In the wind tunnel, it is necessary to accurately reproduce the atmospheric boundary layer flow characteristics and ensure credible results. Namely the flow field in the wind tunnel tests should be similar with the atmospheric boundary layer wind flow in the outside world. Its wind speed and turbulence intensity vary with the height. And there are some certain requirements for fluctuating wind power spectrum.

\subsubsection{The mean wind profile}

Below the gradient wind lever, because of the friction near the ground, near-Earth wind speed decreases with the decrease of its height above the ground. The relation between the average wind speed and the height is described as the velocity profile curve. Usually logarithmic and exponential functions are adopted to describe the curve rule. In this paper, exponential law is used as the following formula (2).

$\frac{U_{(Z)}}{U_{r}}=\left(\frac{Z}{Z_{r}}\right)^{\alpha}$

Where $U_{(Z)}$ represents the average wind speed at arbitrary height, $Z$ represents the height, $U_{(r)}$ represents the average wind speed at the standard reference height, $Z_{(r)}$ represents the reference height, $\alpha$ represents the surface roughness index, the structure is situated at a Class B landform and its index value is 0.15 .

\subsubsection{Turbulent intensity}

Turbulence intensity at arbitrary height is expressed as equation (3)

$I_{z}=\sigma_{u}(z) / U(z)$

Turbulence intensity decreases with the increase of the height, usually $20 \% \sim 30 \%$ close to the ground. Chinese specification has no requirement for this at present and the Japanese specification gives specific recommendations about the turbulence intensity.

\subsubsection{The power spectral density function}

Atmospheric turbulence is a random and fluctuating process. The power spectral density function of fluctuating wind velocity is an important parameter to describe the wind field. At present the power spectrums of Davenport, Karman and Kaimal are frequently used in analysis. 
1) Davenport spectrum (based on the Canadian specification NBC and Chinese specification GBJ [16-19])

$\frac{f S_{u}(f)}{\sigma_{u}^{2}}=\frac{4 x^{2}}{6\left(1+x^{2}\right)^{4 / 3}}$

Where $x=f L_{u} / \bar{U}_{10}, f$ represents the frequency, $L_{u}$ represents the turbulence integral scale, approximate to 200 , and $\bar{U}_{10}$ represents the average wind speed at the height of $10 \mathrm{~m}$.

2) Karman spectrum (based on the Japanese specification AIJ )

$\frac{f S_{u}(f)}{\sigma_{u}^{2}}=\frac{4 x}{\left(1+70.8 x^{2}\right)^{5 / 6}}$

Where $x=f L_{u} / \bar{U}_{10}$.

3) Kaimal spectrum (based on the American specification ASCE)

$\frac{f S_{u}(f)}{\sigma_{u}^{2}}=\frac{200 x}{6(1+50 x)^{5 / 3}}$

Where $x=f z / U(z)$.

\subsubsection{Wind field simulation}

In this paper, passive technology is adopted for the simulation of atmospheric boundary layer in the wind tunnel. The concrete geomorphic type is realized with wedge, the bezel and the roughness, shown in Figure $10 \mathrm{a}$ ). The comparison between measured wind speed values and the theoretical spectrum spectral curve is shown in Figure $10 \mathrm{~b}$ ). Its wind speed profile and the turbulence intensity profile are shown in Figure $10 \mathrm{c}$ ) and d) respectively. It obviously that the measured wind speed spectrum in the wind tunnel is the most close to theoretical Karman spectrum.

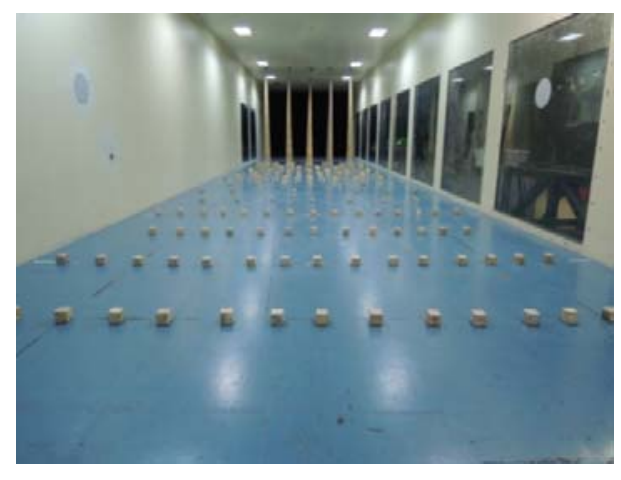

a) Passive simulation device

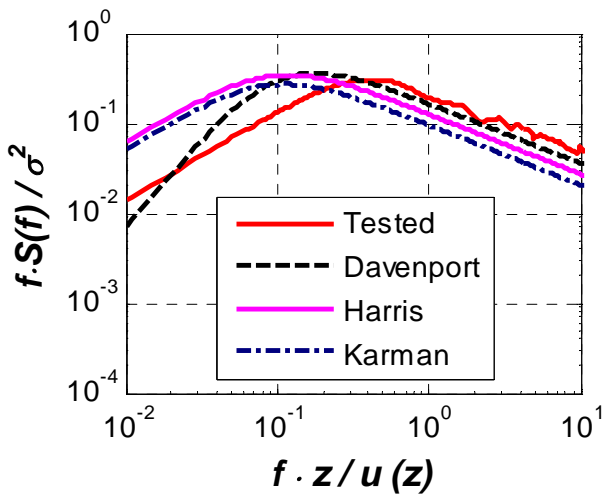

b) Comparison of measurement and theoretical value for wind speed spectrum 


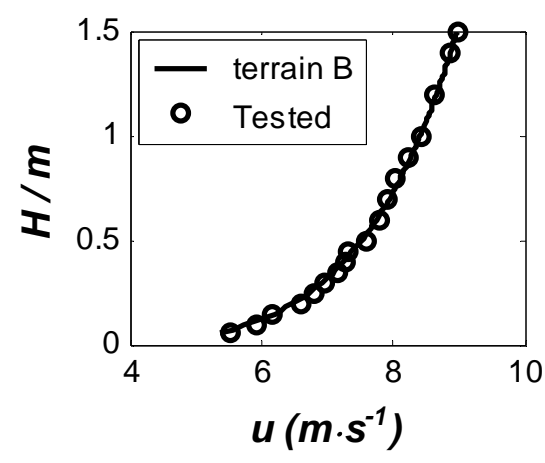

c) Wind profile

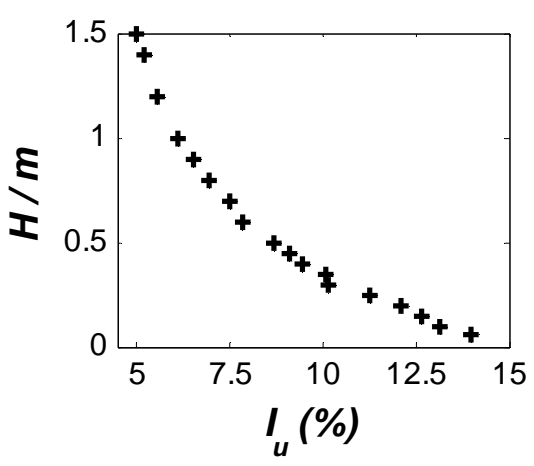

d) Turbulence intensity profile

Figure 10. Wind Tunnel Simulation for Terrain B of the Atmospheric Boundary Layer

\subsection{Test Model and the Procedures Description}

The test model is shown in the Figure 11 . The pitch axis of the lower frame is $250 \mathrm{~mm}$ high off the basement. A series of bolt holes are opened in the lateral and vertical steel pipe on the basis of angular relations to achieve the rotation of the reflector in the pitch direction by arm swing. After each rotation, the lateral and the vertical steel pipes are connected by the corresponding holes to maintain a balance as shown in Figure 12 and 13. In order to acquire not only adequate stiffness and strength of the model, but also facilitation in processing technology, the reflector surface adopts acrylic plexiglass plates. In view of the wind tunnel blockage ratio requirements, the geometry ratio of the model is $1 / 200$. Model has a span of $550 \mathrm{~mm}$ and its ratio of rise to span is 1/4.8. Each acrylic plexiglass plate of two layers has a thickness of $5 \mathrm{~mm}$ and the metal pressure tube has a length of $8 \mathrm{~mm}$. In light of the layout of the pipeline, the minimum interlayer thickness needs $10 \mathrm{~mm}$ space and its size is shown in Figure 14. Convex and concave in the model are arranged by measurement points. Each side has 91 measurement points and these measuring points are shown in Figure 15.

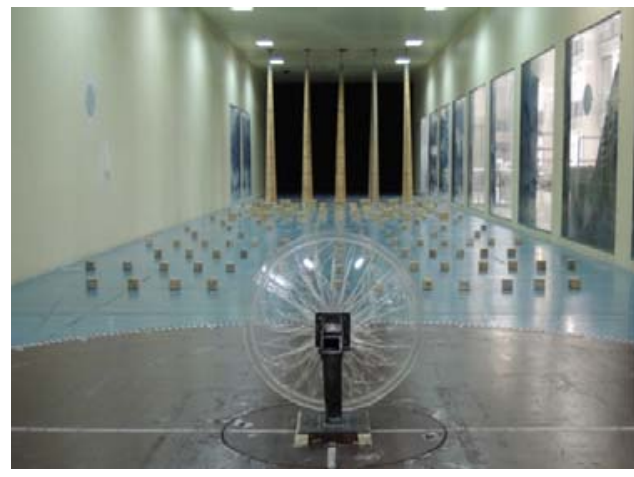

a) Front view

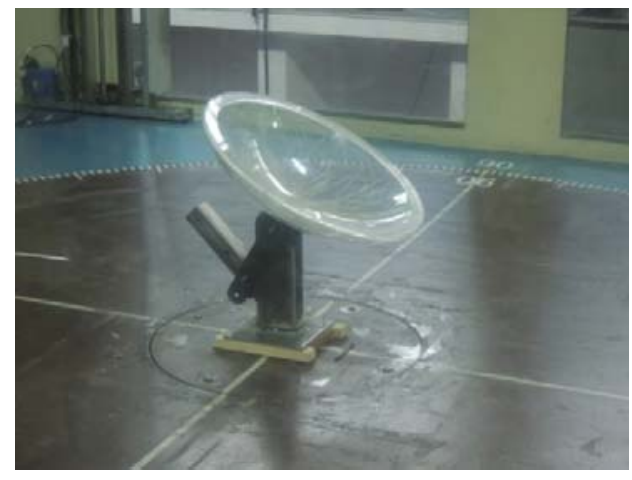

b) Perspective view

Figure 11. Experimental Model in the Wind Tunnel 


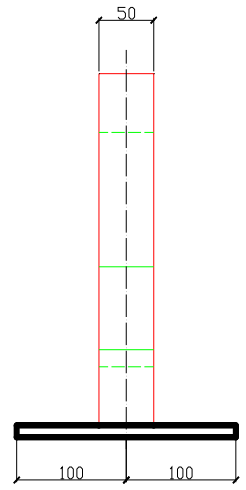

Figure 12. Front View of the Lower Bracket

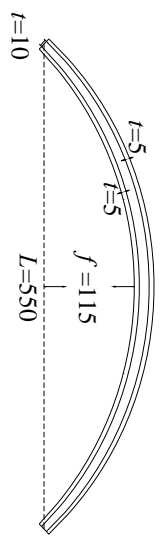

Figure 14. Reflector Section Plan of the Test Model

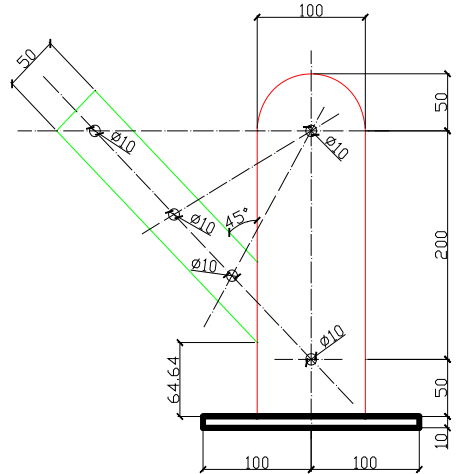

Figure 13. Side View of the Lower Bracket

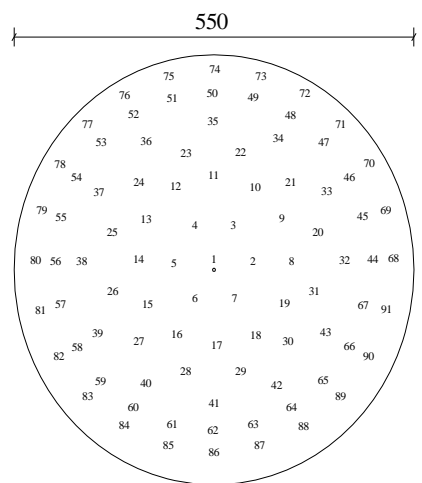

Figure 15. Pressure Tap Arrangement

\subsection{Similarity Ratio Design}

The wind speed in the tunnel is $14 \mathrm{~m} / \mathrm{s}$ and the test speed ratio is $1: 4$. The signal sampling frequency of the pressure valve is $625 \mathrm{~Hz}$ and the sampling duration is 20s. Each individual measurement point collects 12500 times for the data as a sample, five samples in total. According to the similarity theory, the equation (7) shows the relation between the real structure and the test model.

$n_{m} L_{m} / U_{m}=n_{p} L_{p} / U_{p}$

Where $n$ represents the frequency, $L$ represents the geometry size, $U$ represents the wind speed. The subscript $m$ represents the model and $p$ stands for the prototype. It can be obtained from the above equation that $n_{m}=150 \mathrm{~Hz}$. Based on the Naikuitesi sampling criteria, the minimum sampling frequency in the experimental is $150 \mathrm{~Hz} \times 2=300 \mathrm{~Hz}$. It can be concluded that the test sampling frequency $625 \mathrm{~Hz}$ meets the requirements. The similarity ratios of the rest relevant variables are shown in Table 4. In order to obtain reliable experimental data, the final time course of the wind pressure is the average of many samplings.

Table 4. Scaling Laws for Sind Tunnel Tests

\begin{tabular}{cccc}
\hline Clause & Model data & Prototype data & Similarity ratio \\
\hline Diameter & $550 \mathrm{~mm}$ & $110 \mathrm{~m}$ & $1: 200$ \\
Velocity & $14 \mathrm{~m} / \mathrm{s}$ & $56 \mathrm{~m} / \mathrm{s}$ & $1: 4$ \\
Time & $20 \mathrm{~s}$ & $16.6 \mathrm{~min}$ & $1: 50$ \\
\hline
\end{tabular}


The wind pressure value of each measurement point is expressed as the dimensionless pressure coefficient according to the equation (8).

$C_{p i}(t)=\frac{P_{i}(t)-P_{\infty}}{P_{0}-P_{\infty}}$

Where $C_{p i}(t)$ is the pressure coefficient at any hole of the model. $P_{i}(t)$ stands for the measured wind pressure of the structure surface. $P_{0}$ and $P_{\infty}$ represent the average total pressure and the mean static pressure at the reference point respectively. Reference point is the highest point of the reflector surface. For wind-resistant design and comparison with the corresponding specifications, it is necessary to transfer the measured pressure coefficient into the shape factor. For example the relation between the shape factor $\mu_{s i}$ and the average pressure coefficient is expressed as the following equation (9).

$\mu_{s i}=\bar{C}_{p i}\left(\frac{Z_{r}}{Z_{i}}\right)^{2 \alpha}$

Where $Z_{i}$ represents the height of the measuring point, and $Z_{r}$ represents the the height of the standard reference point.

\subsection{Test Results}

Based on the software MATLAB, the corresponding program and the average pressure data contour line drawing process are programmed. The collected process data is processed according to the equation (8). Then the average pressure data is used to make the contour line for all the test conditions as shown in Figure 18 to Figure 21. It can be seen from the figures that when the pitch angle is $5^{\circ}$ and wind angle is within $90^{\circ}$, the reflector surface are completely under the positive pressure, and to the wind angle of $60^{\circ}$, the maximum pressure coefficient is 1.2. When the wind angle is $90^{\circ}$, the negative pressure zone begins to appear at the reflector surface and there is wind suction. When the wind angle is beyond $90^{\circ}$, the reflector surface negative pressure area gradually expands. When the wind angle is $120^{\circ}$, the boundary between the positive and negative pressure zones appears at the centre of the reflector. Until wind angle is $180^{\circ}$, reflective surface is completely controlled by negative pressure. In addition, when pitch angle is $30^{\circ}$ or $60^{\circ}$, contour lines of the pressure distribution are more intensive. It is concretely demonstrated by the edge of the reflector surface where pressure distribution gradient is more intense but the pressure gradient of central area is gentler. When the pitch angle is $90^{\circ}$ and the wind angle is $0^{\circ}$, the reflector surface pressure distribution shows a good symmetry and the maximum wind suction occurs at the windward edge. Along the flow direction, the absolute value of the negative coefficient gradually decreases until the positive pressure appears and gradually increases. Overall the positive pressure area of the reflector surface is bigger than the negative pressure area under the wind load. Nevertheless the negative area mainly focuses on the local region of the windward front of the reflector surface. 


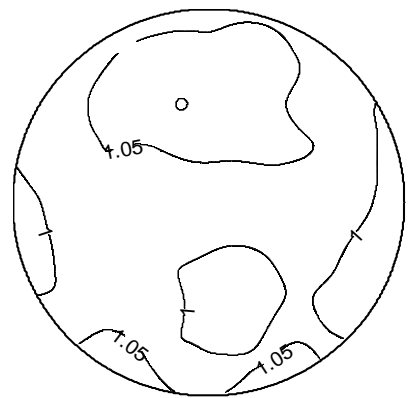

a) $0^{\circ}$

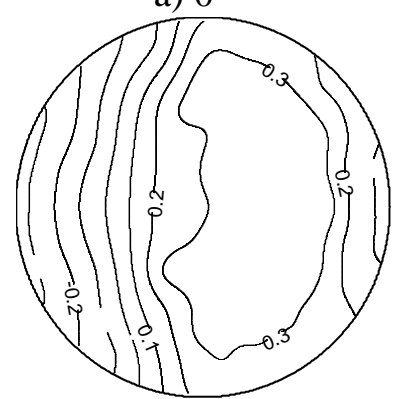

d) $90^{\circ}$

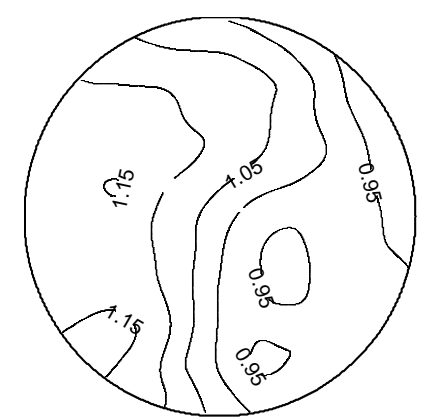

b) $30^{\circ}$

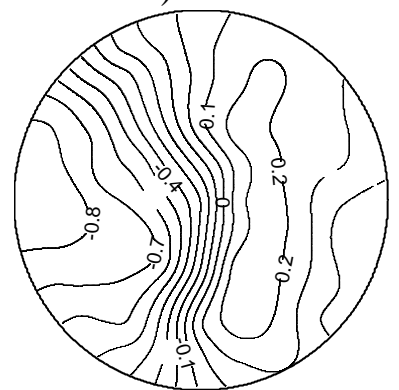

e) $120^{\circ}$

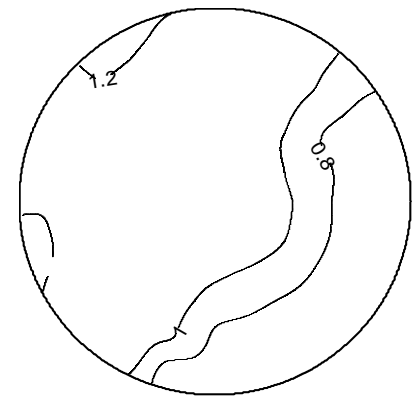

c) $60^{\circ}$

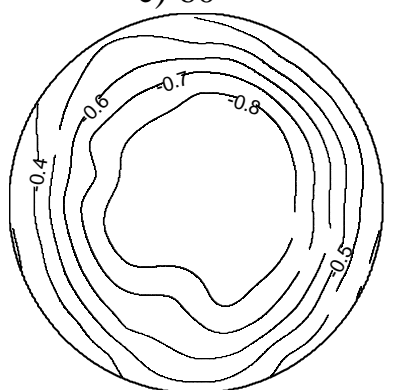

f) $180^{\circ}$

Figure 18. Mean Wind Pressure Coefficients of Reflector in Different Wind Directions for $0^{\circ}$ Pitch Angle

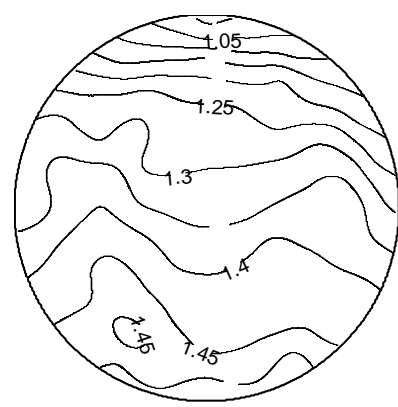

a) $0^{\circ}$

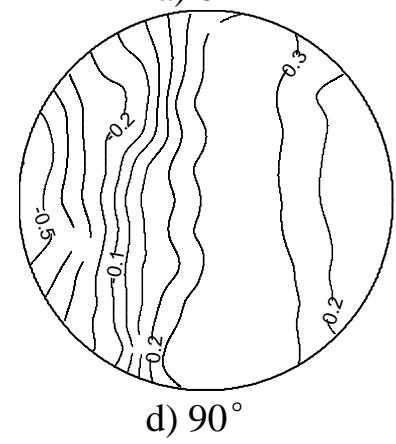

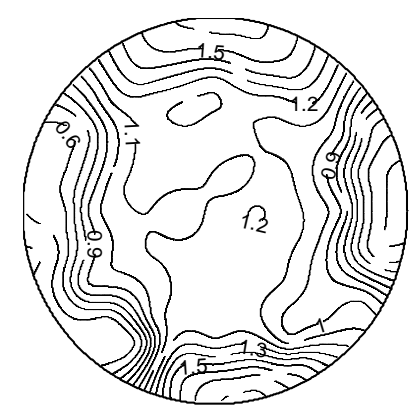

b) $30^{\circ}$

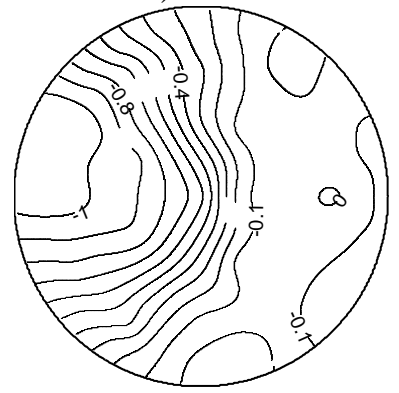

e) $120^{\circ}$

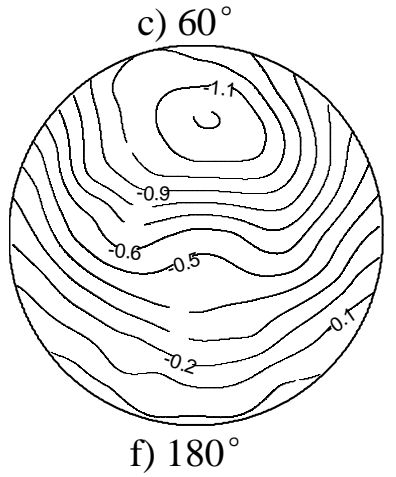

Different Wind Directions for $30^{\circ}$ Pitch Angle 


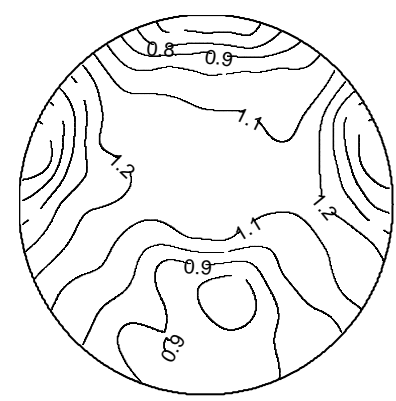

a) $0^{\circ}$

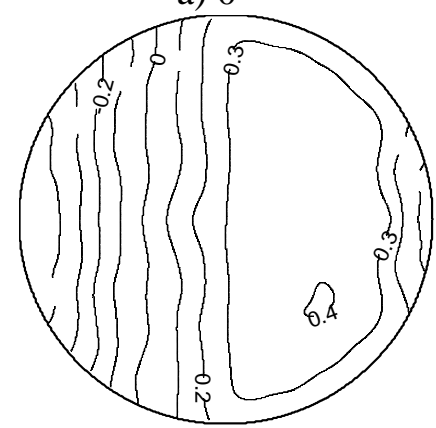

d) $90^{\circ}$

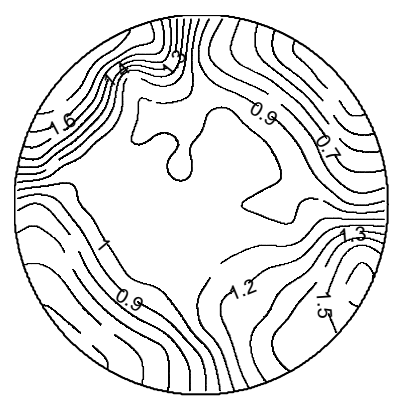

b) $30^{\circ}$

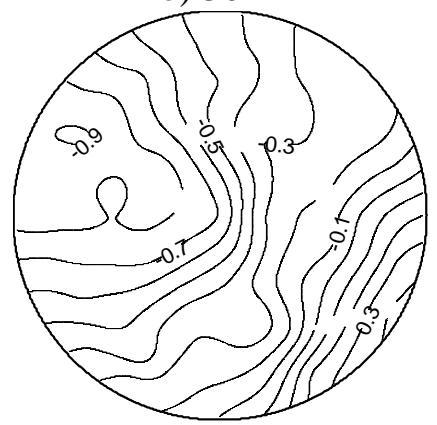

e) $120^{\circ}$

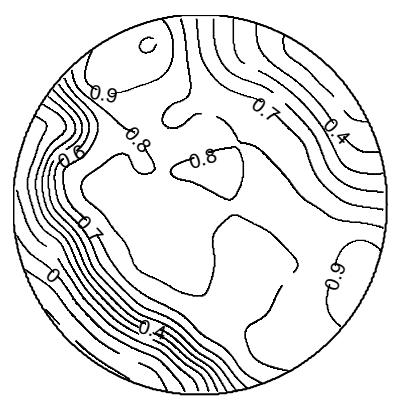

c) $60^{\circ}$

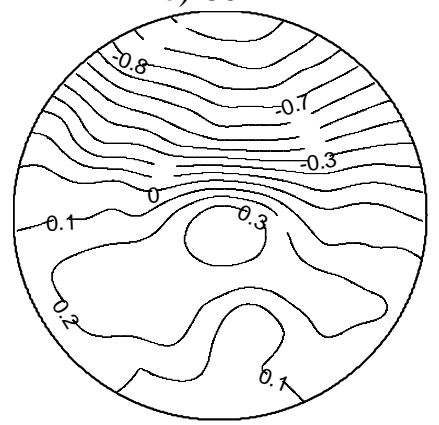

f) $180^{\circ}$

Figure 20. Mean Wind Pressure Coefficients of Reflector in Different Wind Directions for $60^{\circ}$ Pitch Angle

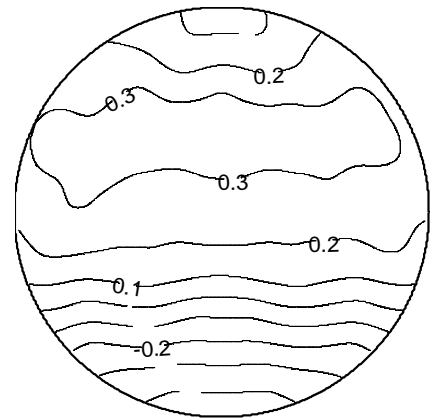

Figure 21. Mean Wind Pressure Coefficients of Reflector for $90^{\circ}$ Pitch Angle

\subsection{Comparison between the Results from Simulation and the Test}

In view of a great deal of test cases, so $0^{\circ}, 90^{\circ}, 180^{\circ}$ in the range of wind angles are selected as typical cases to fully express the gradient variation of the average wind pressure coefficient $\left(C_{\mathrm{p}}\right)$ based on the direction of incoming flow as the symmetrical axis. Figure 22 24 give the comparison of the average wind pressure coefficient between the simulation and the wind tunnel tests. On the whole, under the wind angle $0^{\circ}$, the simulation generally seems to underestimate the pressure coefficients compared to the experimental results. The differences between two approaches are larger than that of two other wind angles. This is mainly under such wind angle, the pressure gradient is so great (wind pressure coefficient varies severely) in the local edge region of the reflector back. This character leads to the difference between the numerical simulation and the test is larger than other wind angles for different pitch angles models, and the contrast effect is not very ideal. As for the wind angle $90^{\circ}$ and $180^{\circ}$, simulation results are slight larger than that of the experiments but then most data are well consonant. This is mainly because the position of separating points for airflow with the wall surface changes significantly which leads to a different wake effect. Specifically for the wind angle $90^{\circ}$, the differences between simulation and test are almost within $8 \%$ and the maximal difference for some individual point reaches $57 \%$ which appears 
at the pitch angle $30^{\circ}$ model. For the wind angle $180^{\circ}$, at each pitch angle model, there are only some single points (just one or two) having the maximal difference which could reaches beyond $50 \%$, but almost the differences from all the data are within $10 \%$. On balance, the results show that the distributions from two research methods above tend to be almost parallel and the data values are well consonant. The results of numerical simulation are well verified by the wind tunnel test. This shows that CFD is a practical and effective method to carry out the wind characteristics analysis to parabolic reflector of the antenna structure.

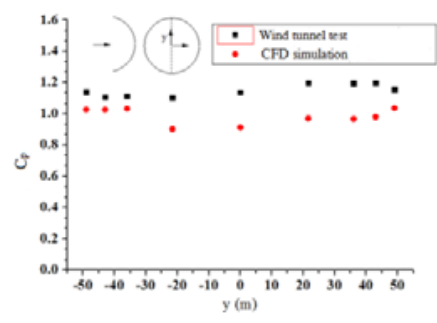

a) $0^{\circ}$ wind angle

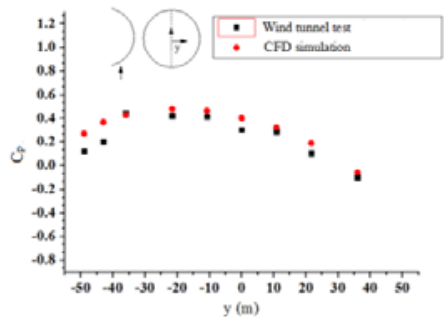

b) $90^{\circ}$ wind angle

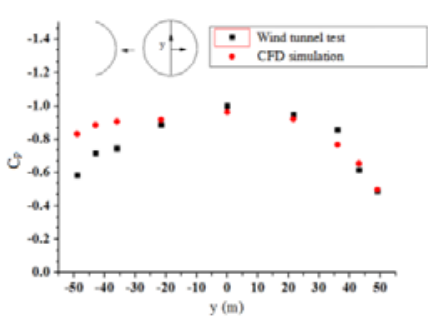

c) $180^{\circ}$ wind angle

Figure 22. Comparison between Numerical Simulated and

Test Results on Reflector at $5^{\circ}$ Pitch Angle

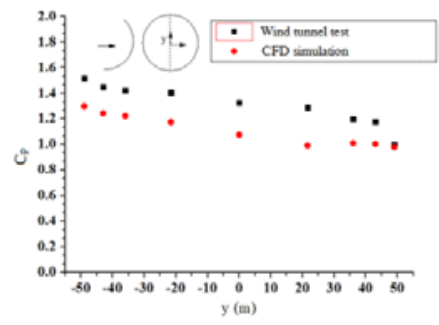

a) $0^{\circ}$ wind angle

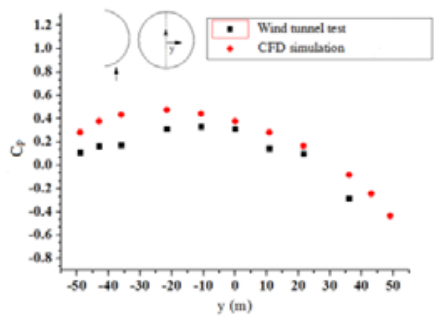

b) $90^{\circ}$ wind angle

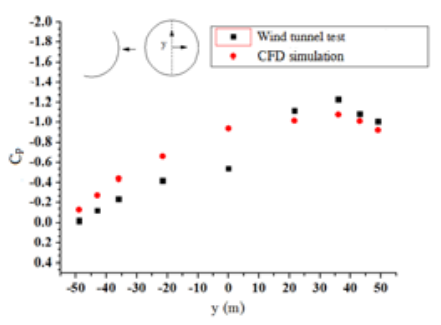

c) $180^{\circ}$ wind angle

Figure 23. Comparison between Numerical Simulated and

Test Results on Reflector at $30^{\circ}$ Pitch Angle

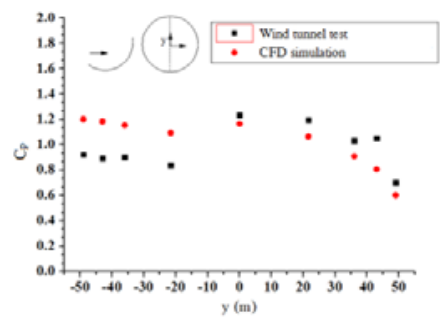

a) $0^{\circ}$ wind angle

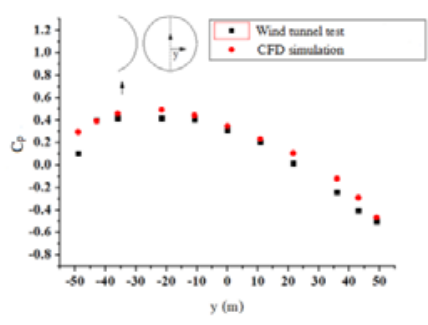

b) $90^{\circ}$ wind angle

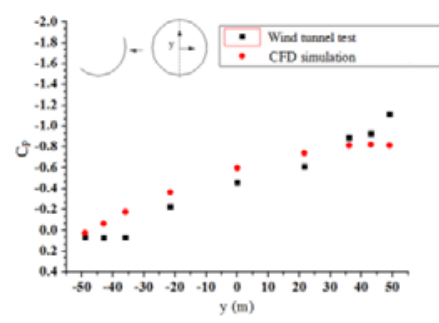

c) $180^{\circ}$ wind angle

Figure 24. Comparison between Numerical Simulated and

Test Results on Reflector at $60^{\circ}$ Pitch Angle 


\section{SHAPE FACTOR OF THE REFLECTOR SURFACE}

Based on the research findings in numerical simulation and wind tunnel test, here in order to acquire the precise wind load for the design of the back frame structure, aiming at different types of reflectors it is necessary to make a partition on the reflector surface and provide the shape factor corresponding with each divided region.

In partition, thanks to the symmetry of the reflector structure, so reflector surface is divided along the ring direction and radial direction according to the formation law of the reflector. Simultaneously in the light of the average wind pressure distribution, the wind pressure gradient of the edge region is large whereas that of the region near the center is relatively flat. So outer ring region is divided densely and inner ring region is divided sparsely. The concrete partition is shown in Figure 25.

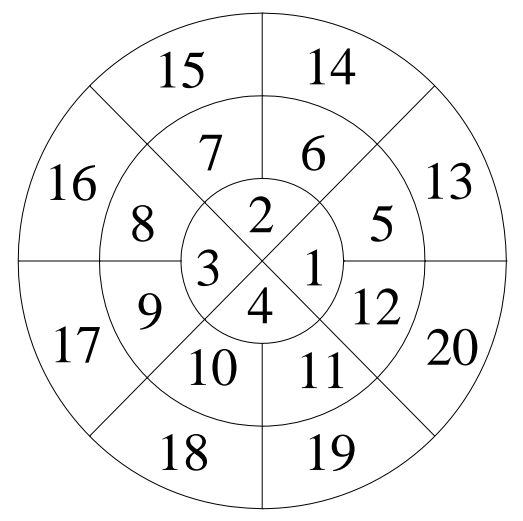

Figure 25. Regional Division of the Telescope Surface

In general, all-movable antenna structures could be classified according to its aperture diameter. The diameters within $50 \mathrm{~m}$ belong to the intermediate region of size and above $100 \mathrm{~m}$ belong to the large span. At present, all-movable antennae within $50 \mathrm{~m}$ are widely distributed throughout the world and the relevant research results constitute a rich harvest. There are about 10 all-movable antennae more or less distributed around the world. Above $100 \mathrm{~m}$ there are only two respectively in the United States and Germany. So on the basis of the current situation, the apertures of $65 \mathrm{~m}$ and $90 \mathrm{~m}$ are selected as illustrating analysis examples in the intermediate region of size meanwhile the aperture of $110 \mathrm{~m}$ is selected as illustrating analysis example in the large span region of size. In addition two kinds of focal length to diameter ratios (0.3 and 0.5 shown in Figure 26) combined with different aperture diameters above are selected as numerical examples to analyze wind field the characteristics by CFD simulation. The obtained mean wind pressure in each node could be calculated and converted into corresponding shape factor according to the formula (9). Finally shape factor for each divided region could be acquired based on the partition in Figure 25 and all computational results are summed up to be shown in Figure 27 32. Based on these 6 figures the shape factor of the reflector surface can be directly found with regard to different diameters, focal length to diameter ratios, pitch angles and wind directions for antenna structures design in the future. 


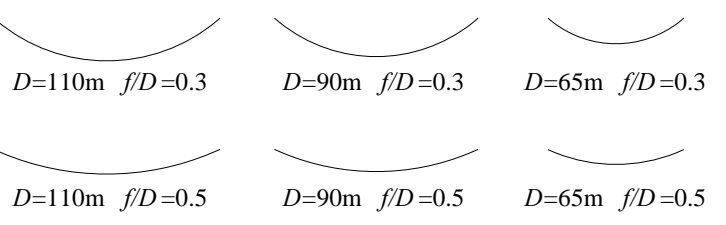

Figure 26. Different Reflector Surfaces

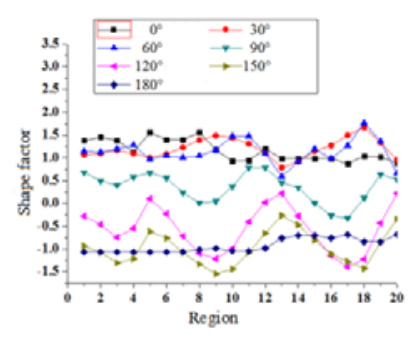

a) $5^{\circ}$

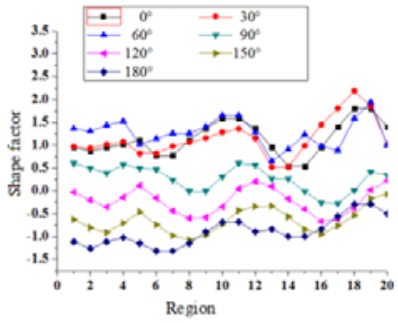

b) $30^{\circ}$

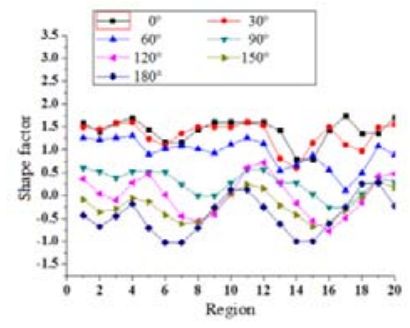

c) $60^{\circ}$

Figure 27. Shape Factor of Wind Load at Different Pitch Angle for 110m Aperture Reflector $(F / D=0.3)$

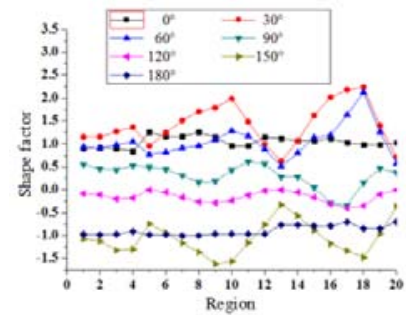

a) $5^{\circ}$

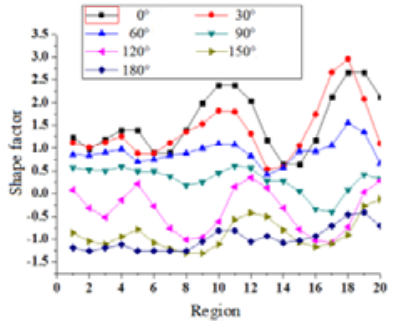

b) $30^{\circ}$

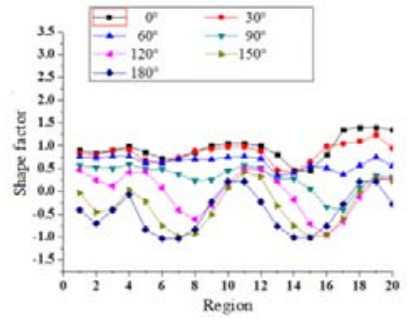

c) $60^{\circ}$

Figure 28. Shape Factor of Wind Load at Different Pitch Angle for 110m Aperture Reflector $(F / D=0.5)$

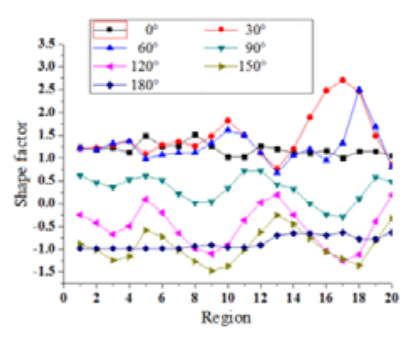

a) $5^{\circ}$

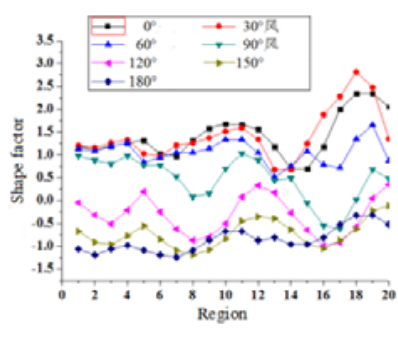

b) $30^{\circ}$

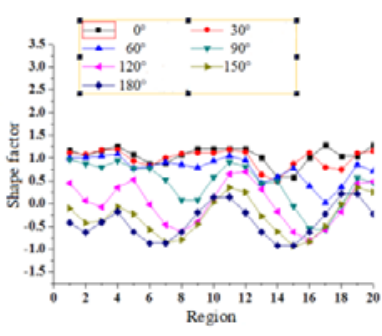

c) $60^{\circ}$

Figure 29. Shape Factor of Wind Load at Different Pitch Angle for 90m Aperture Reflector $(F / D=0.3)$ 


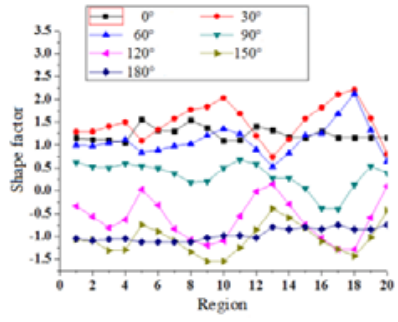

a) $5^{\circ}$

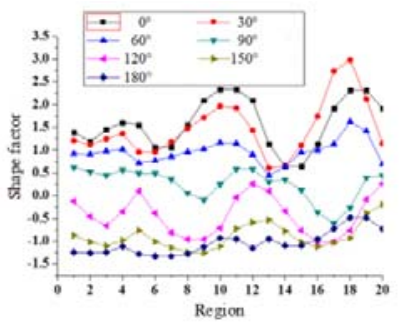

b) $30^{\circ}$

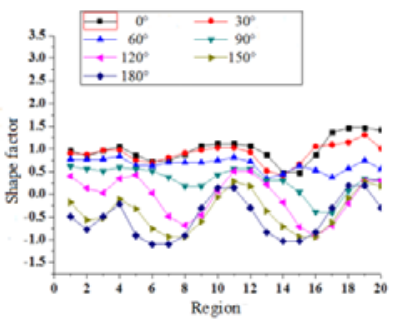

c) $60^{\circ}$

Figure 30. Shape Factor of Wind Load at Different Pitch Angle for 90m Aperture Reflector $(F / D=0.5)$

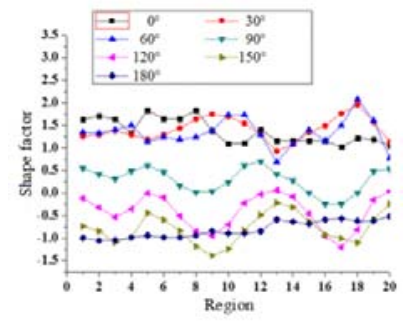

a) $5^{\circ}$

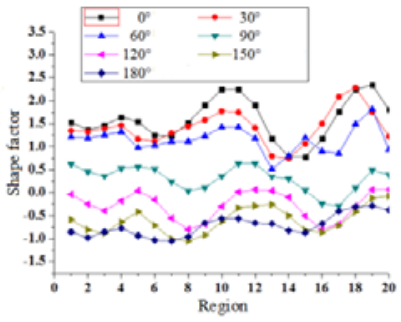

b) $30^{\circ}$

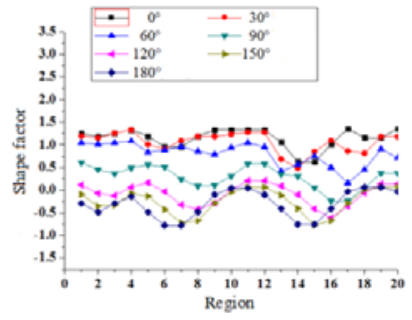

c) $60^{\circ}$

Figure 31. Shape Factor of Wind Load at Different Pitch Angle for 65m Aperture Reflector $(F / D=0.3)$

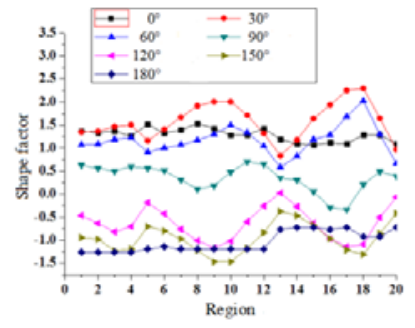

a) $5^{\circ}$

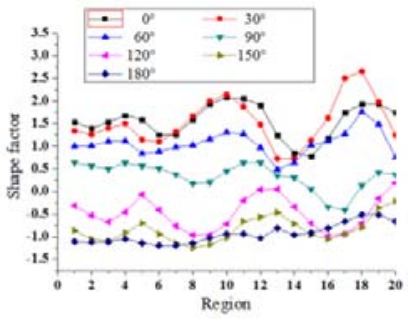

b) $30^{\circ}$

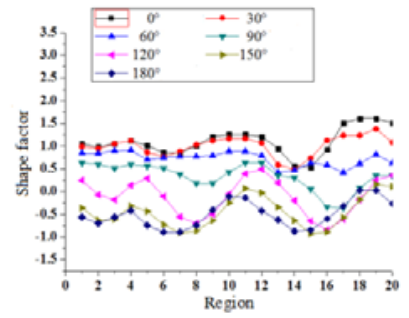

c) $60^{\circ}$

Figure 32. Shape Factor of Wind Load at Different Pitch Angle for 65m Aperture Reflector $(F / D=0.5)$

\section{WIND INDUCED VIBRATION RESPONSE}

The reflector structure of the antenna is a typical large span structure which is not appropriate to use quasi steady assumption under the complex wind load, so it is difficult to estimate the dynamic effect of fluctuating wind. The antenna structure is respectably sensitive to the fluctuating wind in view of its longer natural vibration period and weaker stiffness. Besides dynamic response characteristics for this open type of reflector structure under the fluctuating wind so that it is necessary to furtherly make a dynamic response analysis for the antenna structure based on the time course of wind pressure from the wind tunnel test and probe into the wind induced vibration response of this kind of structure under different pitch angles proposed above. 
The time course of wind pressure obtained from the wind tunnel test is determined according to the similarity ratio relationship between the real structure and the test model, shown in the formula (10).

$(f L / U)_{m}=(f L / U)_{p}$

Where, $f$ represents the frequency, $L$ represents the geometry size, $U$ represents the wind velocity, the subscript $m$ represents test model and $p$ represents the real structure. In the wind tunnel test, sampling frequency is $625 \mathrm{~Hz}$, geometric scaling ratio is $1: 200$, and the wind speed at the height of gradient wind is $14 \mathrm{~m} / \mathrm{s}$ (corresponding to the $56 \mathrm{~m} / \mathrm{s}$ at the actual height of $350 \mathrm{~m}$ ). The basic pressure for the period of 100 years at Qitai County is $0.7 \mathrm{kN} / \mathrm{m}^{2}$.

\subsection{Self Vibration Characteristics Analysis}

The natural frequency is an important parameter to analyze the dynamic response of the structures. In this work the self vibration characteristics are analyzed by subspace iteration method for 4 kinds of typical pitch angles combined with the wind tunnel test. Here taking the model of $90^{\circ}$ pitch angle as an example, from the first 10 order natural frequencies shown in the Table 5 , it can be seen that the frequency distribution of the antenna structure is dense, the frequency of each adjacent mode is very close, the fundamental frequency is low and the structure is more flexible. Due to limited space, Figure 33 gives only first two order modes from which it could be seen that the first order mode is mainly expressed as the rotation of the back frame and the pitching mechanism around the pitch axis, and the second order mode is mainly expressed as the translation of the back frame along the pitch axis with respect to the azimuth pedestal. The remaining modes are mainly expressed as local vibration or torsion of the structure.

Table 5. Ten Order Frequencies of the Telescope Structure

\begin{tabular}{ccccccccccc}
\hline Order & 1 & 2 & 3 & 4 & 5 & 6 & 7 & 8 & 9 & 10 \\
\hline Frequency & 0.887 & 1.032 & 1.158 & 1.214 & 1.358 & 1.545 & 1.681 & 1.843 & 1.972 & 2.125 \\
\hline
\end{tabular}

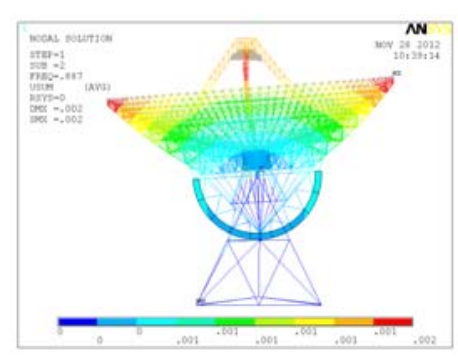

a) The first order

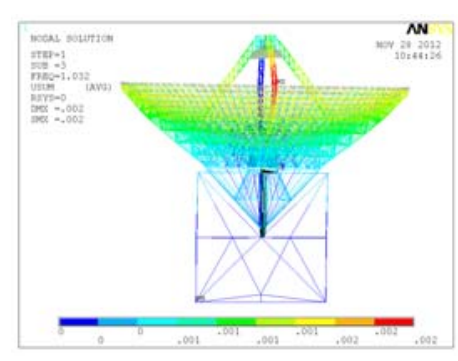

b) The second order

Figure 33. The Mode of Structure Vibration

\subsection{Analysis Method}

The antenna structure is analyzed for the wind-induced response by using nonlinear time-history analysis method. The structure is discretized by using the finite element method and the wind loads are exerted on the corresponding nodes. The structure response is obtained by directly solving the equations of structure motion in the time domain. The calculating results of this method are more realistic than the linear approach in the frequency domain. It could be applied to any system and 
any incentive in principle. And the more complete information about the whole process of structural dynamic response could be got. It is the effective way to analyze the wind induced dynamic response of the antenna structure.

\subsubsection{Wind vibration factor of the displacement and stress}

According to the specification, the dynamic effects of wind load are taken as the static load in the form of wind-induced vibration coefficient. Namely the wind pulse is expressed as the equation (11)

$\beta=\frac{P_{e}}{\bar{P}}=\frac{\bar{P}+P_{d}}{\bar{P}}=1+\frac{P_{d}}{\bar{P}}$

Where $\beta$ is the wind pulse, $P_{e}$ is the equivalent static wind load, $\bar{P}$ is the static wind load, $P_{d}$ is the dynamic wind load.

For the time-history analysis for wind-induced vibration of the complex spatial structure using finite element method, the wind pulse directly bases on the structure response. Namely the wind vibration factor of the displacement and internal force are expressed as the equation (12).

$\beta=\frac{D_{y}}{\overline{D_{y}}}$

The above equation $\bar{D}_{y}$ represents the structural response under the static wind loads, including structural displacement responses and stress responses. $D_{y}$ represents the total extreme wind-induced vibration response of the structure, including static and dynamic response. The relation between them is expressed as the equation (13).

$D_{y}=\bar{D}_{y} \pm g \cdot \operatorname{sign}\left(\bar{D}_{y}\right) \sigma_{y}$

Among them, sign is a sign function, $\sigma_{y}$ is the mean square error of the response for fluctuating wind. $g$ is the peak factor and its value is related with the number of times during which the effect is beyond the average load effect in an average hour. When the probability distribution of the average load effect is normal distribution, $g$ can be expressed according to the equation (14). Where $T$ is the observation time (typically 1 hour), $v$ is the horizontal crossing number, which is in the range from 3.0 to 4.0 , and 3.5 is selected in this paper.

$g=\sqrt{2 \ln v T}+0.577 / \sqrt{2 \ln v T}$

\subsubsection{Whole wind pulse}

The wind pulse of the displacement in each point and of the stress for each element could be obtained according to the equation (15). But for the large span structure, because the spectrum has the intensive modes and the mode contributing a lot may not appear in the first vibration mode, so it is difficult to determine which mode has the significant effect on wind-induced vibration response. In this paper, the wind pulse of the overall displacement and stress based on the maximum dynamic response is used and expressed as the following equation (16). 
$\beta_{d}^{*}=\frac{\left\{\beta_{d i} \times U_{w i}\right\}}{\left\{U_{w i}\right\}_{\text {max }}}$

$\beta_{s}^{*}=\frac{\left\{\beta_{s i} \times S_{w i}\right\}}{\left\{S_{w i}\right\}_{\max }}$

Where $\left\{U_{w i}\right\}$ and $\left\{\beta_{d i} \times U_{w i}\right\}$ are the maximum nodal displacement and time-history displacement respectively under the static wind loads and the total wind loads. Where $\left\{S_{w i}\right\}$ and $\left\{\beta_{s i} \times S_{w i}\right\}$ are the maximum element stress and time-history element stress respectively under the static wind loads and the total wind loads.

\subsection{Vibration Response Results Analysis}

\subsubsection{Analysis scheme and response index}

According to the wind tunnel test results, the overall drag coefficients of the antenna structure under 3 kinds of pitch attitudes are shown in Figure 34, and no matter what pitch angle, the resistance coefficient of $0^{\circ}$ wind angle reaches the maximum value. So the wind angle of $0^{\circ}$ is selected as the analysis condition for wind-induced vibration response analysis respectively under the pitch angle of $5^{\circ}, 30^{\circ}, 60^{\circ}$. Combined with the characteristics of the large span structure and the wind-induced vibration response concerned by the design staff, the normal displacement of each node on the reflector and axial stress + bending stress of the element are used as the indicators of the wind-induced vibration response.

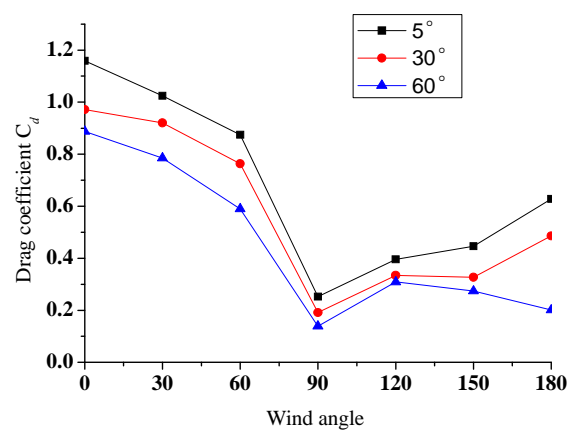

Figure 34. $C_{d}$ in Different Directions

\subsubsection{Results analysis of wind induced vibration response}

Extreme stress and extreme displacement in time-history for the 3 models are shown in Figure 35 and Figure 37. In order to analyze the response characteristics under the fluctuating wind loads in the frequency domain, Fourier transformation is used to convert the response process from the time domain to the frequency domain. The corresponding extreme stress and displacement power spectral density function are shown in Figure 36 and Figure 38. According to the power spectral density function, it can be seen that the wind induced vibration response of the structure is a narrowband process. For the same pitch angle model, the dynamic response from the extreme stress and extreme displacement power spectrum are highly consistent. Combined with the aforementioned natural frequencies of the structure, for the $5^{\circ}$ pitch angle, it is shown that the vibration energy concentrated near the first order frequency $(0.7 \mathrm{~Hz})$ nearby. For the $30^{\circ}$ pitch 
angle, it is still shown that the vibration energy concentrated in the first-order frequency $(0.7 \mathrm{~Hz})$ nearby, nevertheless the amplitude of energy has increased. For the $60^{\circ}$ pitch angle, the higher modes (the third order and the forth order) begin to contribute to the performance of the vibration energy of the structure and from the energy distribution that the peak appear at the frequency of $0.9 \mathrm{~Hz}$ and $1.1 \mathrm{~Hz}$. What's more, the relation between the energy magnitude and the pitch angle shows that the vibration energy increases gradually with the increase of the pitch angle. Later the extreme stress distribution and the displacement distribution of the model are given respectively in Figure 39 and Figure 40. It can be seen in the extreme stress distribution under the wind angle of $0^{\circ}$, the largest stress reaching $170 \mathrm{MPa}$ mainly concentrated in the radius element on the second ring of the upper chord and this condition appears in the model of pitch angle of $30^{\circ}$. It also can be seen from the normal displacement that under the wind angle of $0^{\circ}$, the displacement shows the symmetry along the vertical axis and the extreme displacements of each model appear at the overhangying end and two sides of the reflector surface. In 3 models, the maximal normal displacement is up to $24 \mathrm{~cm}$ and appears in the $5^{\circ}$ pitch angle attitude. Due to space limitations, the calculation results of other models for different pitch angles are shown in Table 6. According to the time-history analysis results, the extreme response for each pitch angle of the antenna structure is determined while the wind pulse for wind force proofing design in the future are provided in Table 6.

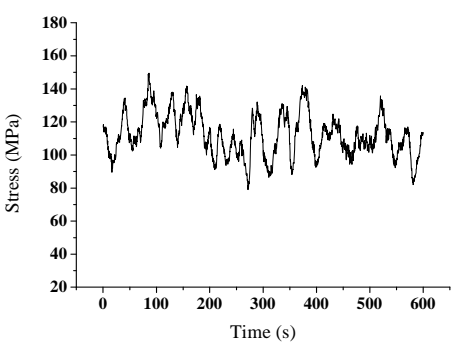

a) $5^{\circ}$

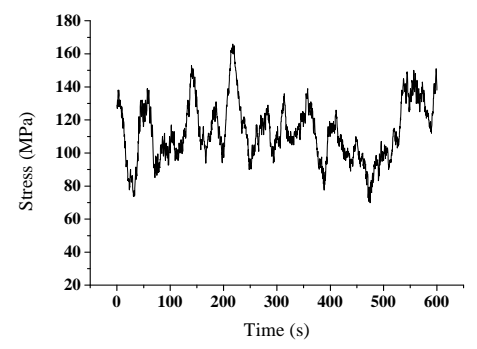

b) $30^{\circ}$

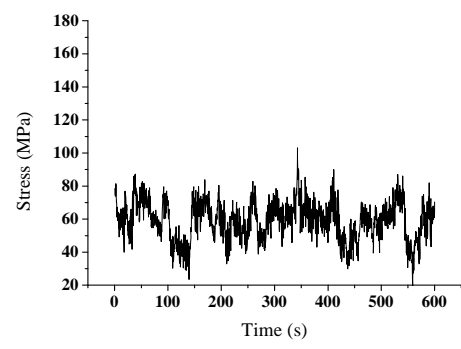

c) $60^{\circ}$

Figure 35. Time-history of the Extreme Stress for Different Kinds of Pitch Angle Models

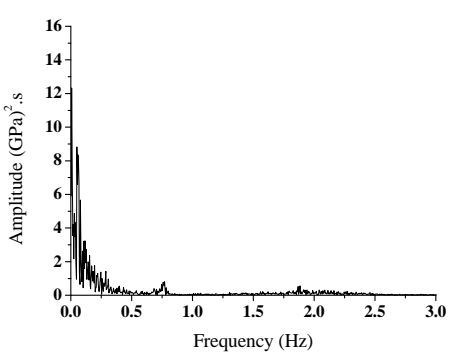

a) $5^{\circ}$

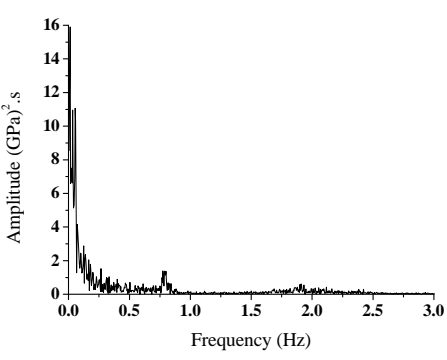

b) $30^{\circ}$

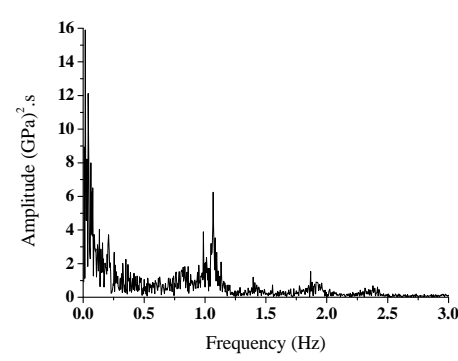

c) $60^{\circ}$

Figure 36. Power Spectral of the Extreme Stress for Different Kinds of Pitch Angle Models

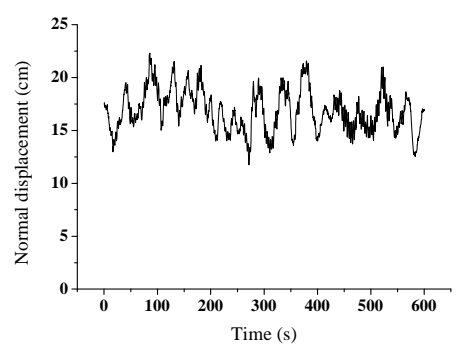

a) $5^{\circ}$

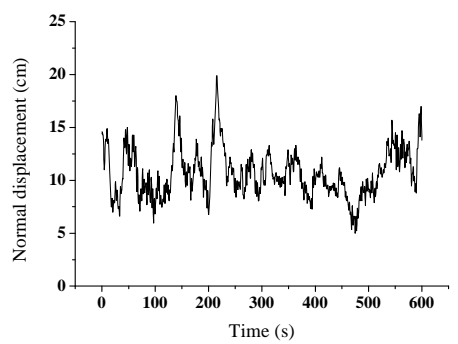

b) $30^{\circ}$

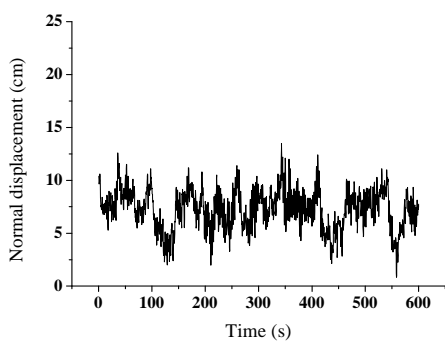

c) $60^{\circ}$

Figure 37. Time-history of the Extreme Displacement for Different Kinds of Pitch Angle Models 


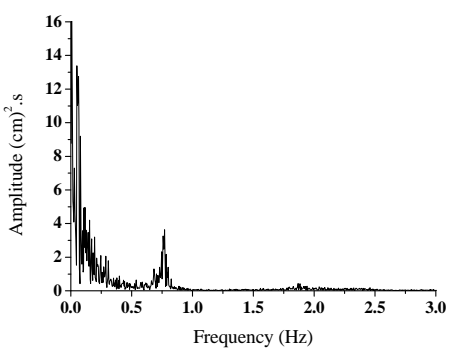

a) $5^{\circ}$

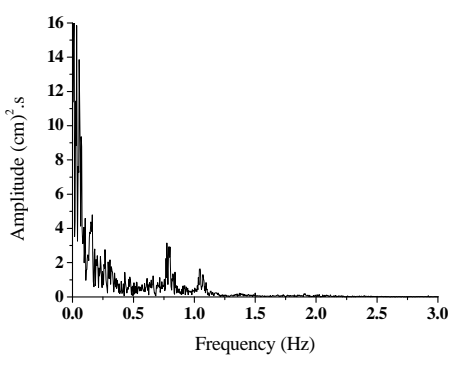

b) $30^{\circ}$

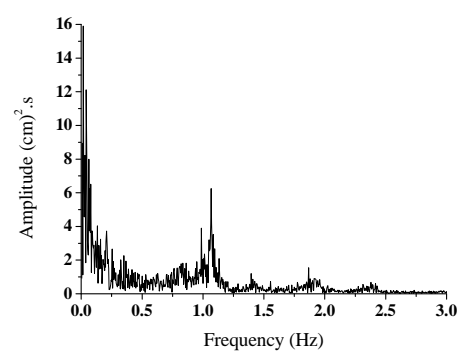

c) $60^{\circ}$

Figure 38. Power Spectral of the Extreme Displacement for Different Kinds of Pitch Angle Models

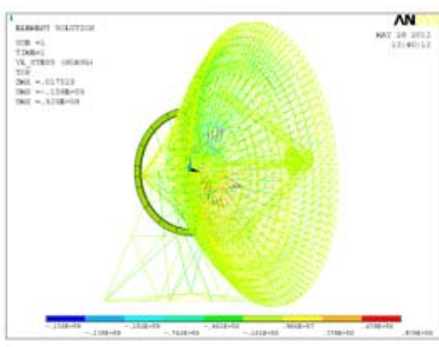

a) $5^{\circ}$

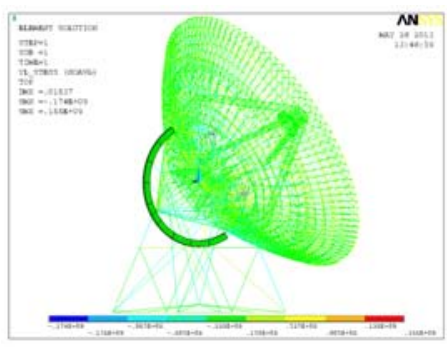

b) $30^{\circ}$

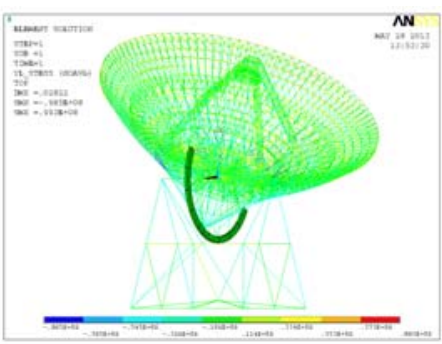

c) $60^{\circ}$

Figure 39. Extreme Value Distribution of Stress for Different Kinds of Pitch Angle Models

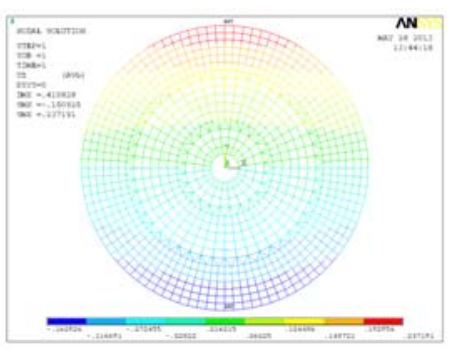

a) $5^{\circ}$

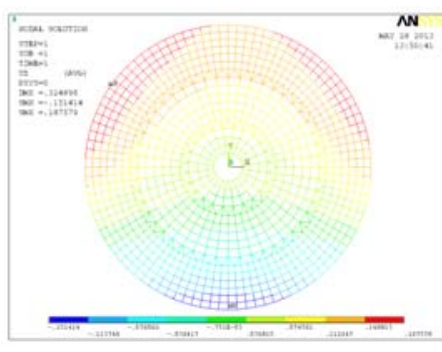

b) $30^{\circ}$

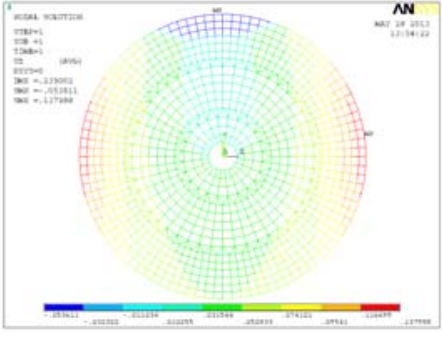

c) $60^{\circ}$

Figure 40. Extreme Value Distribution of Displacement for Different Kinds of Pitch Angle Models

Table 6. Extreme Response and Wind Vibration Factors of the Structure at Different Pitch Angles

\begin{tabular}{ccccc}
\hline Pitch angle & $5^{\circ}$ & $30^{\circ}$ & $60^{\circ}$ & $90^{\circ}$ \\
\hline Maximum displacement & $24 \mathrm{~cm}$ & $19 \mathrm{~cm}$ & $14 \mathrm{~cm}$ & $22 \mathrm{~cm}$ \\
Maximum stress & $158 \mathrm{MPa}$ & $174 \mathrm{MPa}$ & $99 \mathrm{MPa}$ & $152 \mathrm{MPa}$ \\
Whole wind pulse of the displacement & 2.37 & 1.73 & 1.82 & 1.92 \\
Whole wind pulse of the stress & 1.41 & 1.54 & 1.57 & 2.18 \\
\hline
\end{tabular}

\subsubsection{Comment on the nonlinear response of the structure}

According to the analysis of the structural extreme response and power spectral, it can be seen that nonlinear response of the all-movable antenna structure is mainly influenced by the upwind attitudes, and vibration factors are different for different models and structural responses. They are embodied specifically in the followings.

(1) Although the all-movable antenna structure belongs to such kind of rigid structure, its reflector part has a large span up to one hundred meters more or less resulting in that the structure becomes more flexible (this can be inferred by self vibration characteristics analysis). So the effect from 
fluctuating wind could not be neglected in the wind force proofing design and the first four modes of vibration contribute a lot to wind-induced vibration of the whole structure.

(2) From the vibration response results, the whole wind pulse of the displacement is larger than the whole wind pulse of the stress, especially under the pitch angle $5^{\circ}$, because the reflector is almost under the complete upwind state and the top displacement should be focus on. Moreover, although under the pitch angle $5^{\circ}$, the extreme stress is $158 \mathrm{MPa}$ larger than $152 \mathrm{MPa}$ under the pitch angle $90^{\circ}$, the whole wind pulse of stress is 1.41 smaller than 2.18 under the pitch angle $90^{\circ}$. This can be inferred that under the pitch angle $5^{\circ}$, static wind load contribute more than that under the pitch angle $90^{\circ}$. For the model of pitch angle $90^{\circ}$, because wind direction is vertical to the central axis of the reflector, airflow could be separated on the front edge of the reflector and adhere to the end edge again. This phenomenon could form the vortex shedding and severe fluctuating pressure leading to the larger wind pulse.

(3) Under the most unfavorable wind angle $0^{\circ}$, the pitch angles for $5^{\circ}$ and $90^{\circ}$ are two kinds of unfavorable working states because they correspond to the maximal wind pulses of the displacement and the stress respectively. Combined with the wind angle and pitch angle, according to the worst upwind attitude, wind pulses could be determined for the all-movable antenna structure in its whole performance. The whole wind pulse of the displacement could be set as 2.5 and 2.2 could be proper for the stress.

\section{STRUCTURAL ANALYSIS UNDER THE DESIGNED WIND LOAD}

\subsection{Mechanical Analysis under the Survival Wind Speed}

Table 7. Static Combination Conditions

\begin{tabular}{ccccc}
\hline & Combination & $\begin{array}{c}\text { Gravity } \\
\text { coefficient }\end{array}$ & $\begin{array}{c}\text { Snow load } \\
\text { coefficient }\end{array}$ & $\begin{array}{c}\text { Wind load } \\
\text { coefficient }\end{array}$ \\
\hline 1 & Gravity & $1.2 \times 1.0$ & $/$ & $/$ \\
2 & Gravity+wind load 1 & $1.2 \times 1.0$ & $/$ & $1.4 \times 1.0$ \\
3 & Gravity+wind load 2 & $1.2 \times 1.0$ & $/$ & $1.4 \times 1.0$ \\
4 & Gravity+wind load 3 & $1.2 \times 1.0$ & $/$ & $1.4 \times 1.0$ \\
5 & Gravity+snow load & $1.2 \times 1.0$ & $1.4 \times 1.0$ & $/$ \\
6 & Gravity+snow load+wind load 1 & $1.2 \times 1.0$ & $1.4 \times 0.7$ & $1.4 \times 1.0$ \\
7 & Gravity+snow load+wind load 2 & $1.2 \times 1.0$ & $1.4 \times 0.7$ & $1.4 \times 1.0$ \\
8 & Gravity+snow load+wind load 3 & $1.2 \times 1.0$ & $1.4 \times 0.7$ & $1.4 \times 1.0$ \\
\hline
\end{tabular}

For the large antenna structure the member should meet the strength requirement and the deformation need to be limited in the allowable range without collapse under the survival wind $U=40 \mathrm{~m} / \mathrm{s}$. Here the $110 \mathrm{~m}$ antenna structure is selected as a typical object to make the strength and stability analysis under self weight combined with wind load and snow load.

According to the Load Code for the Design of Building Structure combined with the actual environment the antenna structure exists in, the antenna structure is analyzed under the load combination. The load combination is shown in Table 7 and the snow load is considered only for the model of pitch angle $5^{\circ}$. Wind load $1,2,3$, represent $0^{\circ}, 90^{\circ}, 180^{\circ}$ respectively and wind pulse is determined according to the table 6 coming from the wind vibration response analysis. Taking the models of pitch angle $5^{\circ}, 30^{\circ}, 60^{\circ}, 90^{\circ}$, strength and stability analysis is carried on according to the procedures shown in Figure 41. Due to the limited space, only the results from the model of pitch angle $5^{\circ}$ are given in Figure $42 \sim$ Figure 46 and the results for other models are 
generalized in Table 8. These achievements show that under all of the load combinations, the whole structure is in the elastic state, the vast majority of members are in the low stress level within $100 \mathrm{MPa}$ and the maximum deformation is only $128 \mathrm{~mm}$. The value of stress and deformation all meet the relevant specification requirements and the structure is safe.

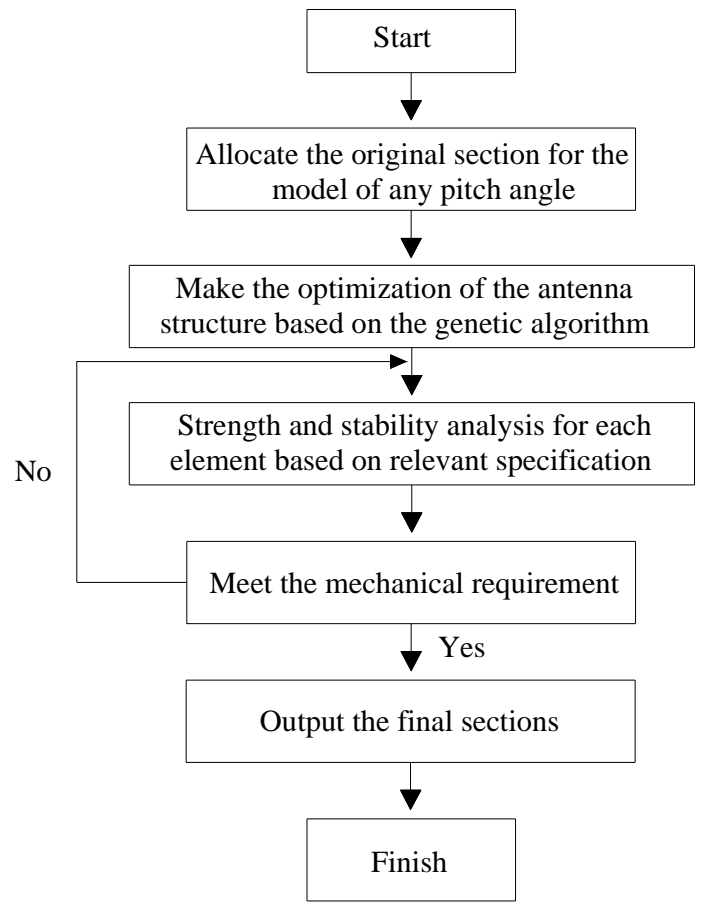

Figure 41. Flowchart of Member Mechanical Performance for the Telescope Structure

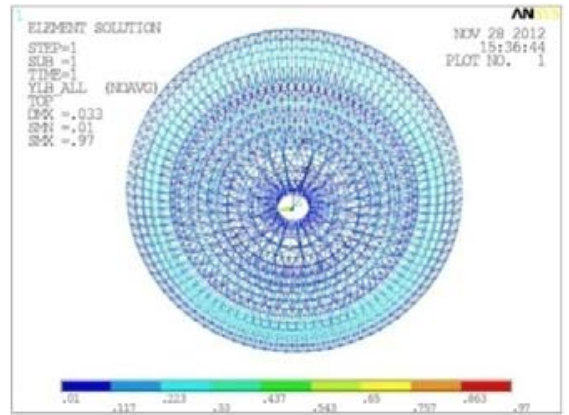

Figure 42. Stress Ratio of Back Frame Structure

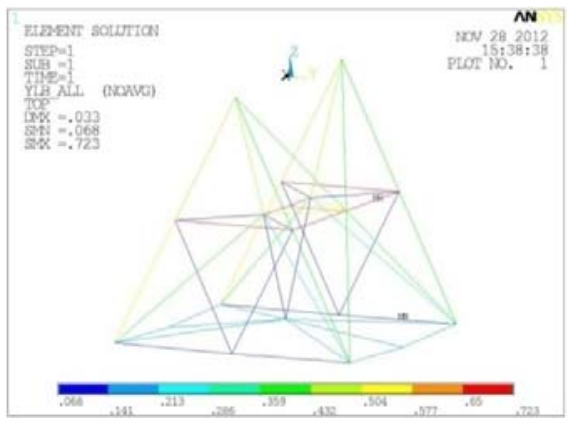

Figure 44. Stress Ratio of Azimuth Holder

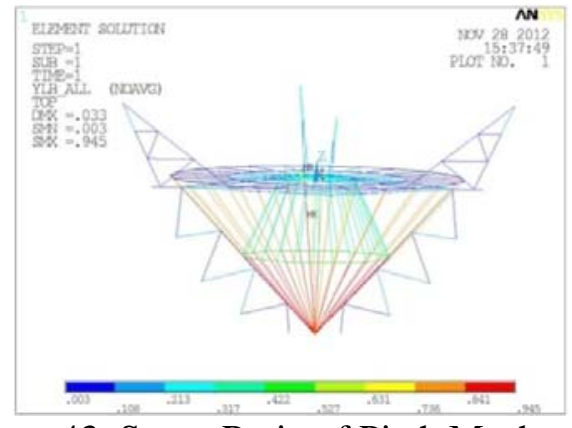

Figure 43. Stress Ratio of Pitch Mechanism

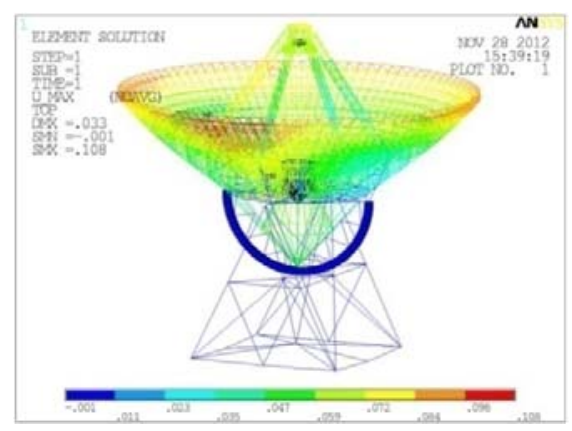

Figure 45. Displacement of the Whole Structure 


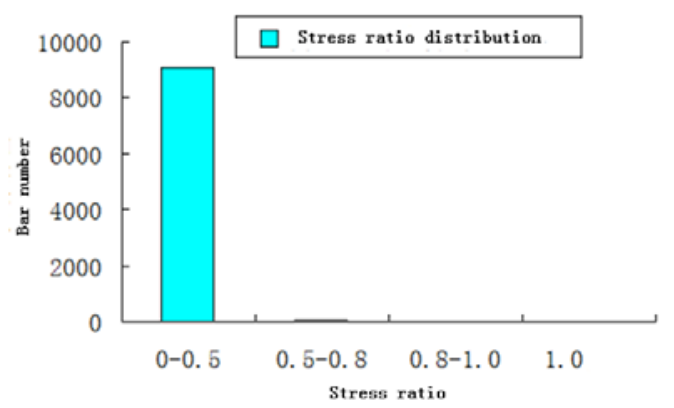

Figure 46. Bar Chart of Stress Ratio for Back Frame Structure

Table 8. Calculating Results of Static Combination Conditions

\begin{tabular}{ccccc}
\hline Pitch angle & Structural response & Back frame & Pitch mechanism & Azimuth mount \\
\hline \multirow{3}{*}{$5^{\circ}$} & Maximum stress ratio & 0.92 & 0.77 & 0.75 \\
& Overrun component & None & None & None \\
& Maximum displacement & & $128 \mathrm{~mm}$ & \\
\multirow{3}{*}{$30^{\circ}$} & Maximum stress ratio & 0.99 & 0.97 & 0.67 \\
& Overrun component & None & None & None \\
& Maximum displacement & & $120 \mathrm{~mm}$ & \\
\multirow{2}{*}{$60^{\circ}$} & Maximum stress ratio & 0.96 & 0.94 & 0.62 \\
& Overrun component & None & None & None \\
& Maximum displacement & & $114 \mathrm{~mm}$ & \\
\multirow{2}{*}{$90^{\circ}$} & Maximum stress ratio & 0.97 & 0.95 & 0.72 \\
& Overrun component & & None & None \\
& Maximum displacement & & $108 \mathrm{~mm}$ & \\
\hline
\end{tabular}

\subsection{Performance Analysis under the Working Wind Speed}

The antenna structure is required to have a good performance under the working speed $U=20 \mathrm{~m} / \mathrm{s}$. That is to say the antenna could still trace the celestial objects and complete the observation mission after the wind deformation is adjusted by the actuators. So it is necessary to make the reflector surface precision analysis under the wind load. Taking the wind angle of $0^{\circ}$ as the typical example, the figure 47 48 give the surface precision RMS and the whole structure displacements for different pitch angles. The surface precision under other wind angles are all given in Table 9 only in the form of data.

\subsubsection{Reflector surface precision analysis under the wind load}

From view of the displacement of the structure, the distribution of the surface deformation is not uniform. For examples, the model of $5^{\circ}$ pitch angle, $0^{\circ}$ wind angle has the maximum displacement on the top and the minimum displacement at the bottom, and the maximum difference reaches $38 \mathrm{~mm}$. The model of $60^{\circ}$ pitch angle, $0^{\circ}$ wind angle has the maximum displacement at the bottom and the minimum value at the center, and the maximum difference reaches $32 \mathrm{~mm}$. For the model of $90^{\circ}$ pitch angle, $0^{\circ}$ wind angle, the maximum displacement appear in the upwind front and thanks to the reflector geometry, in the center of the reflector the displacement reaches the minimum value. These present results are caused by the reflector structure characteristics. In bearing parts of the reflector structure are similar to that of the cantilever roof. With moving on to the inner ring region, the distance to the support region of the reflector structure is much shorter accompanied by the thicker grid height. So the two factors above result in a better stiffness and the displacement naturally decreases in the region near the center of the reflector. Simultaneously 
combined with the results in section 2 3, near the edge of the reflector extreme wind pressure often appears and the pressure gradient is more intense. By contraries, near the center zone of the reflector, the wind pressure gradient is gentler and the stress is naturally more uniform. So in view of the stress condition and the stiffness distribution of the reflector structure, it is inevitable that the reflector surface deforms unevenly and has an undesirable precision.

Table 9. RMS of Reflector Surface under the Wind Load

\begin{tabular}{lcccc}
\hline Pitch angle & Wind angle & $0^{\circ}$ & $90^{\circ}$ & $180^{\circ}$ \\
\hline $5^{\circ}$ & 0.362 & 2.092 & 0.212 \\
& $30^{\circ}$ & 2.206 & 1.715 & 0.377 \\
$60^{\circ}$ & 2.102 & 1.785 & 0.586 \\
& $90^{\circ}$ & 2.096 & 2.092 & 2.103 \\
\hline
\end{tabular}

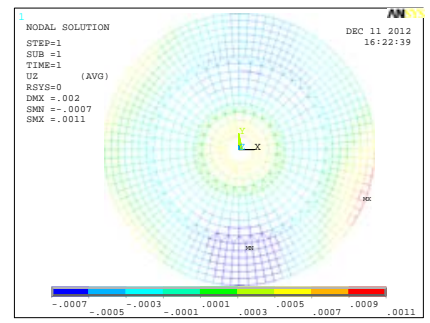

a) $5^{\circ}$

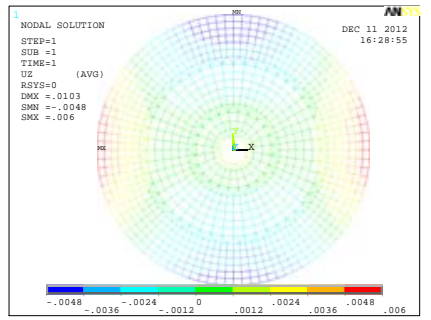

b) $60^{\circ}$

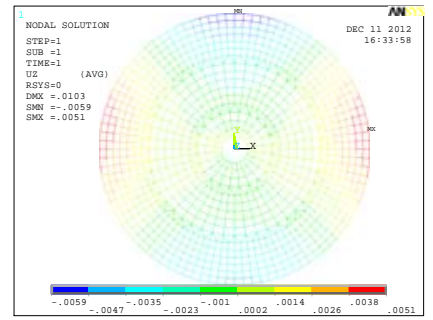

c) $90^{\circ}$

Figure 47. Half Optical Path Error of Reflector Surface

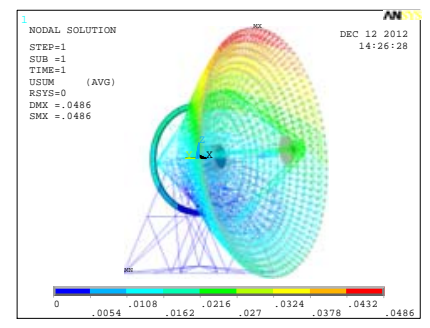

a) $5^{\circ}$

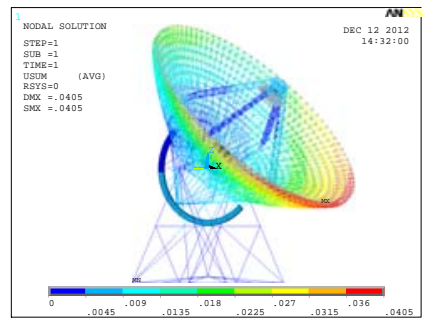

b) $60^{\circ}$

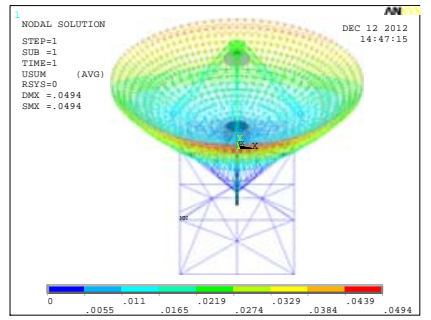

c) $90^{\circ}$

Figure 48. Whole Displacement of the Structure

\subsubsection{Surface precision analysis for different models under different load cases}

In the actual operations, it is necessary to calculate the influence of not only single load but also the combination of different loads because the gravity load coexists with the wind load, and pay special attention to the leading factor. Table 10 gives the reflector surface precision under different load cases. Limitations of space allows for the results of $0^{\circ}$ wind angle if wind load joins in the combination.

From the table above it is obviously that the wind load has a greater effect than gravity load on the reflector surface precision. On the one hand, the structure is more flexible and sensitive to the wind load with the increase of the aperture diameter. Compared with gravity load wind load has a more serious effect and plays a leading role. On the other hand, in the antenna structure scheme approachment, the lectotype and the optimization mainly consider the gravity load that is to say the back frame structure style is determined and the section of each pipe is optimized under the gravity 
load effect. So in order to realize a high reflector surface precision the back frame structure obtains a reasonable stiffness distribution in such a scheme determination course. Namely some part has more weights, more stiffness will appear, vice versa. But from the deformation under the wind load shown in Figure 48, the stress caused by wind load could not fit with the structure stiffness so the deformation heterogeneity caused by wind load is more seriously than that of the gravity load which results in a lower surface precision under the single wind load or the combination the wind load joins in.

Table 10. Surface Precision on Main Reflector under Each Working Condition (RMS)

\begin{tabular}{ccccc}
\hline \multicolumn{5}{c}{ Gravity effect } \\
\hline Pitch angle & $5^{\circ}$ & $30^{\circ}$ & $60^{\circ}$ & $90^{\circ}$ \\
Surface precision & $0.306 \mathrm{~mm}$ & $0.223 \mathrm{~mm}$ & $0.143 \mathrm{~mm}$ & $0.306 \mathrm{~mm}$ \\
\hline \multicolumn{5}{c}{ Wind load effect } \\
\hline Wind velocity & $5^{\circ}$ & $30^{\circ}$ & $60^{\circ}$ & $90^{\circ}$ \\
Pitch angle & $0.362 \mathrm{~mm}$ & $2.206 \mathrm{~mm}$ & $2.102 \mathrm{~mm}$ & $2.096 \mathrm{~mm}$ \\
Surface precision & \multicolumn{5}{c}{$20 \mathrm{~m} / \mathrm{s}$} \\
\hline Effect of the combination of gravity and wind load \\
\hline Wind velocity \\
Pitch angle & $5^{\circ}$ & $30^{\circ}$ & $60^{\circ}$ & $90^{\circ}$ \\
Surface precision & $0.175 \mathrm{~mm}$ & $2.265 \mathrm{~mm}$ & $2.342 \mathrm{~mm}$ & $2.259 \mathrm{~mm}$ \\
\hline \multicolumn{4}{c}{}
\end{tabular}

\section{CONCLUSIONS}

The widely used parabolic reflector $(F / D=0.3)$ is selected as an analysis point of penetration to carry out the numerical simulation for its 22 kinds of gestures. Subsequently, the manometry tests are carried out in the wind tunnel for the working conditions above. The wind tunnel test validates the numerical simulation very well in wind characteristics analysis of parabolic reflector structures by comparisons.

- For most of models with different pitch angles and wind angles, the maximum negative pressure generally appear in the edge region because the incoming flow usually separates significantly at this location. For the model of the same pitch angle at different wind angles, extreme value of the average surface pressure appear at different surface position due to the differences of the separation points position on the wall and the wake effect. In view of the CFD simulation validity for parabolic antenna structure verified by the wind tunnel test, subsequently large scale computations and analysis of different types of reflectors structures are carried out by CFD and the shape factor for each corresponding type of reflector structure under different gestures. This achievement provides abundant wind force proofing design references for those parabolic antennae.

- According to the power spectrum density function it could be seen that the wind induced vibration response of the antenna is a narrow-band course. For the same pitch angle model, the maximum stress power spectrum and displacement power spectrum are highly consistent in the dynamic response of the structure. Although the all-movable antenna structure belongs to such kind of rigid structure, its reflector part has a large span up to one hundred meters more or less resulting in that the structure becomes more flexible. So the effect from fluctuating wind could not be neglected in the wind force proofing design and the first four modes of vibration contribute a lot to wind-induced vibration of the whole structure.

- Under the most unfavorable wind angle $0^{\circ}$, the pitch angles for $5^{\circ}$ and $90^{\circ}$ are two kinds of unfavorable working states because they correspond to the maximal wind pulses of the 
displacement and the stress respectively. Combined with the wind angle and pitch angle, according to the worst upwind attitude, wind pulses could be determined for the all-movable antenna structure in its whole performance. The whole wind pulse of the displacement could be set as 2.5 and 2.2 could be proper for the stress.

- Based on the average wind pressure distribution characteristics and the results of wind induced vibration response, the static wind loads and the corresponding wind vibration coefficient of the reflector are obtained. Taking $110 \mathrm{~m}$ antenna structure $(F / D=0.3)$ as an example, firstly the mechanical analysis under the survival wind speed is carried out and the results show that the whole structure is in the elastic state, the vast majority of members are in the low stress level and all kinds of responses meet the relevant specification requirements. Next, the performance analysis under the working wind speed is carried out. The results show that the antenna structure is more flexible and the wind load takes a leading role on the reflector surface precision.

\section{ACKNOWLEDGEMENTS}

This work was financially supported by the National Natural Science Foundation of China (Grant No. 51378149) and the Natural Science Basic Research Plan in Shaanxi Province of China (Program No. 2016JQ5031).

\section{REFERENCES}

[1] Quattri, Marco., "Proceedings of the International Society for Optical Engineering”, Boston University Press, Boston, 2002, pp. 459-470.

[2] Hiriart, D., Ochoa, J.L. and Garcia, B., "Wind Power Spectrum Measured at the San pedro Martir Sierra”, Revista Mexicana de Astronomia Astrofisica, 2001, Vol. 37, pp. 213-220.

[3] Solari, G. and Piccardo, G., "Probabilistic 3-D Turbulence Modeling for Gust Buffeting of Structures”, Probabilistic Engineering Mechanics, 2001, Vol. 16, pp. 73-86.

[4] Jia, Y.Q., Sill, B.L. and Reinhold, T.A., "Effects of Surface Roughness Element Spacing on Boundary Layer Velocity Profile Parameters”, Wind Eng. Ind. Aerodyn, 1998, Vol. 73, pp. 215-230.

[5] Irwin, H.P.A.H., “The Design of Spires for Wind Simulation”, Wind Eng. Ind. Aerodyn, 1981, Vol. 8, pp. 361-366.

[6] Balendra, T., Shah, D.A. and Tey, K.L., "Evaluation of Flow Characteristics in the NUS-HDB Wind Tunnel”, Wind Eng. Ind. Aerodyn, 2002, Vol. 90, pp. 675-688.

[7] Meroney, Letchford, Sarkar., "Comparison of Numerical and Wind Tunnel Simulation of Wind Loads on Smooth and Dual Domes Immersed in a boundary Layer”, International Journal of Wind and Structures, 2002, Vol. 5, pp. 347-358.

[8] Uematsu, Y., and Tsuruishi, R., "Wind Load Evaluation System for the Design of Roof Cladding of Spherical Domes", Journal of Wind Engineering and Industrial Aerodynamics, 2008, Vol. 96, pp. 2054-2066.

[9] Sterling, M., Baker, C.J. and Quinn, A.D., "Pressure and Velocity Fluctuations in the Atmospheric Boundary Layer”, Wind and Structures, 2005, Vol. 8, No. 1, pp. 13-34.

[10] Kho, S., Baker, C. and Hoxey, R., "The $5^{\text {th }}$ Asia-Pacific Conference on Wind Engineering”, Tokyo University Press, Tokyo, 2001, pp. 509-512.

[11] Chen, Y., Kopp, G.A., and Surry, D., "Prediction of Pressure Coefficients on Roofs of Low Buildings Using Artificial Neural Networks”, Wind Eng. Ind. Aerodyn, 2003, Vol. 91, pp. 423-441.

[12] Launder, B.E. and Spalding, D.B., “The Numerical Computation of Turbulent Flows”, 
Comp. Math. Appl. Mech, 1974, Vol. 3, pp. 35-61.

[13] Canuto, C., Hussaini, M.Y. and Quarterini. A., "Spectral Methods in Fluid Dynamics", Springer-Verlag, 1987, Vol. 12, No. 4, pp. 1473-1490.

[14] Murakami, S. and Mochida, A., "Development of a New Model for Flow and Pressure Fields around Bluff Body”, Journal of Wind Engineering and Industrial Aerodynamics, 1997, Vol. 68, pp. 169-182.

[15] Lin, B., "Application of CFD Simulation Technology in the large Complicated Structure Engineering”, Harbin Institute of Technology, Harbin, 2005, pp. 1-10.

[16] Kato, M. and Launder, B.E., "The 9th Sym. on turbulent shear flow", Tokyo University Press, Tokyo, 1993, pp. 4-16.

[17] Bremer, M. and Penalver, J., “The $6^{\text {th }}$ FE Model based Interpretation of Telescope Temperature Variations”, Bonn, Bonn university Press, 2002, pp. 186-195.

[18] Bremer, M. and Greve, A., "Front and Rear Perspective Heated Prototype Panels for the IRAM 15-m Telescopes in 28th ESA Antenna Workshop on Space Antenna Systems and Technologies”, Netherlands Technology Press, Noordwijk, 2005, pp. 943-960.

[19] Chamberlin, R.A., "Temperature Measurements on the Leighton Telescope”. Surface Memo, 2003, Vol. 5, pp. 124-130. 


\title{
PERFORMANCE OF STEEL-REINFORCED SQUARE CONCRETE-FILLED STEEL HOLLOW SECTION (SRSCFSHS) COLUMNS UNDER UNIAXIAL COMPRESSION
}

\author{
Jing-ming Cai ${ }^{1}$, Jin-long $\mathrm{Pan}^{1,{ }^{*}}$ and Yu-fei $\mathrm{Wu}^{2}$ \\ ${ }^{1}$ Key laboratory of concrete and pre-stressed concrete structures of Ministry of Education, \\ Southeast University, Nanjing, China \\ ${ }^{2}$ Department of Civil and Architectural Engineering, City University of Hong Kong, Hong Kong, China \\ *(Corresponding author: E-mail: jinlongp@gmail.com)
}

Received: 18 February 2015; Revised: 10 December 2015; Accepted: 5 January 2016

\begin{abstract}
Due to high load carrying capacity and convenience of designing column-beam connections, steel-reinforced square concrete-filled steel hollow section (SRSCFSHS) columns have been increasingly employed in the structural engineering. In this study, the mechanical behaviors of SRSCFSHS columns were numerically investigated with the software of ABAQUS/standard solver. To verify the validity of the finite element models of the composite columns, the simulation results were compared with the existing experimental results, and good agreement was achieved. According to the simulation results of SRSCFSHS columns, the encased section steel could restrain the generation or propagation of cracks in core concrete thus the composite column can obtain a higher strength and better ductility than that of normal square concrete filled steel tube (CFST) columns. Then, a total of twenty-six SRSCFSHS columns were numerically studied to examine the effect of steel tube ratio $\left(\alpha_{t}\right)$, section steel ratio $\left(\alpha_{s}\right)$, concrete strength $\left(f_{\mathrm{cu}}\right)$, yield strength of steel tube $\left(f_{\mathrm{y}}^{\mathrm{t}}\right)$, yield strength of section steel $\left(f_{\mathrm{y}}^{\mathrm{s}}\right)$ and the slenderness ratio $(\lambda)$ on the mechanical properties of the SRSCFSHS columns under uniaxial compression. A new model was then proposed since the model in Eurocode 4 comparatively underestimated the strength of SRSCFSHS column. Based on the comparison between the calculation results from the proposed approach and experimental results, the proposed model can provide reliable prediction of the strength of SRSCFSHS columns.
\end{abstract}

Keywords: SRSCFSHS columns, finite element analysis, mechanical behavior, parametric study, new approach

DOI:10.18057/IJASC.2016.12.4.3

\section{INTRODUCTION}

Over the last several decades, the steel-concrete composite systems have been widely used in in the construction of modern buildings and bridges, especially in regions with high seismic precautionary intensity [1-3]. For design of column members of these modern structures, the typical composite systems such as concrete filled steel tubes (CFSTs) and steel reinforced concrete (SRC) are commonly used.

It is well known that CFST structures can offer numerous structural benefits, including high strength, favorable fire resistance and ductility, large energy absorption capacities and so on [4-7]. There are many cross section types for CFST columns, among which square and circle CFST columns are the most typical ones. It is noted that the local buckling is more likely to occur in CFST columns with square cross-sections hence the square CFST columns have a relative low load carrying capacity and ductility [8]. However, the square CFST column is still increasingly used in construction of structures for the reasons of being easier in beam-to-column connection design, high cross sectional bending stiffness and good aesthetic effects. Moreover, with increasing span of bridges and height of buildings, the cross section area of a square CFST column is often designed large enough to provide required high load carrying capacity. For example, the side length of square CFST columns in the first story of Shenzhen KingKey Financial Center even reach $4000 \mathrm{~mm}$ [9]. Such a large cross section of a column may result in reduced useful indoor space and high risk of material defect. Thus, it is important to improve both the carrying capacity and ductility of square CFST column. 
As another kind of composite structures, the steel reinforced concrete (SRC) structures, which are composed of concrete, section steel, longitudinal steel bars and transverse steel bars, are also widely used due to their advantages in terms of high sectional strength [10-12] However, the SRC columns need formwork for casting concrete and transverse reinforcement is also needed to prevent the concrete from spalling and buckling of longitudinal steel reinforcement under axial load and fire hazard. Moreover, the construction process of SRC structures is relative complicated, and the outer concrete around section steel is easily crushed under horizontal cyclic loading [13]

Nowadays, a new form of composite column, namely steel-reinforced square concrete-filled steel hollow section (SRSCFSHS) columns, has been proposed. As shown in Figure 1, a SRSCFSHS column normally consists of section steel reinforced concrete inside and a square steel tube outside, which can be regarded as a combination of square CFST and SRC. An X shape section steel is commonly used as the inner section steel. Since the outside steel tube can provide effective confinement to core steel reinforced concrete, no additional steel reinforcement is needed for this composite column. Self-consolidating concrete (SCC) or self-compacting concrete can be commonly used as core concrete in the steel tube. The design of SRSCFSHS column is an attempt to combine the advantages of SRC and CFST columns, so as to achieve better composite effect for higher load carrying capacity and better ductility.

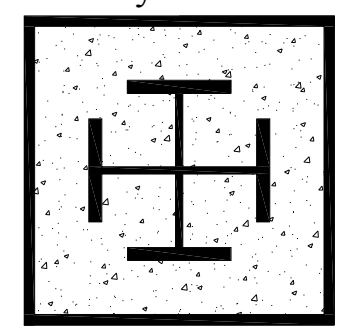

Figure 1. Cross Section of a SRSCFSHS Column

In recent years, some researchers have conducted experimental studies on the mechanical behaviors of SRSCFSHS columns subjected to compressive loading. Zhu et al. [14] finished a series of tests to study compressive behaviors of square steel tubular columns filled with steel reinforced self-consolidating high strength concrete. The experimental results indicated that the encased section steel could restrain the generation or propagation of diagonal shear cracks in core concrete, and could change the failure mode and the post-yield behavior of short composite columns. Wang et al. [15] conducted experimental investigation and theoretical analysis of SRSCFSHS columns subjected to eccentric loading. The experimental results indicated that the increment of eccentricity ratio led to decrease of both load carrying capacity and initial stiffness of the composite columns, and the increase of steel-reinforced ratios could result in gradual improvement of the load carrying capacity and the initial stiffness. Based on theory of the limited strip unit method, Zhao [16] developed a nonlinear analysis on the compression-bending behavior of SRSCFSHS columns. As for the design codes, a formula was proposed to calculate the load carrying capacity of SRSCFSHS columns in Eurocode 4 [17]. It is found that the confinement effect of outer steel tube on core concrete was not considered, as well as the interaction between concrete and section steel, indicating the model in Eurocode 4 may comparatively underestimate the load carrying capacity of the SRSCFSHS columns. Meanwhile, due to the scale and equipment limitation, few researches have been conducted to reveal the composite effect and failure mechanisms of full-size SRSCFSHS columns under uniaxial compression.

Set against the above background, this study aims to investigate the mechanical behaviors of SRSCFSHS columns subjected to uniaxial compressive loading and propose a reliable model for predicting the ultimate bearing capacity of SRSCFSHS columns. For the SRSCFSHS column shown in Figure1, an X shape section steel were embedded in the center of a square CTST column. 
The ABAQUS/standard solver was employed to numerically study the mechanical behaviors of SRSCFSHS columns under uniaxial load. Existing experimental work on SRSCFSHS columns conducted by Zhu [14] were utilized to verify the proposed finite element model and the adopted methodology. Then, an extensive parametric study on different parameters including steel tube ratio $\left(\alpha_{t}\right)$, section steel ratio $\left(\alpha_{\mathrm{S}}\right)$, the strength of the core concrete $\left(f_{\mathrm{C}}\right)$, the yield strength of steel tube $\left(f_{\mathrm{y}}^{\mathrm{t}}\right)$, the yield strength of section steel $\left(f_{\mathrm{y}}^{\mathrm{s}}\right)$ and the slenderness ratio $(\lambda)$, was carried out. Subsequently, a comparison between SRSCFSHS and its components was also made in terms of the mechanical behaviors and failure mode. Then, the calculation model in Eurocode 4 was used to calculate the strengths of the simulated SRSCFSHS columns. Owing to the fact that the current European Code has not yet included an accurate equation to evaluate the load carrying capacity of the SRSCFSHS, a novel model was then proposed.

\section{VERIFICATION OF FINITE ELEMENT MODEL OF SRSCFSHS COLUMNS}

\subsection{Constitutive Models of Materials}

Finite element analysis (FEA) is a theoretical tool which has been widely used in the analysis of steel composite structures [18-19]. In this study, the nonlinear finite element analysis was conducted to simulate the mechanical behaviors of SRSCFSHS columns with the software of ABAQUS [20]. The steel tube and the section steel are modeled as isotropic elastic-plastic materials in the finite element model. For both the steel tube and section steel, a five-stage stress-strain model [21] is used to describe the uniaxial stress-strain relationship, which is shown in Figure2 and given by:

$$
\begin{aligned}
& \sigma_{s}=\left\{\begin{array}{cl}
E_{s} \varepsilon_{s} & \varepsilon_{s}<\varepsilon_{e} \\
-A \varepsilon_{s}^{2}+B \varepsilon_{s}+C & \varepsilon_{e}<\varepsilon_{s} \leq \varepsilon_{e 1} \\
f_{y} & \varepsilon_{e 1}<\varepsilon_{s} \leq \varepsilon_{e 2} \\
f_{y}\left[1+0.6 \frac{\varepsilon_{s}-\varepsilon_{e 2}}{\varepsilon_{e 3}-\varepsilon_{e 2}}\right] & \varepsilon_{e 2}<\varepsilon_{s} \leq \varepsilon_{e 3} \\
1.6 f_{y} & \varepsilon_{s}>\varepsilon_{e 3}
\end{array}\right. \\
& \text { where } \\
& \varepsilon_{e}=0.8 f_{y} / E_{S}, \varepsilon_{e 1}=1.5 \varepsilon_{e}, \quad \varepsilon_{e 2}=10 \varepsilon_{e 1}, \varepsilon_{e 3}=100 \varepsilon_{e 1}, A=0.2 f_{y} /\left(\varepsilon_{e 1}-\varepsilon_{e}\right)^{2}, B=2 A \varepsilon_{e 1}, C=0.8 f_{y}+A \varepsilon_{e}{ }^{2}-B \varepsilon_{e}
\end{aligned}
$$

In order to simulate the plastic behaviour of core concrete in SRSCFSHS columns under compression, the three-stage stress-strain relationship shown in Figure3 was adopted [22]. This model is illustrated as following:

In the initial stage (from Point $\mathrm{O}$ to Point $\mathrm{A}$ in Figure 3), there is no or very little interaction between the steel tube and concrete. Therefore, the ascending branch of the stress-strain relationship of unconfined concrete is given by:

where

$$
\begin{gathered}
\frac{\sigma}{f_{c}^{\prime}}=\frac{A X+B X^{2}}{1+(A-2) X+(B-1) X^{2}} \quad 0<\varepsilon \leq \varepsilon_{c 0} \\
\mathrm{X}=\frac{\varepsilon}{\varepsilon_{c 0}} ; \mathrm{A}=\frac{E_{c} \varepsilon_{c 0}}{f_{c}^{\prime}} ; \mathrm{B}=\frac{A-1^{2}}{0.55}-1 ; \varepsilon_{c 0}=0.00076+\sqrt{\left(0.626 f_{c}^{\prime}-4.33\right) \times 10^{-7}}
\end{gathered}
$$


In the second stage, a plateau (from Point A to Point B) is included to represent the increased peak strain of concrete due to confinement. The strain at Point B $\left(\varepsilon_{c c}\right)$ can be expressed as following:

$\frac{\varepsilon_{c c}}{\varepsilon_{c 0}}=e^{k} \quad \varepsilon_{c 0}<\varepsilon \leq \varepsilon_{c c}$
where k=(2.9224-0.00367f $\left.f_{c}^{\prime}\right)\left(\frac{f_{B}}{f_{c}^{\prime}}\right)^{0.3124+0.002 f_{c}^{\prime}} ; f_{\mathrm{B}}=\frac{0.25\left(1+0.027 f_{y}\right) \mathrm{e}^{\frac{-0.028 \mathrm{~B}}{\mathrm{t}}}}{1+1.6 \mathrm{e}^{-10}\left(f_{c}^{\prime}\right)^{4.8}}$.

For the descending branch of the model (BC) shown in Figure 3, an exponential function was used, which is defined by:

$$
\sigma=0.1 f_{c}^{\prime}+0.9 f_{c}^{\prime} \exp \left[-\left(\frac{\varepsilon-\varepsilon_{c c}}{\alpha}\right)^{0.92}\right] \quad \varepsilon \geq \varepsilon_{c c}
$$

where $\alpha=0.005+0.0075 \xi_{c} ; \xi_{c}=\frac{A_{s} f_{y}}{A_{c} f_{c k}}$, respectively.

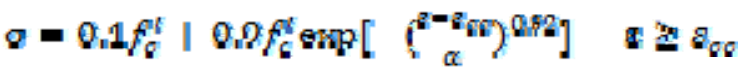

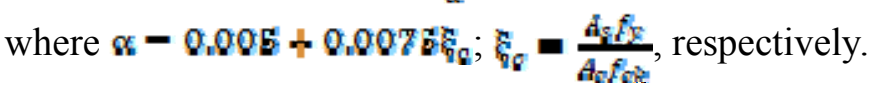

In the above formula $A_{s}$ and $A_{c}$ are the cross-sectional areas of steel tube and concrete respectively, $f_{\varepsilon}^{\prime}$ is the cylinder strength of concrete, $f_{c k}$ is the characteristic strength of concrete, $F_{S}$ is the Elastic modulus of steel and $f_{\gamma}$ is the yield strength of steel tube. The elastic modulus of concrete $\left(E_{C}\right)$ is taken as $4730, F_{R}$ according to ACI 318-11[23], and the Poisson's ratio of concrete is taken as 0.2. A fracture energy model proposed by Hillerborg et al. [24] is used to simulate the tensile-soften behavior of concrete.

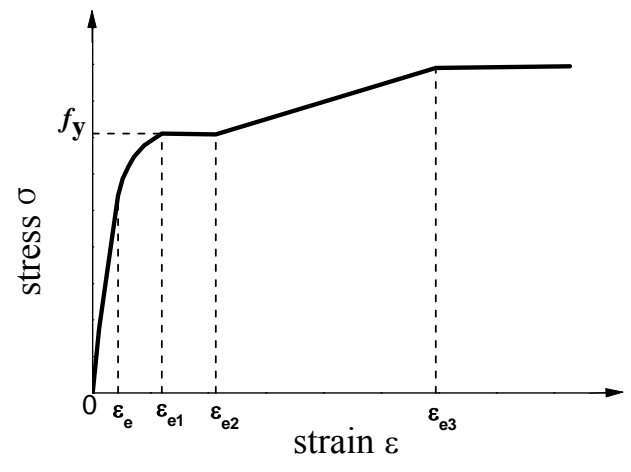

Figure 2. Typical $\sigma-\varepsilon$ curve for steel

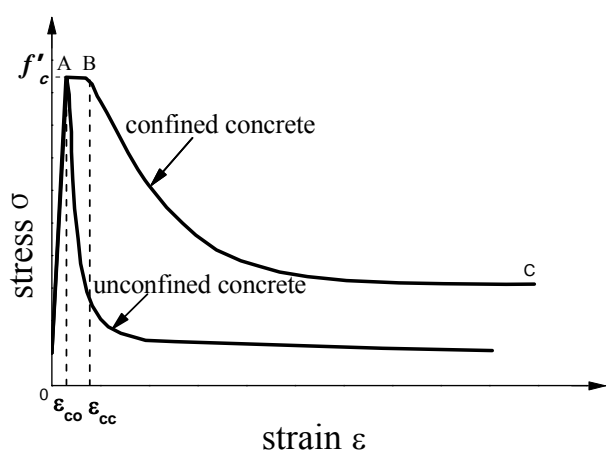

Figure 3. Typical $x-\varepsilon$ curves for concrete

\subsection{Description of Finite Element Model of SRSCFSHS Column}

To achieve identical vertical deformations for the entire cross section, two steel end plates were used at both the top and bottom of the SRSCFSHS column in the finite element model. Herein, for each specimen, there are five individual components including outer square steel tube, section steel, core concrete, top and bottom end plates. The interactions between these components were defined by contact surfaces, where one surface acted as the master surface and the other as the slave surface. 
The difference between a master and a slave surface lies in that the former can penetrate the latter, but the reverse cannot take place. Core concrete was defined as the slave surface since it contacted with both the end plates and the steel tube, while the steel tube were treated as the slave surface for its contact with the end plates. "Tie contact" was defined for the contact between the end plate and the steel tube, which ensures the contact elements have the same displacements and rotational angles during the loading process. The contact between the end plate and concrete was defined as "hard contact", meaning that no contact pressure occurs unless one surface contacts another, and the contact surfaces were allowed to separate from each other after they contacted. "Hard contact" was also used to define the contact between steel tube and core concrete in the normal direction. The Mohr-Coulomb friction model was applied in the tangential direction for the contact between steel tube and core concrete while the friction coefficient is set to be 0.25 [4]. Since the section steel was embedded in the core of the CFST column, the "Tie contact" constraint was used to describe the contact between concrete and section steel. The slip between core concrete and section steel was neglected.

The bottom end plate was fixed against all degrees of freedom whereas the top plate was able to deform along the longitudinal axis (in the direction of $\mathrm{z}$ coordinate). The uniaxial compressive load was applied on the top plate by displacement increments. A mesh convergence study was performed to identify an appropriate mesh density for achieving reliable results. In the FEA model of the SRSCFSHS column, the steel tube was simulated by four-node conventional shell element (SR4) while the section steel, the end plates and core concrete were modelled by 3D eight-node solid elements with reduced integration (C3D8R). Figure 4 shows the meshing configurations of the SRSCFSHS column and its components.

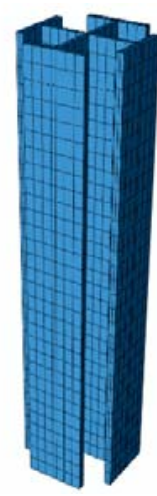

(a) Section steel

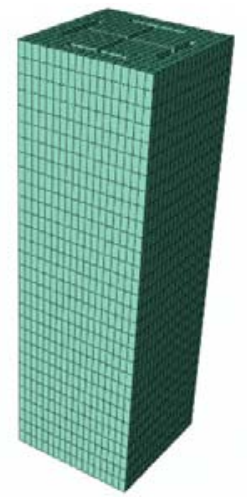

(b) Core concrete

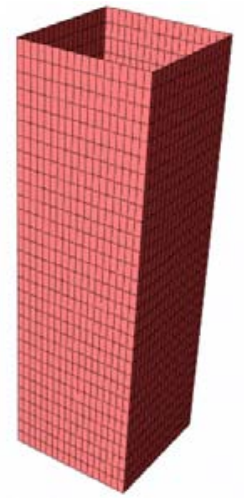

(c) Steel tube

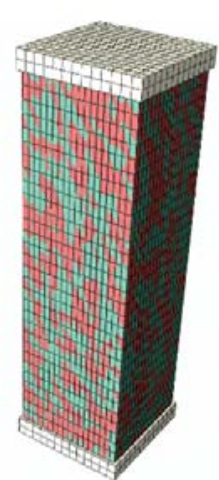

(d) SRSCFSHS

Figure 4. Meshing and Configuration of the SRSCFSHS Column Model

\subsection{Verification of the Proposed Finite Element Model}

To verify the validity of the FEA model described above, existing experiments conducted by Zhu et al. [14] were selected and analyzed with the proposed FE models. A total of four SRSCFSHS columns from the tests were numerically studied, and the dimensions and material properties of the columns are shown in Table 1. Figure 5 shows axial load $(\mathrm{L})$ versus average axial strain $(\varepsilon)$ curves of the SRSCFSHS columns from both the experimental and simulation results. As can be seen in Table 1, the maximum error of load carrying capacity was less than $8 \%$. Generally, the simulation results are in good agreement with the experimental results, indicating that the proposed finite element models of the SRSCFSHS columns are valid. 
Table 1. Dimensions and Material Properties of the SRSCFSHS Columns

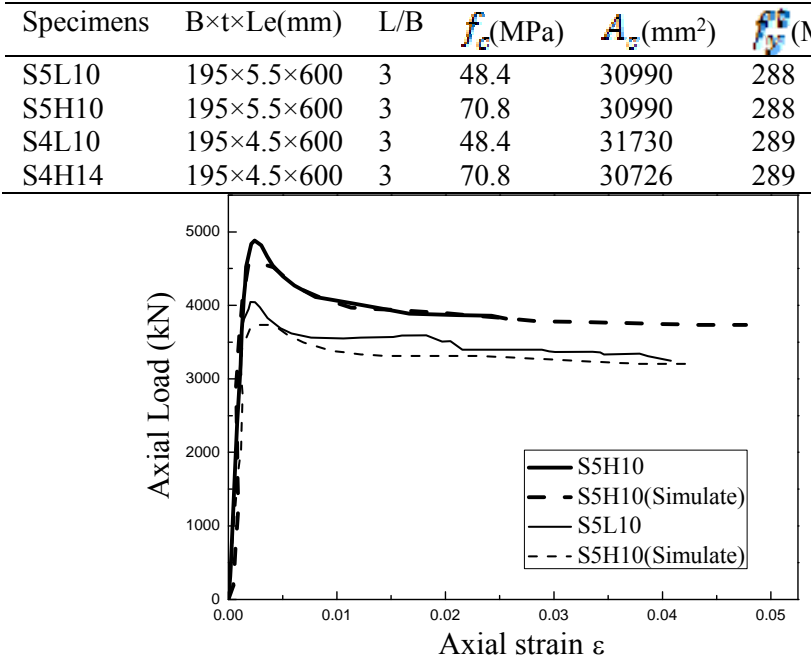

(a) for S5L10, S5H10

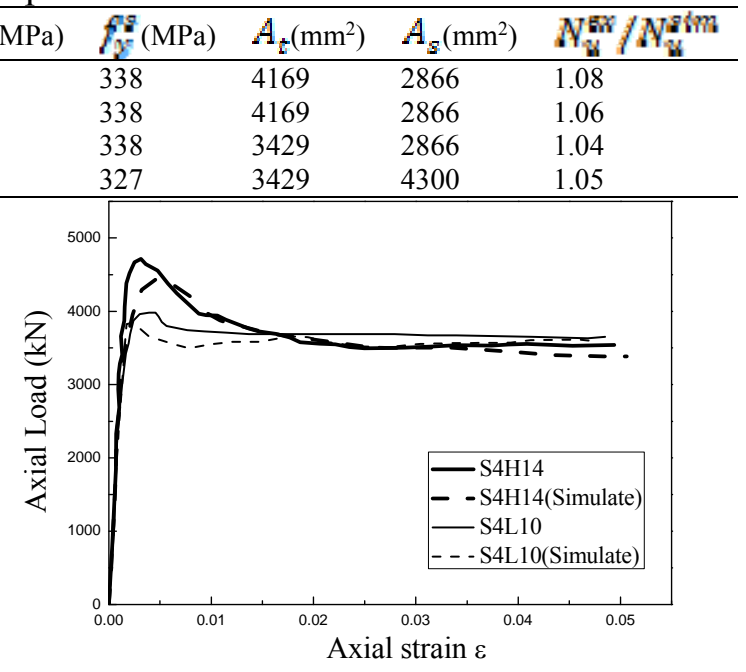

(b) for S4L10, S4H14

Figure 5. Axial Load-average Axial Strain Curves from Both Experiments and FE Analysis

\section{MECHANICAL BEHAVIORS OF SRSCFSHS COLUMNS IN UNIAXIAL COMPRESSION}

In this section, the simulation results of a typical specimen S4H14 were employed to discuss the failure mode and mechanical behavior of the SRSCFSHS columns.

\subsection{Failure Mode}

The typical failure modes of SRSCFSHS components are shown in Figure 6. It is found that the failure mode of SRSCFSHS column is quite similar to normal CFST columns. In the final stage, outward local bulking is observed in the middle of the steel tube, while inward bucking is avoided due to the support from steel reinforced core concrete. For the embedded section steel, no local buckling is observed due to ambient complete support from steel tube confined core concrete. In the ultimate stage, outward bulge occurs in the middle of the SRSCFSHS column. The transverse deformation of concrete in the region close to the two ends is smaller than that of concrete in the middle of the column, which is due to constraint of transverse deformation caused by the end steel plates.

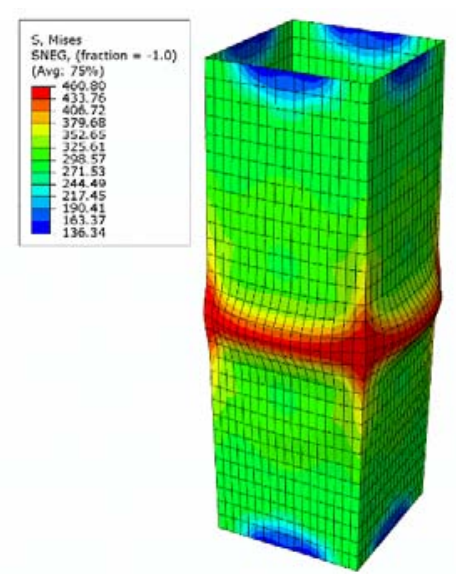

(a) Steel tube

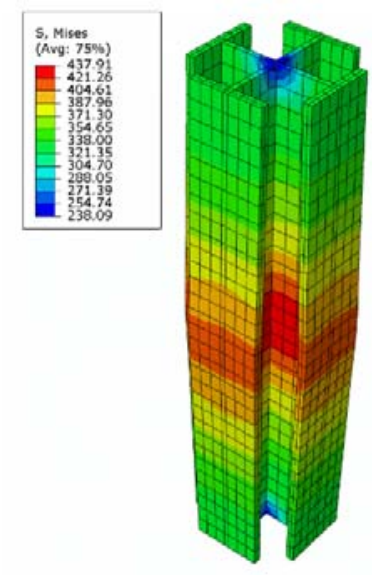

(b) Section steel

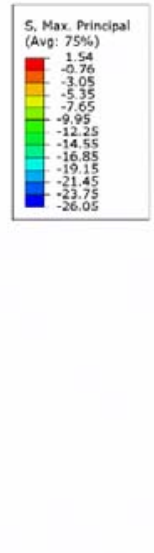

(c) Core concrete

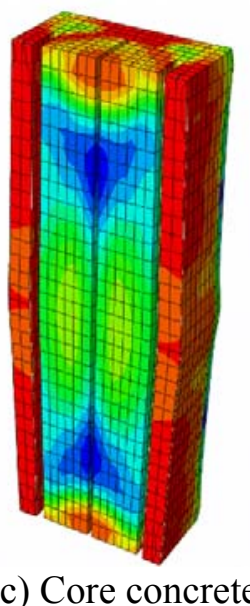

Figure 6. Typical failure mode of the components of the SRSCFSHS column 


\subsection{Axial Load Versus Average Axial Strain Curves}

The calculated axial load (L) versus axial strain ( $\varepsilon$ ) curve of the SRSCFSHS column is shown in Figure 7. The axial load (L) versus axial strain ( $\mathrm{z}$ ) curves of the components including core concrete, steel tube, section steel are also shown in Figure7. Four characteristic points are marked on the curve of the SRSCFSHS column. Point A defines the moment when the steel tube begins to yield. Point B indicates the moment when core concrete just reaches the peak strength. Point $\mathrm{C}$ indicates the section steel reaches the peak strength, and Point D defines the final failure of the composite column due to large deformation. Thus, the L versus $\varepsilon$ curve of the SRSCFSHS column can be generally divided into four stages. In the first stage (OA), the composite column generally shows elastic behavior. At Point A, the stress of core concrete and section steel are about $80 \%$ and $70 \%$ of their peak strength, respectively. In the second stage (AB), the average axial strain $(\varepsilon)$ increases more quickly than that in the first stage. At Point $\mathrm{B}$, while the core concrete just reaches its peak strength, the steel tube has entered the plastic stage. In this stage, the maximum stress of the section steel is about $80 \%$ of its peak strength. The column approaches its peak strength at the end of the stage. The segment of BC defines the third stage of the axial load-average axial strain curves. In this stage, the stress of the column and the core confined concrete decreases with further axial deformation even though the stress of the section steel continues to increase. At Point $\mathrm{C}$ the section steel reaches its peak strength, which is later than the composite column yields (point B), indicating the section steel can provide "strength reserve" and can increase the post-yielding strength of the composite column. This also has a significant benefit for the fire resistance of the SRSCFSHS column. In the last stage (CD), the load almost keeps stable with increasing axial deformation. In this stage, the core concrete sustains about $50 \%$ of the strength of the composite column, while the steel tube and section steel sustain the remaining $50 \%$ of the strength. The composite column finally fails by excessive axial and transverse deformation due to the yielding of steel tube and section steel as well as the nonlinear deformation of core confined concrete.

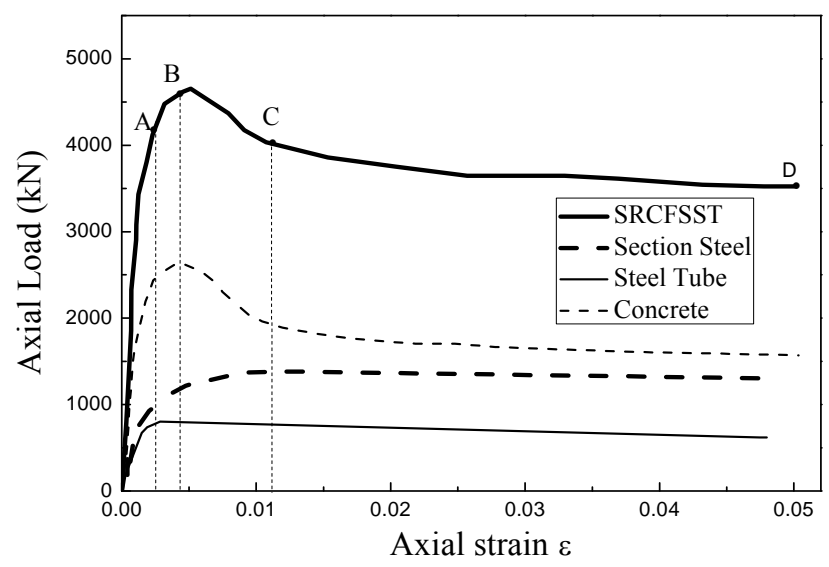

Figure 7. Typical Axial Load (L) Versus Axial Strain ( $\varepsilon$ ) Response of SRSCFSHS Column

\subsection{Comparison of Mechanical Behavior between SRSCFSHS Column and Its components}

In order to analyze the composite effects of the components in SRSCFSHS columns, the mechanical behaviors of individual CFST and section steel are also numerically simulated. 


\subsubsection{Comparison between section steel in SRSCFSHS column and single section steel}

The comparison of mechanical behavior between section steel in SRSCFSHS column and single section steel under uniaxial compression is shown in Figure 8. In order to simulate the performance of single section steel under uniaxial compression, nonlinear buckling analysis method provided by ABAQUS was applied in this paper [20]. The section steel in the SRSCFSHS column fails due to compression yielding, while the individual section steel fails by buckling in the middle of the length under uniaxial compression, as shown in Figure 9. According to the calculation results, the load carrying capacity of the section steel in the composite column is $40 \%$ higher than that of the individual section steel. This is due to the fact that the inner section steel is under the confinement of the square CFST, while the individual section steel has no support from the surrounding concrete and local buckling occurs under axial loading.

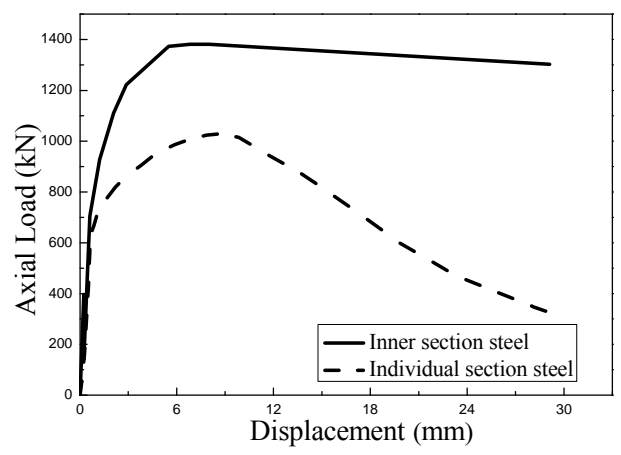

Figure 8. Comparison of Mechanical Behavior between Inner Section Steel and Individual Section Steel
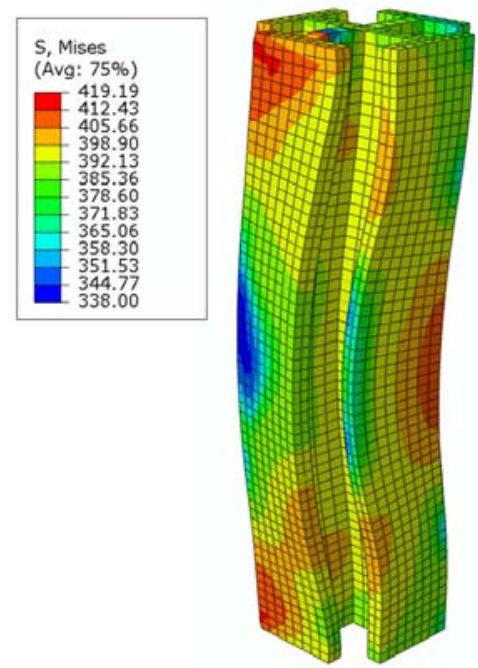

Figure 9. Failure Mode of Single Section Steel

\subsubsection{Comparison between SRSCFSHS Column and Square CFST Column}

Figure10 is depicted to illustrate the L- $\varepsilon$ curves of the SRSCFSHS column and the individual CFST column. It should be noticed that the CFST column has the same cross-section and the material properties as the SRSCFSHS column except that there is no section steel embedded in the CFST column. According to the simulation results, the load carrying capacity of the SRSCFSHS column is about $28 \%$ higher than that of the individual CFST column due to the existence of the 
section steel. After the peak load, the L- $\varepsilon$ curve of the SRSCFSHS column drops more gradual than that of the individual CFST column. This is due to the fact that the section steel can provide "strength reserve" for the SRSCFSHS column. In order to compare the ductility of SRSCFSHS and CFST columns, the ductility coefficient (u) was introduced which can be calculated as $u=a_{w} / a_{y}$, where $\varepsilon_{u}$ is the ultimate strain and $\varepsilon_{y}$ is the yield strain. As can be seen in Figure11, $\boldsymbol{s}_{u}$ is equal to the strain corresponding to a $15 \%$ drop of the peak load in the descending part of L- $\varepsilon$ curves, while $s_{y}$ is calculated according to the criteria for equivalent elastoplastic yield [25]. The ductility coefficients of the two columns are presented in Table 2. It can be seen that the ductility coefficient of SRCFST column is about $80 \%$ higher than that of CFST column.

Figure 12 shows the maximum principal plastic strain of core concrete for both SRSCFSHS column and CFST column. The maximum principal plastic strain can be regarded as the cracking of concrete in FEA model and the cracks are perpendicular to the orientation of the maximum principal plastic strain. It can be seen that maximum principal plastic strain of SRSCFSHS column is much lower than that of CFST columns. The outward deformation of core concrete in SRSCFSHS column is much smaller than that of core concrete in the CFST column. Especially, for the CFST column, the outward deformation almost concentrates in the middle of the edge. Concrete cracks can be represented by the maximum principal plastic strain and the cracks are perpendicular to the orientation of the maximum principal plastic strain. Therefore, according to Figure12, the encased section steel can effectively restrain the generation or propagation of cracks in the core concrete.

Figure 13 shows the distribution of contact pressure between core concrete and square steel tube for both SRSCFSHS and CFST columns. Contact pressure can reflect the confinement of steel tube to core concrete. For a certain cross section, the contact pressure concentrates at the corner areas of both SRSCFSHS column and CFST column. Along the length of columns, the contact pressure of SRSCFSHS column is higher than that of CFST column. The contact pressure of SRCFST column distributes uniformly along the edges, while the contact pressure of CFST column generally concentrates in the middle part of the edges.

According the aforementioned analysis, the cracks in core concrete of SRSCFSHS column are restrained due to the existence of section steel, thus the contact pressure between the square steel tube and core concrete distributes more uniformly and better composite effects can be achieved. Therefore, the SRCFST columns have both higher load carrying capacity and ductility than the square CFST columns.

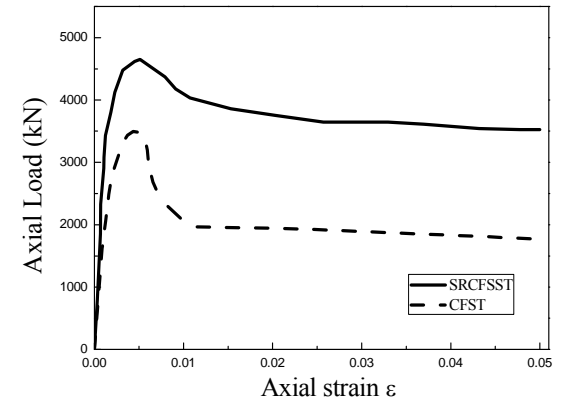

Figure 10. L- $\varepsilon$ Curves of SRSCFSHS and CFST

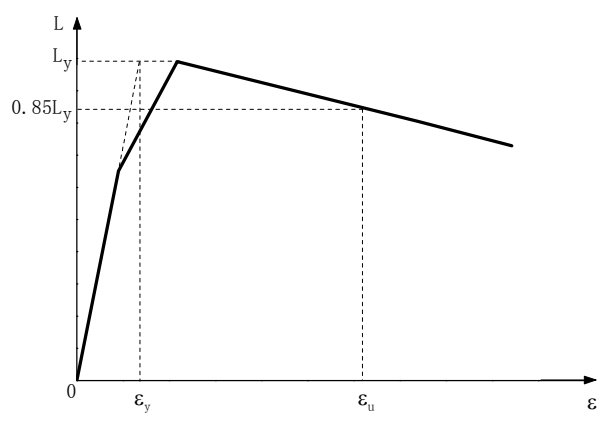

Figure 11. Definition of Ductility Coefficient 
Table 2. Ductility Coefficients of SRSCFSHS and CFST Columns

\begin{tabular}{ccc}
\hline Coefficients & SRSCFSHS & CFST \\
\hline$\varepsilon_{u}$ & 0.018 & 0.008 \\
$\varepsilon_{y}$ & 0.002 & 0.0016 \\
$\mathrm{u}$ & 9 & 5 \\
\hline
\end{tabular}

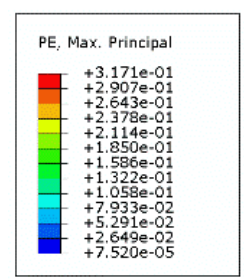

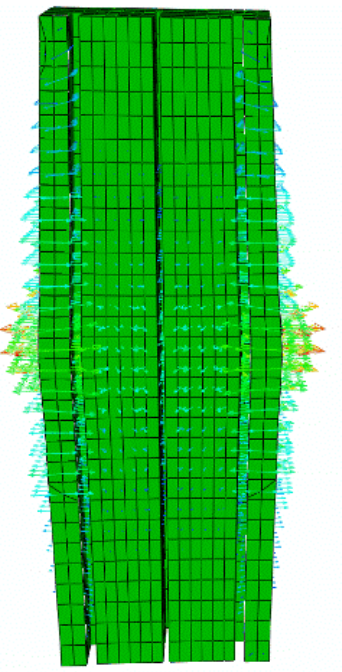

(a) For SRSCFSHS column

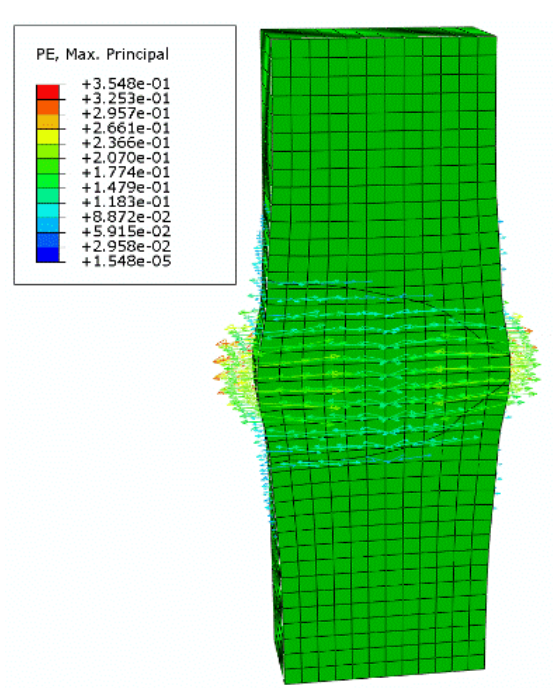

(b) For CFST column

Figure 12. Maximum Principal Plastic Strain of Core Concrete

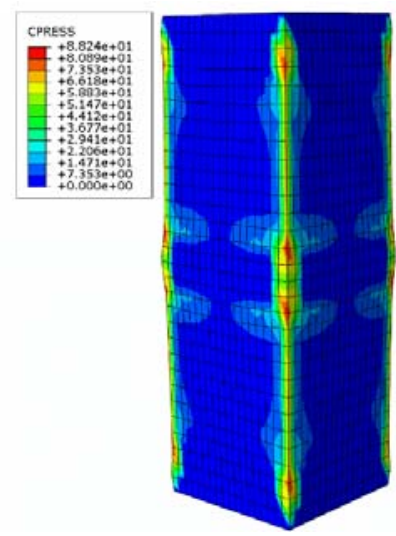

(a) For SRSCFSHS column
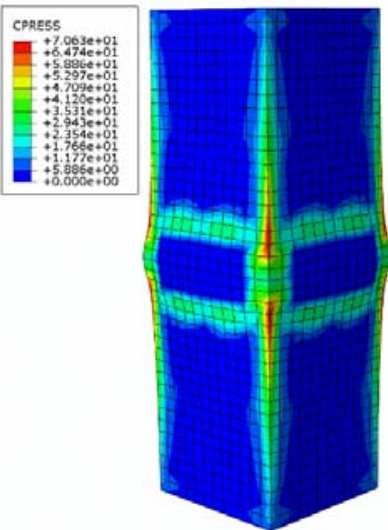

(b) For CFST column

Figure 13. Contact Pressure of Core Concrete

\section{PARAMETRIC STUDY}

In this section, a total of 26 SRSCFSHS columns were analyzed to study the effect of the dimensions and material properties on the mechanical behaviors of the composite columns. Table 3 summarizes the characteristics of the SRSCFSHS columns in the parametric study.

\subsection{Effect of Section Steel Strength}

According to the simulation results in Figure 14, increasing section steel strength $\left(f_{\gamma}\right)$ leads to gradual increase of the peak strength and the initial stiffness as well as the residual strength of SRSCFSHS columns. For the cases with different strengths of section steel, the shapes of the L- $\varepsilon$ 
curves are quite similar and the curves are almost parallel to each other after the peak strength, and the influence of section steel strength $\left(y_{y}\right)$ on the ductility of SRSCFSHS columns is not significant.

Table 3. Dimensions and Material Properties of Circular SRSCFSHS in the Parametric Study

\begin{tabular}{|c|c|c|c|c|c|c|c|c|c|c|}
\hline \multirow[t]{2}{*}{ Group } & \multirow[t]{2}{*}{ Specimens } & \multicolumn{7}{|c|}{ Dimensions } & \multicolumn{2}{|c|}{ Material properties } \\
\hline & & $\mathrm{L}_{0} \times \mathrm{B} \times \mathrm{t}$ & $\lambda$ & $A_{\varepsilon}$ & $A_{z}$ & $\alpha_{t}$ & $\alpha_{g}$ & $f_{c u}(\mathrm{MPa})$ & $f(\mathrm{MPa})$ & $f^{\prime}(\mathrm{MPa})$ \\
\hline \multirow[t]{4}{*}{1 (SS) } & SS-1 & $600 \times 195 \times 4.5$ & 10.6 & 3429 & 2866 & 0.11 & 0.09 & 70.8 & 235 & 345 \\
\hline & SS-2 & $600 \times 195 \times 4.5$ & 10.6 & 3429 & 2866 & 0.11 & 0.09 & 70.8 & 345 & 345 \\
\hline & SS-3 & $600 \times 195 \times 4.5$ & 10.6 & 3429 & 2866 & 0.11 & 0.09 & 70.8 & 390 & 345 \\
\hline & SS-4 & $600 \times 195 \times 4.5$ & 10.6 & 3429 & 2866 & 0.11 & 0.09 & 70.8 & 420 & 345 \\
\hline \multirow[t]{4}{*}{$2(\mathrm{CS})$} & CS-1 & $600 \times 195 \times 4.5$ & 10.6 & 3429 & 2866 & 0.11 & 0.09 & 30 & 235 & 345 \\
\hline & $\mathrm{CS}-2$ & $600 \times 195 \times 4.5$ & 10.6 & 3429 & 2866 & 0.11 & 0.09 & 40 & 235 & 345 \\
\hline & $\mathrm{CS}-3$ & $600 \times 195 \times 4.5$ & 10.6 & 3429 & 2866 & 0.11 & 0.09 & 50 & 235 & 345 \\
\hline & CS-4 & $600 \times 195 \times 4.5$ & 10.6 & 3429 & 2866 & 0.11 & 0.09 & 60 & 235 & 345 \\
\hline \multirow[t]{4}{*}{ 3(TS) } & TS-1 & $600 \times 195 \times 4.5$ & 10.6 & 3429 & 2866 & 0.11 & 0.09 & 70.8 & 235 & 235 \\
\hline & TS-2 & $600 \times 195 \times 4.5$ & 10.6 & 3429 & 2866 & 0.11 & 0.09 & 70.8 & 235 & 345 \\
\hline & TS-3 & $600 \times 195 \times 4.5$ & 10.6 & 3429 & 2866 & 0.11 & 0.09 & 70.8 & 235 & 390 \\
\hline & TS-4 & $600 \times 195 \times 4.5$ & 10.6 & 3429 & 2866 & 0.11 & 0.09 & 70.8 & 235 & 420 \\
\hline \multirow[t]{5}{*}{$4(\mathrm{TR})$} & TR-1 & $600 \times 195 \times 3$ & 10.6 & 2286 & 2866 & 0.11 & 0.09 & 70.8 & 235 & 345 \\
\hline & TR-2 & $600 \times 195 \times 6$ & 10.6 & 4572 & 2866 & 0.15 & 0.09 & 70.8 & 235 & 345 \\
\hline & TR-3 & $600 \times 195 \times 9$ & 10.6 & 6858 & 2866 & 0.22 & 0.09 & 70.8 & 235 & 345 \\
\hline & TR-4 & $600 \times 195 \times 12$ & 10.6 & 9144 & 2866 & 0.29 & 0.09 & 70.8 & 235 & 345 \\
\hline & TR-5 & $600 \times 195 \times 15$ & 10.6 & 11430 & 2866 & 0.37 & 0.09 & 70.8 & 235 & 345 \\
\hline \multirow[t]{5}{*}{$5(\mathrm{SR})$} & SS-1 & $600 \times 195 \times 4.5$ & 10.6 & 3429 & 2866 & 0.11 & 0.09 & 70.8 & 235 & 345 \\
\hline & SS-2 & $600 \times 195 \times 4.5$ & 10.6 & 3429 & 3622 & 0.11 & 0.12 & 70.8 & 235 & 345 \\
\hline & SS-3 & $600 \times 195 \times 4.5$ & 10.6 & 3429 & 4304 & 0.11 & 0.14 & 70.8 & 235 & 345 \\
\hline & SS-4 & $600 \times 195 \times 4.5$ & 10.6 & 3429 & 5230 & 0.11 & 0.17 & 70.8 & 235 & 345 \\
\hline & SS-5 & $600 \times 195 \times 4.5$ & 10.6 & 3429 & 6124 & 0.11 & 0.20 & 70.8 & 235 & 345 \\
\hline \multirow[t]{4}{*}{$5(\mathrm{SL})$} & SL-1 & $564 \times 195 \times 4.5$ & 10 & 3429 & 2866 & 0.11 & 0.09 & 70.8 & 235 & 345 \\
\hline & SL-2 & $1127 \times 195 \times 4.5$ & 20 & 3429 & 2866 & 0.11 & 0.09 & 70.8 & 235 & 345 \\
\hline & SL-3 & $2816 \times 195 \times 4.5$ & 50 & 3429 & 2866 & 0.11 & 0.09 & 70.8 & 235 & 345 \\
\hline & SL-4 & $5635 \times 195 \times 4.5$ & 100 & 3429 & 2866 & 0.11 & 0.09 & 70.8 & 235 & 345 \\
\hline
\end{tabular}

\subsection{Effect of Core Concrete Strength}

According to the simulation results in Figure 15, increasing the strength of core concrete $\left(f_{c u}\right)$ can result in improvement in the peak strength and the residual strength of SRSCFSHS columns. Since the deformation capacity of the composite column is governed by the deformation ability of the steel tube and section steel, all SRSCFSHS columns show high ductility. However, as the concrete strength increases from $30 \mathrm{MPa}$ to $60 \mathrm{MPa}$, the increase of the ultimate strength is much smaller than that of the peak strength, indicating the strength of core concrete has little effect on the ultimate strength of SRSCFSHS column. This is due to the fact that the increase of concrete strength may lead to higher brittleness, and high strength concrete softens significantly and can sustain similar external load to low strength concrete in the ultimate stage. 


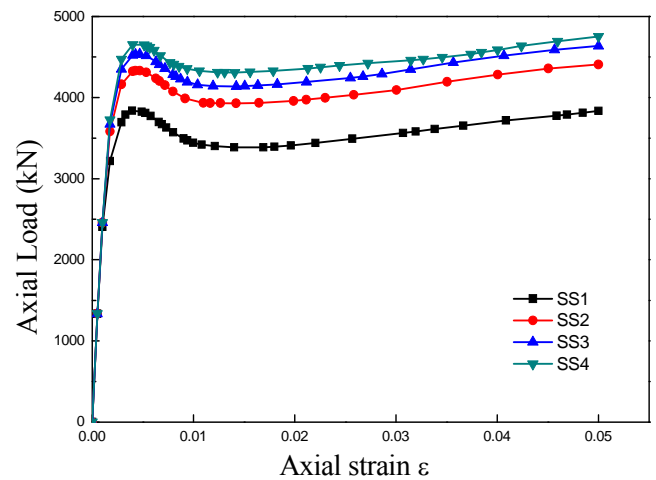

Figure 14. Effect of Section Steel Strength

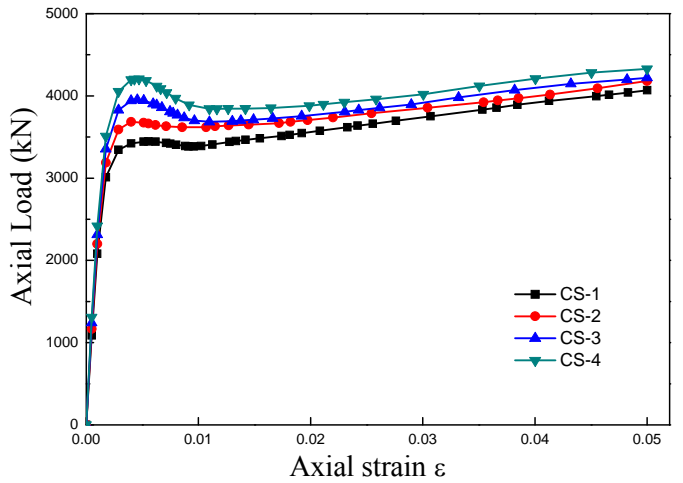

Figure 15. Effect of Concrete Strength

\subsection{Effect of Steel Tube Strength}

Figure 16 shows the effect of steel tube strength $\left(f_{\gamma}\right)$ on the mechanical behavior of the SRSCFSHS column. It can be seen that the curves become smoother with the increase of steel tube strength after the peak strength. From one hand, the increase of steel tube strength can certainly increase the bearing capacity of the steel tube. From the other hand, increasing the strength of steel tube can provide more effective confinement to core concrete, resulting in improvement of bearing capacity of the core concrete. Therefore, increasing steel tube strength can both increase the peak strength and the ultimate strength of the composite SRSCFSHS column.

\subsection{Effect of Steel Tube Ratio}

Steel tube ratio $\left(\alpha_{t}\right)$ is an important factor that affects the axial compression behavior of SRSCFSHS columns. The steel tube ratio is defined as $\alpha_{i}=A_{3} / A_{0}$, where $A_{t}$ represents the area of steel tube and $A_{c}$ represents the area of core concrete. According to the simulation results in Figure 17, increasing steel tube ratio $\left.\alpha_{t}\right)$ can lead to significant increase of the peak strength or the ultimate strength of SRSCFSHS column. With increasing steel tube ratio, the SRSCFSHS columns exhibited various post-yield behaviors. Specimen TR-1 shows softening behavior, while TR-5 exhibits strain hardening behavior in the post-yield stage, which is due to the fact that increasing the ratio of steel tube can significantly improve the confinement to core concrete and result in the change from strength softening behavior to strength or strain hardening behavior of the SRSCFSHS column.

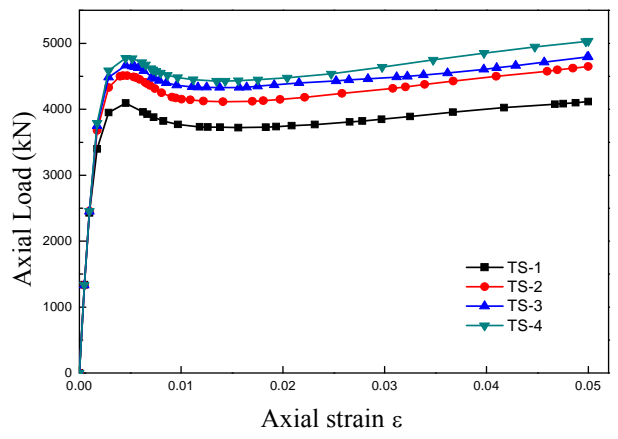

Figure 16. Effect of Steel Tube Strength

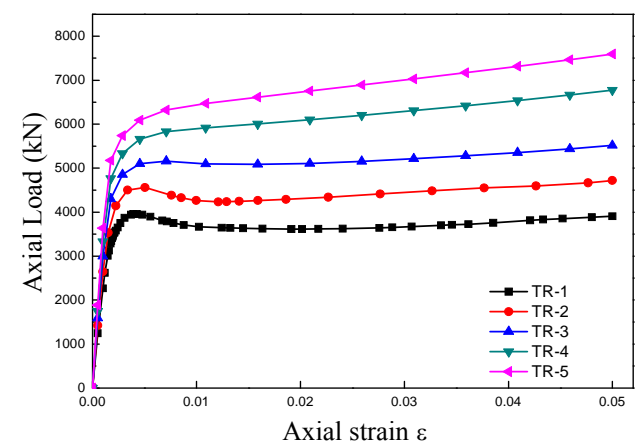

Figure 17. Effect of Steel Tube Ratio

\subsection{Effect of Section Steel Ratio}

The section steel ratio is defined as $\alpha_{g} \boldsymbol{m} \mathrm{A}_{g} / \mathrm{A}_{\mathrm{g}}$, where $\mathrm{A}_{g}$ represents the area of section steel and $A_{u}$ represents the area of core concrete. Figure18 shows the effect of section steel ratio $\left(\alpha_{y}\right)$ on the 
axial compression behavior of SRSCFSHS columns. The shapes of the curves are very similar, and the peak strength and the ultimate strength of the composite column increase with significantly with the section steel ratio, indicating increasing the section steel ratio is an effective way to enhance peak strength or ultimate strength of the SRSCFSHS columns.

\subsection{Effect of Slenderness Ratio}

The slenderness ratio $(\lambda)$ of SRSCFSHS columns is defined as $\lambda-L_{0} / t$, where $L_{0}$ is the effective column length, $i$ is radius of gyration. The initial out-of-straightness is the main factor that influence the compression behavior of slender columns. In this study, the out-of-straightness is taken as L/5000 [26]. The compression behavior of SRSCFSHS column can be discussed with the

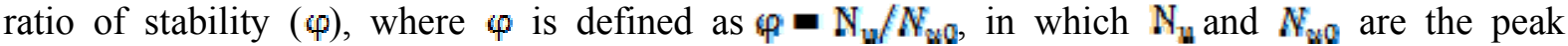
strength and the sectional strength of the composite column. The schematic view of $q-A$ relation is shown in Figure20. Figure19 shows the effect of slenderness ratio $(\lambda)$ on the axial compression behavior of SRSCFSHS columns. The shapes of curves are quite different even though they have same cross section and material properties. Generally, specimen SL-1 can be classified as strength failure, SL-2, SL-3 can be classified as elastic-plastic instability failure while SL-4 can be classified as elastic instability failure. The typical $\varphi-\lambda$ relation of SRSCFSHS column is shown in Figure21. It can be seen that the SRSCFSHS column shows strength failure mode when $A \mathbb{A} 15$, and shows elastic-plastic instability failure mode when $15 \mathrm{~m}, \lambda \mathbf{3}$ and shows elastic instability failure mode when $\lambda$ s. 6 .

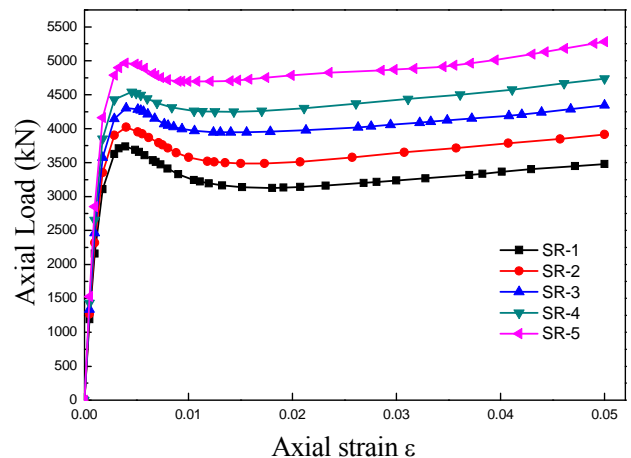

Figure 18. Effect of Section Steel Ratio

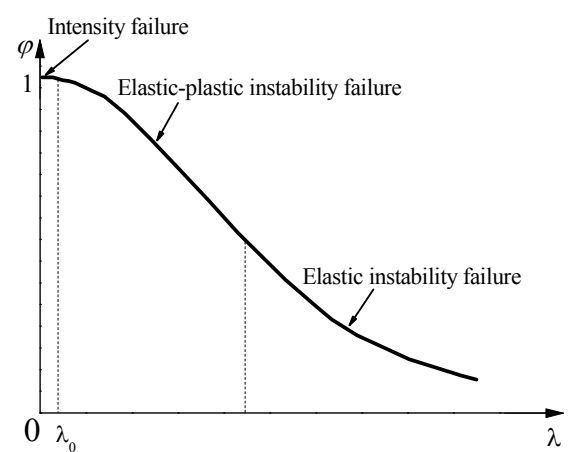

Figure 20. Schematic View of $\varphi_{p}-\lambda$ Relation

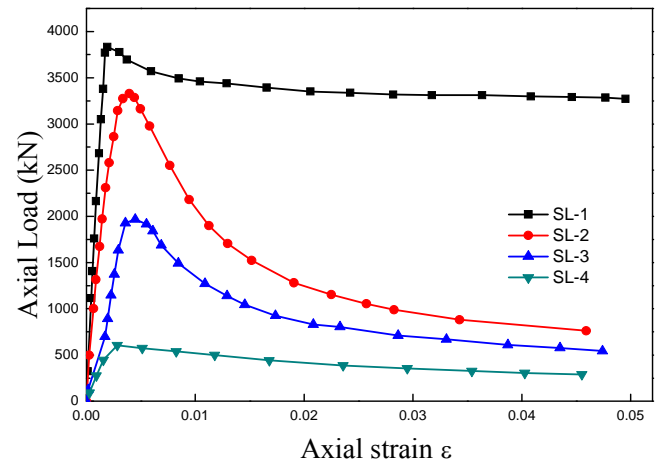

Figure 19. Effect of Slenderness Ratio

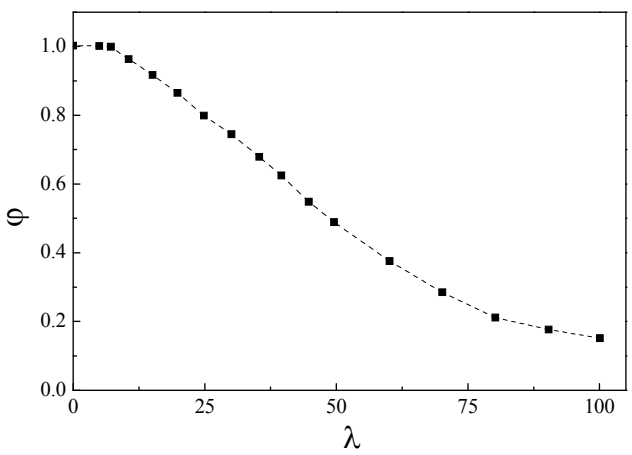

Figure 21. Typical $\varphi-\lambda$ relation of SRSCFSHS 


\section{A NEW APPROACH FOR PREDICTING STRENGTH OF SHORT SRSCFSHS COLUMN}

In this study, the approach of Eurocode 4 [17] (EC4) was adopted to estimate the compressive strength of the short SRSCFSHS columns (A $1 \mathrm{~b})$. According to the calculation approach in Eurocode 4, the compressive strength of short SRSCFSHS columns can be calculated by

$$
N_{\mathrm{w}}=A_{g} f_{Q}^{\prime}+A_{g} f_{y}^{t}+A_{g} f_{y}^{g}
$$

In the above equation, $f_{g}^{t}$ is the yield strength of steel tube, $f_{\varepsilon}^{\prime}$ is the cylinder compressive strength of concrete and $f_{y}$ is the yield strength of section steel. $A_{s}, A_{g}$ and $A_{g g}$ are the cross-sectional areas of the steel tube, core concrete and section steel, respectively.

Table 5 shows the comparison between the simulation results and the predicted results from Eq. 5 . It is found that the approach in Eurocode 4 underestimates the strength of SRSCFSHS specimens, and the maximum deviation reaches as great as $15 \%$. As can be seen in Table 3 , with the increase of steel tube ratio and steel tube strength, the maximum deviation reaches as great as $36 \%$, indicating that neglecting the confinement effect in SRSCFSHS column may lead to severe conservative predication for real design. Therefore, a reliable approach needs to be developed for predicting the load carrying capacity of SRSCFSHS columns.

The SRSCFSHS column can be regarded as a combination of CFST and section steel, in this way, the bearing capacity of SRSCFSHS can be expressed as follow:

$$
N_{\text {SRERST }}=N_{\text {GEST }}+N_{S Q}
$$

where $N_{\text {SEFYF }}$ is the load capacity of SRSCFSHS, $N_{\text {GEST }}$ is the load capacity of square CFST and $N_{S S}$ is load capacity of section steel.

Up to now, a number of models for predicting the load carrying capacity of CSFT tubular members have been proposed [27-29]. Tao [30] made comparison of these models, and found that the DBJ/T13-5 [26] gave comparatively accurate prediction. The equation in DBJ/T13-51 can be simplified as follow:

$$
\begin{aligned}
& f_{F Y}=\left(1.18+0.85 \xi f_{O K}\left(0.2 \alpha_{n} \xi_{1}<5\right)\right. \\
& N_{G F Y}=f_{F Y} A_{S S}
\end{aligned}
$$

where $\xi$ is a confinement factor, $f_{c k}$ is the characteristic compressive strength of concrete cube, $f_{s g y}$ is the strength index of CFST column and $A_{g e}$ is the cross-sectional areas of CFST column.

As for the strength of section steel $\left(N_{\mathscr{S}}\right)$, the local buckling of inner section steel $(\lambda \leqslant 15)$ can be avoided due to effective support of steel tube confined core concrete. Therefore section steel can fully contribute its strength to SRSCFSHS column. As has been analyzed above, the section steel reaches its peak strength after the yielding of SRSCFSHS column, indicating the strength of section steel has not been thoroughly utilized when the SRSCFSHS reached its peak strength. Therefore, $N_{M N^{\prime}}$ can be expressed as follow:

$$
N_{S S}=\lambda f_{u}^{s} A_{s s}
$$


where $f_{u}$ is the ultimate stress of steel, and $\mathbf{A}_{g z}$ is the cross-sectional area of section steel. In this equation, $\lambda$ is a coefficient considering the "hysteresis effect" of section steel, and $\lambda$ can be calculated as follow:

$\lambda=\frac{\nabla\left(g_{g}{ }^{2}\right.}{f(x)}$

where $\varepsilon_{e c}$ is the peak strain of the core concrete and can be calculated according to equation (3), which can also represent the peak strain of the SRSCFSHS column as can be seen in Figure (7). The $\sigma\left(a_{0}\right)$ represents the stress of the section steel when SRSCFSHS column reaches its peak load and $f_{\alpha}$ is the ultimate stress of the section steel.

Both $\sigma\left(\sigma_{\sigma o}\right)$ and $f_{u}^{g}$ can be calculated according to the equation (1), (2) and (3) above, therefore $\lambda$ can be expressed as following:

$A=\frac{2}{2}+\frac{E_{s} E_{\mathrm{N}}}{232 f_{\mathrm{f}}}$

As can be seen in equation (11), $\lambda$ will decrease with the increase of $f_{y}$, which indicates that there is no need to apply high strength section steel in SRSCFSHS column.

In this way, Eq. 6 can be modified as follow:

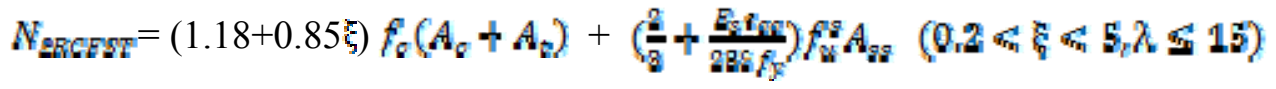

As can be seen in Table 4, the suggested equation appears to provide more reliable predictions with the maximum error less than $10 \%$. In order to verify the validity of the proposed equation, the comparison was also made between the experimental results and the predicted results from the proposed model. A total of seven specimens from the past experiments conducted by Wang [15] were adopted. Table 5 shows the comparison of the experimental results with the calculated results from the proposed equations. It is found that the proposed model can provide precise predications of the strength of tested SRSCFSHS columns.

Table 4. Comparison of the Simulation Results with the Modelling Results

\begin{tabular}{cccccc}
\hline Specimen & $N_{E \varepsilon}(k W)$ & $\begin{array}{c}N_{u}(k N) \\
{[\text { Eq. 5] }}\end{array}$ & $\begin{array}{c}N_{F F} / N_{w} \\
{[\text { Eq. 5] }}\end{array}$ & $\begin{array}{c}N_{w}(k N) \\
{[\text { Eq. 12] }}\end{array}$ & $\begin{array}{c}N_{F \xi} / N_{w} \\
{[\text { Eq. 12] }}\end{array}$ \\
\hline SS-1 & 3838 & 3308 & 1.16 & 3726 & 1.06 \\
SS-2 & 4408 & 3642 & 1.21 & 4544 & 1.05 \\
SS-3 & 4635 & 3768 & 1.23 & 4372 & 1.02 \\
SS-4 & 4753 & 3833 & 1.24 & 4442 & 1.07 \\
CS-1 & 4069 & 3477 & 1.17 & 4238 & 0.96 \\
CS-2 & 4181 & 3635 & 1.15 & 3700 & 1.03 \\
CS-3 & 4219 & 3835 & 1.1 & 3906 & 0.96 \\
CS-4 & 4330 & 4123 & 1.05 & 4123 & 0.94 \\
TS-1 & 4117 & 3402 & 1.21 & 4036 & 0.98 \\
TS-2 & 4648 & 3688 & 1.26 & 4694 & 1.07 \\
TS-3 & 4796 & 3633 & 1.32 & 4611 & 1.04 \\
TS-4 & 5033 & 3673 & 1.37 & 4748 & 1.05 \\
TR-1 & 3956 & 3269 & 1.21 & 3697 & 1.03 \\
TR-2 & 4717 & 3773 & 1.25 & 4579 & 1.06 \\
\hline
\end{tabular}




\begin{tabular}{llllll}
\hline TR-3 & 5515 & 4342 & 1.27 & 5202 & 1.08 \\
TR-4 & 6773 & 5131 & 1.32 & 6575 & 1.08 \\
TR-5 & 7596 & 5585 & 1.36 & 7447 & 0.95 \\
SR-1 & 3738 & 3307 & 1.13 & 3560 & 1.09 \\
SR-2 & 4021 & 3466 & 1.16 & 3757 & 1.04 \\
SR-3 & 4344 & 3590 & 1.21 & 4137 & 1.06 \\
SR-4 & 4735 & 3849 & 1.23 & 5037 & 0.97 \\
SR-5 & 5282 & 4192 & 1.26 & 5128 & 1.06 \\
\hline
\end{tabular}

Table 5. Comparison of the Experimental Results with the Modelling Results

\begin{tabular}{cccccc}
\hline Specimen & $N_{E W}(k N)$ & $\begin{array}{c}N_{u}(k N) \\
{[\text { Eq. 5] }}\end{array}$ & $\begin{array}{c}N_{E N} / N_{\text {u }} \\
\text { [Eq. 5] }\end{array}$ & $\begin{array}{c}N_{w}(k N) \\
{[\text { Eq. 12] }}\end{array}$ & $\begin{array}{c}N_{E W} / N_{\text {u }} \\
\text { [Eq. 12] }\end{array}$ \\
\hline S5L10 & 4047 & 3669 & 1.1 & 3929 & 1.05 \\
S5H10 & 4882 & 4363 & 1.12 & 5085 & 0.98 \\
S4L10 & 3980 & 3495 & 1.14 & 3790 & 1.04 \\
S4H10 & 4820 & 4206 & 1.15 & 4918 & 0.96 \\
\hline
\end{tabular}

\section{CONCLUSIONS}

In this paper, the mechanical behaviors of SRSCFSHS columns in uniaxial compression were investigated with nonlinear finite element analysis. The validity of the applied finite element models was verified with existing experimental results. The composite effect of SRSCFSHS column was comprehensively studied with the finite element model. The strength and ductility of SRSCFSHS are much higher than that of the square CFST column with same cross section due to the existence of inner section steel. The inner section steel can provide "strength reserve" for the SRSCFSHS columns. On the other hand, the local buckling of inner section steel can be avoided due to effective support of square steel tube confined concrete.

A total of twenty-six SRSCFSHS columns were modelled to investigate the effects of different parameters on the mechanical behaviors, including the steel tube ratio $\left(\alpha_{t}\right)$, section steel ratio $\left(\alpha_{g}\right)$, concrete strengths $\left(f_{c}\right)$, yield strength of steel tube $\left(f_{y}^{*}\right)$, yield strength of section steel $\left(f_{y}^{*}\right)$ and the slenderness ratio $(\lambda)$. According to the calculation results, the peak strength and initial stiffness of CFST columns increases with the increase of the mentioned parameters except for slenderness ratio. However, the increase of section steel ratio $\left(\alpha_{g}\right)$, yield strength of steel tube $\left(f_{y}\right)$ or section steel $\left(f_{y}^{z}\right)$ has little influence on the axial compression behaviors of SRSCFSHS columns after peak strength. The SRSCFSHS columns generally shift from strength softening behavior to strength hardening behavior with increasing steel tube ratio $\left(\alpha_{t}\right)$. The increase of slenderness ratio $(\lambda)$ will change the failure model of the SRSCFSHS column. When $\lambda$ is smaller than 15 , the SRSCFSHS column can be classified as a short column.

The model in Eurocode 4 comparatively underestimates the load carrying capacity of of SRSCFSHS column due to neglecting the strength increase of core concrete and section steel caused by confinement effect. In this study, a new model for predicting the strength of SRSCFSHS columns was proposed and verified with the experimental results.

\section{ACKNOWLEDGMENT}

Financial support of this work by National Natural Science Foundation of China under 51278118 and Priority Academic Program Development of Jiangsu High Education Institutions under 1105007002 is gratefully acknowledged. 


\section{REFERENCE}

[1] Bungale, S.T., "Structural Analysis and Design of Tall Buildings: Steel and Composite Construction", The Chemical Rubber Company Press, 2011.

[2] Liu, S.W., Liu, Y.P. and Chan, S.L., "Advanced Analysis of Hybrid Steel and Concrete Frames: Part 1: Cross-section Analysis Technique and Second-order Analysis", Journal of Constructional Steel Research, 2012, Vol. 70, pp. 326-336.

[3] Liu, S.W., Liu, Y.P. and Chan, S.L., "Advanced Analysis of Hybrid Steel and Concrete Frames: Part 2: Refined Plastic Hinge and Advanced Analysis", Journal of Constructional Steel Research, 2012, Vol. 70, pp. 337-349.

[4] Han, L.H., Li, W. and Bjorhovde, R., "Developments and Advanced Applications of Concrete-Filled Steel Tubular (CFST) Structures: Members", Journal of Construction Steel Research, 2014, Vol.100, No.5, pp. 211-228.

[5] Kodur, V.K., "Performance-based Fire Resistance Design of Concrete-filled Steel Columns", Journal of Construction Steel Research, 1999, Vol.51, No.1, pp. 21-36.

[6] Varmaa, A.H., James, M. and Riclesb, R.S., "Seismic Behavior and Modeling of High-strength Composite Concrete-filled Steel Tube (CFT) Beam-columns", Journal of Construction Steel Research, 2002, Vol.58, No.5, pp. 725-758.

[7] Fu, Z.H., Ji, B.H. and Lv, L., "Behavior of Lightweight Aggregate Concrete Filled Steel Tubular Slender Columns under Axial Compression”, Advanced Steel Construction, 2011, Vol.7, No.2, pp. 144-156.

[8] Cai, J., Pan, J. and Shan, Q., "Failure Mechanism of Full-size Concrete Filled Steel Circle and Square Tubes under Uniaxial Compression", Science China Technological Sciences, 2015, Vol. 58, No. 10, pp. 1638-1647.

[9] Wang, Y.Y., Wu, X.R. and Gang, Y., "Application of Concrete Filled Steel Tubular Arch Bridges in China", Taylor Francis Group, 2012, pp. 465-472.

[10] Pisano, A.A., Fuschi, P. and Domenico, D., "Peak Loads and Failure Modes of Steel-reinforced Concrete Beams: Predictions by Limit Analysis", Engineering Structures, 2013, Vol. 56, No. 5, pp. 477-488.

[11] Ehab, E., Young, B. and Dennis, L., "Eccentrically Loaded Concrete Encased Steel Compodite Columns", Thin-Walled Structure, 2011, Vol.49, No.1, pp.53-65.

[12] Sherif, E.T. and Gregory, G.D., "Strength and Ductility of Concrete Encased Composite Columns", Journal of Structural Engineering, ASCE, 1999, Vol.125, No.9, pp.1009-1019.

[13] Chen, C.H., Wang, C.K. and Sun, H.Z., "Experimental Study on Seismic Behavior of Full Encased Steel-Concrete Composite Columns", Journal of Structural Engineering, ASCE, 2014, Vol.140, No.6, pp. 1-10.

[14] Zhu, M., Liu, J. and Wang, Q., "Experimental Research on Square Steel Tubular Columns Filled with Steel-reinforced Self-consolidating High-strength Concrete under Axial Load" Engineering Structures, 2010, Vol.32, No.8, pp. 2278-2286.

[15] Wang, L.G., Zhao, T.F. and Li, H.N., "Experimental Research and Theoretical Analysis of Square Steel Tube Columns Filled with Steel-reinforced High-strength Concrete Subjected to Eccentric Loading"(in Chinese), Journal of Building Structure, 2010, Vol.31, No.7, pp. 907-915.

[16] Zhao, T.F. and Wang, L.G., "Calculation on Compression-bending of Square Tube Filled with Steel Reinforced High Strength Concrete" (in Chinese), Engineering Mechanics, 2008, Vol. 25, No.10, pp. 122-125.

[17] Eurocode 4, "Design of Composite Steel and Concrete Structures-part1-1: General Rules-structural Rules for Buildings", Brussels: European Committee for Standardization, 2004. 
[18] Li, G.C., Di, C.Y. and Tian, L., "Nonlinear Finite Element Analysis On Long Columns Of High-Strength Concrete-Filled Square Steel Tube With Inner CFRP Circular Tube Under Axial Load", Advanced Steel Construction, 2013, Vol.9, No.2, pp. 124-138.

[19] Hatami, S., Rahmani, A. and Parvaneh, A., "A Parametric Study on Seismic Characteristics of Cold-formed Steel Shear Walls by Finite Element Modeling", Advanced Steel Construction, 2014, Vol.10, No.1, pp. 53-71.

[20] Hibbitt, K., “ABAQUS Version 6. 7: Theory Manual, Users' Manual, Verification Manual and Example Problems Manual", 2007.

[21] Han, L.H., Yao, G. H. and Tao, Z., "Performance of Concrete-filled Thin-walled Steel Tubes under Pure Torsion", Thin-Walled Structure, 2007, Vol.45, No.1, pp.24-36.

[22] Tao, Z., Wang, Z. B. and Yu, Q., "Finite Element Modelling of Concrete-filled Steel Stub Columns under Axial Compression", Journal of Construction Steel Research, 2013, Vol.89, No. 2013, pp.121-131.

[23] ACI318-11, "Building Code Requirements for Structural Concrete and Commentary", Detroit (USA): American Concrete Institute, 2011.

[24] Hillerborg, A., Modéer, M. and Petersson, P.E., "Analysis of Crack Formation and Crack Growth in Concrete by Means of Fracture Mechanics and Finite Elements", Cement and Concrete Research, 1976, Vol.6, No.6, pp. 773-782.

[25] Park, R., "Evaluation of Ductility of Structures and Structural Assemblages from Laboratory Testing", Bulletin of the New Zealand National Society for Earthquake Engineering, 1989, Vol.22, No.3, pp. 155-166.

[26] An, Y. F., Han, L. H. and Zhao, X. L., "Behavior and Design Calculations on Very Slender Thin-walled CFST Columns”, Thin-Walled Structure, 2012, Vol.53, No.1, pp. 161-175.

[27] AIJ, "Recommendations for Design and Construction of Concrete Filled Steel Tubular Structures", Tokyo, Japan: Architectural Institute of Japan (AIJ), 2008.

[28] ANSI/AISC 360-10, "Specification for Structural Steel Buildings", Chicago, USA: American Institute of Steel Construction (AISC), 2010.

[29] DBJ/T13-51-2010, "Technical Specifications for Concrete-Filled Steel Tubular Structures" (in Chinese), The Housing and Urban-Rural Development Department of Fujian Province, 2010 .

[30] Tao. Z. and Han. L.H., "Design of Concrete Filled Square Steel Tubular Members" (in Chinese), Journal of Harbin University of Engineering \&Architecture, 2001, Vol.34, No.3, pp. 16-19. 


\title{
TUBULAR STEEL POLES UNDER LATERAL LOAD PATTERNS
}

\author{
Edgar Tapia-Hernández \\ Professor, Universidad Autónoma Metropolitana-Azcapotzalco. México, D.F. \\ (Corresponding author: E-mail: etapiah@azc.uam.mx)
}

Received: 10 November 2015; Revised: 21 December 2015; Accepted: 2 January 2016

\begin{abstract}
Hurricane Odile hit Baja California Sur, Mexico in 2014, causing substantial damage to local steel pole structures (light poles and electricity poles). Based on the failure characteristics observed on such poles, this paper develops an analytical study aimed at evaluating the wind-excited inelastic response of slender vertical cantilever structures. Displacement-controlled pushover analyses are performed in OpenSees. The research pretends to establish a reference of the deformation limit for the serviceability limit state in order to contribute to make conservative decisions in the design phase of steel poles.
\end{abstract}

Keywords: steel, wind, poles, serviceability limit state, inelastic analyses

DOI:10.18057/IJASC.2016.12.4.4

\section{INTRODUCTION}

In recent years, partial or total collapse of steel poles (light-poles and electricity poles) related with wind patterns have increased in Mexico. Despite that these damages are controllable, the vulnerability of poles under severe natural hazards is one of major concern of designers, owners, managers and society. The fact is that there are several uncertainties related to the exposed structures, storms and the particular conditions of each pole, etc., that make it difficult to quantify the probability of failure or the rate of failure over a period of time (Figure 1).

An impressive number of collapses of poles related to wind actions are continually reported in Mexico, which emphasizes their vulnerability. For example, in September 2014 in Baja California Sur, Mexico, Hurricane Odile represents the largest damage in the history of the electrical network in Mexico, where it is estimated that 1,800 poles were affected [1]. Some of them may fail due to many reasons under wind actions such as incorrect design assumptions, improper detailing, material defects, fabrication errors, force fitting during erection and variation in material strength [2]. In addition, safety management such as regular checking of corrosion or damage during the operation conditions might be an additional source of collapses. Careful attention to the design requirements for poles structures will extend their lifespan and ensure public safety.

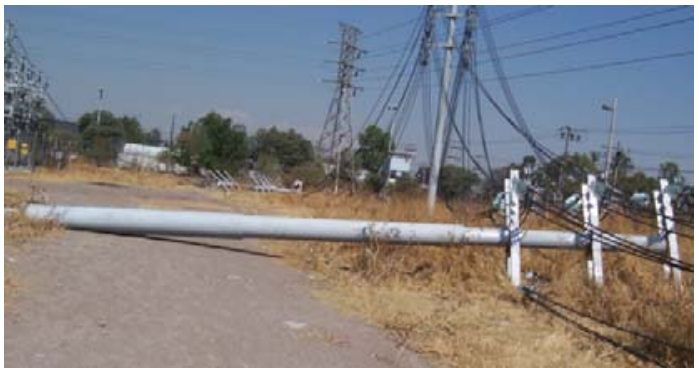

a) Power pole collapse. Electrical substation, Mexico City, January, 2009

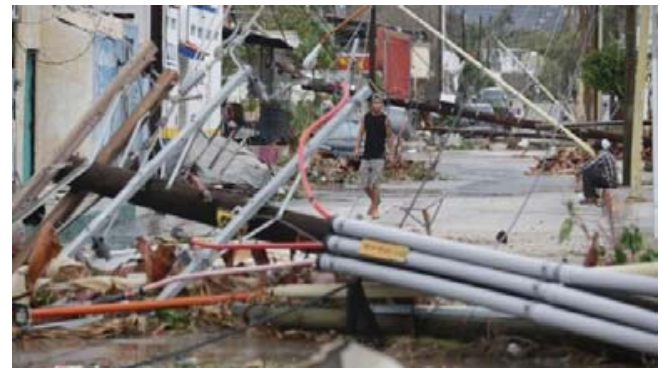

b) Damage by Hurricane Odile in Baja California Sur, September 2014 [3]

Figure 1. Examples of Poles Collapses 
Nowadays, Mexico does not have a code with the minimum standards for non-building structures. And local codes usually establish performance requirements which just outline what the required level of performance is and leave it up to the designer how this is achieved. Poles might be designed under different criteria depending on the designer, producer or local market.

In contrast, in the United States, design of tubular steel poles is governed by the ASCE Manual \#72 [4], which have been published more than 20 years ago. This manual provides a uniform basis on the design and manufacture of steel pole structures: light poles and electricity poles [5]. It also defines the requirements for fabrication, erection, load testing, and quality assurance according to the United States steel market conditions of those years.

It should be noted that steel pole structures have several unique design features as compared to other steel structures. For example, poles design is based on the use of the large displacement analysis to account for the $P-D$ effect and check for stability. To prevent excessive deflection effects, the lateral deflection under factored loads is usually limited to 5 to $15 \%$ of the total pole length, for poles structures under load combination (dead load and wind load). This limit is not precisely a serviceability requirement, but it constitutes a safeguard against the design of highly flexible structures. So, service deformation limit is not clearly defined.

To clarify the role and importance of the above remarks, this paper develops an analytical study aimed at evaluating the wind-excited inelastic response of slender vertical cantilever structures. The research pretends to establish a reference of the deformation limit for the serviceability limit state in order to contribute to make conservative decisions in the design phase of steel poles.

Poles were designed to fulfill all the recommendations of the wind and steel guidelines of Mexico's Federal District Code [6] and the Chapter of Wind Design of the Federal Electricity Commission of Mexico [7] and they were designed following the common Mexican practice for tubular steel poles with typical dimensions and the local equipment, as it is discussed in the following sections. Wind-excited response is investigated by pushover nonlinear analyses, focusing on the deformation restrictions for the service limit state under different lateral load patterns in order to contribute to protect life and property during intense wind demands and to improve the acquired knowledge.

\section{TESTING AND PROVEN PRODUCT EXPERIENCE}

In the Mexican practice, full scale cold bend tests may be conducted on poles design to verify the proper behavior and to withstand the design loads specified for these structures as a function of the maximum deformation. Nevertheless, usually these tests do not exceed the yielding limit (Figure 2), because the owner is not willing to pay a destructive test. So, the global drift at the service deformation (at yielding) is not clearly defined for all the possible cases. (Here, the global drift is computed as the difference of the deflections at the top and bottom divided by the total pole length).

In fact, the maximum allowed deformation (serviceability limit state) according to the Specification for steel poles of the Federal Electricity Commission of Mexico (CFE-J6200 [8]) is not function of the length of the pole (Table 1). This may mean that the limit value is not based on a formal study of the desirable structural performance, but on the needs of the electrical equipment, lights, batteries, circuits, etc. 

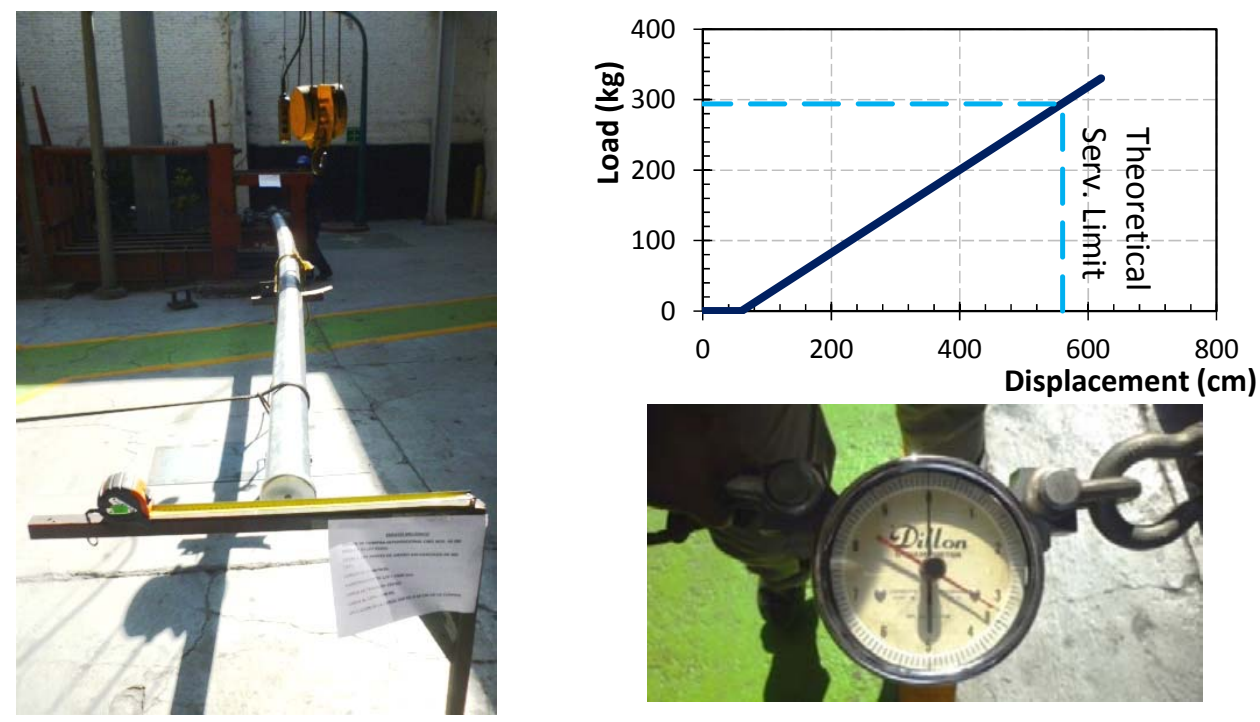

Figure 2. Example of the Non-destructive Test for a A13 Steel Pole

Table 1. Deformation Service Limits According to the Specification CFE-J6200 [8]

\begin{tabular}{cccc}
\hline \multirow{2}{*}{ Normative Poles } & $\begin{array}{c}\text { Pole length } \\
(\mathrm{mm})\end{array}$ & $\begin{array}{c}\text { Seformation } \\
(\mathrm{mm})\end{array}$ & Drift (\%) \\
\hline A13 & 10,300 & 560 & 5.44 \\
\hline A14 & 11,500 & 680 & 5.91 \\
\hline A15 & 12,700 & 820 & 6.47 \\
\hline A17 & 14,500 & 980 & 6.76 \\
\hline
\end{tabular}

Additionally, in the local market, some pole structures are purchased to meet a recognized structural code and many others are sold as general commercial design. Design issues include improper safety factors, inadequate base plate design, insufficient anchor bolts, improper application of wind velocities and wind coefficients, undersized weld and improper damage in the manufacture process. Standardizing the design process would improve the safety of poles and reduce confusion during the procurement process [9].

\section{CONDITION OF MANUFACTURING}

Steel poles are fabricated from uniformly tapered hollow steel sections and for structural efficiency, the structures taper over their height to a smaller tip diameter at the top. The poles are cold formed by standard methods such as bending, stretch, forming, roll forming, etc. from plates of thickness of $0.48 \mathrm{~mm}$ until $12.7 \mathrm{~mm}$ (because the maximum plate thickness that a hydraulic press is able to bend is around $12.7 \mathrm{~mm}$ ). For these structures the industry practice is that the analysis, design and structure detail are usually performed by a steel pole supplier in order to develop the cheapest structures (lightest weight) and more compatibles with fabrication practice and available equipment.

Because the selling price of the poles is directly proportional to the weight, companies spend time and money in the engineering to greatly simplify the manufacturing process with the minimal waste. For this reason, the structural design of the poles is highly dependent on the cuts in the plates (Figure 3a). In the Mexican practice, the most common widths, for this purpose, are 48 inches $(1,219.2 \mathrm{~mm})$ and 60 inches $(1,524.0 \mathrm{~mm})$; although it is possible to find plates with up to 72 
inches $(1,828.8 \mathrm{~mm})$ width.

The tapered steel pole is formed from a trapezoid-shaped plate and depending on the dimensions; the pole might be formed with a single longitudinal weld seam. Figure 4 shows some cutting configurations used in the industry. This is a common practice to reduce material waste and, therefore, reduce the cost of the poles.

On poles manufacturing, once cutting has been performed, the rough cross-section is formed by presses (Figure 3b), and then the cross-section is detailed through small presses (Figure 3c). Finally, shell is long-seamed with vertical weld along pole axis, through submerged arc welding techniques or electric resistance welding methods (Figure 3d).

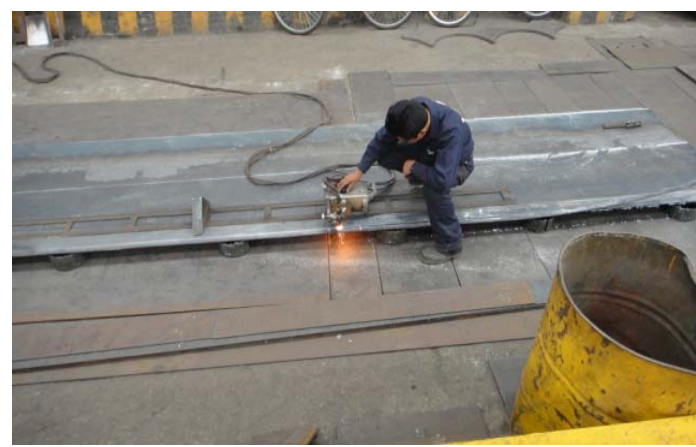

a) Cut of plate

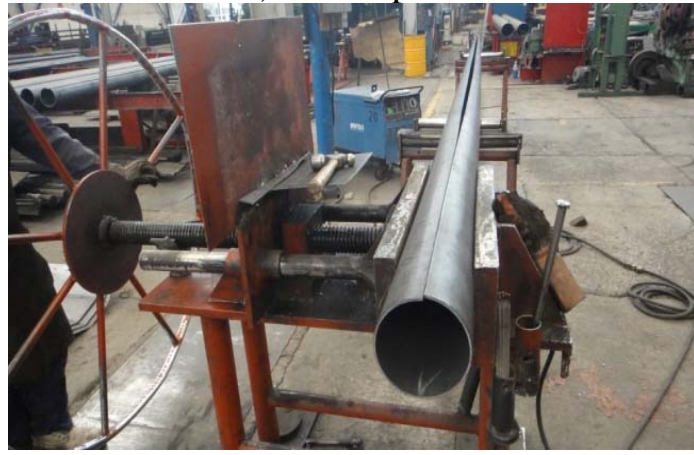

c) Detailed of the cross-section through smaller presses

Figure 3. Manufacturing Process of Tubular Steel Poles

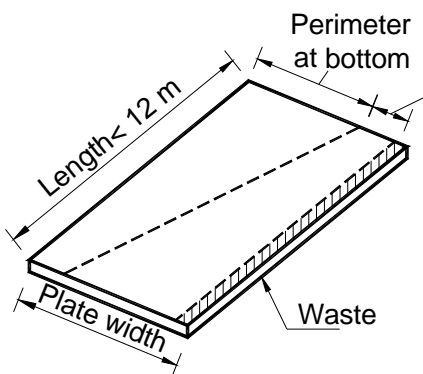

a) Cutting plate for two poles

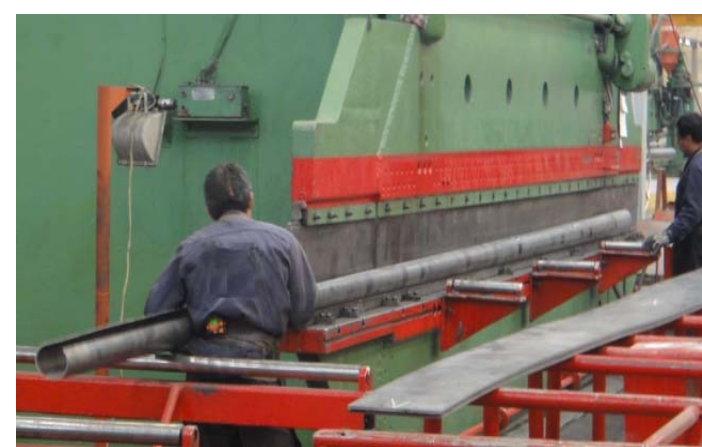

b) Bending of the plate with hydraulic press

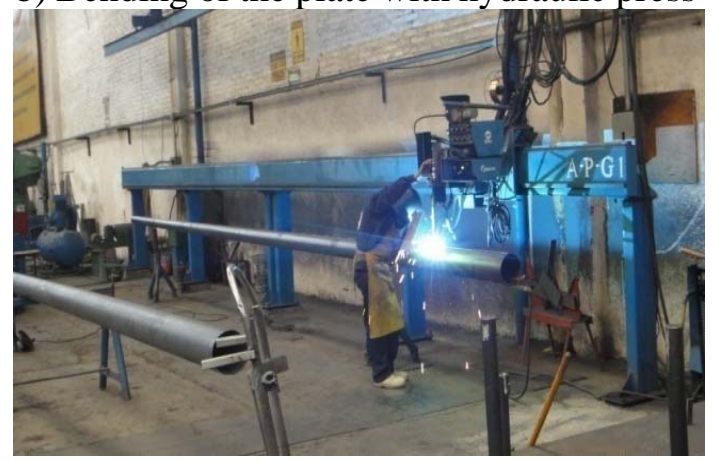

d) Longitudinal weld seam 
Corrosion protection must be considered for steel poles, mainly for structures with conditions of wetness and atmospheric pollution level. In Mexico, this protection represents an increase of the 30 percent of the final cost; so, it is important to assess the corrosivity of the environment to which the pole would be exposed and in defining clear and appropriate coating specifications.

Selection of a specific coating or the use of weathering steel depends on exposure to severe weather conditions, past experience, appearance and economics. The most used corrosion protection technique on steel poles is the hot-dip galvanizing. In the galvanizing process a zinc coating is metallurgically bonded to the steel surface. The zinc layer provides both a barrier coating for the steel and galvanic protection since the zinc preferentially is consumed before the steel corrodes. Nevertheless, frequently this alternate work might deform the pole due the thickness of the plate (48 mm) (Figure 5a); so, it is common that the cross-section should be detailed through presses again (Figure 5b). Other problems during the transportation to the galvanizing machine are related to damage and rupture of the longitudinal weld (Figure 5c) or strokes in the surface (Figure 5d). Once in field, preventive maintenance is highly recommended through a regular checking of corrosion.

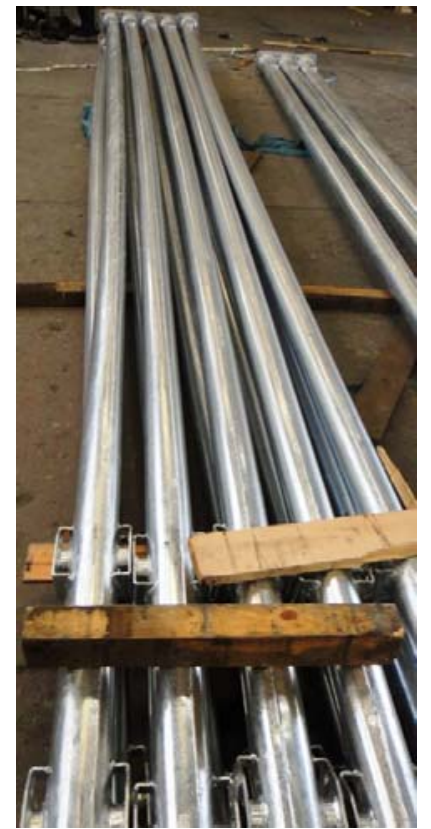

a) Deformation after hot-dip galvanizing

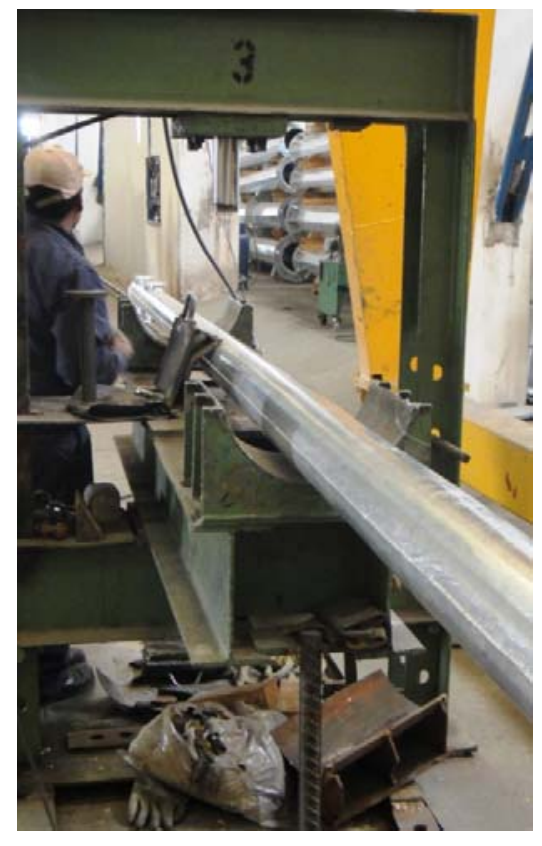

b) Repair of straightening

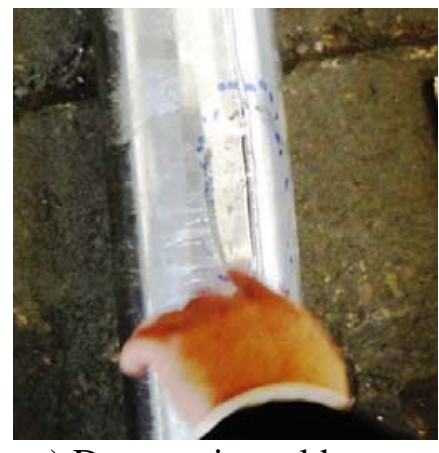

c) Damage in weld seam

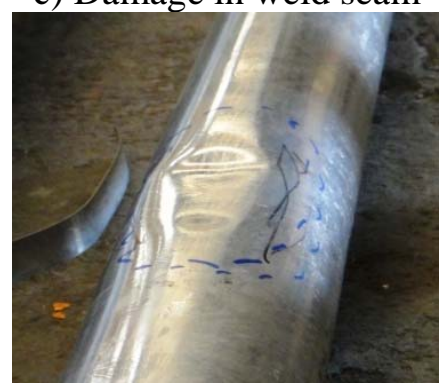

d) Hit on surface

Figure 5. Damage related with the hot-dig galvanizing

Because of transportation conditions, in the Mexican practice, the maximum pole length is restricted to 12,000 $\mathrm{mm}$. So, pole sections are normally joined by slip splices to transfer shears and moments. They are detailed to have a lap length $L$ no less than 1.05 times the largest inside diameter (Figure 6a). It is important to have a tight fit in slip joint to allow load transfer by friction between sections. Locking devices or flanged joints will be needed if the splice is subjected to uplift forces. 


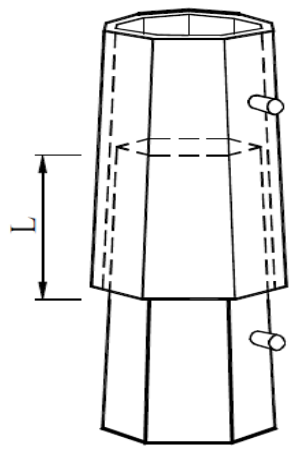

a) Schematic overlap

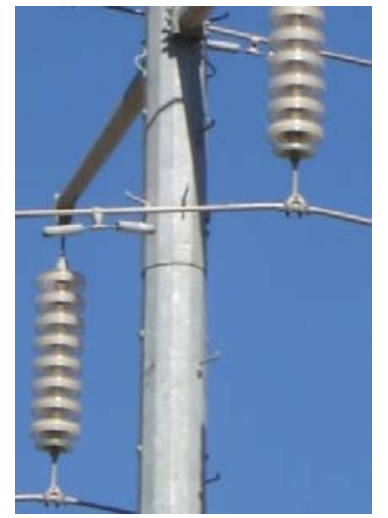

b) Overlap in power pole

Figure 6. Typical overlap in pole sections

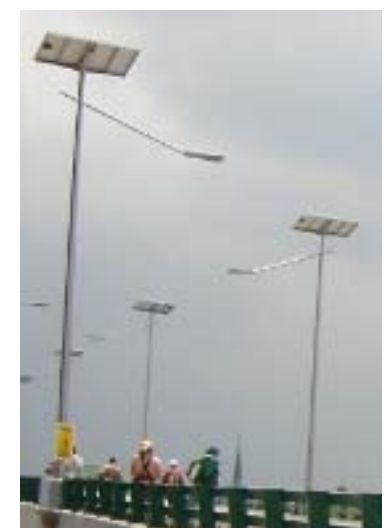

Figure 7. Typical light-pole in Mexico City

\section{MODELS DESCRIPTION}

Ten tubular steel poles from $10 \mathrm{~m}$. to $30 \mathrm{~m}$. were designed to fulfill all the recommendations of the steel guidelines of Mexico's Federal District Code [6] and the Chapter of Wind Design of the Federal Electricity Commission of Mexico [7] and by following the local manufacturing practice. Poles are representative of typical light-poles in Mexico City (Table 2, Figure 7).

The cryptograms for the identification of the models are PxxTy, where $P$ indicates that the structure is a pole, $x x$ indicates the structure height in meters and $y$ (after $T$ ) identifies the number of sections.

Table 2. Structural Specifications

\begin{tabular}{lcccccccc}
\hline Model & $\begin{array}{c}\text { Length } \\
\text { of pole, } \\
L_{p}(\mathrm{~mm})\end{array}$ & $\begin{array}{c}\text { Bottom } \\
\text { diameter } \\
(\mathrm{mm})\end{array}$ & $\begin{array}{c}\text { Top } \\
\text { diameter } \\
(\mathrm{mm})\end{array}$ & $\begin{array}{c}\text { Sheet } \\
\text { thickness } \\
(\mathrm{mm})\end{array}$ & $\begin{array}{c}\text { Number } \\
\text { of pole } \\
\text { sections }\end{array}$ & $\begin{array}{c}1^{\text {st }} \& \\
2^{\text {nd }} \\
\text { Period } \\
(\mathrm{sec})\end{array}$ & $\begin{array}{c}\text { 3er. \& } \\
4^{\text {th }} \\
\text { Period } \\
(\mathrm{sec})\end{array}$ & $\begin{array}{c}\text { Design } \\
\text { deformation at } \\
\text { the top }(\mathrm{cm})\end{array}$ \\
\hline P10T1 & 10,000 & 110 & 90 & 4.76 & 1 & 0.928 & 0.162 & 25.516 \\
\hline P12T1 & 12,000 & 150 & 110 & 4.76 & 1 & 0.944 & 0.179 & 25.601 \\
\hline P15T2 & 15,000 & 160 & 110 & 4.76 & 2 & 1.335 & 0.258 & 55.308 \\
\hline P18T2 & 18,000 & 185 & 120 & 4.76 & 2 & 1.707 & 0.326 & 94.876 \\
\hline P20T2 & 20,000 & 200 & 125 & 4.76 & 2 & 1.937 & 0.376 & 126.919 \\
\hline P22T2 & 22,000 & 250 & 140 & 4.76 & 2 & 1.840 & 0.372 & 116.445 \\
\hline P24T3 & 24,000 & 290 & 150 & 4.76 & 3 & 1.863 & 0.387 & 121.926 \\
\hline P26T3 & 26,000 & 310 & 170 & 4.76 & 3 & 2.060 & 0.419 & 151.039 \\
\hline P28T3 & 28,000 & 320 & 185 & 4.76 & 3 & 2.330 & 0.464 & 197.343 \\
\hline P30T3 & 30,000 & 350 & 190 & 4.76 & 3 & 2.422 & 0.494 & 220.641 \\
\hline
\end{tabular}

Poles were analyzed in SAP2000 [10] by linear static analysis in $3 D$ model under: a) weight of the pole, battery, luminaries and solar panels (Table 3) and b) the pressure of the wind acting horizontally on the pole and equipment. 
Table 3. Characteristics of Considered Equipment

\begin{tabular}{lccl}
\hline Supplement & $\begin{array}{c}\text { Weight } \\
(\mathrm{kN})\end{array}$ & $\begin{array}{c}\text { Exposed area } \\
\left(\mathrm{m}^{2}\right)\end{array}$ & \multicolumn{1}{c}{ Characteristics } \\
\hline Luminary & 696.3 & 0.121 & Light emitting diode. 18 W. \\
\hline Battery & 951.3 & 0.090 & 12V, 1200 Ah @10hr \\
\hline Solar panel & 147.1 & 0.252 & 185 W. Mono-crystalline. 2x120W \\
\hline
\end{tabular}

The adequate lighting distribution for exterior commercial poles is a function of its height and location. So, more luminaries and solar panels were considered for taller poles, because they usually are designed to illuminate large areas (Table 4).

Table 4. Estimated Weight of the Equipment for the Design

\begin{tabular}{lcccc}
\hline \multicolumn{1}{c}{ Model } & Luminary & Battery & $\begin{array}{c}\text { Solar } \\
\text { panels }\end{array}$ & $\begin{array}{c}\text { Weight } \\
(\mathrm{kN})\end{array}$ \\
\hline $\begin{array}{l}\text { P10T1, P12T1, P12T1, P15T2, P18T2, } \\
\text { P20T2 }\end{array}$ & 1 & 1 & 1 & $1,794.7$ \\
\hline P22T2 & 4 & 1 & 1 & $3,883.6$ \\
\hline P24T3, P26T3, P28T3 & 4 & 1 & 2 & $4,030.7$ \\
\hline P30T3 & 6 & 1 & 3 & $5,570.4$ \\
\hline
\end{tabular}

In the analytical model, a pole was considered as a continued element in order to exhibit full flexural strength and stiffness continuity. In addition, pole was modeled with a set of elements of length $20 \mathrm{~cm}$ to reproduce the response of an axially loaded element including large translational displacement and P-delta effects.

Through $n=69$ certified laboratory coupon tests of steel samples available in the Mexican market, a better reference of the real yielding steel stress were considered. The sample is based on steel plates with thickness varying from $0.48 \mathrm{~mm}$ (3/16”) to $0.64 \mathrm{~mm}$ (1/4”) [11]. According to the results, the mean value of ratios between effective and nominal material overstrength at yielding is $\mu=\Sigma\left(f_{y}\right.$ Effective/ $\left.f_{\text {y Nominal }}\right) / \mathrm{n}=1.277$, which is larger than the one proposed in current codes; for example AISC 341-10 [12] equal to $R_{y} A I S C=1.10$ for A50 steel (Figure 8).

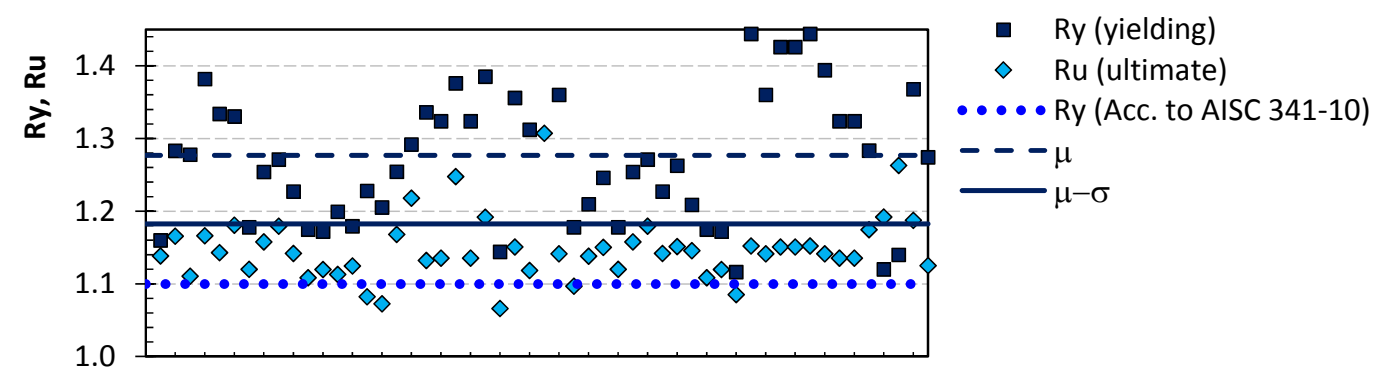

Figure 8. Local Material Overstrength

In order to account for the deviation, a conservative magnitude of the factor related to the material overstrength was developed from the mean minus one standard deviation ( $\sigma=0.095)$ in a normal distribution. Thus, the proposed material overstrength considered in this research is equal to $R_{y}=\mu$ $\sigma=1.183$, which is also included in Figure 8. 


\section{DESIGN CONSIDERATIONS}

In the design process, the strength was derived from varying diameter and thickness and by using methods to evaluate designed strength to required strength as it is discussed in further detail in Flores-Montaño [13]. According to the results, the use of this design methodology provides consistent structural performance for steel poles.

The high flexibility of poles makes them susceptible to wind resonant vibration $[14,15]$. So, the aerodynamic effects, which accounts for the interaction of the geometry of the pole on surface pressure, due to wind, must be included. According to the specialized codes, the dynamic response factor shall be determined for structures with natural first mode fundamental frequencies less than 1 Hertz (period of vibration of 1 second).

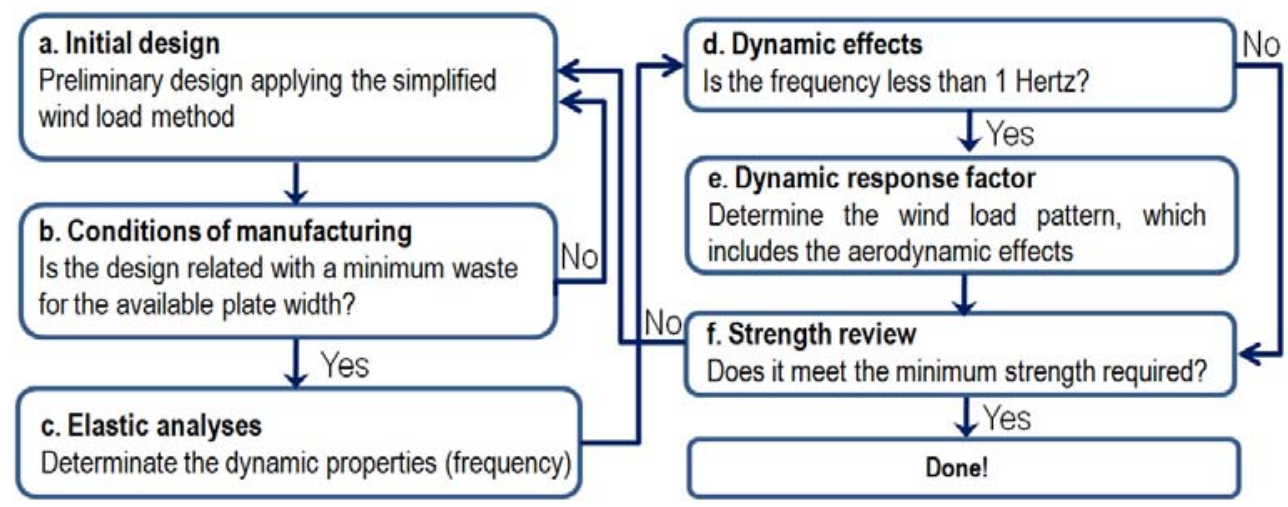

Figure 9. Design Methodology of Steel Poles

The considered design methodology in this research is schematically explained in Figure 9. According to the Guidelines for the wind guidelines [16] of Mexico's Federal District Code [6], the design wind pressure calculation is based on fundamental fluid-flow theory and is computed as follows:

$F(z)=0.50 \rho G V(z)^{2} F_{A D A}$

Where $F(z)$ is the total force at height $z$ over the projected surface area $A$ normal to the wind direction, due to wind speed at the same height $V(z)$. $F_{A D}$ is the dynamic response factor. In the Code, the calculation of pressure coefficients has been simplified by the adoption of this dynamic response factor, where the analysis takes into account the dynamic nature of wind pressure and the response of the structure to result in equivalent static design data. Further details on the steel poles design can be found in $[4,13,17]$.

The first two couples of natural (flexural) frequencies are shown in Table 1, whereas the corresponding modal shapes are plotted in Figure 10a. Due to mechanical symmetry, this figure exhibits similar rotations of the two couples of modes with respect to the reference axes $\mathrm{x}$ and $\mathrm{y}$ (Figure 10b and 10c). 


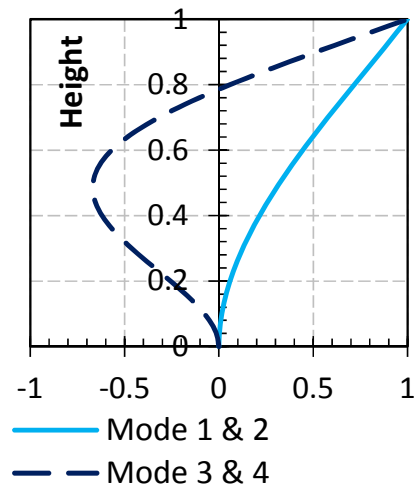

a) Mode shapes lateral view

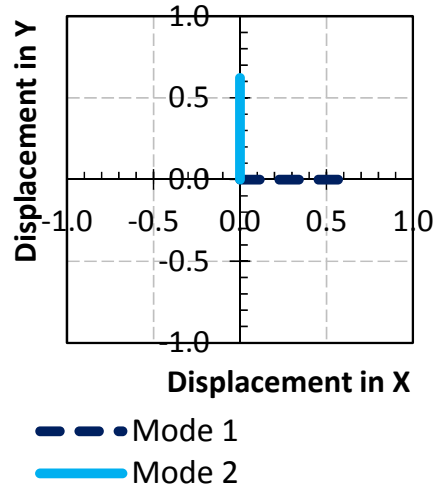

b) First and second modes in top view

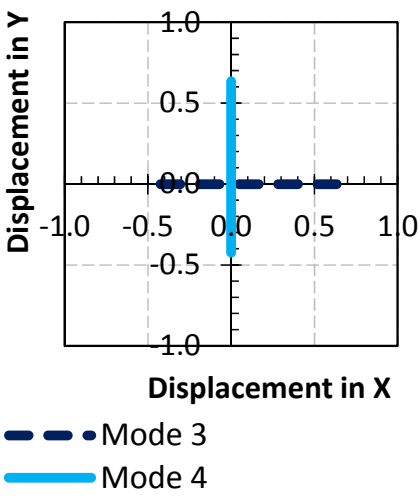

c) Third and fourth modes in top view

Figure 10. Typical First Four Modal Shapes

Since, it was supposed that equipment induces a small and negligible eccentricity with respect to the shaft, any excitation passes through the stiffness center. It is worth mentioning that different results may be obtained due the role of eccentricities. The presence of additional devices on the pole (peculiar features such as stairs, cable bundles, antennas, top balcony and/or parabolas) changes the aerodynamic properties and also the mechanical properties of the structural system [15].

The design wind pressure is the dynamic pressure multiplied by factors related to the configuration of the structure and the interaction of the dynamic fluctuations of wind and the response of the pole (Figure 9e). Factors may be available from wind tunnel testing or other sources (alternative solutions) for wind effects from more directions than those indicated in the Codes.

The calculation of pressure coefficients has been simplified by the adoption of the aerodynamic factor, where the analysis takes into account the dynamic nature of wind pressure and the response of the structure to result in equivalent static design data. The dynamic factor accounts for the following actions of wind:

a) Correlation effects of fluctuating along-wind forces on poles.

b) Effective pressures due to inertial forces resulting from resonant vibrations.

c) Fluctuating pressures in the wake of the structure (vortex shedding forces), producing resultant forces acting transversely as well as torsionally.

In the design (Figure 9a, 9f), second-order effects caused by the axial load was accounted by an approximate simplified method. According to the Steel Guidelines [18] of the Code [6], structures subject to axial compression and bending moment should satisfy the following requirement:

$e=\frac{\mathrm{P}_{\mathrm{u}}}{\mathrm{R}_{\mathrm{c}}}+\frac{\mathrm{M}_{\mathrm{ux}}}{\mathrm{M}_{\mathrm{Rx}}}+\frac{\mathrm{M}_{\mathrm{uy}}}{\mathrm{M}_{\mathrm{Ry}}}<1.0$

Where, $P_{u}, M_{u x}$ and $M_{u y}$ are the demands related with axial load and the bending moments; whereas, $R_{c}, M_{R x}$ and $M_{R y}$ are the capacities. According to the results, the structures (Table 1) fulfill all the limits of the wind and steel guidelines of MFDC-04 [6].

Peak deformations at the top obtained from the elastic analyses are also included in Table 1; whereas in order to exemplify the procedure, characteristics along height of model P12T1 are shown in Figure 11. 


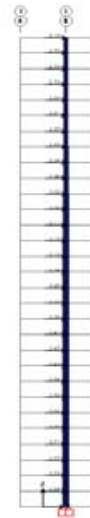

a) $3 \mathrm{D}$ model

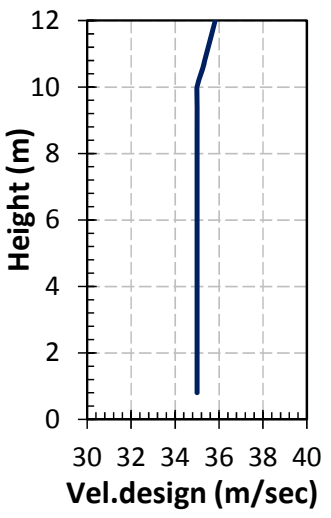

b) Velocity design, $V_{D}$

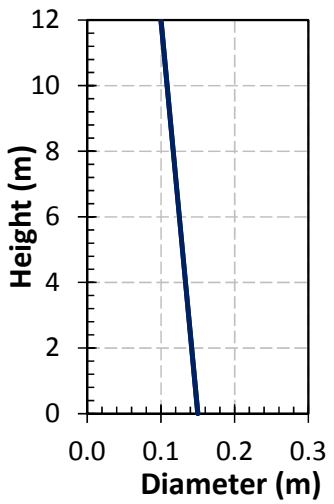

c) Variation of the diameter in height

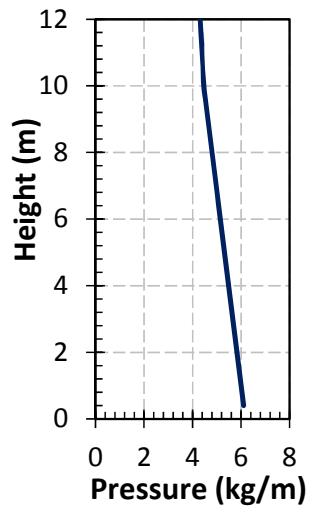

d) Normative load pattern

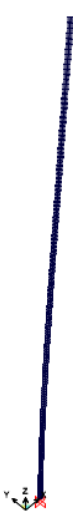

c) Deformed configuration

Figure 11. Characteristics of model P12T1 along height

\section{NONLINEAR ANALYSES}

Pushover analyses are useful to assess the structural capacity or to characterize the capacity curve by monotonically increasing the lateral loads. Usually, the application of inelastic analyses (static and dynamic) in wind engineering is not common because the design for wind actions requires the structures to remain in the elastic range. So that, its application is used for characterization of the capacity for structures under seismic excitations, due to the fact that in the seismic design philosophy the structures can be designed in the inelastic range under severe excitations [19]. However here, pushover analyses were carried out in order to evaluate the nonlinear response of the structures under wind loading to estimate the inelastic capacities.

Three-dimensional inelastic analyses were performed using the OpenSees computer program [20]. Nonlinear beam-column elements with plasticity spread along the length element were used to model all elements. A circular shaped patch was used to generate the cross-section of poles. Patches were discretized into fibers with three subdivisions in the circumferential direction and 16 divisions in the radial direction as it is shown in Figure 12a.

In the model, torsional restraint of the element was also included when out-of-plane buckling is studied. Torsional element properties have been added to the fibre nonlinear beam-column element using the aggregation tool in OpenSees [20]. In addition, poles were modeled with nonlinear beam-column sub-segments (elements of length $20 \mathrm{~cm}$ ) to reproduce the response of an axially loaded element including large translational displacements and P-delta effects as shown in 12b. 


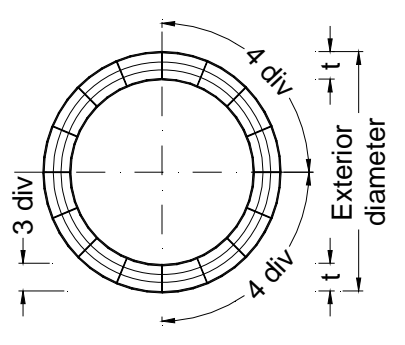

a) Cross-section discretization

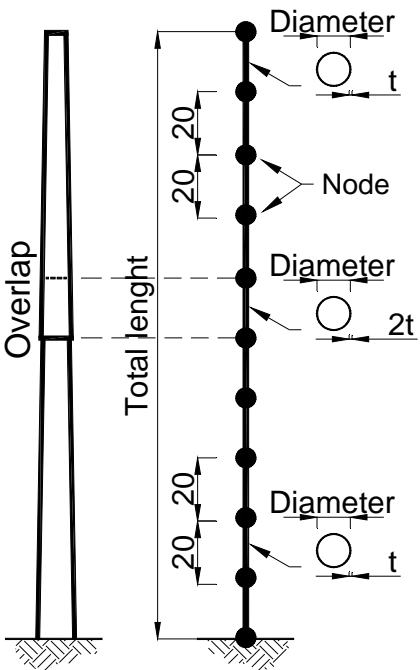

b) Nonlinear beam-column elements

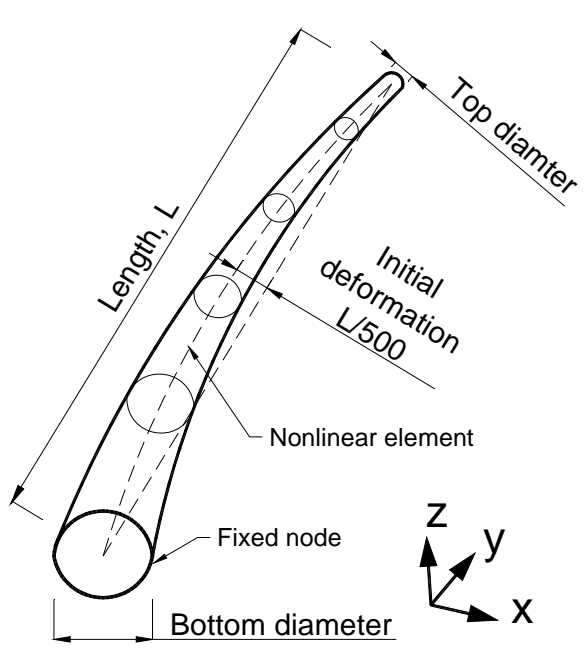

c) Initial imperfection

Figure 12. Inelastic Model Considerations

Steel with nominal $F_{y}=345 \mathrm{MPa}, E=200,000 \mathrm{MPa}$ and $G=77 \mathrm{GPa}$ was used for the studied structures. Realistic values for the steel yielding stress were used considering coupon test certificates through an overstrength material factor equal to $R_{y}=1.18$ as it was discussed above. Depending on the design, the overlap was included in the model through a double thickness of the plate at the cross section (Figure 12b).

The uniaxial Giuffre-Menegotto-Pinto (GMP) steel material with kinematic and isotropic hardening was used in OpenSees [20] to simulate Bauschinger effect in order to provide a more realistic representation of the elements response compared to the simpler bi-linear model. Thus, structure model was found to give realistic predictions of the inelastic response of a member. Reasonable agreement can be observed between the model in OpenSees and experimental test to predict the capacity of a member subject to flexo-axial loading [21]. Further details and validation of this modeling technique can be found elsewhere in Tapia-Hernández and Tena-Colunga [22].

Poles are flexible structures and may undergo relatively large lateral deflections under design loads. A secondary moment will develop in the poles due to the lateral deflections at the load points. This secondary moment can be a significant percent of the total moment. Therefore, three components can contribute to reduce the strength of poles: a) initial imperfection, b) eccentricity of application of loads and c) residual stresses locked into the cross section. Based on this, realistic conditions of the studied structures was considered (Figure 12c) through an initial imperfection at midspan of L/500 assuming a parabolic shape, in agreement with the deformation after hot-dip galvanizing (Figure 5a). A wide discussion on the influence of out-of-straightness imperfection in the effective length and the second-order effect in advanced analysis of slender steel structures can be found in $[23,24,25]$.

Additionally, the inherent residual stresses induced by the differential heating as consequence of the welding process (Figure 3a, 3d) and the rolling and forming process (Figure 3b, 3c) was included through the command uniaxialMaterial in OpenSees [20]. 


\section{LATERAL LOAD PATTERNS}

Three possible load distribution patterns were considered: a) the rectangular pattern, b) a modal pattern based on the fundamental mode and c) the pattern obtained from the application of the codified design wind load on the pole. In Figure 13, the normalized patterns are depicted for the P30T3 model to better explain the analyses.

Poles were assumed to be located in terrain characterized by a roughness length $z 0=0.3 \mathrm{~m}$ and a basic reference wind velocity $u_{b}=39 \mathrm{~m} / \mathrm{s}$; the mean wind velocity at $10 \mathrm{~m}$ height above ground, in a flat homogeneous terrain and with return period of 50 years.

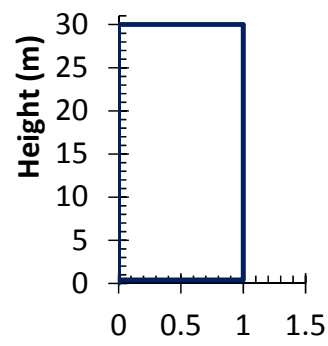

a) Rectangular pattern

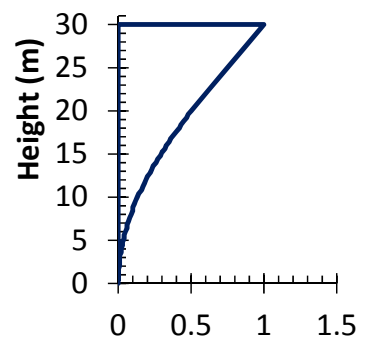

b) Modal pattern

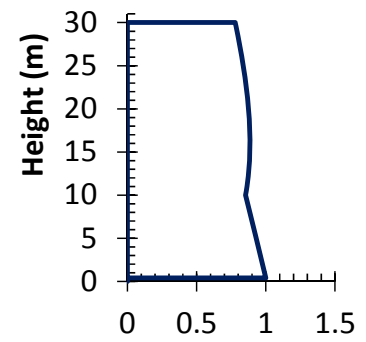

c) Normative pattern

Figure 13. Considered Lateral Load Patterns

A Newton with line search solution algorithm was selected in the OpenSees library [20] to achieve rapid convergence and because of the material nonlinearities. The solution algorithm uses an energy increment test which checks the positive force convergence if half of the inner-product of the displacement increment and the unbalanced force is less than a tolerance equal to $10^{-5}$. The equations are formed using a SparseGeneral scheme and they are numbered using the reverse Cuthill-McKee numberer (RCM), which optimizes the node numbering in order to reduce the storage bandwidth. This method outputs an error message when the structure is disconnected (collapsed). The constraints were represented with a Plain constraint handler, which enforces homogeneous single-point constraints (homogenous boundary conditions).

A single load step is performed using a load control integrator for the vertical loads: self-weight of the structure and equipment (luminaries, batteries and solar panels). In here, the time in the domain is then set to 0.0 and this load is kept constant. Subsequently, load wind patterns on the accessories and structure body were added as static incremental loadings. The results of the analysis are then employed to define the capacity curves in terms of the total horizontal force (basal shear force) against the global drift in percentage.

\section{DEFORMATION CAPACITIES}

Pushover curves from nonlinear analyses (base shear against displacement at the top of the steel pole divided by the total height $L$ ) are shown in Figure 14. Capacity curves changing the slope value so slightly in the inelastic range as the obtained are typical of detailed models with a cross-section discretized with fibers. 

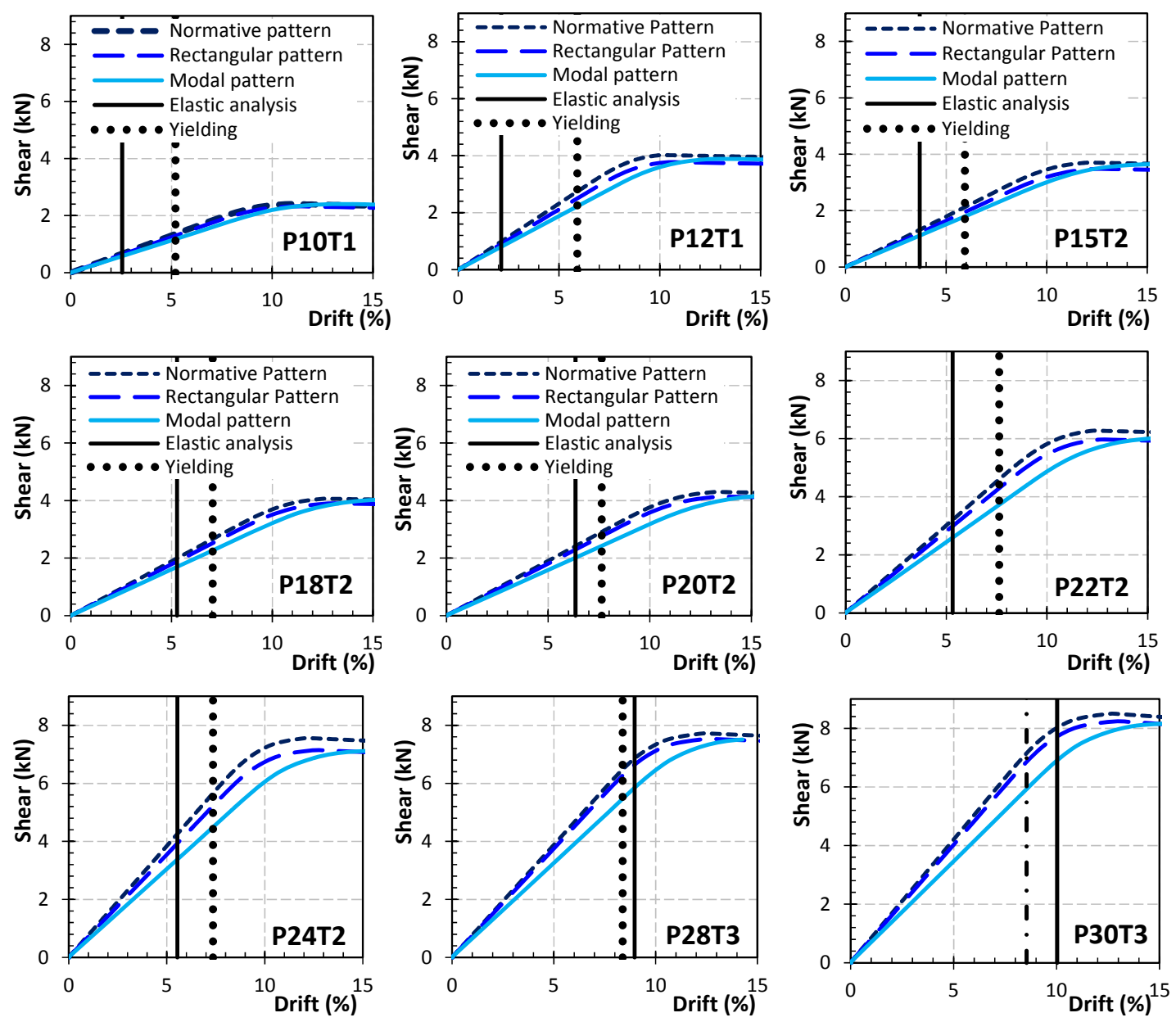

Figure 14. Pushover Curves

No dependency on the lateral load pattern has been noticed for low-height models. However, the modal pattern becomes critical as the height increases, whereas, the normative pattern related to the more conservative response. It is worth mentioning that the pattern modal pattern and the rectangular one are difficult to be naturally developed [26], since the wind load pattern is tightly related to the solidity area and the height $z$. Then, the discussion about the deformation capacities are focused on the results of the normative curve.

Drift values were studied through two different profiles: a) the drift reported in the elastic analyses, which is usually considered into a typical design process and b) the drift at yielding $\delta$ in the inelastic analyses, which is related to the serviceability state limit. These magnitudes were included in Figure 14 and summarized in Table 5.

As depicted in Figure 15, it was found that, in general, the design drift curve obtained at the elastic analysis for each pole (full rectangles) does not envelope the drift at yielding obtained in the inelastic analysis (full circles). This implies that the actual deformation capacity that steel poles are able to develop is larger than the one obtained in ordinary elastic analysis. This might explain why in conducted full scale tests, the poles usually satisfy the imposed demands with no damage (Figure 2). So, a flag is set on in the importance to close the gap between the predicted behavior, in the design stage, and the actual behavior especially in the inelastic range of steel poles. 
Table 5. Drifts Related with the Lateral Wind Pattern

\begin{tabular}{ccccc}
\hline \multirow{2}{*}{ Model } & \multicolumn{2}{c}{ Obtained at the design } & \multirow{2}{*}{ At yielding (inelastic analyses) } \\
\cline { 2 - 5 } & $\delta_{\text {design }}(\%)$ & Step & $\delta_{\mathrm{y}}(\%)$ & Step \\
\hline P10T1 & 2.55 & 1.037 & 5.19 & 2.076 \\
\hline P12T1 & 2.13 & 1.029 & 5.91 & 2.888 \\
\hline P15T2 & 3.69 & 1.007 & 5.92 & 1.614 \\
\hline P18T2 & 5.27 & 1.002 & 7.04 & 1.339 \\
\hline P20T2 & 6.35 & 1.003 & 7.63 & 1.202 \\
\hline P22T2 & 5.32 & 1.004 & 7.62 & 1.466 \\
\hline P24T3 & 5.42 & 1.009 & 7.35 & 1.469 \\
\hline P26T3 & 6.87 & 1.003 & 7.48 & 1.302 \\
\hline P28T3 & 8.97 & 1.002 & 8.37 & 1.185 \\
\hline P30T3 & 10.03 & 1.001 & 8.54 & 1.134 \\
\hline
\end{tabular}

Now, for lateral load applications, building codes state that the design story drift of the structure shall not exceed the allowable drift which is a function of the story height. Here this methodology cannot be followed, because despite of the fact that a relationship between the drift at yielding $\delta_{y}$ and pole height $L$ was noticed (Figure 14), drift in steel poles is not a direct function of the poles height $L$.

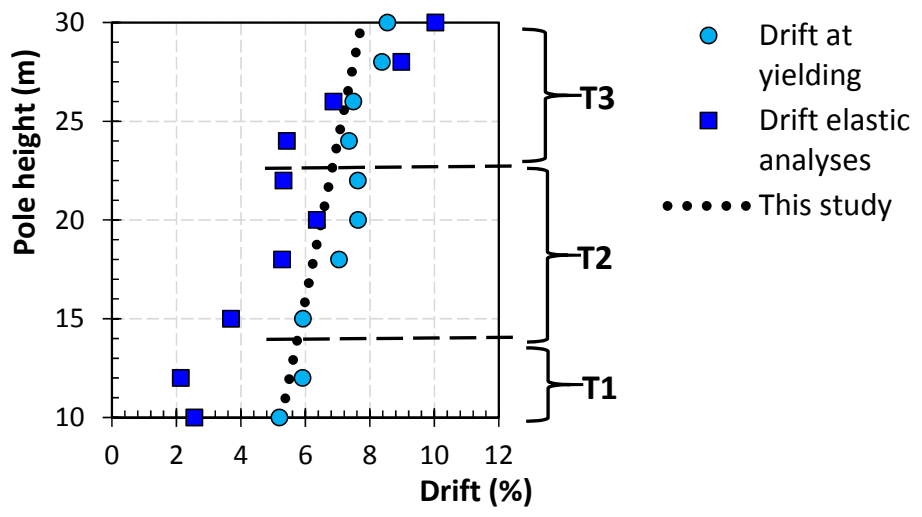

Figure 15. Developed Drift in Relationship of the Structure Height

Based on the above, an interpolation of the obtained results was performed in order to develop a conservative proposal to predict the deformation capacity (Eq. 4), which is also included in Figure 15.

$\delta_{\text {perm }}(\%)=4+L / 8$

A slightly relationship of the obtained drifts and the amount of overlapping (T1, T2 and T3) on each pole is also noted (Figure 15).

\section{OVERSTRENGHT CAPACITIES}

The inelastic response was also evaluated through the overstrength capacity $\Omega$. Demanded overstrength was assessed as the peak base shear obtained in the nonlinear pushover analyses, divided by the base shear at the design state. 
In Table 6, the shear obtained at the design stage $V_{\text {design }}$, the shear at yielding $V_{y}$ and the peak value $V_{\text {Max }}$ obtained for each studied model are compared. The overstrength factor $\Omega$ obtained for each pole is the relation between the lateral shear of the code design $V_{\text {design }}$ and the peak shear $V_{\text {Max }}$ resisted by the model. The ratio between the shear at yielding $V_{y}$ and the peak shear $V_{\operatorname{Max}}$ was also calculated.

Table 6. Overstrength Demands of the Studied Models

\begin{tabular}{ccccccc}
\hline Model & $\begin{array}{c}\text { Design } \\
\text { stage, } \\
V_{\text {Design }}(\mathrm{kN})\end{array}$ & $\begin{array}{c}\text { Yielding, } \\
V_{y}(\mathrm{kN})\end{array}$ & $\begin{array}{c}\text { Peak shear, } \\
V_{\text {Max }}(\mathrm{kN})\end{array}$ & $\begin{array}{c}\text { Overstrength } \\
\Omega\end{array}$ & $V_{\text {max }} / V_{y}$ & $\Omega / R_{\text {mat }}$ \\
\hline P10T1 & 0.654 & 1.358 & 2.408 & 2.08 & 1.77 & 1.76 \\
\hline P12T1 & 0.951 & 2.197 & 4.025 & 2.31 & 1.47 & 1.96 \\
\hline P15T2 & 1.317 & 2.126 & 3.704 & 1.61 & 1.74 & 1.37 \\
\hline P18T2 & 1.99 & 2.666 & 4.068 & 1.34 & 1.53 & 1.14 \\
\hline P20T2 & 2.425 & 2.914 & 4.304 & 1.20 & 1.48 & 1.02 \\
\hline P22T2 & 3.135 & 4.599 & 6.275 & 1.47 & 1.36 & 1.24 \\
\hline P24T3 & 3.852 & 5.661 & 7.566 & 1.47 & 1.34 & 1.25 \\
\hline P26T3 & 4.674 & 6.087 & 7.917 & 1.30 & 1.30 & 1.10 \\
\hline P28T3 & 5.466 & 6.478 & 7.725 & 1.19 & 1.19 & 1.00 \\
\hline P30T3 & 6.304 & 7.149 & 8.503 & 1.13 & 1.19 & 0.96 \\
\hline
\end{tabular}

In a significant number of poles, the developed overstrength is larger than 1.50, and only in the low-height poles it is larger than 2.0. A trend between the demanded overstrength and the pole height (or fundamental period) was noticed (Figure 16), where the overstrength capacity is reduced as the period increases. The application of the current local code criteria [6] to evaluate the overstrength factor for regular buildings is also included in Figure 16, in order to show that the obtained trend as a function of the structure height was previously identified; although, it has not been enough studied for non-building structures [27].

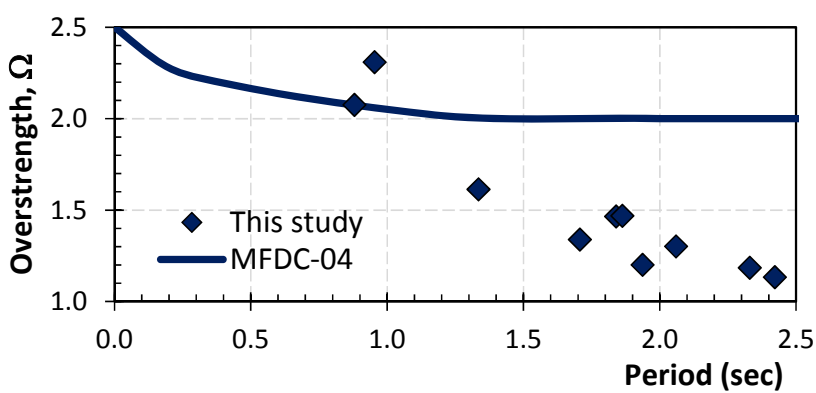

Figure 16. Overstrength Capacity in Relation to the Fundamental Period

In steel poles, the overstrength capacity arises from: a) the rounding of sizes and dimensions for elements diameters in relationship to the waste and the available plate size, $R_{\text {size }}$; b) the difference between nominal and factored resistances equal to $R_{\phi}=1 / \phi$, where $\phi$ is the material resistance factor as defined in Codes; c) the ratio of actual yield strength to minimum specified yield strength (this was directly accounted in models), $R_{m a t}$; d) the development of strain hardening, $R_{s h}$; e) the development of the spread plasticity of cross sections, $R_{c s}$; f) the adjustments to adapt the necessary design details to the dimensions and geometry of the real structure, $R_{d e t}$; among other parameters.

So, to account for the various components contributing to the overstrength-related factor $\Omega$, the following formulation is usually proposed [28]: 
Taking into account that the overstrength material was supposed equal to $R_{\text {mat }}=R_{y}=1.183$ in this research, the proportion $\Omega / R_{\text {mat }}$ represents the magnitude related to the other overstrength sources (Table 6) that might develop a reserve of strength, especially in low-height poles, which is not explicitly considered in current Codes $[6,7]$. According to the results, the proportion $\Omega / R_{m a t}$ has a high dependency on the pole height.

\section{CONCLUDING REMARKS}

This paper develops an analytical study aimed at evaluating the wind-excited inelastic response of slender vertical cantilever structures. Specifically, the attention of this research is focused on the deformation restrictions for the service limit state in order to contribute to protect life and property during intense wind demands.

Despite the relatively simple structure, inherent variability on configurations and the uncertainly related to the exact characterization of field situation (environmental loads, geometric and physical characteristics of the poles), were accounted based on actual steel poles with typical dimensions, equipment and the local manufacturing process.

Realistic values of the steel's yielding stress considering 59 coupon test certificates of A-572 Gr. 50 steel were used. Wind-excited response is investigated by pushover nonlinear analyses in detailed models, focusing on the behavior between different lateral load patterns: a) rectangular pattern, b) modal pattern and c) normative pattern. The main contributions of this investigation to wind-resistant design of steel poles are as follows:

- Capacity curves were very similar regardless of the applied loading profile for low-height models $(L<18 \mathrm{~m})$; no dependency on the lateral load pattern has been noticed. However, as the height increases, the modal pattern becomes critical and the normative pattern becomes the more conservative response.

- Although several designs of steel poles are widely used over the country, some design and construction procedures, which are based only on the manufacture process and waste of the steel plates, seems to be unfavorable.

- According to the results, the response could not be adequately estimated in common elastic analyses by following only the current code; specifically they could not predict the actual capacity. In fact, steel poles may have a better inelastic performance; but their inelastic capacities would be difficult to predict from the current normative tools and design practices. This notes the importance to close the gap between the predicted behavior, in the design stage, and the actual behavior especially in the inelastic range of steel poles. This might explain why in conducted full scale tests, poles usually satisfy the imposed demands with no damage.

- In the local market, there are no guidelines for the designer to limit the damage and to prevent the subsequent collapse. So, a conservative methodology was proposed, which pretends to predict the deformation capacity as a function of the height of the pole by following the current codes and local practices. The proposed equation follows the trends of the results obtained from this research study. More transparent and conservative deformation limits might be taken into account by codes and design practices in order to help to keep the structure safe and stable, even under strong wind demands.

- It was found that the overstrength capacities obtained have a strong relationship to the height of the poles (or structure period), something that it is not currently considered in specialized codes. 
The results illustrate the need to improve the current design criteria in order to quantify their reliability by means of refined analyses. Long-term field monitoring could further improve the understanding of the actual behavior and prevent failures of this structure type. Finally, active involvement of the owner, manufacturer, designer and professional responsibility is crucial for the accurate structural design of steel poles.

\section{REFERENCIAS}

[1] García, K., "Este huracán, el más destructor en la historia de la red eléctrica", El Economista, Newspaper, September 22th (In Spanish), 2014.

[2] Prasad, R.N., Knight, G.M.S., Mohan, S.J. and Lakshmanan, N., "Studies on Failure of Transmission Line Towers in Testing”, Engineering Structures, 2012, Vol. 35, pp. 55-70.

[3] Juárez, H., Personal Communication, 2015.

[4] ASCE, Design of Steel Transmission Pole Structures, ASCE Manual No. 72, 2nd Edition. American Society of Civil Engineers, New York, 1990.

[5] AASHTO, Standard Specifications for Structural Supports for Highway Signs, Luminaries and Traffic Signals, American Association of State Highway and Transportation Officials. Fifth edition. Washington, DC, 2009.

[6] MFDC-04, Reglamento de Construcciones para el Distrito Federal, Gaceta Oficial del Departamento del Distrito Federal (in Spanish), 2004.

[7] MOC-CFE-08, "Manual de Diseño de Obras Civiles. Capítulo de Diseño por Viento", Instituto de Investigaciones Eléctricas, Comisión Federal de Electricidad, México (in Spanish), 2008.

[8] CFE-J6200, "Postes de acero troncocónicos", Federal Electricity Commission of Mexico. Specification (in Spanish), 2002.

[9] Reese, B.R., "Design of sports lighting support structures - Will your structures perform to expectation?”, Proceeding, Structures Congress, American Society of Civil Engineers. Pp. 1269-1285. April, 2014.

[10] CSI, "SAP 2000 Analysis Software”, Computers and Structures, Berkeley, California, EEUU, 2009.

[11] García-Carrera S., "Respuesta inelástica de edificios regulares estructurados con marcos dúctiles de acero con contraventeo concéntrico", Master Thesis, Universidad Autónoma Metropolitana - Azcapotzalco. October (In Spanish), 2015.

[12] AISC 341-10, "Seismic Provisions for Structural Steel Buildings”, American Institute of Steel Construction, Chicago, IL, 2010.

[13] Flores-Montaño M., "Demandas de Rigidez Lateral de Postes Tronco-Piramidales de Acero ante Vientos Intensos", Undergraduate Thesis, Universidad Autónoma Metropolitana Azcapotzalco. August (In Spanish), 2014.

[14] Caracoglia L. and Jones N.P., "Numerical and Experimental Study of Vibration Mitigation for Highway Light Poles. Engineering Structures, 2007, Vol. 29, No. 5, pp. 821-31.

[15] Nguyen, C.H., Freda, A., Solari, G. and Tubino, F., "Aeroelastic Instability and Wind-excited Response of Complex Lighting Poles and Antenna Masts”, Engineering Structures, 2015, Vol. 85, pp. 264-276.

[16] NTCV-04, "Wind Design Guidelines of Mexico's Federal District Code", Gaceta Oficial del Distrito Federal, décimo cuarta época, tomo II, octubre (in Spanish), 2014.

[17] Fang S.J., Roy, S. and Kramer, J., "Transmission Structures", Structural Engineering Handbook, Ed. Chen Wai-Fah. Boca Raton; CRC Press LLC, 1999.

[18] NTCM-04, "Steel guidelines of Mexico's Federal District Code", Gaceta Oficial del Distrito Federal, décimo cuarta época. Tomo II. No. 103-Bis. Distrito Federal, México (in Spanish), 2004. 
[19] Banik, S., Hong, H. and Kopp, G.A., "Assessment of Structural Capacity of an Overhead Power Transmission Line Tower Under Wind Loading", Proceedings, VI International Colloquium on: Bluff Bodies Aerodynamics and Applications, 2008, Milano, Italy, July. pp. 20-24.

[20] Mazzoni, S., McKenna, F., Scott, M. and Fenves, M.Y.G., “Open System for Earthquake Engineering Simulation, User Command-language Manual”, Report NEES grid-TR 2004-21, Pacific Earthquake Engineering Research, University of California, Berkeley, CA, 2006.

[21] Uriz, P. y and Mahin, S., “Toward Earthquake-Resistant Design of Concentrically Braced Steel-Frames Structures”, Report of Pacific Earthquake Engineering Research Center, PEER 2008/08, November, 2008.

[22] Tapia-Hernández E. and Tena-Colunga, A., "Code-Oriented Methodology for the Seismic Design of Regular Steel Moment Resisting Braced Frames”. Earthquake Spectra, November 2014, Vol. 30, No. 4, pp. 1-27.

[23] Liu, Y.P. and Chan, S.L., "Second-Order and Advanced Analysis of Structures Allowing for Load and Construction Sequences", Advances in Structural Engineering, 2011, Vol. 14, No. 4, pp. 635-646.

[24] D'Aniello, M., La Manna, G., Portioli, F. and Landolfo, R., "The Influence of Out-of-straightness Imperfection in Physical Theory Models of Bracing Members on Seismic Performance Assessment of Concentric Braced Structures", The Structural Design of Tall and Special Buildings, 2015, Vol. 24, pp. 176-197.

[25] Repetto, M.P. and Solari, G., "Wind-induced Fatigue Collapse of Real Slender Structures", Engineering Structures, 2010, Vol. 32, Issue 12. pp. 3888-3898.

[26] Holmes J.D. "Wind Loading of Structures”, Spon Press, Second Edition, London, United Kingdom, 2007.

[27] Keshavarzian, M. and Priebe, C., ”Wind Performance of Short Utility Pole Structures.” Practice Periodical on Structural Design and Construction, November 2002, Vol. 7, Issue 4, pp. 141-146.

[28] Mitchel, D., Tremblay, R., Karacabeyli, E., Paultre, P., Saatcioglu, M. and Anderson, D., "Seismic Force Modification Factors for the Proposed 2005 Edition of the National Building Code of Canada”, Canadian Journal of Civil Engineering, 2003, Vol. 30. pp.308327. 


\title{
A PERFORMANCE STUDY OF BEAM COLUMN CONNECTIONS OF SELF-CENTERING STEEL FRAME WITH U-SHAPED STEEL DAMPERS
}

\author{
Yanxia Zhang ${ }^{1,2,{ }^{*}}$, Zhenxing $\mathrm{Li}^{2}$,Wenzhan $\mathrm{Zhao}^{2}$, Rui $\mathrm{Li}^{2}$ and Jiarui Li ${ }^{2}$ \\ 1 Associate Professor, Beijing Higher Institution Engineering Research Center of Structural Engineering and New \\ Materials, Beijing University of Civil Engineering and Architecture, Beijing 100044, China \\ 2 Postgraduate, School of Civil and Transportation Engineering, Beijing University of Civil Engineering and \\ Architecture, Beijing 100044, China \\ *(Corresponding author: E-mail: zhangyanxia@bucea.edu.cn)
}

Received: 2 November 2015; Revised: 26 November 2015; Accepted: 2 December 2016

\begin{abstract}
This study proposes a new type of self-centering beam-column connection with U-shaped steel dampers. A simplified hysteresis model of the connection was derived firstly. Then the preliminary design of self-centering beam-column connection with U-shaped steel dampers was proposed. A pseudo-static test and numerically simulation was conducted. The test results showed that the proposed self-centering connection could provide reliable energydissipation and self-centering capacities. The capacity that the hysteresis model could predict the moment-rotation behavior of the U-shaped steel damper and the connection was proved by the comparison of the experiments and the theories. The simulation results are consistent with the test results and simplified hysteresis model. The effects of the width and the height of the U-shaped steel damper and the thickness of the steel plate of the U-shaped steel damper on the performance of the connection were also analyzed by the numerically simulation. The results showed that the height of the U-shaped steel damper had a relatively small impact on the connection; a change in the thickness of the U-shaped steel damper mainly affects the load-bearing capacity and stiffness of the connection but does not affect the energydissipation capacity of the connection significantly. The width of the U-shaped steel damper has the greatest impact on the connection. The load-bearing capacity, the post-opening stiffness and the energy-dissipation capacity of the connection would all increased with increasing width of the U-shaped steel damper.
\end{abstract}

Keywords: Self-centering steel frame, beam-column connection, U-shaped steel damper, energy dissipation

DOI:10.18057/IJASC.2016.12.4.5

\section{INTRODUCTION}

Self-centering steel moment-resisting frames (SC-MRF) have received wide attention since they were proposed. The beams and columns of an SC-MRF are connected differently from that of a conventional frame with rigid connections. In a SC-MRF, the beams and columns are pressed tightly against each other by the pretension of pre-stressed steel strands, gap openings are generated at the beam-column connections and energy dissipated elements, such as angle steel, develop plastic deformation to dissipate energy during an earthquake. Thus, the main structure will sustain little or no damage and can recover to the initial position after the earthquake. Since. Garlock et al.[1] from Princeton University completed the first test of the beam-column connections of a SC-MRF s in 1997, Ricles et al.[2], Garlock et al.[3] and Christopoulos et al.[4] have studied SC connections that dissipate energy through top-seat angle steel and energy-dissipation rods, and Cruz[5] proposed a SC beam-column connection that dissipates energy through friction, Iyama et al. [6] used two types of friction devices: a PT friction damped connection placed on the top and the bottom of the beam flanges, and a bottom flange-only friction device. In the same year, Wolski et al. [7] designed beam bottom flange friction devices (BFFD) and avoided interference with the floor slab. Lin et al. [8] used web friction devices (WFDs) on beams for energy dissipation in the SC-MRF. This study proposes a beam-column connection with U-shaped steel damper connection (SCCUD) for SC-MRF. A test and a numerical simulation of the proposed connection are conducted under low-cycle repeated loading conditions, and nine connection finite element model of the SCCUD is developed for the analysis of variable parameters. 


\section{CONNECTION DETAILS AND THE THEORETICAL HYSTERESIS MODEL $2.1 \quad$ Connection details}

The main elements of SCCUD connection include a beam, a column, pre-stressed steel strands and U-shaped steel dampers (Figure 1). Steel supports are placed symmetrically on the two sides of the beam web and are welded to the column flanges during the manufacturing process in the factory. A U-shaped steel damper is welded onto both the top and bottom surfaces of each steel support. Figure 2 shows the main assembly process. First, the bolts that connect the U-shaped steel dampers with the beam flanges are initially screwed. Steel strands are then passed through the pre-drilled holes. Pressure sensors are installed at the anchor ends to measure the tension of each strand (Figure 2(a)). The steel strands are tensioned, and the tension of each strand is accurately adjusted (Figure 2(b), (c)). Finally, the bolts that connect the U-shaped steel dampers to the beam flanges are screwed, which completes the assembly process. Figure 2(d) shows a photograph of the connection after assembly is completed. The beam is pressed tightly against the surface of the column by the pretension of the steel strands and bears the shear forces at the beam ends through the friction on the contact surfaces. Under seismic loading, an opening is generated at the contact between the beam and the column. The U-shaped steel dampers begin to deform plastically as the opening increases and thus dissipate the energy to reduce or even prevent damage to the main beam-column structure. After the seismic event, the structure recovers to its original position under the pretension of the prestressed steel strands.

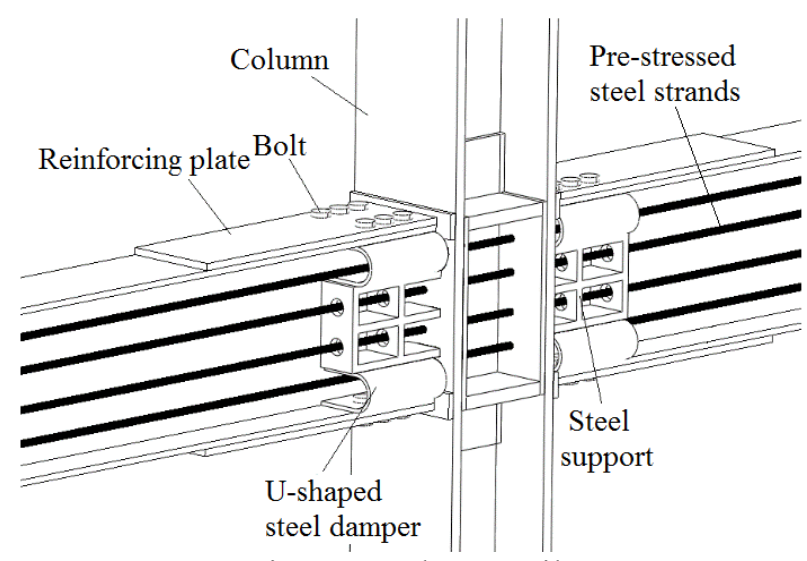

Figure 1. The Details

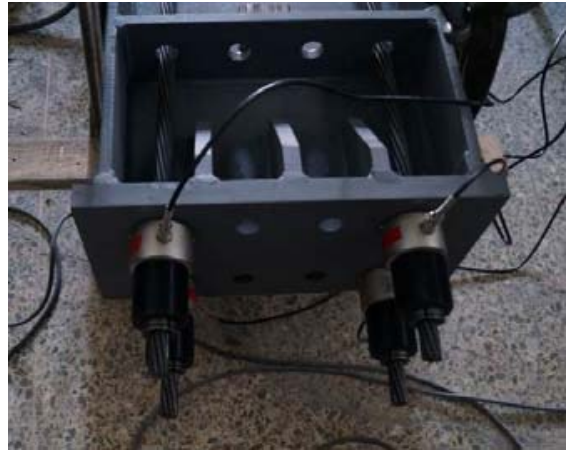

(a)Installing the pressure sensor

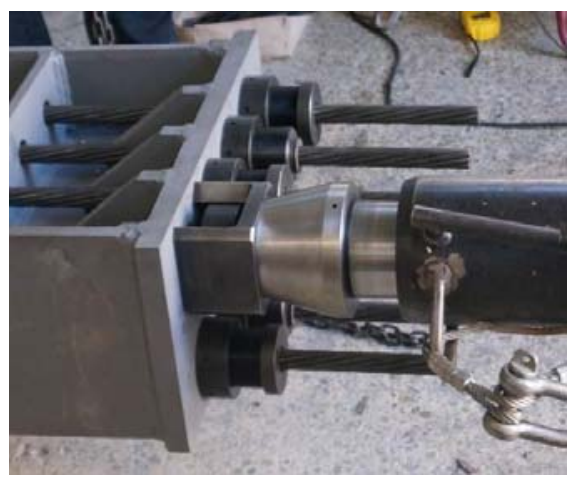

(b)Pretensioning the strands 


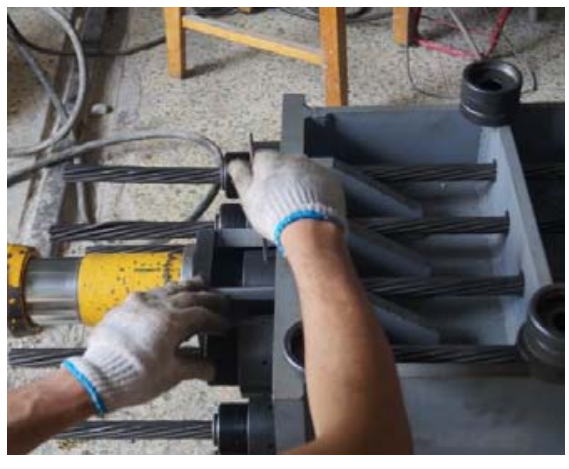

(c)Adjust posttension force

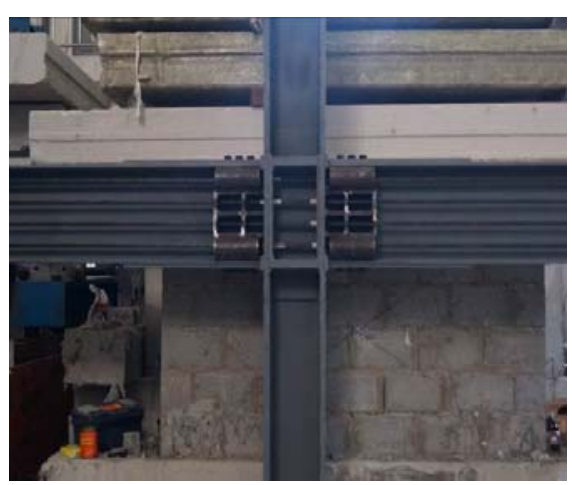

(d)Assembly is completed

Figure 2. The Assembly Process of the SCCUD Connection

\subsection{Hysteresis Model}

The rotational stiffness of the SCCUD connection is provided by the pre-stressed steel strands and the U-shaped steel dampers. When an opening is generated in the beam-column structure, the moment that is needed for the deformation and yielding of the U-shaped steel dampers can be calculated using the equation $M_{U}=K_{U} \theta_{r}$, where $K_{U}$ represents the rotational stiffness of each U-shaped damper, and $\theta_{r}$ represents the rotation angle of the opening between the beam and the column. The value of $K_{U}$ can be considered to have two parts based on the bilinear hardening model of the steel: the value in the elastic section $K_{u, e}$ and the value in the hardening section $K_{u, p}$.

In order to clarify the mechanism of deformation and yielding of the U-shaped steel dampers, it is necessary to determine the $K_{U}$ of the U-shaped steel damper under applied loads. When the gap opening, the loads and boundary conditions of U-shaped steel damper as shown in Figure 3. If the $\mathrm{U}$-shaped steel damper is projected onto the plane yox, then $\mathrm{AB}$ will be shown as a line segment, for the same time, BCD will be presented as a semi-circular. In yoz plane, point A and the center of the bolts that connect the U-shaped steel dampers with the beam flanges are collinear. Since the ratio of width $(w)$ to thickness $(t)$ of the U-shaped steel damper is large, the stiffness of the damper in $\mathrm{z}$ direction is much greater than in other directions. Therefore, compared with the load $F_{z}$, the influences of $M_{y z}$ is negligible. Under the load effect of $F_{z, a}$ horizontal displacement will be generated at point $\mathrm{A}$ in $z$-direction. In addition, both the cross-sections at point $\mathrm{C}$ and $\mathrm{D}$ will bear the effects of bending moment, shear force and torsional moment at the same time, while the torque at section-D will be greater than at section-C. According to the maximum shear stress theory, the section-D will yield firstly. Figure4 shows the assumed bilinear elastic-plastic force-displacement behavior of the U-shaped steel damper. Whenever the gap opening at point 1, the U-shaped steel damper will start to deform, and the elastic stiffness can be marked as $K_{u, e}$. As the deformation increases, the U-shaped steel damper will entered the yield state which is shown in Figure4 (point 2). After the U-shaped steel damper yield, the stiffness of U-shaped steel damper $K_{u, p}$ will be much smaller than the $K_{u, e}$, and the contribution of the U-shaped steel damper in the connection behavior is far less than that of the strands. For this reason, after the U-shaped steel damper yield, the following research will ignore the contribution of the U-shaped steel damper. 


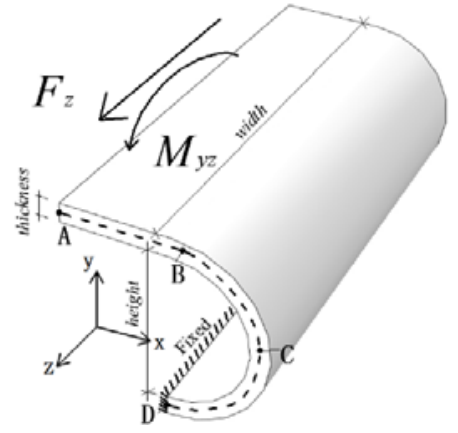

Figure 3. Load and Boundary Condition of the U-shaped Steel Damper

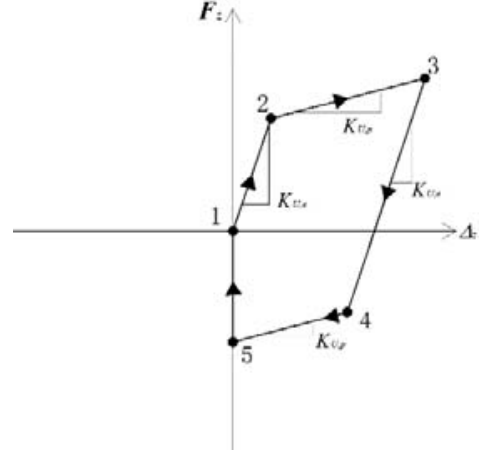

Figure 4. Force-displacement Relationship of the U-shaped Steel Damper

In order to determine the elastic stiffness $K_{u, e}$, the U-shaped steel damper has been simplified to a spatial truss structure as is shown in Figure 5. In the elastic state, under the load $F_{z}$, the displacement of Point $\mathrm{A}$ is caused by the bending deformation, shearing deformation and the torsion deformation of circular arc segment. Therefore, $\Delta_{z}$ can be calculated as the sum of two parts, which are shown as $\Delta_{z}=\Delta_{a}+\Delta_{b}$

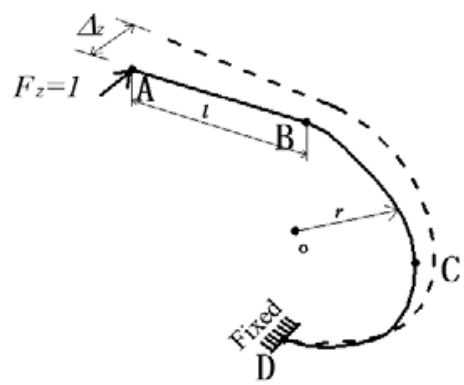

Figure 5. The Simplified Model of U-shaped Steel

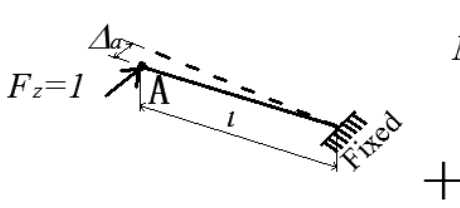

(a)

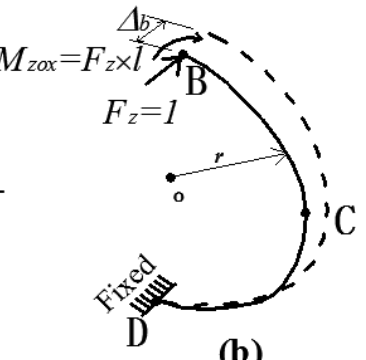

(b)

Figure 6. The Components of A Point's Displacement

$\Delta_{a}$ is the displacement of point $\mathrm{A}$ when the straight segment $\mathrm{AB}$ is under the action of $F_{z}$ (as shown in Figure $6(\mathrm{a})) . \Delta_{b}$ is the displacement of point $\mathrm{B}$ when the semi-circular BCD is under the combined effect both of the load $F_{z}$ and the moment $M_{z o x}$ around the $y$ axis (as shown in Figure 6 (b)). According to the translation theorem of force, $M_{z o x}=F_{z} \times l$. additionally, $\Delta a$ and $\Delta_{b}$ can be determined due to the principle of virtual displacement respectively. The calculation method of $\Delta a$ is shown in the Eq. 1 . As a result of the large ratio of $w$ to $l$, the displacement of point $\mathrm{A}$ is mainly caused by the shearing deformation of $\mathrm{AB}$ which has ignored the influences of the bending moment. During the computation of $\Delta b$, the expression has to consider all the possible influences as shown in Eq. 2 for that the internal forces of semi-circular BCD consists of moment, shear force and torque simultaneously. In this equation, $E G$ represents the elastic modulus and shear modulus of the steel respectively; I represents the inertia moment of the cross-section; $k$ represents the non-uniform coefficient of shear force (the value of the rectangular section is 1.2$)$; $I_{t}$ represents the torsional moment of inertia of the crosssection.

$\Delta_{a}=\sum \int \frac{k Q_{1, a} Q_{F, a}}{G A} d s=1.2 \frac{l}{G A}$

$\Delta_{b}=\sum \int \frac{M_{1, b} M_{F, b}}{E I} d s+\sum \int \frac{M_{1, b} M_{M, b}}{E I} d s+\sum \int \frac{k Q_{1, b} Q_{F, b}}{G A}+\sum \int \frac{T_{r 1, b} T_{r F, b}}{G I_{t}} d s+\sum \int \frac{T_{r 1, b} T_{r M, b}}{G I_{t}} d$

The internal force values $\left(M_{1, b}, M_{F, b}, M_{M, b}, Q_{1, b}, Q_{F, b}, T_{r l, b}, T_{r F, b}, T_{r M, b}\right)$ of each cross-section on the semi-circular segment BCD can be calculated according to the knowledge of the structural 
mechanics. During the integral force calculation, polar coordinates shall be utilized to acquire the result shown in Eq.3. The calculation formula (Eq.4) of the $\Delta_{z}$ is shown as follow:

$\Delta_{b}=\frac{\pi r^{3}}{2 E I}+\frac{r l}{E I}+\frac{1.2 \pi r}{G A}+\frac{\pi r^{3}+\frac{\pi r}{2}}{G I_{t}}+\frac{l r^{2}}{G I_{t}}$

$\Delta_{z}=\frac{\pi r^{3}+2 r l}{2 E I}+1.2 \frac{\pi r+l}{G A}+\frac{2 \pi r^{3}+\pi r+2 l r^{2}}{G I_{t}}$

The elastic stiffness of U-shaped steel damper $K_{u, e}$ is equal to $1 / \Delta_{z}$. Nevertheless, during the calculation process of the displacement at point $\mathrm{A}$, the above mentioned method has not given consideration to two factors. The one is the torsional deformation of the U-shaped steel damper has been restrained by the flange of beam, and the restraint effect will enhances with the increase of the deformation capacity of U-shaped steel damper. The other one is the friction between the U-shaped steel damper and the beam flange, caused by the high-strength bolts, resulting the increase of $K_{u, e}$. Based on the above two factors, the $K_{u, e}$ needs to be multiplied by an amplification factor $\mu_{1}$. According to the results of test and finite element analysis(FEA) that will be mentioned later, the value of $\mu_{1}$ is related to the value of $r / t$ and friction force, the recommended calculation formula is $\mu=(1.02 \sim 1.2) r / t$. Therefore, the $K_{u, e}$ is calculated as:

$K_{u, e}=\frac{\mu}{\frac{\pi r^{3}+2 r l}{2 E I}+1.2 \frac{\pi r+l}{G A}+\frac{2 \pi r^{3}+\pi r+2 l r^{2}}{G I}}$

By the geometric relationships, whenever the degree of the relative angle which is represented by $\theta_{r}$ is determined, the displacement of point $\mathrm{A}$ on the U-shaped steel damper can be expressed as: $\Delta_{z}=$ $H \theta_{r}$; where $H$ represents the distance from the rotation center to the point A, which is approximately equal to the height of the beam's cross-section. Therefore, the rotational stiffness of the U-shaped steel damper can be expressed as follow:

$K_{e}=K_{u, e} H^{2}$

Figure 7(a) shows the curve of the relationship between the moment that is provided by the U-shaped steel dampers $M_{U}$ and $\theta_{r}$. Since the post-yield stiffness of the U-shaped steel damper, $K_{u, p}$, is much smaller than $K_{p t}$, a bilinear model has been used without considering hardening. The U-shaped steel dampers do not provide rotational stiffness before an opening is generated (point 0 coincides with point 1). From point 1 to point 2, the rotational stiffness $K_{e}$ can be obtained by Eq.6. The moment of U-shaped steel damper at point 2, where the U-shaped steel damper is yielding, is marked as $M_{U, 2}$. According to the above process:

$M_{U, 2}=F_{z, y} H$

$F_{z, y}$ is defined to represent the horizontal load whenever the plastic hinge occurred in the U-shaped steel damper. The proceeded analysis above testifies that the most dangerous cross-section should be the section-D in Figure 3; that the section is under the combined effect of the bending moment, shearing force and torque simultaneously, as well as the values of both the normal stress and shear stress tend to be relatively large at the same time. Supposed that the plastic hinge develops along section-D, according to the maximum shearing stress theory, the yield criterion for the U-shaped steel damper can be shown in the following expression:

$\sigma_{r}=\sqrt{\sigma^{2}+4 \tau^{2}} \leq[\sigma]$

$\sigma=\frac{M_{z x}}{W}=\frac{6 F_{z} l}{t w^{2}}$ 
$\tau=\frac{T_{r}}{W_{p}}=\frac{6 F_{z} r}{w t^{2}}$

In the equation, $\sigma$ represent the allowable stress of the steel. The yield force of U-shaped damper can be determined by Eq. 8-9, and Eq.10, as follows:

$F_{z, y}=\frac{w^{2} t^{2}}{6 \sqrt{l^{2} t^{2}+4 r^{2} w^{2}}}[\sigma]$

Analogously, two factors that considered during the derivation of $K_{u, e}$ has to be taken into account; that the result of the $F_{z, y}$ should multiply a amplification factor $\mu_{1}$, and then the plastic hinge not only develops along section-D but also develops along the arc, so the area of plastic hinge region is extended, the amplification factor $\mu_{2}$ of the plastic hinge region has to be considered, according to the finite element analysis that will be referred later, the recommended value for $\mu_{2}$ is $2.5 \sim 3.2$. Therefore, the result of $F_{z}, y$ can be shown in the following expression:

$F_{z, y}=\mu_{1} \mu_{2} \frac{w^{2} t^{2}}{6 \sqrt{l^{2} t^{2}+4 r^{2} w^{2}}}[\sigma]$

Substitute Eq. 12 into Eq. 7, the yield moment of the damper can be estimated by the following equation:

$M_{U, 2}=\mu_{1} \mu_{2} \frac{w^{2} t^{2}}{6 \sqrt{l^{2} t^{2}+4 r^{2} w^{2}}}[\sigma] H$

Figure 7(b) shows the relationship between the moment that is provided by the pre-stressed steel strands $\left(M_{p t}\right)$ and $\theta_{r}$. When the moment that is generated by the load does not overcome the moment that is provided by the initial PT(post-tensioned)force, i.e. decompression moment $M_{d}=T_{0} d$, the gap does not open (point 0 to point 1), and the steel strands remain elastic throughout the entire loading process. The value of $K_{p t}$ is given by the following equation:

$K_{p t}=2 d^{2} \frac{k_{s} k_{b}}{k_{s}+k_{b}}$

Where the $d$ is the distance between the beam mid-depth and the center of rotation; $k_{s}$ is the axial stiffness of all the strands; $k_{b}$ is the axial stiffness of the beam. Eq.14 was established by Rojas [9] by considering that the increase in the total tension force $T$ in the strands is equal to the increase in compressive force in the beam. The curve of the theoretical $M-\theta_{r}$ relationship of the connection is obtained by superimposing Figure 7(a) and Figure 7(b) (Figure 7(c)). At point 1, the connection starts to open, and the corresponding moment is referred to as the critical opening moment (MIGO), which is completely provided by the initial PT force; i.e., $M_{I G O}=M_{d}=\sum T_{0 i} d_{i}$, where $T_{0 i}$ and $d_{i}$ represent the initial PT force of the $i$-th strand and the distance between the $i$-th strand and the center of rotation, respectively. 
Between point 1 and point 2, the U-shaped steel dampers start to deform and provide a certain amount of rotational stiffness, at which time the rotational stiffness of the connection $K_{l}$ is formed by the superposition of the elastic stiffness of the steel strands and the U-shaped steel dampers. When the gap opening, the deformation will be generated in two U-shaped steel dampers with the rotation of the beam, so the $K_{l}$ is calculated as:

$K_{l}=K_{p t}+2 K_{e}$

The connect moment $M_{2}$ at point 2 in Figure.3(c) is expressed as follows:

$M_{2}=M_{I G O}+2 M_{U, 2}+K_{p t} \theta_{r, U f}$

Where $\theta_{r, U f}$ is the relative rotation causing the U-shaped steel yield, as follows:

$\theta_{r, U f}=\frac{M_{U, 2}}{K_{e}}$

As the loading process proceeds, the U-shaped steel dampers start to yield, at which time the rotational stiffness of the connection, $K_{2}$, is mainly composed of the elastic stiffness of steel strands, $K_{2}=K_{p t}$. The unloading process begins at point 3. Between points 3 and 4 , the U-shaped dampers gradually reverse; the slope of the line in this section is equivalent to the slope of the line between point 1 and point 2, and $M_{3}-M_{4}=2\left(M_{2}-M_{1}\right)$. The U-shaped steel dampers will dissipate energy between point 3 and 5 until the gap between the beam flange and the column face is closed at point 5 .

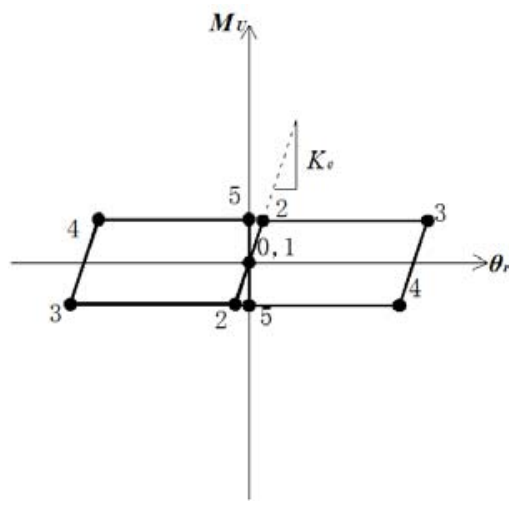

(a) $M_{U}-\theta_{r}$ relationship

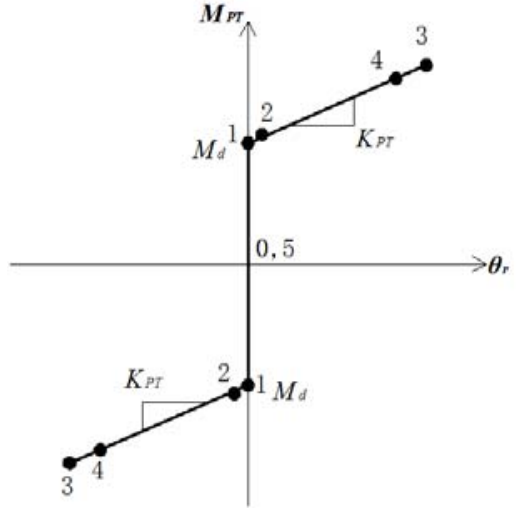

(b) $M_{p t}-\theta_{r}$ relationship

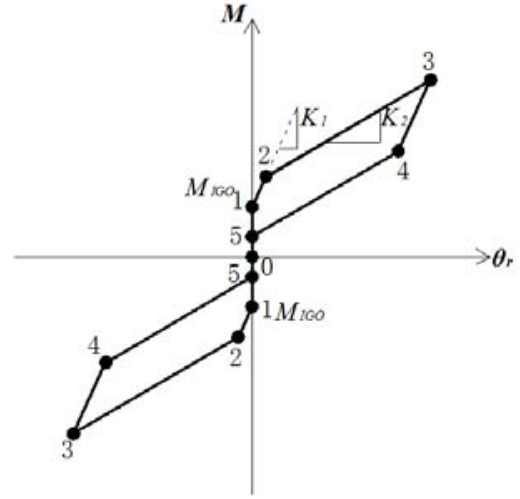

(c) $M-\theta_{r}$ relationship

Figure 7. Theoretical Moment-rotation Relationship of the SCCUD Connection

\subsection{Connection Design}

\subsubsection{Design Criteria}

Before the particular design of the SCCUD connection, relative rotation $\theta_{r}$ demand and under the design base earthquake (DBE) and the maximum considered earthquake (MCE) need to be obtained according to the design method presented by Garlock [10]. To design the proposed SCCUD connection, based on the given $\theta_{r, D B E}$ and $\theta_{r, M C E}$, several limit states should be satisfied: 
1. Dissipating energy through plastic deformation is the main function of the U-shaped steel damper, so it should meet the following requirement:

$\theta_{r, U f} \leq \theta_{r, D B E}$

2. The strand should be kept elastic under the maximum considered earthquake, i.e. $\theta_{r, \max } \geq \theta_{r, M C E}$. As the connection relative rotation increases, the strands elongate. They reach yield when $\theta_{r}$ reaches $\theta_{r, \max }$ which is estimated as Garlock [10]:

$\theta_{r, \max }=\frac{N_{s}\left(T_{y}-T_{0}\right)}{d_{2}} \frac{k_{b}+k_{s}}{k_{b} k_{s}}$

Where $T_{y}$ is the yield force in one strand, $N_{s}$ is the number of strands.

3. In order to ensure the SCCUD connection has good self-centering capacity, according to the results of Garlock's research [10], the decompression moment $M_{d}$ is recommended to be as follows:

$M_{d} \geq 0.6 M_{2}$

$M_{2} \geq(0.75 \sim 1.2) M_{d e s}$

where the $M_{2}$ is determined from the Eq.18; the $M_{\text {des }}$ is the design moment in the beam at the column face, will be obtained from ELF (Equivalent Lateral Force) procedure. (Garlock.[11])

2.3.2 Design Procedure. The connection design is a part of the design process of self-centering steel frame. An iterative seismic design procedure for self-centering frame systems has been proposed by Garlock [11]. Accordingly, the design base shear $V_{d e s}$, design moment $M_{d e s}$ and the story drift limit will be obtained by this design procedure. The design procedure of the SCCUD connection (including the additional U-shaped steel dampers) is as follows:

Step 1: Determine the cross section of beam and column The design of beam, column and reinforcing plate of SCCUD connection is similar with the design method of posttensioned steel frame systems that presented by Garlock[10]. The strong column-weak beam criterion and the limit values of the slenderness should be taken into consideration during the process of structural design. In addition, it will be necessary to reselect the cross-section of the column and beam continually until the story drift, which is obtained through the elastic analysis, satisfies the service requirements.

Step 2: Determine the design parameters of strands The values range of $M_{2}$ could be determined based on the design moment $\left(M_{\text {des }}\right)$ in the beam at the column face, and then the decompression moment $M_{d}$ (equal to $M_{I G O}$ ) will be obtained from the Eq.20. According to the calculation method of $M_{I G O}$ and Eq.19, the initial PT force $T_{0}$ and the number of strands can be selected, and the restrictions of the installation space should be considered before determine the arrangement method of strands.

Step 3: Design the U-shaped steel dampers According to the Eq.16 and Eq.17, the yield moment of U-shaped steel damper $\left(M_{U, 2}\right)$ will be obtained. Different combinations of $w, h$, and $t$ may be chosen based on the value of $M_{U, 2}$, however, the design criteria must be considered, the required condition for assembly also should be considered before determine the parameters of the U-shaped steel damper. 


\section{TEST SCHEME}

\subsection{Specimen Design}

This study designs a SCCUD connection and conducts a test on this connection. Q235B steel is used for the U-shaped steel dampers, while Q345B steel is used for all of the other components. Each Ushaped steel damper has dimensions of $250 \times 80 \times 10 \mathrm{~mm}$. The ratio of the initial PT force to the ultimate $T_{u}$, of the steel strands is 0.2 . The column has a cross-sectional dimension of $\mathrm{HW}$ $350 \times 350 \times 12 \times 19 \mathrm{~mm}$, and the beam has cross-sectional dimensions of $450 \times 250 \times 14 \times 16 \mathrm{~mm}$. Furthermore, 3M24 grade 10.9 large hexagonal bolts are used to connect the U-shaped steel dampers to the beam flanges. The specification for the steel strands is $1 \times 19-1860$; the steel strands have a nominal diameter of $21.6 \mathrm{~mm}$ and a nominal area of $312.9 \mathrm{~mm}^{2}$. Figure 8 shows the dimensions of other components and the layout of the steel strands.

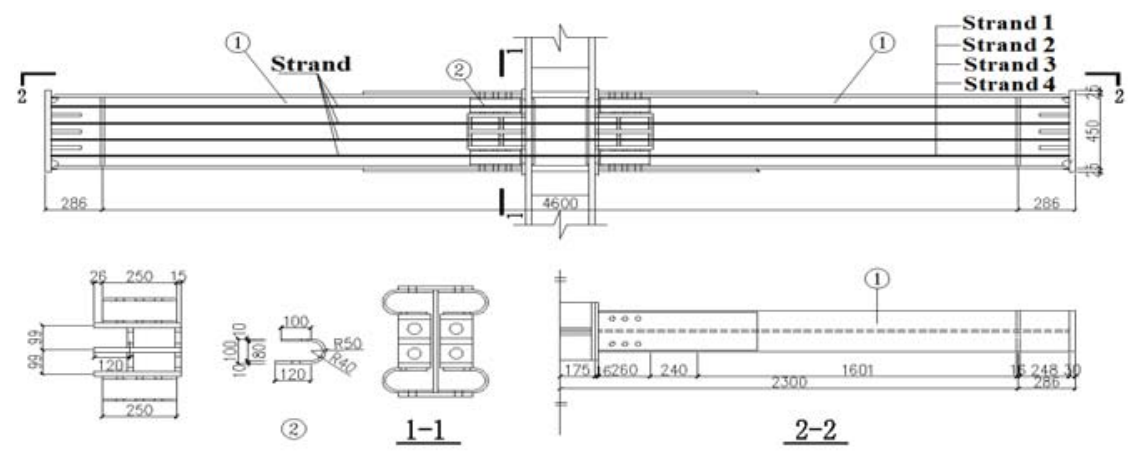

Figure 8. Details of the SCCUD Specimen

\subsection{Test Setup and Cyclic Loading History Instrumentation}

The specimen was tested in the setup as shown in Figure 9. The loading device of this test was a frame-type adjustable self-balancing loading system and the photograph has shown in Figure 10. The setup assumed that the column midheight is points of inflection in the SC-MRFs. The column was pinned at the top and base with clevis, which allowed the column ends to rotate freely but restricted the movements in the vertical and horizontal directions. According to the test equipment conditions, the beam loading point was taken to be $2.3 \mathrm{~m}$ from the center of the column. The servo actuator at the top of the column was used to emulate the column axial force, with a column axial compression ratio of 0.2 . Two 100-t electro-hydraulic servo actuators were used on the two free ends of the cantilever beams for cyclic displacement loading.

The cyclic loading history made reference to the AISC 2005, using story drift control loading as follows: (1) $0.375 \%$ rad, 6 cycles; (2) $0.5 \%$ rad, 6 cycles; (3) $0.75 \%$ rad, 6 cycles; (4) $1 \%$ rad, 4 cycles; (5) $1.5 \%$ rad, 2 cycles; (6) $2 \%$ rad, 2 cycles; (7)3\% rad, 2 cycles; (8) $4 \%$ rad, 2 cycles; (9) $5 \%$ rad, 2 cycles. 


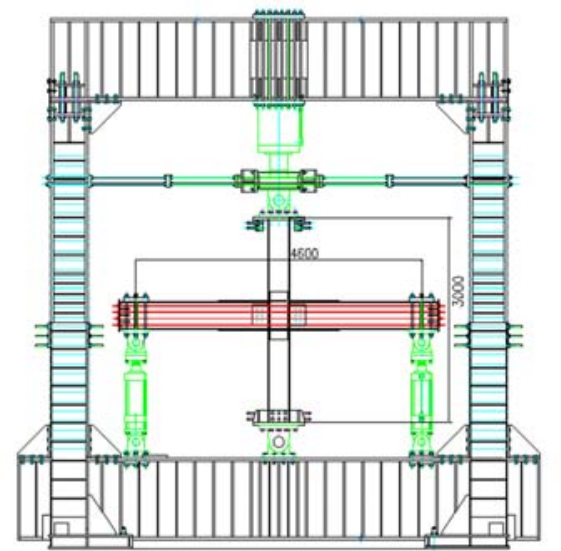

Figure 9 Test setup

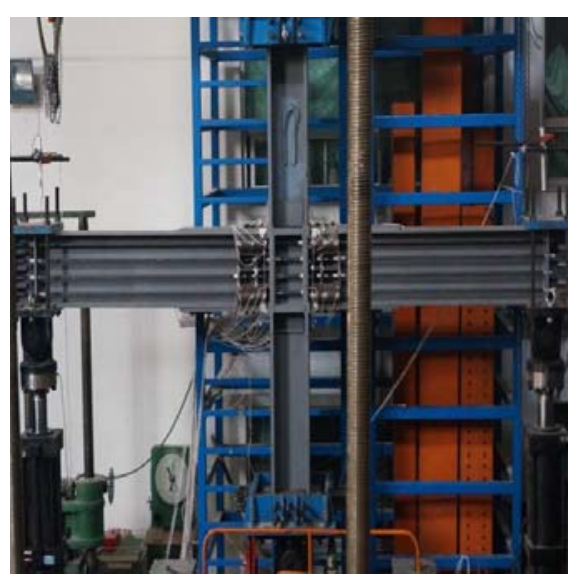

Figure 10 Test photograph

\subsection{Instrumentation}

The instrumentation is illustrated in Figure 11. The column capital is subjected to an axial force by a 600T actuator, and an additional two 100T actuators on the beam ends apply cyclic loadings. Each strand has a force transducer to monitor the PT force. The displacement data for the beam ends is collected by two displacement meters arranged on the top flanges. Linear displacement potentiometers fixed on the junctions of the column flanges and the beams are used to measure the gap width. The column flanges, column stiffeners, top and bottom beam flanges, and vertical and horizontal directions of the beam webs are pasted with strain gauges that measure the strain changes during loading in each position.

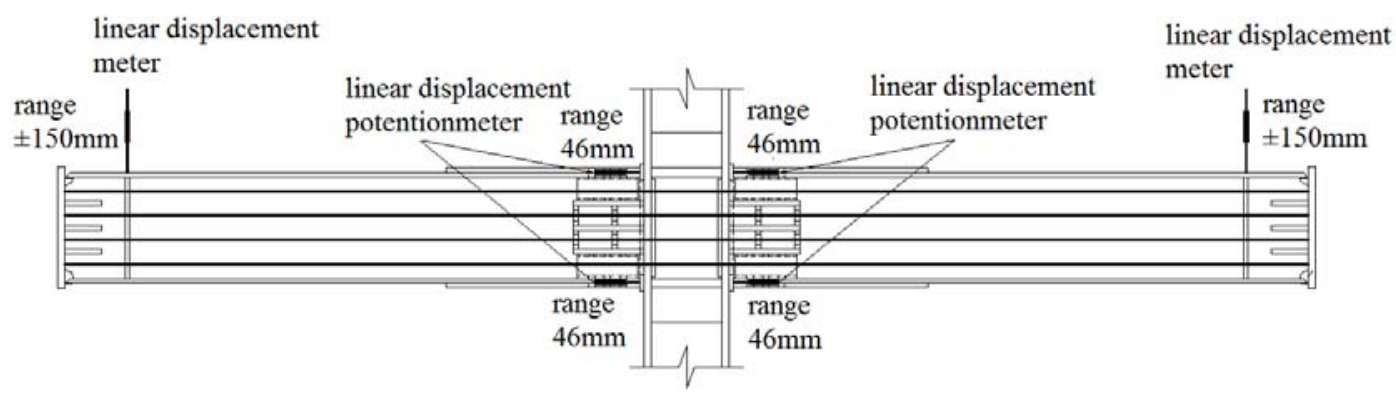

Figure 11. Arrangement of Displacement Meter

\section{TEST RESULTS}

\subsection{Hysteretic Behavior and Energy-dissipation Capacity}

The experimental force-displacement response of the system along with the loading protocol are shown in the Figure 12. At the initial stage of the loading process (i.e. before the opening is generated), the force-displacement relationship is similar to the welded moment connection, and the initial stiffness is $9.7 \mathrm{kN} / \mathrm{mm}$. Figure 13 shows the moment-rotation angle relationship that was obtained from the test. After the gap opens, the stiffness decreases significantly, and the U-shaped steel dampers start to yield, at this time the stiffness of the connection is mainly related to the stiffness of the U-shaped steel dampers and the axial stiffness of the pre-stressed steel strands. After the U-shaped steel dampers have completely yielded, the rotation angle increases rapidly; the rotational stiffness of the connection is mainly determined by the stiffness of the pre-stressed steel strands. After the loading process ends, the residual rotation angle at the opening of the connection $\left(\theta_{\text {res }}\right)$ is $0.078 \%$, which indicates that the connection has a relatively good self-centering capacity. During the entire 
loading process, the pre-stressed steel strands provide the connection with a self-centering capacity; the U-shaped steel dampers are mainly used to dissipate energy. The energy-dissipation coefficient $\left(\beta_{E}\right)$ is an important index that evaluates the energy-dissipation capacity. According to the definition of $\beta_{E}$ that was provided by Seo and Sause [12], the value of $\beta_{E}$ of the connection is calculated to be 0.43 .

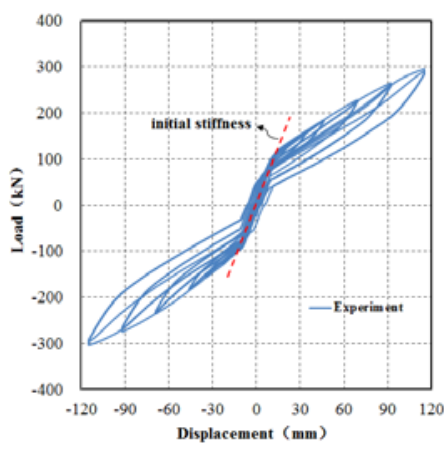

Figure 12. Experimental Force-displacement response of the Test Specimen

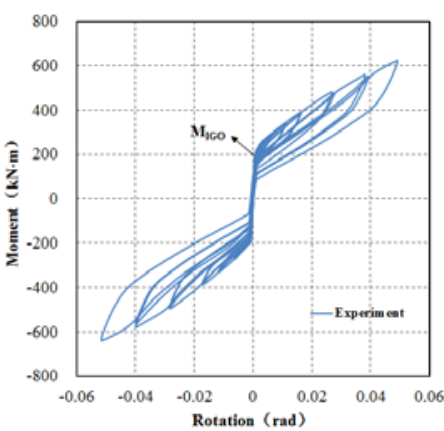

Figure 13. Experimental Moment-rotation response of the Test Specimen

\subsection{Change of PT Force}

The steel strands are placed symmetrically. Therefore, four steel strands on one side are selected to study the change in the PT force during the test. Figure 14 shows the relationship between the PT force and the inter-story drift of one steel strand on the outer side and the relationship between the PT force and the inter-story drift of one steel strand in the middle. $T$ represents the magnitude of the PT force during the test; the yield PT force of the steel strands $\left(T_{y}\right)$ is $540 \mathrm{kN}$. The figure shows the change in the PT force during the test, and Table 1 lists the analysis results of the PT force. $T_{0}$ represents the initial PT force of the steel strands; $T_{r 0.2}, T_{r 0.3}, T_{r 0.4}$ and $T_{r 0.5}$ represent the force of the steel strands after the loading levels of $\theta=0.02 \mathrm{rad}, \theta=0.03 \mathrm{rad}, \theta=0.04 \mathrm{rad}$ and $\theta=0.05 \mathrm{rad}$ are completed, respectively, and $T_{\max }$ represents the maximum PT force during the entire loading process. During seismic loading, the steel strands must maintain their elasticity during the entire process to prevent the structure from losing its load-bearing capacity. Table 1 shows that the value of $T_{\max }$ of each of the outer strands (strand 1 and 4) is slightly greater than the value of $T_{\max }$ of each of the strands in the middle (strand 2 and 3). During the test, the maximum PT force is $0.507 T_{y}$, and the steel strands remain elastic throughout the test. A comparison between the changes in the PT force at different stages based on the results in Table 1 shows that the PT force decreases by only approximately $10 \%$ after the 26 loading cycles before the loading level of $\theta=0.03$ rad is completed, but the maximum ratio of PT force decreased is $30.3 \%$ after the last six loading cycles are completed (i.e., after the loading level of $\theta=0.05 \mathrm{rad}$ is completed). These results indicate that as the inter-story drift increases, the width of the gap opening increases, and the PT force also decreases significantly.

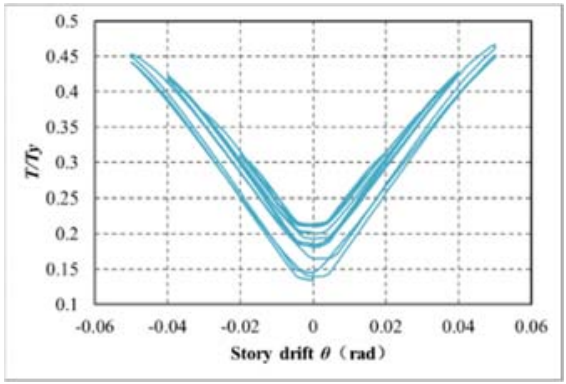

Strand 1

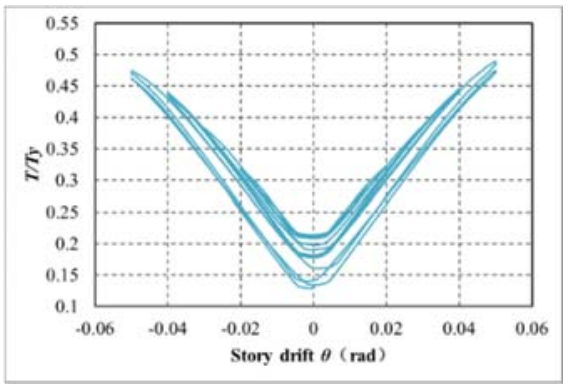

Strand 2

Figure 14. PT Force-Story Drift response of the Test Specimen Table 1. Experimental Results of PT Force 


\begin{tabular}{ccccccc}
\hline Number & $T_{0} / T_{y}$ & $\left(T_{0}-T_{r 0.2}\right) / T_{0}$ & $\left(T_{0}-T_{r 0.3}\right) / T_{0}$ & $\left(T_{0}-T_{r 0.4}\right) / T_{0}$ & $\left(T_{0}-T_{r 0.5}\right) / T_{0}$ & $T_{\max } / T_{y}$ \\
\hline 1 & 0.217 & $10.6 \%$ & $14.9 \%$ & $22.8 \%$ & $27.8 \%$ & 0.507 \\
2 & 0.218 & $9.3 \%$ & $13.4 \%$ & $19.9 \%$ & $24.8 \%$ & 0.498 \\
3 & 0.216 & $10.0 \%$ & $14.3 \%$ & $21.1 \%$ & $27.6 \%$ & 0.495 \\
4 & 0.215 & $10.7 \%$ & $15.8 \%$ & $22.5 \%$ & $30.3 \%$ & 0.502 \\
\hline
\end{tabular}

\subsection{Change in the Strain}

The strain data at key locations are selected for analysis. Figure 15 and Figure 16 show the relationships between the strain and the inter-story drift at several locations, B represents the beam, $\mathrm{C}$ represents the column, $\mathrm{P}$ represents the flange, $\mathrm{W}$ represents the web plate, and BP1 and BP2 are located on the beam flange reinforcing plate. When the inter-story drift reached 0.05 rad, several parts of the column are still in the elastic state, and the plasticity in the beam is still concentrated at the beam flange reinforcing plates (the locations where the beam flange reinforcing plates contact the column flanges) and the beam flanges at the ends of the reinforcing plates. In contrast, the strains at all of the other locations are still lower than the yield strain, which indicates that the connection has good seismic performance.

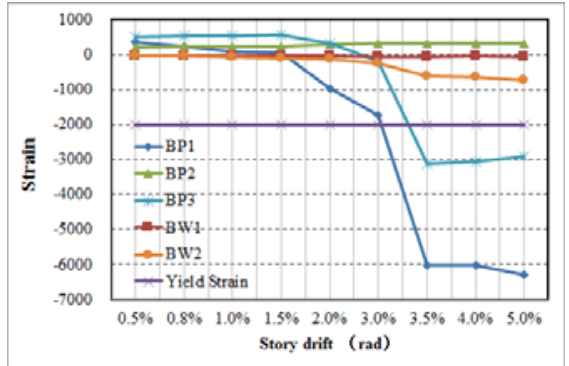

Figure 15. Strain of Crucial Positons for the Beam of Specimen

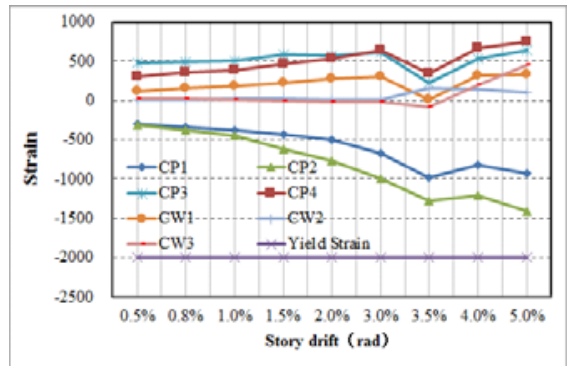

Figure 16. Strain of Crucial Positons for the Column of Specimen

\section{COMPARISON BETWEEN THE NUMERICAL SIMULATION AND THE TEST}

\subsection{Model for the SCCUD Connection}

A finite element model to simulate the test is developed using the Abaqus 6.11 [13]. Solid C3D8R elements are used for the main body of the finite element model, and T3D3 truss elements are used for the pre-stressed steel strands. Figure 17 shows the finite element model and the mesh generation. The Bolt Load function in Abaqus is used to apply pretension to the high-strength bolts. The boundary conditions of the model are the same as those of the test.

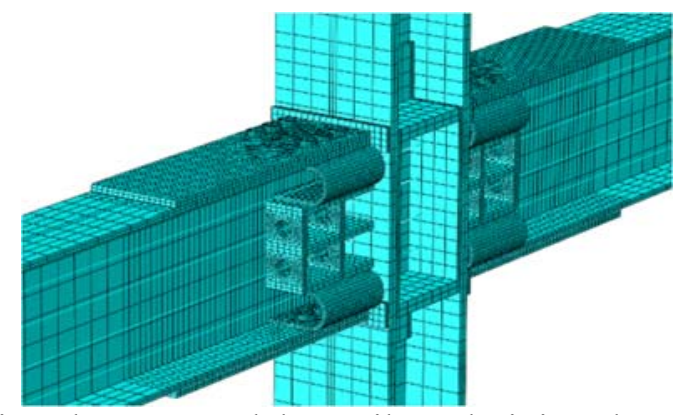

Figure 17. Finite Element Model Details and Finite Element Mesh Generation 


\subsection{Comparison between the Numerical Simulation and the Test}

Figure 18 compares the deformations of the SCCUD connection that were obtained from the test and the finite element analysis under cyclic loading conditions. When the inter-story drift reaches 0.05 $\mathrm{rad}$, the widths of the openings in the test and in the finite element model are $21.93 \mathrm{~mm}$ and $21 \mathrm{~mm}$, respectively. When the loading process is completed and the structure returns to the initial position, the widths of the maximum residual openings during the test and in the finite element model are 0.04 $\mathrm{mm}$ and $0.03 \mathrm{~mm}$, respectively. The slight difference in the widths of the openings that are generated during the test and simulated using the finite element model is attributed to manufacturing process of the specimen and installation deviation. The results of the finite element analysis are generally consistent with the test results.

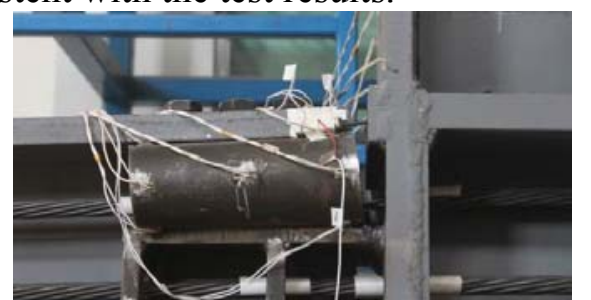

story drift $\theta=5 \%$, gap opening $21.93 \mathrm{~mm}$

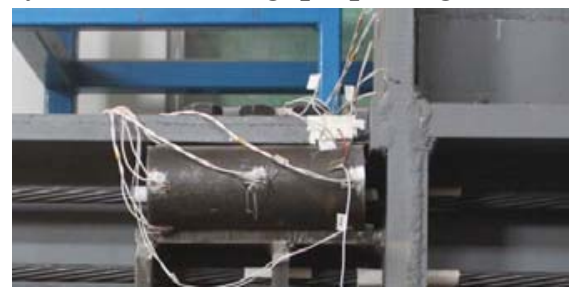

loading completed, residual gap opening $0.04 \mathrm{~mm}$

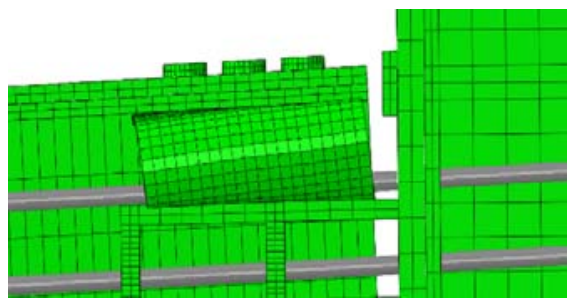

story drift $\theta=5 \%$, gap opening $21.00 \mathrm{~mm}$

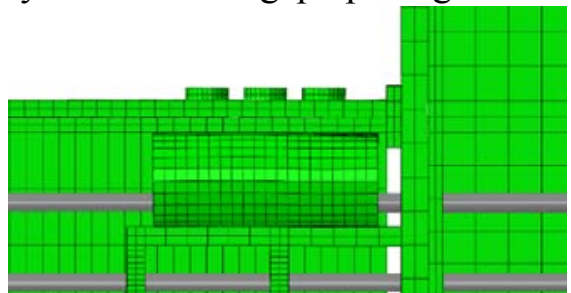

loading completed, residual gap opening $0.03 \mathrm{~mm}$

Figure 18. Comparison of Experimental and FEA Deformation of SCCUD

Figure 19 (a) shows the load-displacement relationship curves that were obtained from the test and the finite element analysis. The load-displacement curves show that the results of the finite element analysis are consistent with the test results in terms of the initial stiffness, post-opening stiffness and stiffness degradation of the connection. The maximum load-bearing capacities of the connection that were obtained from the test and the finite element analysis are $303.34 \mathrm{kN}$ and $303.78 \mathrm{kN}$, respectively. So the simulation method can accurately reflect the experiments. Figure 19 (b) plots not only $M-\theta_{r}$ relationship curves that were obtained from the test and the finite element analysis, but also the theoretical $M-\theta_{r}$ hysteresis of the SCCUD specimen based on the theoretical expressions described in the previous sections. Figure 19 (b) shows that the results of the theoretical formula calculations, finite element analysis, and the test were consistent, and the theoretical hysteresis model can predict the connection stiffness and strength with reasonable accuracy.

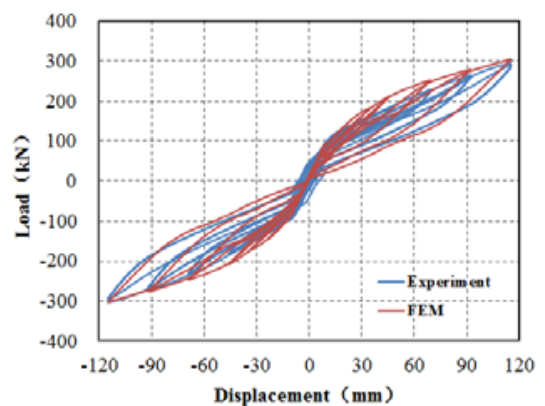

(a)Force-displacement hysteresis loop

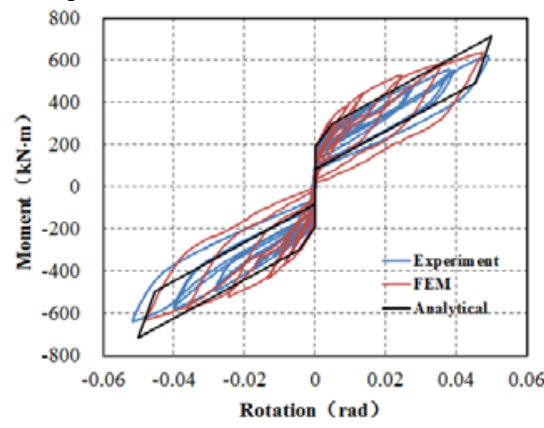

(b)Moment-rotation hysteresis loop

Figure 19. Comparison of FEA and Experimental Results 


\section{ANALYSIS OF THE FACTORS THAT AFFECT THE PROPERTIES OF THE SCCUD CONNECTION}

The effects of the width, height and thickness of the U-shaped steel damper are considered. Eight other connections of the same type that were used in the test are also designed for comparison. Table 2 lists the detailed parameters of the connection models.

Table 2. Test Matrix

\begin{tabular}{cccccc}
\hline Specimens & \multicolumn{2}{c}{ size $(w \times h \times t)$} & $T_{0} / T_{u}$ & Bolt specification \\
\hline SCCUD & 250 & 80 & $10(\mathrm{~mm})$ & 0.2 & 3M24 Grade10.9 \\
SCCUD-W150 & 150 & 80 & $10(\mathrm{~mm})$ & 0.2 & 2M24 Grade10.9 \\
SCCUD-W200 & 200 & 80 & $10(\mathrm{~mm})$ & 0.2 & 3M24 Grade10.9 \\
SCCUD-W300 & 300 & 80 & $10(\mathrm{~mm})$ & 0.2 & 3M24 Grade10.9 \\
SCCUD-W350 & 350 & 80 & $10(\mathrm{~mm})$ & 0.2 & 3M24 Grade10.9 \\
SCCUD-H70 & 250 & 70 & $10(\mathrm{~mm})$ & 0.2 & 3M24 Grade10.9 \\
SCCUD-H100 & 250 & 100 & $10(\mathrm{~mm})$ & 0.2 & 3M24 Grade10.9 \\
SCCUD-T6 & 250 & 80 & $6(\mathrm{~mm})$ & 0.2 & 3M24 Grade10.9 \\
SCCUD-T16 & 250 & 80 & $16(\mathrm{~mm})$ & 0.2 & 3M24 Grade10.9 \\
\hline
\end{tabular}

\subsection{Effect of the Width of the U-shaped Steel Damper on the Properties of the Connection}

To study the effect of the width of the U-shaped steel damper on the connection, the finite element analysis(FEA) results of the SCCUD connection (base-element $250 \times 80 \times 10$ ) are compared with the analysis results of the SCCUD-150, the SCCUD-W200, the SCCUD-W300 and the SCCUD-W350 (Figure 20). The force-displacement curve of each connection is linear, and the stiffness of each connection remains nearly constant before the opening is generated, which further demonstrates that the initial stiffness of the connection is mainly related to the magnitude of the initial PT force. Table 3 lists the main results of the analysis of the five connections. The SCCUD-W150 connection has the lowest load-bearing capacity $(246.77 \mathrm{kN})$, and the SCCUD-W350 connection has the highest loadbearing capacity $(346.92 \mathrm{kN})$; the load-bearing capacities of the connections increase with increasing width of the U-shaped steel damper. The maximum openings of the five connections show that for all but the SCCUD-W150 connection, the width of the gap opening, which occurs when the interstory drift is largest $(0.05 \mathrm{rad})$, decreases with increasing width of the U-shaped steel damper. The SCCUD-W150 connection has the lowest value of $\beta_{E}$ and a relatively poor energy-dissipation capacity. With increasing width of the U-shaped steel damper, the values of $\beta_{E}$ of the SCCUD-W150, the SCCUD-W200, the SCCUD-W 300 and the SCCUD-W350 connection are 0.38, 0.44, 0.49 and 0.48 , respectively, which indicates that the energy-dissipation capacity of the connection increases with increasing width of the U-shaped steel damper within a certain range. The SCCUD-W300 connection has the highest value of $\beta_{E}$ and a relatively small maximum opening, which indicates that the SCCUD-W300 connection not only can reduce the deformation of the SC-MRFs but also has reliable energy dissipation capacity. The results of the SCCUD-W350 connection show that a continuous increase in the width of the U-shaped steel damper has no impact on the energydissipation capacity of the connection. The widths of the residual openings of the five connections increase with increasing width of the U-shaped steel damper; the width of the residual opening of the SCCUD-W350 connection increases significantly to $0.479 \mathrm{~mm}$, which indicates that an increase in the width of the U-shaped steel damper does not provide any benefits now. Figure 21 shows nephogram of the equivalent plastic strains (PEEQ) in the column panel zone regions of the SCCUDW300 connection and the SCCUD-W350 connection. When the width of the U-shaped steel damper reaches $300 \mathrm{~mm}$, plasticity occurs in the panel zone. The maximum PEEQ value is $1.986 \times 10^{-3}$. When 
the width of the U-shaped steel damper is increased to $350 \mathrm{~mm}$, the plasticity of the column panel zone increases to $2.959 \times 10^{-3}$.

Therefore, for constant dimensions of the cross sections of the beam and the column, an increase in the width of the U-shaped steel damper within a certain range can improve the load-bearing and energy-dissipation capacities of the connection but also will have a negative impact on the selfcentering capacity of the connection.

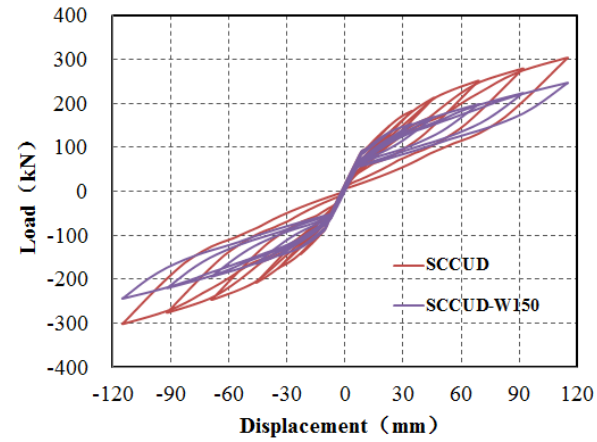

(a) SCCUD and SCCUD-W150

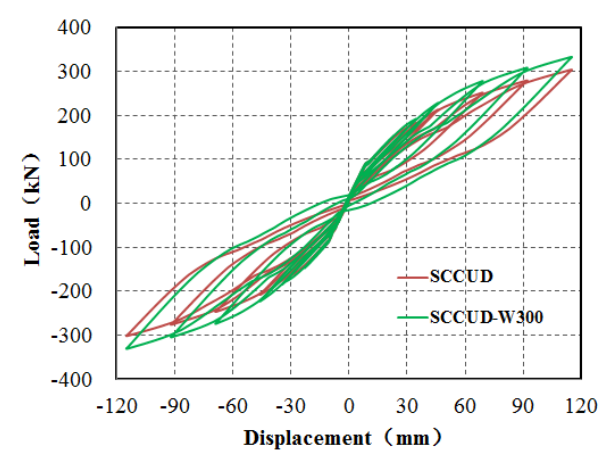

(c) SCCUD and SCCUD-W300

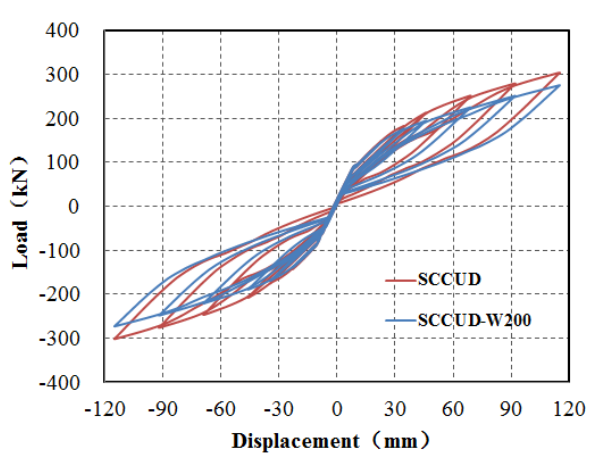

(b) SCCUD and SCCUD-W200

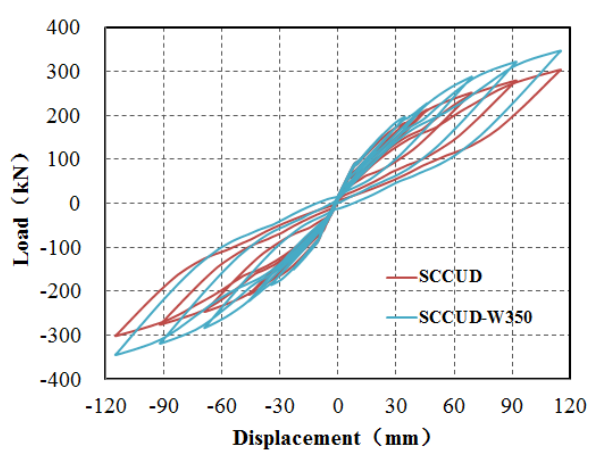

(d) SCCUD and SCCUD-W350

Figure 20. Comparison of Force-displacement Response for SCCUD SCCUD-W350

Table3 FEA Results

\begin{tabular}{ccccc}
\hline Specimens & $\begin{array}{c}\text { Maximum load } \\
(\mathrm{kN})\end{array}$ & $\begin{array}{c}\text { Maximum gap } \\
\text { opening }(\mathrm{mm})\end{array}$ & $\begin{array}{c}\text { Residual gap } \\
\text { opening }(\mathrm{mm})\end{array}$ & $\begin{array}{c}\text { energy dissipation } \\
\text { ratio }\end{array}$ \\
\hline SCCUD -W150 & 246.77 & 20.94 & 0.003 & 0.26 \\
SCCUD -W200 & 275.17 & 22.06 & 0.038 & 0.38 \\
SCCUD & 303.78 & 21.00 & 0.028 & 0.44 \\
SCCUD -W300 & 332.80 & 20.01 & 0.196 & 0.49 \\
SCCUD -W350 & 346.92 & 18.63 & 0.479 & 0.48 \\
\hline
\end{tabular}




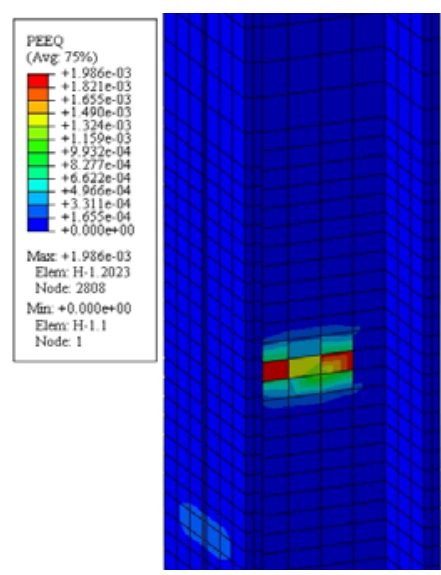

(a) SCCUD-W300

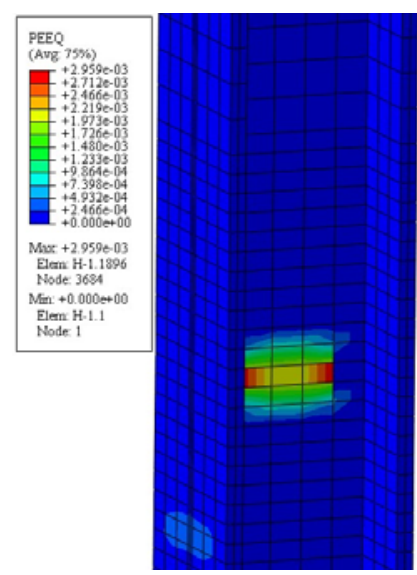

(b) SCCUD-W350

Figure 21. Nephogram of the PEEQ in the Column Panel Zone

\subsection{Effect of the Height of the U-shaped Steel Damper on the Properties of the Connection}

The height of the U-shaped steel damper is limited by the height of the beam web and the arrangement of the steel strands. To study the effect of the height of the U-shaped steel damper on the behavior of the connection, finite element analyses are conducted on the SCCUD-H70 and the SCCUD-H100. Figure 22 (a) compares the hysteretic curves of the SCCUD connection and the SCCUD-H70 connection. To conveniently observe the regular pattern, Figure 22 (b) compares the hysteretic curves of the SCCUD-70 and the SCCUD-H100. The results show that even a $30 \mathrm{~mm}$ difference in the height of the U-shaped steel damper causes a relatively small change in the stiffness after the gap opens and no significant change in the hysteretic loops.

The main analysis results that are shown in Table 4 demonstrate that the maximum load-bearing capacity of the joint gradually decreases from $317.28 \mathrm{kN}$ to $283.86 \mathrm{kN}$ with increasing height of the U-shaped steel damper and that the decrease is significant. The maximum widths of the gap openings of the SCCUD-H70, the SCCUD and the SCCUD-H100 are $20.52 \mathrm{~mm}, 21 \mathrm{~mm}$ and $19.87 \mathrm{~mm}$, respectively. Thus, there is little difference in the widths of the largest openings in these three joints; therefore, a change in the height of the U-shaped steel damper has a relatively small impact on the width of the largest opening of the connection. In terms of the energy-dissipation capacity, the value of $\beta_{E}$ decreases gradually from 0.48 to 0.46 with increasing height of the U-shaped steel damper. The SCCUD-H70 connection has a higher load-bearing capacity and a higher energy-dissipation capacity than the SCCUD-H100 and the SCCUD (base-element $250 \times 80 \times 10$ ) connection. The SCCUD-H70, the SCCUD-H100 and the SCCUD connection all have very small residual openings; the width of the residual gap opening increases with decreasing height of the U-shaped steel damper. However, due to the spatial requirements of the structure, the height of the U-shaped steel damper is generally not small enough to affect the closing of the gap. 


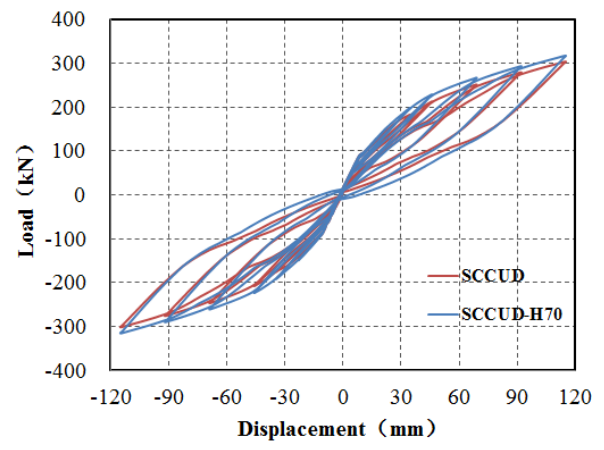

(a) SCCUD and SCCUD -H70

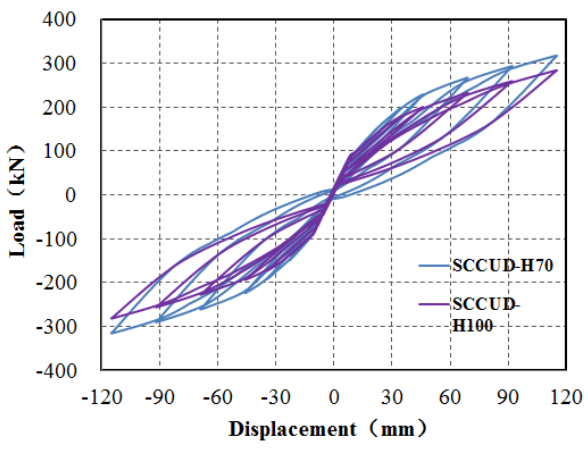

(b) SCCUD -H70 and SCCUD -H100

Figure 22. Comparison of Force-displacement Response for SCCUD, SCCUD-70、SCCUDH100

Table 4. FEA Results

\begin{tabular}{ccccc}
\hline Specimens & $\begin{array}{c}\text { Maximum load } \\
(\mathrm{kN})\end{array}$ & $\begin{array}{c}\text { Maximum gap } \\
\text { opening }(\mathrm{mm})\end{array}$ & $\begin{array}{c}\text { Residual gap } \\
\text { opening }(\mathrm{mm})\end{array}$ & $\begin{array}{c}\text { energy dissipation } \\
\text { ratio }\end{array}$ \\
\hline SCCUD-H70 & 317.28 & 20.52 & 0.1225 & 0.48 \\
SCCUD & 303.78 & 21.00 & 0.0277 & 0.44 \\
SCCUD-H100 & 283.86 & 19.87 & 0.0008 & 0.36 \\
\hline
\end{tabular}

\subsection{Effect of the Thickness of the U-shaped Steel Damper on the Behavior of the Connection}

To study the thickness of the U-shaped steel damper on the behavior of the connection, finite element analyses are conducted on the SCCUD-T6 and the SCCUD-T16 connection. Figure 23 compares the hysteretic curves of the SCCUD-T6, the SCCUD (base-element $250 \times 80 \times 10$ ) and the SCCUD-T16 connection. The results show that the initial stiffness of the connection is mainly controlled by the initial pre-stress of the steel strands; therefore, a change in the thickness of the steel plate of the Ushaped steel damper has little impact on the initial stiffness of the connection and the magnitude of the imminent gap opening load. There is a relatively large difference in the post-opening stiffness of the connection, which is mainly due to the fact that the elastic stiffness of the U-shaped steel damper increases with increasing thickness of the steel plate. The post-opening stiffness of the SCCUD-T6 connection decreases significantly compared to that of the SCCUD connection, whereas the postopening stiffness of the SCCUD-T16 connection increases significantly.

Table 5 lists the main analysis results. The load-bearing capacity of each connection increases with increasing thickness of the steel plate of the U-shaped steel damper. The maximum openings of the SCCUD-T6 and the SCCUD connection are $20.56 \mathrm{~mm}$ and $21.00 \mathrm{~mm}$, respectively; thus, there is essentially no change in the width of the maximum opening. In contrast, the maximum opening of the SCCUD-T16 connection decreases significantly $(17.66 \mathrm{~mm})$, which indicates that for constant dimensions of the cross sections of the beam and column, the opening of the gap decreases significantly with increasing thickness of the steel plate of the U-shaped steel damper $(t)$ when thickness is equal and greater than $10 \mathrm{~mm}$. Moreover, the width of the residual opening increases significantly with increasing $t$, and the value of $\beta_{E}$ of the joint also increases with increasing $t$, but the increase is insignificant. In addition, when $t=16 \mathrm{~mm}$, the maximum PEEQ value of the SCCUDT16 connection reaches $1.034 \times 10^{-2}$ (as shown in the nephogram of the PEEQ in the column panel zone region of the SCCUD-T16 connection in Figure 24), and a relatively large degree of plasticity develops. Therefore, an increase in the thickness of the U-shaped steel damper will cause significant increases in the load-bearing capacity and post-opening stiffness of the connection. However, for constant dimensions of the cross sections of the beam and the column, an increase in the thickness of 
the U-shaped steel damper will not significantly improve the energy-dissipation capacity of the connection. An excessively thick U-shaped steel damper will affect the self-centering capacity of the connection and also increase the plastic development of other components, such as the beam and the column.

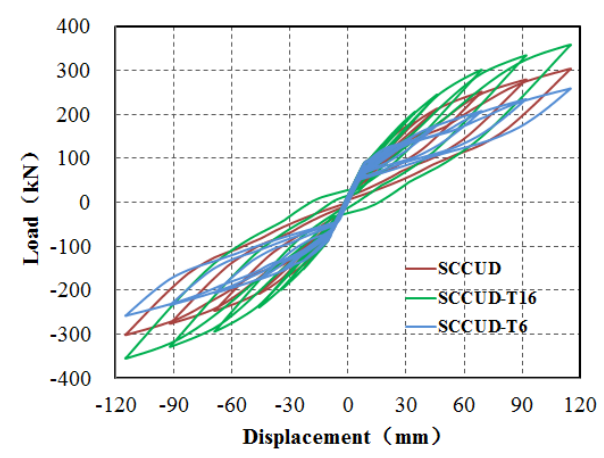

Figure 23. Comparison of Force-displacement Response for SCCUD、SCCUD-T6 and SCCUD-T16

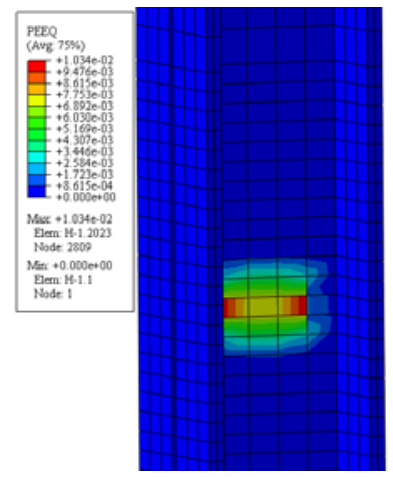

Figure 24. Nephogram of the PEEQ in the Column Panel Zone of the SCCUD-T16 Connection

Table 5. FEA Analysis Results

\begin{tabular}{ccccc}
\hline Specimens & $\begin{array}{c}\text { Maximum load } \\
(\mathrm{kN})\end{array}$ & $\begin{array}{c}\text { Maximum gap } \\
\text { opening }(\mathrm{mm})\end{array}$ & $\begin{array}{c}\text { Residual gap } \\
\text { opening }(\mathrm{mm})\end{array}$ & $\begin{array}{c}\text { energy dissipation } \\
\text { ratio }\end{array}$ \\
\hline SCCUD-T6 & 258.74 & 20.56 & 0.0021 & 0.28 \\
SCCUD & 303.78 & 21.00 & 0.0277 & 0.44 \\
SCCUD-T16 & 358.44 & 17.66 & 1.3132 & 0.48 \\
\hline
\end{tabular}

\section{CONCLUSIONS}

This study proposes a new type of self-centering beam-column connection with U-shaped steel damper for steel SC-MRFs. A simplified connection hysteresis model was developed using simple mechanics, and an iterative seismic design procedure for SCCUD connection was presented. The test of the proposed connection is simulated using the Abaqus 6.11 finite element software. After verifying the feasibility of the numerical simulation method, this study analyzes the influencing parameters using nine FEA model and investigates the effects of the width, height and thickness of the U-shaped steel damper on the connection. The following conclusions are obtained:

1. The SCCUD connection for steel SC-MRFs can realize the self-centering mechanism. Under cyclic loads, the U-shaped steel damper dissipates energy through plastic deformation and has good energydissipation capacity.

2. The width of the U-shaped steel damper has a relatively large impact on the behavior of the connection. Increasing the width of the U-shaped steel damper can significantly improve the loadbearing capacity, the post-opening stiffness and the energy-dissipation capacity of the connection but also has a negative impact on the self-centering capacity. An increase in the width of the U-shaped steel damper beyond a certain limit will not further improve the behavior of the connection but will decrease the self-centering capacity of the connection and increase plastic damage to other components. It is recommended to firstly change the width of the U-shaped steel damper to improve the energy-dissipation capacity of the connection. 
3. The height of the U-shaped steel damper has a relatively small impact on the behavior of the connection. The height of the U-shaped steel damper is limited by the height of the beam web and the arrangement of the steel strands. Therefore, changing the height of the U-shaped steel damper is not recommended for improving the behavior of the connection.

4. The thickness of the steel plate of the U-shaped steel damper has a relatively large impact on the load-bearing capacity and post-opening stiffness. The load-bearing capacity and post-opening stiffness will be increased with the thicker steel plate of the U-shaped steel damper. However, for constant dimensions of the cross section of the beam and the column, changing the thickness of the U-shaped steel damper will not significantly improve the energy-dissipation capacity of the connection. An excessively thick U-shaped steel damper will weaken the self-centering capacity of the connection and also increase the plastic development of other components.

5. Compared with the experimental and FEA results, theoretical hysteresis model proved to have reasonable accuracy in the prediction of the connection stiffness and strength.

\section{ACKNOWLEDGMENTS}

The research reported herein is supported by the National Natural Science Foundation of China under Grant No. 51278027, National Key Project of Research and Development Plan of Key Technology in Design of Industrialized Buildings of China under Grant No. 2016YFC0701500 and Project of Constructing Beijing Energy Saving and Emission Reduction Technology Collaborative Innovation Center.

\section{REFERENCES}

[1] Garlock, M.M. and Ricles, J.M., et al., "Post-tensioned Seismic Resistant Connections for Steel Frames//Structural Stability Research Council Conference Workshop, Rolla Missouri: Structural Stability Research Council, 1998.

[2] Ricles, J.M., Sause, R., Peng, S. and Lu, L., "Experimental Evaluation of Earthquake Resistant Post-tensioned Steel Connections" Journal of Structural Engineering, 2002, Vol. 128, No. 7, pp. 850-859.

[3] Garlock, M.M., Ricles, J.M. and Sause, R., "Cyclic Load Tests and Analysis of Bolted Topand-seat Angle Connections", Journal of Structural Engineering, 2003, Vol. 129, No. 12, pp. 1615-1625.

[4] Christopoulos, C., Filiatrault, A., Uang, C.M. and Folz, B., "Post-tensioned Energy Dissipating Connections for Moment-resisting Steel Frames", Journal of Structural Engineering, 2002, Vol. 128, No. 9, pp. 1111-1120.

[5] Cruz, P.R., "Analysis, Design, and Evaluation of Post-tensioned Friction Damped Connections for Steel Moment Resisting Frames", Bethlehem, Pennsylvania: Lehigh University, 2003.

[6] Iyama, J., Seo, C.Y., Ricles, J.M. and Sause, R., "Self-centering MRFs with Bottom Flange Friction Devices under Earthquake Loading”, Journal of Constructional Steel Research, 2009, Vol. 65, pp. 314-325.

[7] Wolski, M., Ricles, J.M. and Sause, R., "Experimental Study of a Self-centering Beamcolumn Connection with Bottom Flange Friction Device", Journal of Structural Engineering, 2009, Vol. 135, No. 5, pp. 479-488.

[8] Lin, Y.C., Ricles, J.M. and Sause, R., "Earthquake Simulations on Self-centering Steel Moment Resisting Frame with Web Friction Devices", Structures Congress 2009, Reston Virginia: American Society of Civil Engineers, 2009. 
[9] Rojas, P., "Seismic Analysis, Design, and Evaluation of Post-tensioned Friction Damped Connections for Steel Moment Resisting Frames", Department of Civil and Environmental Engineering: Lehigh University, 2003.

[10] Garlock, M.M., Sause, R. and Ricles, J.M., "Behavior and Design of Posttensioned Steel Frame Systems", Journal of Structural Engineering, 2007, Vol. 133, No. 3, pp. 389-399.

[11] Garlock, M.M., "Full-scale Testing, Seismic Analysis, and Design of Post-tensioned Seismic Resistant Connections for Steel Frames", Civil and Environmental Engineering Dept., Lehigh University, 2002.

[12] Seo, C.Y. and Sause, R., "Ductility Demands on Self-centering Systems under Earthquake Loading, ACI Structural Journal, 2005, Vol. 102, No. 2, pp. 275-85.

[13] Abaqus Documentation. ABAQUS Analysis User's Manual, 2011. 


\title{
GENERALISED ELEMENT LOAD METHOD WITH WHOLE DOMAIN ACCURACY FOR RELIABLE STRUCTURAL DESIGN
}

\author{
Chi-Kin Iu \\ Lecturer, School of Civil Engineering and Built Environment \\ Queensland University of Technology \\ QUT Brisbane, QLD, Australia \\ (Corresponding author: E-mail: iu.jerryu@gmail.com)
}

Received: 6 November 2015; Revised: 29 November 2015; Accepted: 7 December 2015

\begin{abstract}
This paper presents a formulation to capture all kinds of second-order effects (i.e. discrete nodal displacement as the numerical approach: P- $\delta \&$ P- $\Delta$ effect, large displacement, snap-through buckling, initial imperfection, etc.) for members under loads along their lengths. The efficient computational formulation of the generalised element load method (GELM) is proposed which gives accurate element and nodal solutions when using the one-element-per-member model. It is believed the GELM provides a reliable and efficient method for improving the second-order analysis for design of practical structures.
\end{abstract}

Keywords: Generalised element load method; second-order elastic analysis; one element per member; higher-order element formulation; initial imperfection; element solutions

DOI:10.18057/IJASC.2016.12.4.6

\section{INTRODUCTION}

Nonlinear numerical analysis for a structure was prevalent from the past half century, likely because of availability of low-cost and powerful computers. The popular displacement-based finite element approach was devoted by (hierarchic displacement element: mesh refinement required) a number of scholars; Meek and Tan [1], Chan and Kitipornchai [2] and Iu and Bradford [3][4] among others and hence the conventional displacement-based finite element approach have been well established.

In spite of its robustness, versatility and applicability, the conventional displacement-based finite element analysis possesses a drawback of element discretisation for a member to give accurate solutions when loads are along a member. To overcome the drawback, Chan and Zhou [5][6] presented a PEP finite element to simulate the second-order effect on a member with an initial geometric imperfection. Izzuddin [7] later formulated a fourth-order displacement-based finite element for structures under thermal loads. Iu and Bradford [8] provided a higher-order finite element analysis to examine various kinds of geometric nonlinearities for framed structures using a single element per member.

Previous methods and their applications on second-order analysis for members under element loads are very limited to conversion of element loads to the nodal solutions and hence the major setback of these approaches is less accurate solutions obtained when using a single element to simulate a member with loads along its length. In order to take the element load effect into account for the member behaviour, Zhou and Chan $[9,10]$ presented a second-order elastic analysis that is capable of modelling the element load effect in the element stiffness formulation, in lieu of by a system analysis for the nodal solutions. Unfortunately, each element load case requires a specific element stiffness matrix, which is limited in practical applications because of the multiplicity of load patterns imposed on an element. And also no accurate solution along an element was evaluated in their research works. 
Research in forced-based finite element approach seems to lag behind its displacement-based counterpart. To overcome the obstacle of the flexibility approach, Neuenhofer and Filippou [11] developed a procedure for determining the nonlinear element state. Later, Neuenhofer and Filippou [12] extended their work to study the effects of force distribution along a single element and it is another element force solution. Their flexibility approach (i.e. Valipour and Bradford [13]), in principle, is difficult to evaluate the deformation accurately along a single element when compared to the displacement-based stiffness approach.

In summary, the objective of research on higher-order element by the one-element-per-member approach is confined to the use of less elements for a structure with accurate nodal solutions of its members under element loads. As a result, the accurate element solutions cannot be obtained when an element is subjected to element load. It means that a reliable structural analysis for members subjected to external element loads is unavailable with an error contained in analysis by one-element-per-member model for members with loads along the lengths. The lumping and consistent load methods alone are unable to produce accurate first- and second-order elastic solutions due to element load effect within an element itself as reported by Iu and Bradford [14] and $\mathrm{Iu}[15]$. In this paper, a qualified element for these purposes is proposed and it transforms the traditional discretised nodal solution into continuous displacement and force element solutions for the geometric nonlinear effects. As a natural result, the present method can ensure the adequate and reliable structural safety for the whole domain not only at the element nodes, but also along an element, when one-element-per-member model is adopted. This method strikes a balance between simplicity in the formulation (similar stiffness form preserved) and accuracy in describing the element load effect for both nodal (robust system analysis) and element responses (sophisticated element formulation).

\section{STIFFNESS FORMULATION FOR HIGHER-ORDER ELEMENT WITH ELEMENT LOAD EFFECTS}

The internal strain energy $U$ due to axial strain $\varepsilon_{x}$ and twist strain $\gamma_{x}$ in the continuum medium are considered to formulate the stiffness matrices of the present higher-order beam-column element. Axial strain $\varepsilon_{x}$ is expressed through linear axial deformation and the nonlinear elastic transverse displacement function [Iu [15]] of which the strain energy dissipated in flexural bending and member bowing are consisted. The internal strain energy $U$ caused by the axial strain $\varepsilon_{x}$ and twist strain $\gamma_{x}$ along the beam-column continuum can be accumulated by integration of $\delta U_{A}=E \varepsilon_{x} \delta \varepsilon_{x}$ and of $\delta U_{T}=G \gamma_{x} \delta \gamma_{x}$ over the domain of element length and element section, which can be expressed in terms of $u, v, w$ and $\phi$ from an appropriate expansion of Green's strain tensor as

$U=\int_{V o l}\left(\int_{\varepsilon_{x}} E \varepsilon_{x} \mathrm{~d} \varepsilon_{x}+\int_{\gamma_{x}} G \gamma_{x} \mathrm{~d} \gamma_{x}\right) \mathrm{d} V o l=\frac{1}{2} \int_{V o l}\left(E \varepsilon_{x}^{2}+G \gamma_{x}^{2}\right) \mathrm{d} V o l$,

The internal strain energy $U$ including various components becomes

$$
\begin{aligned}
U= & \int \delta U=E \int_{V o l} \int_{\varepsilon_{x}} \varepsilon d \varepsilon d V=\frac{E}{2} \int_{V o l} \varepsilon_{x}^{2} d V o l \\
U= & \frac{E A}{2} \int_{L}\left(\frac{\mathrm{d} u}{\mathrm{~d} x}\right)^{2} \mathrm{~d} x+\frac{P}{2} \int_{L}\left(\frac{\mathrm{d} v}{\mathrm{~d} x}\right)^{2} \mathrm{~d} x+\frac{P}{2} \int_{L}\left(\frac{\mathrm{d} w}{\mathrm{~d} x}\right)^{2} \mathrm{~d} x+\frac{E I_{z}}{2} \int_{L}\left(\frac{\mathrm{d}^{2} v}{\mathrm{~d} x^{2}}\right)^{2} \mathrm{~d} x \\
& +\frac{E I_{y}}{2} \int_{L}\left(\frac{\mathrm{d}^{2} w}{\mathrm{~d} x^{2}}\right)^{2} \mathrm{~d} x+\frac{G J}{2} \int_{L}\left(\frac{\mathrm{d} \phi}{\mathrm{d} x}\right)^{2} \mathrm{~d} x
\end{aligned}
$$


in which $u, v$ and $w$ are dependent variables for axial deformation, for lateral deflections in the direction in $y$-axis and $z$-axis, respectively, which is given in [Iu [15]]; $\phi$ is for twist angle about $x$-axis; $E A, E I$ and $G J$ are the axial rigidity, flexural rigidity about corresponding axes and torsional rigidity, respectively; $P$ is the axial element load.

In this study, external loads produce by nodal load $\mathbf{f}_{k}$ and element load $\Phi_{k}$. Hence, the external work done $V$ constitutes two components; first component $V_{f}$ (Lumping load method) is the work done by nodal loads $\mathbf{f}_{k}$ in going through nodal displacements $\mathbf{u}_{k}$; second component $V_{\Phi}$ (Consistent load method) is the work done by transverse element load $\Phi_{k}$ in going through the assumed transverse displacement field associated with the element displacement function $\mathbf{N}$ over the element length. In accord with the assumption of conservative loads, the work done going through the deflected element $\mathbf{N}$ due to element loads is independent of the axial load $q$ at all stages, such as setting $q=0$ in the higher-order element function in [Iu [15]][15], as given by

$V=V_{\Phi}+V_{f}=\int_{L} \mathbf{u}_{k}^{\mathrm{T}} \mathbf{N}^{\mathrm{T}} \boldsymbol{\Phi}_{k} d x+\mathbf{u}_{k}^{\mathrm{T}} \mathbf{f}_{k}$.

The elastic force-displacement relationship is derived from the total potential energy of the general beam-column element subjected to both nodal and element loads. The total potential energy for nonlinear elastic analysis of column-beam element is the summation of internal strain energy $U$ in Eq. 2 and external work done $V$ in Eq. 3 as

$$
\begin{aligned}
\Pi= & \frac{E A}{2} \int_{L}\left(\frac{\mathrm{d} u}{\mathrm{~d} x}\right)^{2} \mathrm{~d} x+\frac{P}{2} \int_{L}\left(\frac{\mathrm{d} v}{\mathrm{~d} x}\right)^{2} \mathrm{~d} x+\frac{P}{2} \int_{L}\left(\frac{\mathrm{d} w}{\mathrm{~d} x}\right)^{2} \mathrm{~d} x+\frac{E I_{z}}{2} \int_{L}\left(\frac{\mathrm{d}^{2} v}{\mathrm{~d} x^{2}}\right)^{2} \mathrm{~d} x \\
& +\frac{E I_{y}}{2} \int_{L}\left(\frac{\mathrm{d}^{2} w}{\mathrm{~d} x^{2}}\right)^{2} \mathrm{~d} x+\frac{G J}{2} \int_{L}\left(\frac{\mathrm{d} \phi}{\mathrm{d} x}\right)^{2} \mathrm{~d} x-\int_{L} \mathbf{u}_{k}^{\mathrm{T}} \mathbf{N}^{\mathrm{T}} \mathbf{\Phi}_{k} d x-\mathbf{u}_{k}^{\mathrm{T}} \mathbf{f}_{k}
\end{aligned}
$$

where $\mathbf{u}_{k}$ and $\mathbf{f}_{k}$ are the column vectors of the displacement and external applied force with respect to the corresponding degrees of freedom, respectively. $\mathbf{u}_{k}$ is a column vector as given by $\left\langle\Delta u, \theta_{z 1}, \theta_{z 2}, \Delta \theta_{x}, \theta_{y 1}, \theta_{y 2}\right\rangle^{T}$ in notations, in which $\Delta u=u_{1}-u_{2}$ and $\Delta \theta_{\mathrm{x}}=\phi_{1}-\phi_{2}$.

The equilibrium equation of higher-order element subjected to the general transverse element load can be obtained by first variation of total potential energy functional of Eq. 4 for a stable structure as,

$$
\delta \Pi=\frac{\partial}{\partial \mathbf{u}_{k}}(U-V) \delta \mathbf{u}_{k}=0
$$

for which the internal strain energy of Eq. 2 depends not only on the dependent variables $\mathbf{u}_{k}$, but also on the axial load parameter $q$, and thereby the differential operator becomes

$$
\frac{\partial}{\partial \mathbf{u}_{k}}=\frac{\partial}{\partial \mathbf{u}_{k}}+\frac{\partial q}{\partial \mathbf{u}_{k}} \cdot \frac{\partial}{\partial q}
$$


According to the Eq. 5, the nonlinear equilibrium equation is provoked as,

$$
\begin{aligned}
\delta \Pi & =\left(\frac{\partial U}{\partial \mathbf{u}_{k}}+\frac{\partial U}{\partial q} \cdot \frac{\partial q}{\partial \mathbf{u}_{k}}-\frac{\partial V_{\Phi}}{\partial \mathbf{u}_{k}}-\frac{\partial V_{\Phi}}{\partial q} \cdot \frac{\partial q}{\partial \mathbf{u}_{k}}-\frac{\partial V_{f}}{\partial \mathbf{u}_{k}}\right) \delta \mathbf{u}_{k}=0 \\
& =\left(\frac{\partial U}{\partial \mathbf{u}_{k}}+\frac{\partial U}{\partial q} \cdot \frac{\partial q}{\partial \mathbf{u}_{k}}-\frac{\partial V_{\Phi}}{\partial \mathbf{u}_{k}}-\mathbf{f}_{k}\right) \delta \mathbf{u}_{k}=0
\end{aligned}
$$

in which it is noteworthy that the terms of $\partial V_{\Phi} / \partial q \cdot \partial q / \partial \mathbf{u}_{k}$ in Eq. 7 can be neglected. If the local nonlinear effect of axial load $q$ in $V_{\Phi}$ is taken into account $\left(\partial V_{\Phi} / \partial q \cdot \partial q / \partial \mathbf{u}_{k} \neq 0\right)$, the reliable convergent of this nonlinear analysis cannot be preserved, while the total external load level of a structure depends on the element deformations, which violates against the assumption of conservative load of this study. The element resistance or the secant stiffness formulation can be obtained from

$$
\begin{aligned}
M_{\alpha 1}=\frac{\partial U}{\partial \theta_{\alpha 1}}= & \frac{E I_{\alpha}}{L}\left[\frac{19200+800 q+\frac{61}{7} q^{2}+\frac{23}{1260} q^{3}}{(80+q)^{2}}+\frac{2304+288 q+\frac{29}{5} q^{2}+\frac{11}{420} q^{3}}{(48+q)^{2}}\right] \theta_{\alpha 1} \\
+ & \frac{E I_{\alpha}}{L}\left[\frac{19200+800 q+\frac{61}{7} q^{2}+\frac{23}{1260} q^{3}}{(80+q)^{2}}-\frac{2304+288 q+\frac{29}{5} q^{2}+\frac{11}{420} q^{3}}{(48+q)^{2}}\right] \theta_{\alpha 2} \\
& +\frac{E I_{\alpha}}{L}\left[-\frac{q^{2} \bar{M}_{0}}{210(48+q)^{2}}-\frac{q^{2} \bar{S}_{0} L}{630(80+q)^{2}}\right] \\
M_{\alpha 2}=\frac{\partial U}{\partial \theta_{\alpha 2}}= & \frac{E I_{\alpha}}{L}\left[\frac{19200+800 q+\frac{61}{7} q^{2}+\frac{23}{1260} q^{3}}{(80+q)^{2}}+\frac{2304+288 q+\frac{29}{5} q^{2}+\frac{11}{420} q^{3}}{(48+q)^{2}}\right] \theta_{\alpha 2} \\
& +\frac{E I_{\alpha}}{L}\left[\frac{19200+800 q+\frac{61}{7} q^{2}+\frac{23}{1260} q^{3}}{(80+q)^{2}}-\frac{2304+288 q+\frac{29}{5} q^{2}+\frac{11}{420} q^{3}}{(48+q)^{2}}\right] \theta_{\alpha 1} \\
& +\frac{E I_{\alpha}}{L}\left[\frac{M^{2} \bar{M}_{0}}{210(48+q)^{2}}-\frac{q^{2} \bar{S}_{0} L}{630(80+q)^{2}}\right] \\
\text { or } M_{\alpha 2}= & \frac{E I_{\alpha}}{L}\left(C_{1} \theta_{\alpha 2}+C_{2} \theta_{\alpha 1}+C_{m} \bar{M}_{0}-C_{s} \bar{S}_{0} L\right)
\end{aligned}
$$

in which the subscript $\alpha$ denotes $y$ or $z$, and

$$
\begin{aligned}
& P= P_{1}-P_{2}=\frac{\partial U}{\partial e}+\frac{\partial U}{\partial q} \cdot \frac{\partial q}{\partial e} \\
&= \frac{E A e}{L}+E A \sum_{\alpha=y, z}\left[b_{1}\left(\theta_{\alpha 1}+\theta_{\alpha 2}\right)^{2}+b_{2}\left(\theta_{\alpha 1}-\theta_{\alpha 2}\right)^{2}\right. \\
&\left.\quad+b_{m 1}\left(\theta_{\alpha 1}-\theta_{\alpha 2}\right) \bar{M}_{0}+b_{s 1}\left(\theta_{\alpha 1}+\theta_{\alpha 2}\right) \bar{S}_{0} L+b_{m 2} \bar{M}_{0}^{2}+b_{s 2} \bar{S}_{0}^{2} L^{2}\right] \\
&=E A\left[\frac{e}{L}+\sum_{\alpha=y, z}\left(C_{b}+b_{m 1}\left(\theta_{\alpha 1}-\theta_{\alpha 2}\right) \bar{M}_{0}+b_{s 1}\left(\theta_{\alpha 1}+\theta_{\alpha 2}\right) \bar{S}_{0} L+b_{m 2} \bar{M}_{0}^{2}+b_{s 2} \bar{S}_{0}^{2} L^{2}\right)\right]
\end{aligned}
$$


in which

$$
\begin{aligned}
& b_{1}=\frac{12800+2080 q / 7+46 q^{2} / 21+23 q^{3} / 2520}{(80+q)^{3}} ; \\
& b_{2}=\frac{4608+672 q / 5+66 q^{2} / 35+11 q^{3} / 840}{(48+q)^{3}} ; \\
& b_{m 1}=\frac{-16 q}{35(48+q)^{3}} \\
& b_{m 2}=\frac{12 / 35+q / 105}{(48+q)^{3}} \\
& b_{s 1}=\frac{-16 q}{63(80+q)^{3}} \\
& b_{s 2}=\frac{20 / 63+q / 315}{(80+q)^{3}}
\end{aligned}
$$

Right subscript symbol $m$ and $s$ in Eqs. (13) to (18) stand for the contribution from moment $\bar{M}_{0}$ and shear force $\bar{S}_{0}$ component, respectively. $C_{m}$ and $C_{s}$ provoke the second-order moment due to coupling effect of both axial and lateral element loads, whereas $b_{m 1}, b_{m 2}, b_{s 1}$ and $b_{s 2}$ exhibit axial force resistance subjected to the coupling effect. However, when axial load $q$ does not exist, $b_{m l}$ and $b_{s} l$ vanish and hence the coupling effect between the axial force and the lateral loads is eliminated. On the contrary, i.e. $q=0, b_{m 2}$ and $b_{s 2}$ still take part in providing the axial tensile resistance $P$ in Eq. 12 that means element load exerting the positive axial resistance $P$ due to elongation. It can be seen that the secant stiffness coefficients, such as $C_{m}, C_{s}, b_{m l}, b_{m 2}, b_{s 1}$ and $b_{s 2}$ accounting for the element load effect in Eqs. 9, 11, 13 to 18 varying from different load cases by adjusting $\bar{M}_{0}$ and $\bar{S}_{0}$, can contribute to the nodal solutions insignificantly. It means the element load effect on the nodal solutions is well replicated by the lumping and consistent load method except the buckling modes, at which the common denominators $(48+q)$ and $(80+q)$ vanish in order to magnify the nodal solutions from Eqs. 8 to 12, corresponding to symmetric and anti-symmetric buckling modes, respectively.

Because of load-dependent characteristic in the internal strain energy, the coupling effect between external element load and deformations becomes inherent in the present stiffness formulation from Eq. 8 to 12 . The Eq. 12 contains two independent bowing functions, which are symmetric and complete, while both force equilibrium equations of bending moment and shear force are incorporated into this element stiffness formulation. Instead of the lumping load and consistent load method formulated through the work done, the generalised element load method (GELM) can measure the strain energy dissipated into an element due to element load coupling with axial load effect that disregard in member bowing and flexural terms of the strain energy equation as Eq. 4. It means it regards the different strain energy terms as individual independent component. Because of this, the element load terms, such as $\bar{M}_{0}$ and $\bar{S}_{0}$, vanish or become very insignificant when subjected to no axial load. The element load method heralds the element load can cause the additional internal strain energy dissipation into both member bowing and flexural components as nodal solutions when subjected to axial compression. 
It is of importance to note that, despite subjected to different element loads, the line integration in Eq. 4 is identically carried out along the domain of an element, as the pattern of displacement function in [Iu [15]] remains unchanged regardless of a variety of element loading distribution but the magnitude of element load coefficients $\bar{M}_{0}$ and $\bar{S}_{0}$. It produces a crucial insight that the principle of superposition is valid to integrate the individual element load type $\bar{M}_{0}$ and $\bar{S}_{0}$ as listed in Appendix I in order to form a general element load case respectively in advent of nonlinear analysis being implemented, and subsequently can be allowed for by updating the element load coefficients $\Delta \lambda \cdot \bar{M}_{0}$ and $\Delta \lambda \cdot \bar{S}_{0}$ in the course of the system solution procedures as mentioned in Section 3. Therefore, the second-order solution due to a diverse kind of element loading can be unified by summing up the standardized and fundamental simple element load cases given in Appendix I of [Iu [15]]. This unique feature avoids tedious and enormous stiffness coefficients under a considerable combination of general element loads, and hence leads to a versatile stiffness formulation in the form of simplicity and brevity.

The tangent stiffness matrix can be obtained by taking a second differentiation of the total potential energy functional in Eq. 4 with respect to the dependent variables $\mathbf{u}_{k}$ and axial load $q$. When the external work done $V$ is linear as aforementioned, the tangent stiffness can be derived by second derivative of internal strain energy $U$ as given by

$$
\mathbf{K}_{t}=\frac{\partial^{2} \Pi}{\partial \mathbf{u}_{j} \partial \mathbf{u}_{k}}=\frac{\partial}{\partial \mathbf{u}_{j}}\left(\frac{\partial U}{\partial \mathbf{u}_{k}}\right)+\frac{\partial}{\partial \mathbf{u}_{k}}\left(\frac{\partial U}{\partial q} \cdot \frac{\partial q}{\partial \mathbf{u}_{j}}\right)
$$

The tangent stiffness of the present beam-column element with element load effect can then be written in Eq. 20, which relates the incremental deformation to the corresponding external loads imposed on an element in the member coordinate.

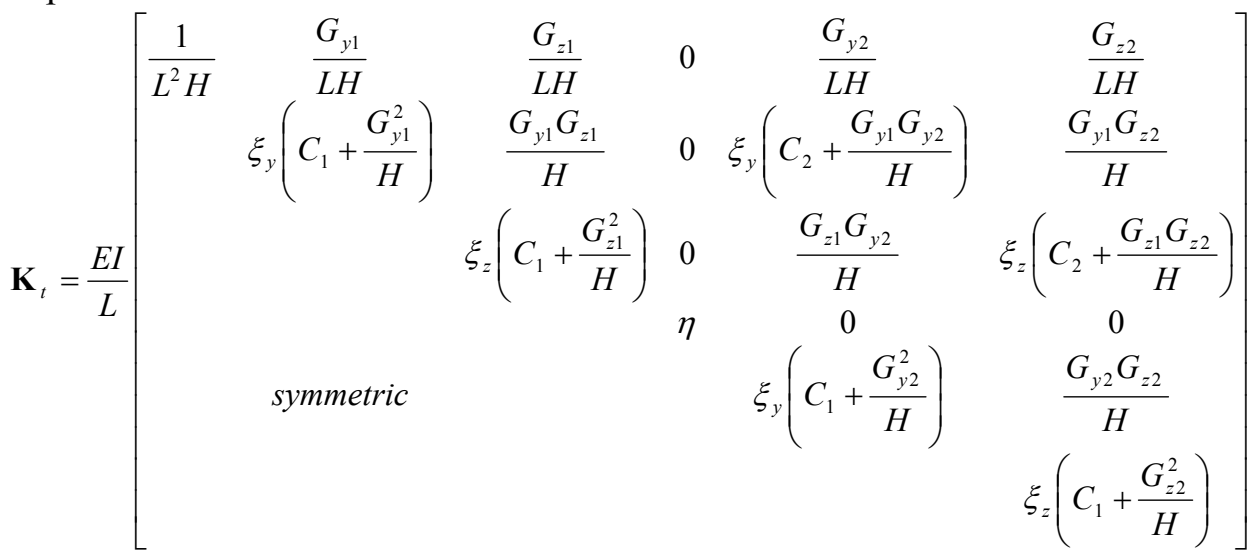

in which the coefficients $G_{n}$ and $H$ expressed in the tangent stiffness formulation in Eq. 20 are shown in the Appendix I. $I$ is the second moment of inertia about the axis in which the buckling effect is considered. Also $\xi_{z}=I_{z} / I$ and $\xi_{y}=I_{y} / I$. The tangent stiffness matrix should assemble and transform into global coordinate as written in Eq. 21, as the incremental nodal displacements of a structure can then be obtained by tangent stiffness relationship.

$$
\mathbf{K}_{T}=\sum_{\text {elements }} \mathbf{L} \mathbf{K}_{e} \mathbf{L}^{\mathrm{T}}=\sum_{\text {elements }} \mathbf{L}\left(\mathbf{T}^{\mathrm{T}} \mathbf{K}_{t} \mathbf{T}+\mathbf{N}\right) \mathbf{L}^{\mathrm{T}}
$$

in which $\mathbf{T}$ is transformation matrix relating the member forces to element force in local coordinate. $\mathbf{L}$ is the transformation matrix from local ordinate to global coordinate. And $\mathbf{N}$ is a stability matrix to allow for the work done of rigid body motion. 


\section{SYSTEM SOLUTION PROCEDURES}

For being well-formulated to yield the accurate solutions, the fundamental physical laws must incorporate to govern behaviour of a structure properly; they are force equilibrium equation, compatibility condition and material law, which can be accounted for at the system level when resorted to the numerical method (nodal solution). To evaluate the nonlinear elastic behaviour of a structure, the equilibrium solution at the nodes within $\Delta \lambda$ load factor can be given as,

$\Delta \mathbf{f}^{n}=\mathbf{f}^{n}-\mathbf{R}_{i}^{n}=\mathbf{K}_{T} \Delta \mathbf{u}_{i}^{n}$,

with which the law of compatibility condition of a structural system is complied. And the elastic material law is embodied in the stiffness formulation, i.e. $\mathbf{K}_{T}$. Therefore, the total nodal deformations can be written as,

$\Delta \mathbf{u}_{i}^{n}=\mathbf{K}_{T}^{-1} \Delta \mathbf{f}^{n} ; \mathbf{u}_{i+1}^{n}=\mathbf{u}_{i}^{n}+\Delta \mathbf{u}_{i}^{n}$

The nodal element resistance can be evaluated either dependent of total deformations $\mathbf{u}_{i+1}^{n}$ as written,

$\overline{\mathbf{u}}_{i+1}^{n}=\mathbf{L}^{T} \mathbf{u}_{i+1}^{n} ; \overline{\mathbf{R}}_{i+1}^{n}=\mathbf{K}_{s} \overline{\mathbf{u}}_{i+1}^{n} ; \mathbf{R}_{i+1}^{n}=\mathbf{L} \overline{\mathbf{R}}_{i+1}^{n}$

in which $\overline{\mathbf{u}}_{i}^{n}$ and $\overline{\mathbf{R}}_{i}^{n}$ are respectively total deformations and nodal element resistance at element level. The unbalanced force at $n$-th load increment is therefore obtained as,

$\Delta \mathbf{f}^{n}=\mathbf{f}^{n}-\mathbf{R}_{i+1}^{n}$

The above process is repeated until the unbalanced forces $\Delta \mathbf{f}^{n}$ at the nodes are eliminated, and the next $(n+1)$-th load increment $\mathbf{f}^{n+1}$ as given in Eq. 29 should begin until numerical instability.

$\mathbf{f}^{n+1}=\mathbf{f}^{n}+\Delta \lambda \mathbf{f}$

By satisfying these three conditions at global system level, the solutions of deformations $\mathbf{u}_{i+1}$ and element resistances $\mathbf{R}_{i+1}$ at equilibrium point can be attained at the nodes of the elements at global system level only, and no accurate element solutions at element level can be secured according to the above system solution procedures. Therefore, the system solution procedures alone do not suffice to yield the accurate element solutions. On contrary, the present higher-order element, which satisfies all three conditions of physical law at element level, enables to replicate the accurate firstand second-order elastic element solutions.

For the sake of applicability, the principle of superposition is favourably applied. To this end, the element loading distribution is converted into a single loading magnitude (i.e. $\bar{M}_{0} \& \bar{S}_{0}$ ) at mid-span in order to provide the initial perturbation for triggering the second-order member bowing effect due to its transverse element loads. In other words, this approach is a trade-off between the distribution of element load effect and the generality of a plethora of element stiffness under a diverse kind of element load cases. Meanwhile, the magnitude of both equivalent moment $\bar{M}_{0}$ and shear $\bar{S}_{0}$ components are updated to corresponding load level as Eq. 29 according to load factor $\Delta \lambda$ to measure the second-order member bowing effect commensurate at each specific load level. 


\section{VERIFICATION EXAMPLES}

The objective of this paper is on the accurate element solutions together with the nodal behaviour, which are compared with the nodal solution from the others. Hence, the ranges of the validity of the proposed numerical analysis are on the second-order elastic displacements and forces including the large deformation, P- $\delta \&$ P- $\Delta$ effect, snap-through buckling behaviour, are numerically exemplified through several examples, which were reported by independent studies. Finally, the side-track application by using this GELM is the initial imperfection as shown in this Section.

\subsection{Second-order Member Bowing effect (P- $\delta$ effect)}

\subsubsection{Superposition principle valid in second-order member bowing effect}

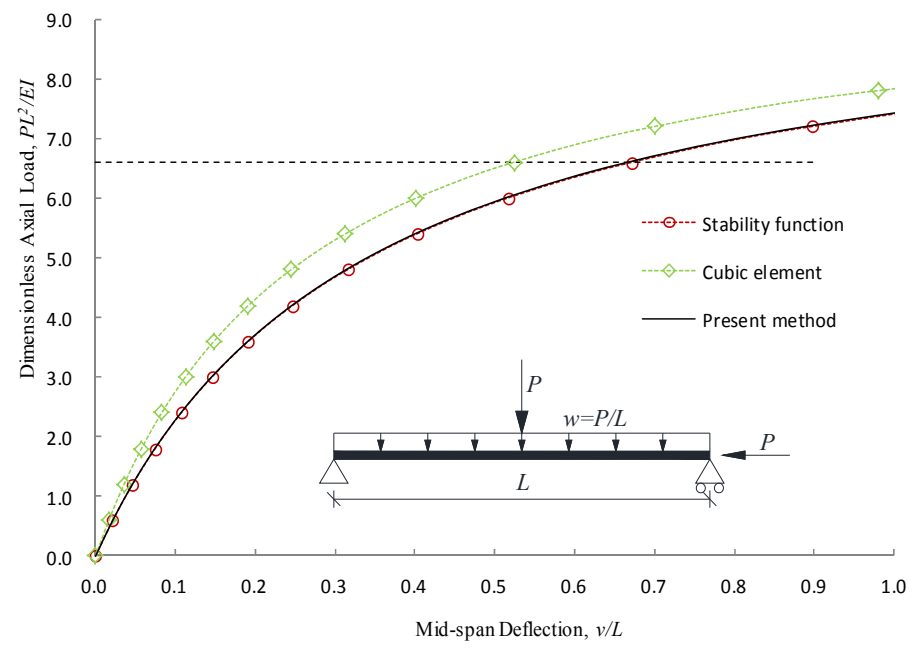

Figure 1. Second-order Bowing Effect of a Simple Supported Element under Element Combined Load

The present example exemplifies second-order member bowing effect on a simple supported element subjected to combination loads of uniform distributed load and point load. And, eventually, it leads to profound implication of using superposition principle for load combination, which can facilitate its application without loss of accuracy. The nonlinear solution procedure of incorporating element load effect in the second-order behaviour using superposition principle is studied.

Figure 1 indicates the mid-span deflection of an element using different approaches subjected to the load combination and axial compression. Similarly, present method can well capture the first-order bending due to element load and second-order coupling effect between element load and axial compression. Further, the element displacement and force solutions at highly second-order regime, which is illustrated in Figure 1 by horizontal dashed line, are well represented by the present method as shown in Figures 2 \& 3, respectively. 


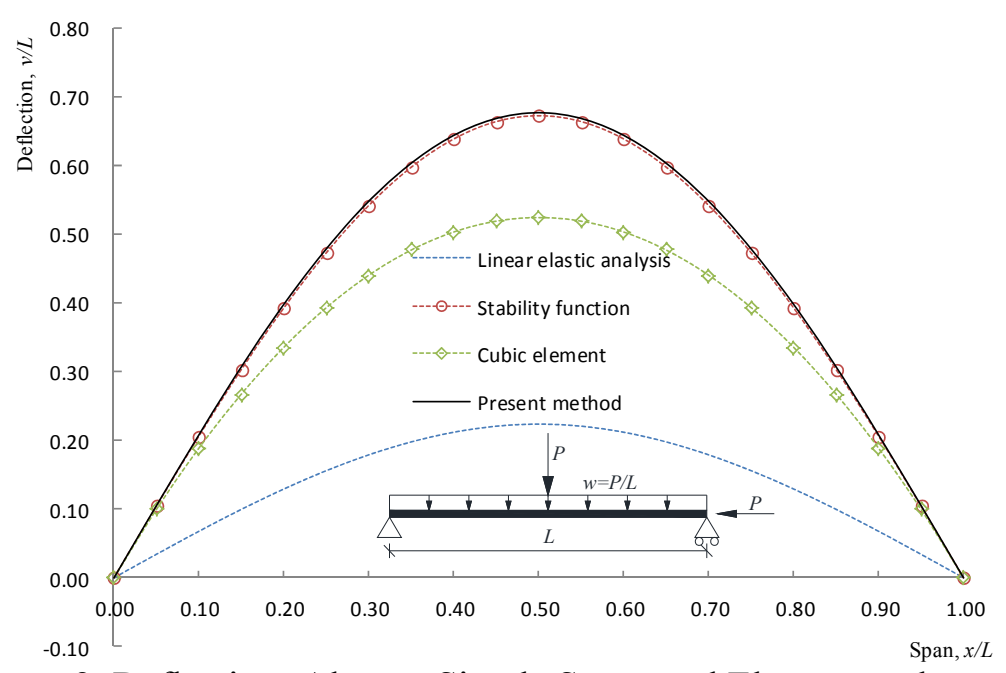

Figure 2. Deflections Along a Simple Supported Element under Combined Load Subjected to P- $\delta$ Effect

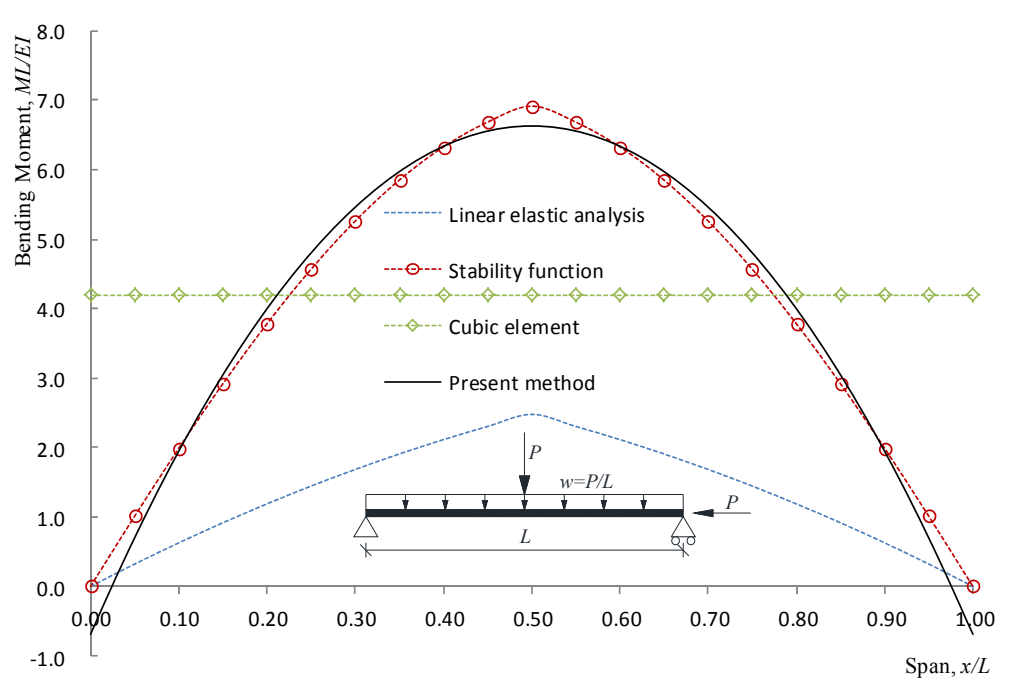

Figure 3. Bending Moment Along a Simple Supported Element under Combined Load Subjected to P- $\delta$ Effect

In conclusion, the present method can achieve the high level of accuracy in element deflection at all ranges particularly. Moreover, the profound insight of this example is that the superposition principle is valid to evaluate the second-order coupling P- $\delta$ effect due to the element loads. The present higher-order element function can therefore generalize and replace the multiplicity of the stability functions with particular element load cases. In addition, the present higher-order continuous function can reproduce the various kinds of element solution subjected to various element loads, even the discontinuous point load and their combination load case. It is noteworthy that there is a trivial bending moment at pinned end. This inaccuracy is attributed to that no force equilibrium condition is enforced at the element nodes at element level. Under this circumstance, the nodal force solution can be adopted at the supports instead. 


\subsection{Large Deformation Behaviour}

\subsubsection{Large deformation of a simply supported element under uniform load}

This example aims at validating the capacity of the present element load method to capture the large deformation of a structure, including the deformations and load distribution along an element. A simple supported beam under uniform load is studied as shown in Figure 4, whose mid-span deflection and end nodal axial displacement are also plotted against the load factor $\lambda$. And the load level $P$ is $10 \mathrm{kN}$ and the dimensions and sections of the element are normalized as the previous examples. In this example, the present method is compared with others, including NIDA [16] and $\mathrm{Iu}$ and Bradford. The axial deformation and mid-span deflection among all three methods are very consistent as shown in Figure 4, at which the axial deformation less stiffen at about load level 1kN, and when the deformations of an element becomes outstanding, the element stiffens in terms of both axial deformation and mid-span deflection; obviously the mid-span deflection decreases significantly compared to the axial deformation. It means the resistance of an element against the transverse load relies on the axial stiffness due to large geometry change instead of bending action. It in turn heralds to release the reserve of strength of an element. Therefore, the present method is capable of capturing the large deformation behaviour, such as the catenary action. However, it is noteworthy to remark that the present method exploits 4 elements, whereas NIDA [16] and Iu and Bradford [3][4] use 4 and 8 elements, respectively. It is impossible to base on an element to reproduce the large deformation behaviour of a member no matter which numerical method or the finite element in the open literature is resorted to, because the axial component of an element cannot render to any transverse component without recourse to the transformation system, even though the terms $b_{m 2} \bar{M}_{0}^{2}$ and $b_{s 2} \bar{S}_{0}^{2} L^{2}$ in Eq. 12 of the present method can contribute to the axial component solely due to transverse loads that are absent from other approaches. These axial components cannot be transformed into transverse components effectively by the element itself under this circumstance. It means the transverse load is impossibly taken by the axial resistance of an element, even when the deformations of an element become prominent. All axial components can only align along with the element, not in transverse direction, because the transformation of an element is merely formulated from two end nodes straightly. Hence, Figures $5 \& 6$ shows one present element can only simulate the linear elastic deflection and bending moment solutions, respectively.

Figures $5 \& 6$ illustrate the deflection and bending moment distribution along a simple supported beam at load level $9 \mathrm{kN}$, which is also indicated at Figure 4 by the horizontal dashed line. In regard to the large deformation behaviour, 4 present higher-order elements are required to achieve the same accuracy of Iu and Bradford [3][4] when using 8 elements.

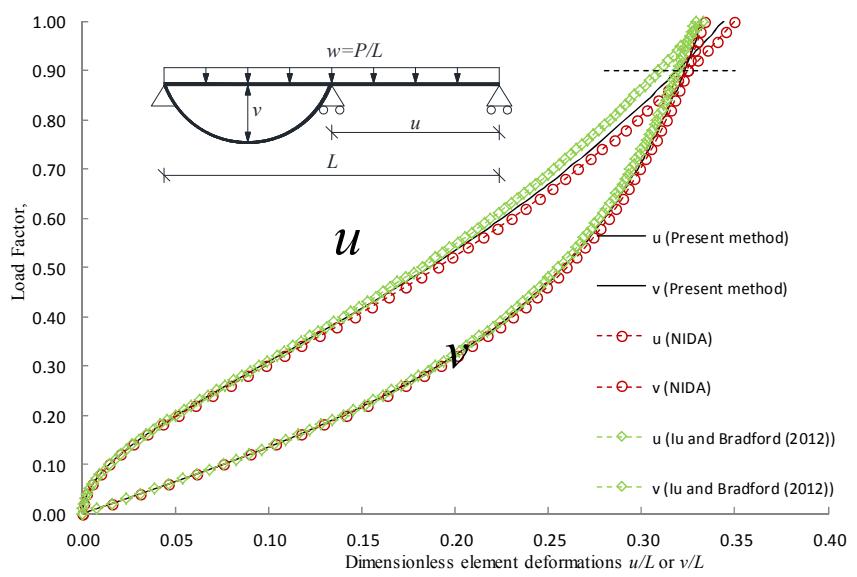

Figure 4. Large Deformation of a Simple Supported Element under Uniform Load 


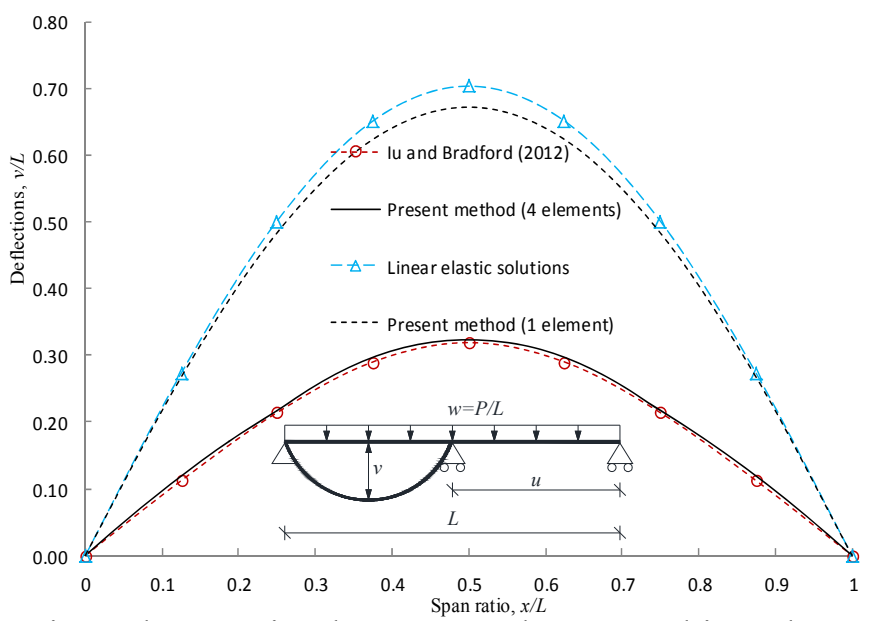

Figure 5. Deflections along a Simple Supported Beam Subjected to Large Deformation

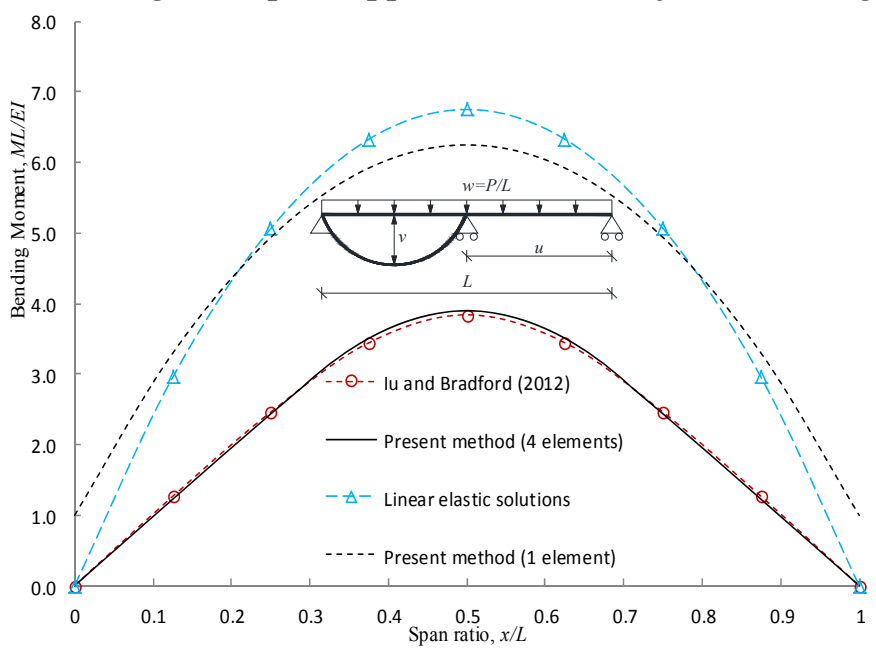

Figure 6. Bending Moment along a Simple Support Beam Subjected to Large Deformation

\subsection{Second-order Sway Effect (P- $\Delta$ effect)}

\subsubsection{A cantilever subjected to uniform element load and axial compression}

A cantilever is subjected to both transverse uniform distributed load, i.e. $10 \mathrm{kN} / \mathrm{m}$, and axial compression as given in Figure 7, and subsequently undergoes the P- $\Delta$ effect. On the basis of the numerical methods (including NIDA and present method), the load-deflection curves of the nodal axial $u_{L}$ and transverse $v_{L}$ deformations at tip are plotted in Figure 7, as well as the mid-span transverse deformation $v_{L / 2}$ of the cantilever is given in Figure 7. It should be noted that the mid-span transverse deformation $v_{L / 2}$ from NIDA (using 2 elements) is nodal solution, which is compared with the element solution from the present method. In Figure 7, the present method (1 element) is very consistent with the NIDA ( 1 element) in terms of all deformations. However, there is some discrepancy of the load-deflection curves from the present method ( 1 element) and NIDA (2 elements); especially the axial deformation after the buckling load at about 1.5 and at the post-buckling regime, when the cantilever exhibits axial stiffening due to catenary action. In general, all results from both approaches in terms of axial and transverse deformations are consistent. 


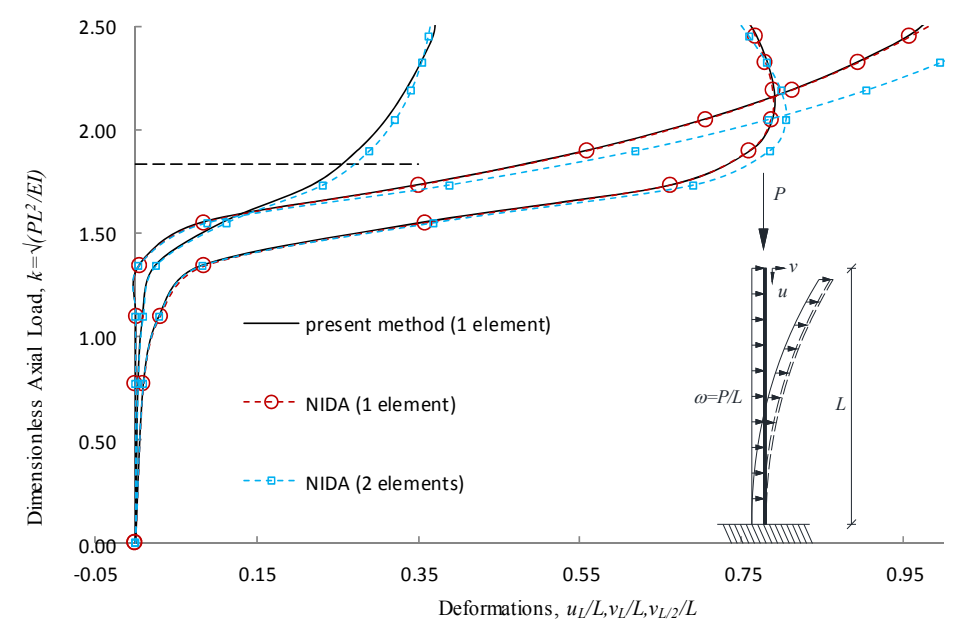

Figure 7. P- $\Delta$ Effect on a Cantilever with Uniform Distributed Load and Axial Compression

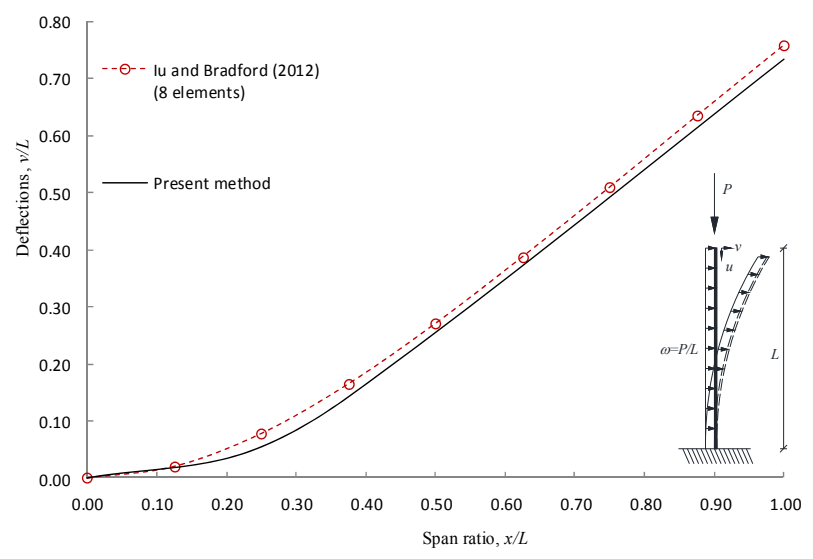

Figure 8. Deflections along a Cantilever Subjected to P- $\Delta$ Effect

In regard to the element displacement and force solutions, Figures 8 and 9 display the deflection and bending moment distribution along a cantilever at a specific level 1.83 (load factor $\lambda=0.56$ ), which is indicated by dash line in Figure 7. Similarly, the element responses, such as deflection and bending moment as respectively shown in Figures $8 \& 9$, from the present method are consistent with the nodal solutions from those of Iu and Bradford [3][4]. It is interesting to note that the rigid body motion is taken into account for P- $\Delta$ effect, whereas the bending moment is directly generated from the natural deformation of an element, such as its curvature. And the bending moment at the mid-span of an element is more accurate than other locations as noted and explained in [Iu [15]]. Further, it is remarked that this structure encounters the large deflection as well. Hence the example can also demonstrate that one proposed element is adequate to replicate the large deformation behaviour. 


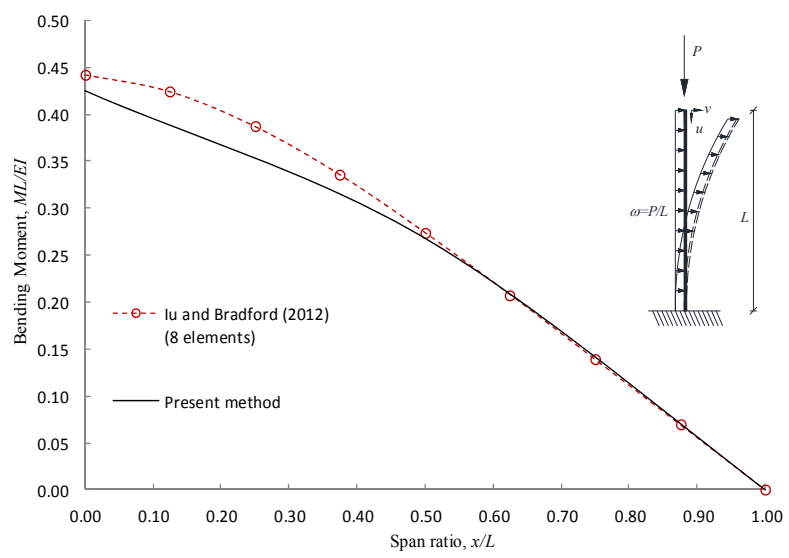

Figure 9. Bending Moment along a Cantilever Subjected to P- $\Delta$ Effect

\subsubsection{A simple portal sway frame subjected to vertical uniform load only}

A portal frame subjected to distributed uniform load $\omega=10 \mathrm{kN} / \mathrm{m}$ is studied, of which the columns have an initial inclination of $\psi=1 / 200$ and the geometry and the properties are depicted in Figure 10. This example can verify the sway effect (P- $\Delta$ effect) of a portal frame. The lateral nodal displacement of the sway frame is normally of great concern for P- $\Delta$ effect, and hence the element solutions of the members are always ignored under this circumstance. Therefore, this example exemplifies the element displacements including the rigid body motions as well as the bending moment distribution of all members. The lateral nodal displacements $u_{L}$ of the frame and element deflections $v_{L / 2}$ at mid-span of the beam are plotted in Figure 10. In order to generate the accurate mid-span deflection of the beam, NIDA discretises the beam into 2 elements, whereas Iu and Bradford [3][4] makes use of 4 elements for each member, which implies the mid-span deflections are transformed into the nodal displacement from these approaches. Conversely, the present method relies on 1 element for each member to cater for both lateral nodal displacements $u_{L}$ of a frame and vertical element mid-span deflection $v_{L / 2}$ of the beam. Figure 10 shows all displacements are very consistent with each other. It is emphasized that the element solution (mid-span deflection $v_{L / 2}$ ) from the present method can reach a good agreement with the nodal solution of both approaches from linear to second-order ranges before the numerical divergence at $\lambda=2.8$. It also remarks that the mid-span deflection $v_{L / 2}$ of the beam is well predicted by the linear elastic solutions $\Delta_{\mathrm{v}}$ in Figure 10 till $\lambda=2.5$; especially the mid-span deflection $\nu_{L / 2}$ increases considerably at $\lambda=2.6$ because of the $\mathrm{P}-\Delta$ effect.

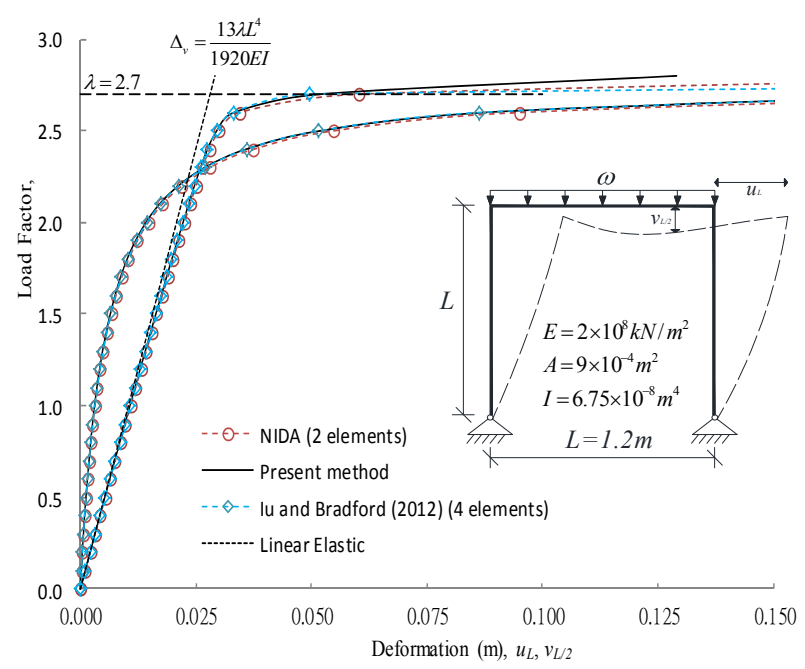

Figure 10. Mid-span Deformations of a Transversely Loaded Beam at the Sway Portal Frame 


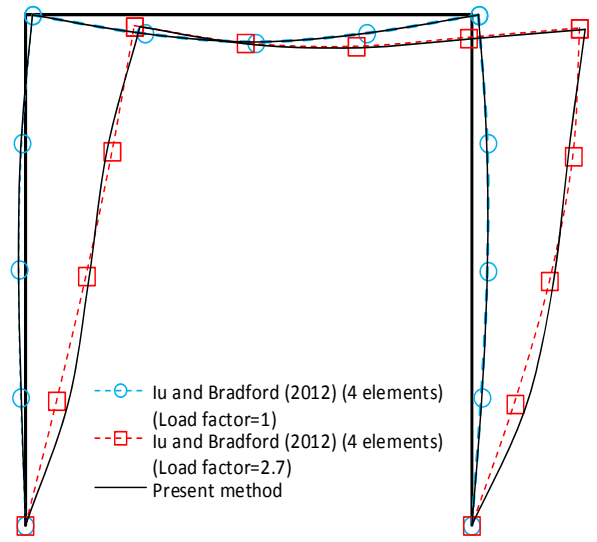

Figure 11. Deflection Shapes of the Sway Frame from Various Methods at $\lambda=1$ and $\lambda=2.7$

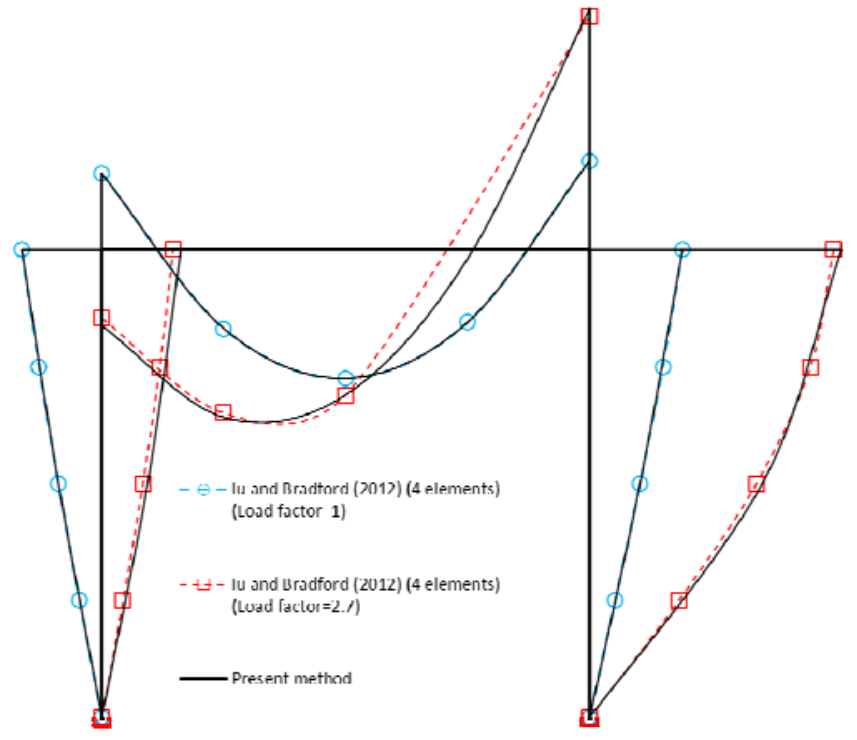

Figure 12. Bending Moments of the Sway Frame from Various Methods at $\lambda=1$ and $\lambda=2.7$

Figures 11 and 12 respectively illustrate the element solutions in terms of displacement and bending moment of all members of the sway frame at different load levels. In Figure 11, the element displacements (i.e. $\lambda=1$ ) from the present method are exactly same as the nodal displacements from the Iu and Bradford [3][4]. However, at $\lambda=2.7$, the deflections of the columns of the frame emerge slight discrepancy with the nodal solutions from Iu and Bradford [3][4] as given in Figure 11, which can be attributed to the solutions near the numerical instability at divergence. The accuracy of element solution is, however, still regarded to be reasonable. Similarly, the present method can generate the accurate bending moment along an element by itself, especially at its mid-span, when compared to those nodal solutions obtained from Iu and Bradford [3][4] as illustrated in Figure 12, but the discrepancy become obvious at load level $\lambda=2.7$.

\subsection{Snap-through, Pre- and Post-buckling}

\subsubsection{A toggle frame subjected to the uniform distributed element load}

A two-bar toggle frame, which originates from Williams [17] under a point load at its apex, was modified by Zhou and Chan [9][10] for the study of the snap-through buckling behaviour being influenced by uniformly distributed element load $\omega=1 \mathrm{kN} / \mathrm{m}$ in global axis as given in Figure 13. Its 
boundary condition, properties and geometry are depicted in Figure 13. This frame is used for validating the capacity of the present method to capture the snap-through, pre- and post-buckling responses of a member due to element load effect using one sophisticated higher-order element, in which the pre-buckling behaviour is regarded as the combination of P- $\delta$ and P- $\Delta$ effects; snap-through buckling is referred to the stiffness deterioration transit between pre- and post-buckling; post-buckling associates with the large deformation behaviour.

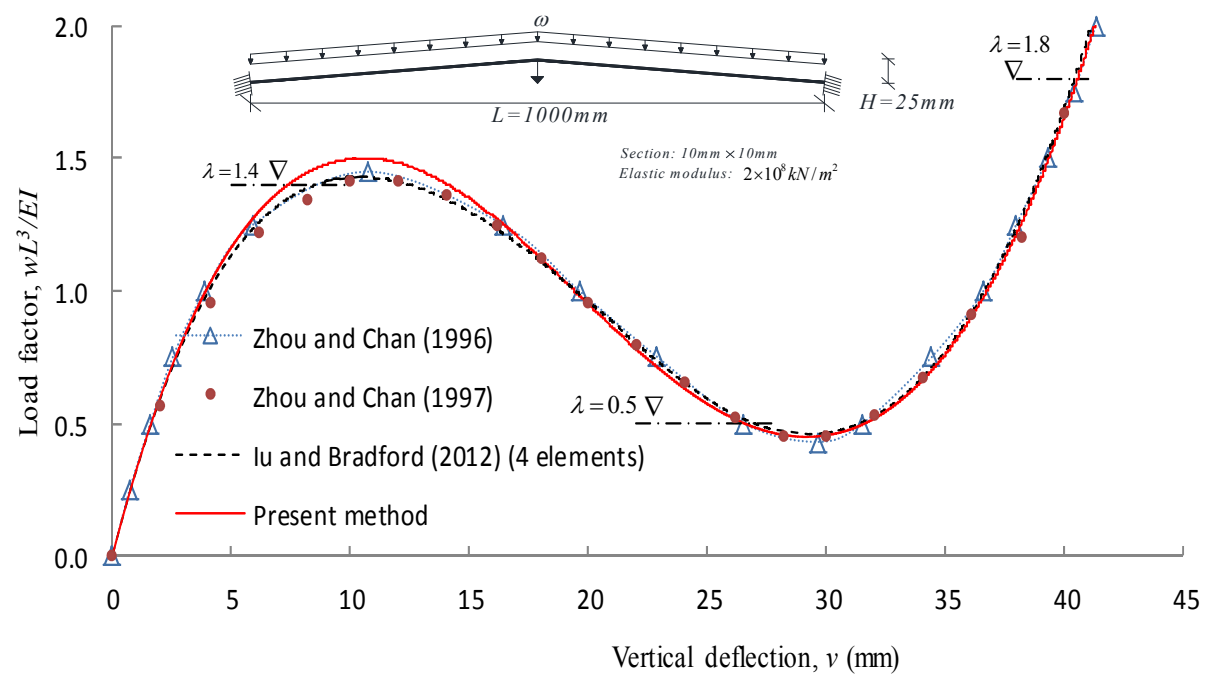

Figure 13. Load-deflection Curve at Top of Toggle Frame

The deflection at the top of toggle frame against the dimensionless load factor $\lambda=\omega L^{3} / E I$ is plotted in Figure 13 by using 4 elements for a member (Iu and Bradford [3][4]), which is well matched in all ranges by Zhou and Chan [9][10]. The present element load method using one element per a member cannot seamlessly replicate the accurate pre-buckling response of the toggle frame. The ultimate pre-buckling load is at $\lambda=1.5$ by virtue of the present method, whereas the pre-buckling load are at $\lambda=1.43$ and 1.45 from Iu and Bradford [3][4] and Zhou and Chan [9], respectively. Its accuracy is within the acceptable degree for engineering application. Apart from the pre-buckling regime, the snap-through and post-buckling behaviour of the toggle frame reach a good agreement with each other as shown in Figure 13. It is important to note that the disparity in pre-buckling behaviour may be attributed to the element load distribution being very sensitive to the pre-buckling behaviour, while the effect of element load distribution is converted into the single load magnitude of equivalent element load terms, such as $\bar{M}_{0}$ and $\bar{S}_{0}$, and therefore this effect is ignored in the higher-order element stiffness formulation.

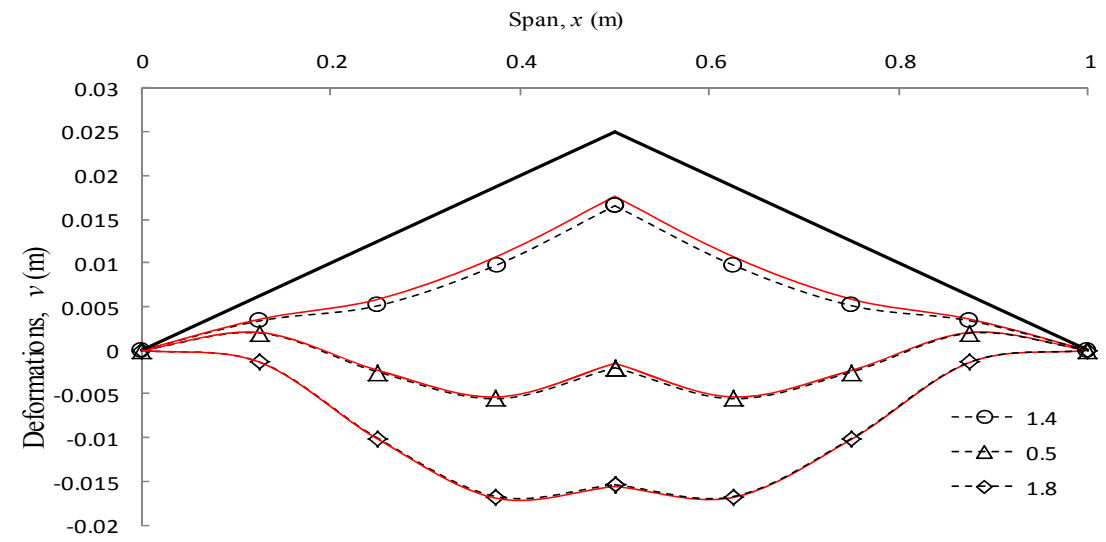

Figure 14. Deflection Shapes of Toggle Frame from Present Method and Iu and Bradford (2012) 
at $\lambda=1.4, \lambda=0.5$ and $\lambda=1.8$

Figure 14 demonstrates that the present method using one element generates continuous element displacement solution of a member at different load factors as indicated by the solid lines, i.e. $\lambda=1.4$ (pre-buckling), $\lambda=0.5$ (snap-through buckling) $\& \lambda=1.8$ (post-buckling), at which is also illustrated in Figure 13 by the dash-dot lines at respective levels. On the other hand, Iu and Bradford [3][4] produces the element deflections of a member by reliant on the nodal displacements as indicated by the dash lines with symbols in Figure 10. The accuracy of element deflection distributions among them is very consistent.

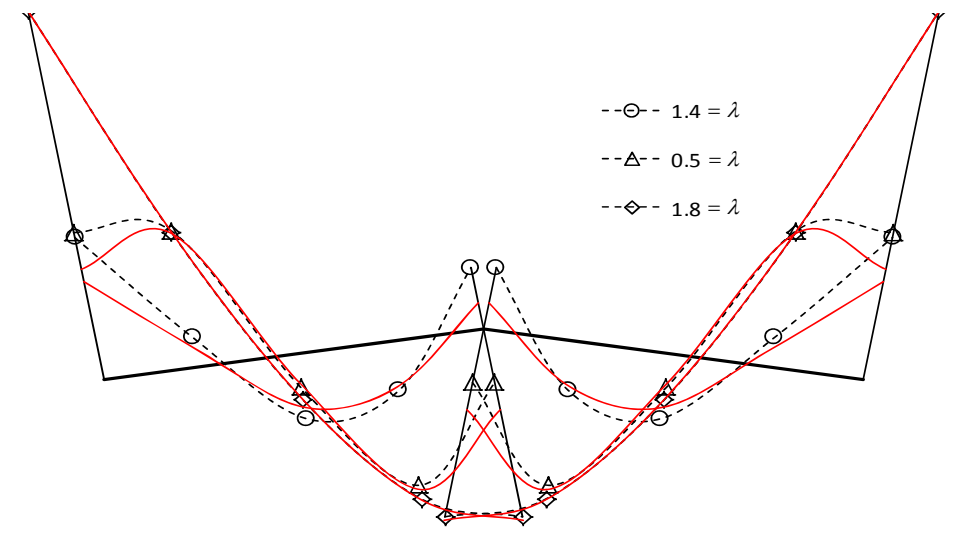

Figure 15. Bending Moments of Toggle Frame from Present Method and Iu and Bradford (2012) at $\lambda=1.4, \lambda=0.5$ and $\lambda=1.8$

Similarly, the element solutions in bending moment from the present method (solid lines) and $\mathrm{Iu}$ and Bradford [3][4] (dash lines with symbols) are given in Figure 15. The bending moment at the post-buckling level $(\lambda=1.8)$ from the present method is very consistent with those from Iu and Bradford [3][4]. The distribution of bending moment at other load levels ( $\lambda=1.4 \& 0.5)$ are also reasonably consistent between both methods.

\subsection{Geometrical Initial Imperfection}

\subsubsection{Application of element load method for the imperfection of a member}

According to Eurocode 3 [18], the assumed local imperfection of an element may be replaced by an equivalent transverse element load. In this sense, the present method can be extended to provoke the additional application to incorporate the initial imperfection along an element, which can degrade the stiffness of an element and trigger the member bowing effect prematurely. A dummy uniform distributed element load is imposed to include the local imperfection of an element, whose magnitude $\alpha_{0}$ in turn represents the geometrical initial imperfection $e_{0}$. Hence, larger dummy load magnitude $\alpha_{0}$ enables to cover larger allowance of geometrical imperfection $e_{0}$ of an element, of which the capacity of an element in deflection and internal moment resistance is deteriorated by the imperfection. For example, the buckling curves $a, a, b, c$ and $d$ in Eurocode 3 [18][17]. In principle, different $\alpha_{0}$ can represent the corresponding buckling curves in the various design codes. A column having the equivalent initial imperfection $\alpha_{0}=0.01,0.02$ and 0.05 is under axial compression $P=10 \mathrm{kN}$, of which the mid-span deflection and bending moment are plotted in Figs. 16 and 17, respectively. They can be seen that the larger equivalent imperfection $\alpha_{0}$ can stand for the larger buckling curves (i.e. $c$ or $d$ ). Both Figures $16 \& 17$ demonstrate the deterioration of capacities when the equivalent imperfection becomes larger, but also approach to their elastic critical buckling load factor $\lambda_{E}=0.164$. 


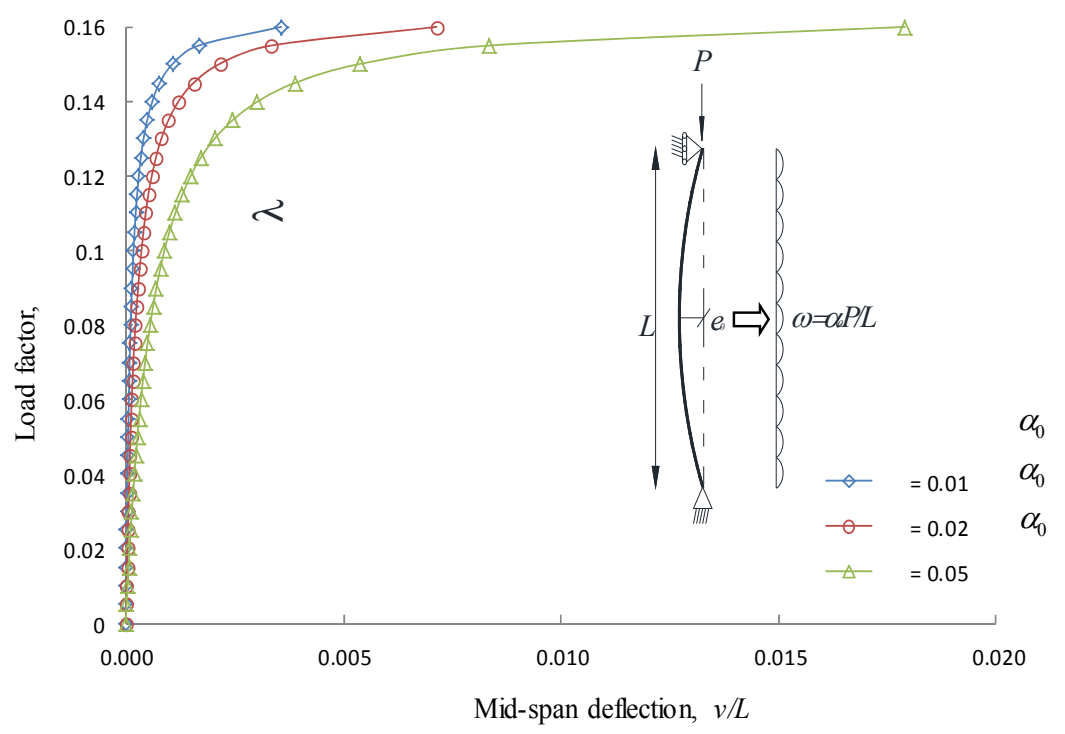

Figure 16. Deflection of a Column with Various Initial Imperfection $\alpha_{0}$

It is noteworthy that, in numerical modelling viewpoint, if a perfect straight element is under axial compression, the flexural buckling behaviour can never be produced by that element because of no transverse component to trigger the second-order bowing effect. On the other hand, the incorporating equivalent imperfection $\alpha_{0}$ through the GELM can allow for the modelling of flexural buckling using one-element-per-member approach. Hence no special consideration in the numerical modelling is required to capture second-order bowing effect, and thereby the present element facilitates the modelling preparation in the practical design.

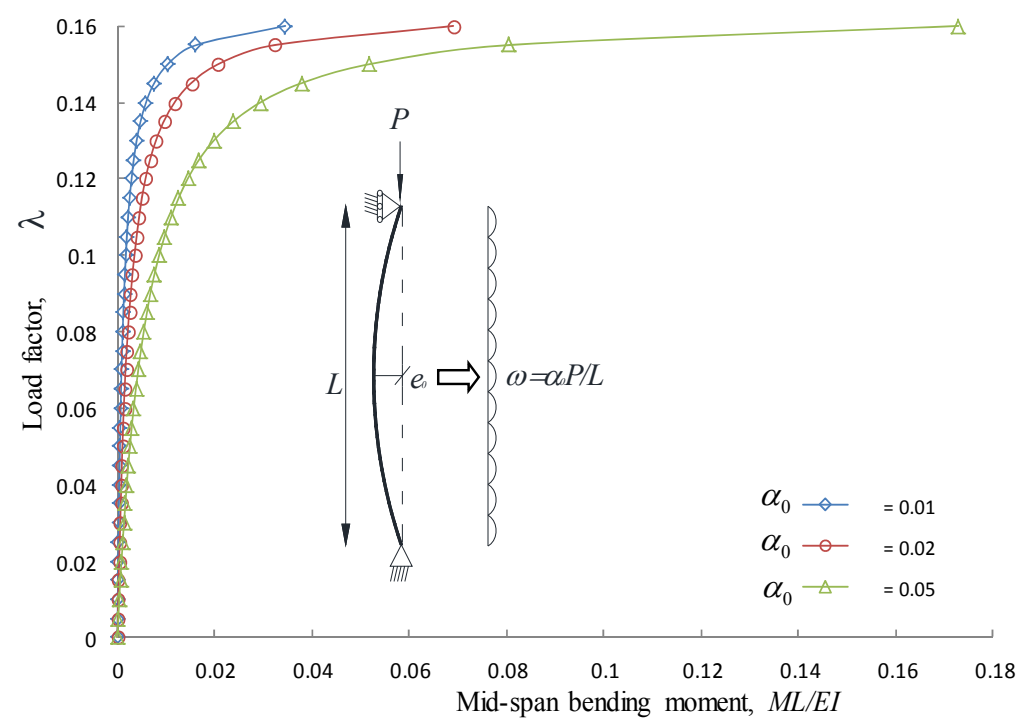

Figure 17. Bending Moment of a Column with Various initial imperfection $\alpha_{0}$ 


\section{DISCUSSIONS AND CONCLUSIONS}

There are a few emphases from this paper as below;

- Superposition principle valid in nonlinear solution procedure

The significant impact of this study is to impose the superposition principle as proved in this paper in order to generalise and unify the myriad of element load scenarios inherent in the standardised element stiffness formulation, e.g. Eqs. (8) to (12). In principle, this approach trades off the distribution of element load effect for the generality in element stiffness for a diverse kind of element load cases. In this sense, the distribution of element load is converted into a single magnitude of element load at mid-span of a sophisticated higher-order element. It leads to the same form of the element stiffness but various magnitudes of element load components (i.e. $\bar{M}_{0} \& \bar{S}_{0}$ ) for various element load scenarios, which is succinctly customized from individual load case in the advent of nonlinear solution procedures. These element load components are then updated through the system solution procedures so that the second-order equilibrium path due to the coupling element load effect and the axial load can be traced successfully.

- Inaccuracy in element load solution if sensitive to the element load distribution

This paper shows that the effect of the element load distribution is not sensitive to the typical buckling problem (i.e. P- $\delta$ effect) and thereby the application of superposition principle is valid. However, the slight discrepancy of the load-deflection relation is observed in the snap-through buckling behaviour, but still within the adequate level of accuracy in the engineering applications.

- $\quad$ Superiority over other low- and higher-order element approaches

A) When the lower-order element function (e.g. cubic element or hierarchic h-version element) is exploited, the nonlinear equilibrium equation of a member must be linearized by dividing into a few low-order elements as known the element discretization. Moreover, the accuracy of the solutions by using the low-order element is inevitably restricted to the nodes. B) When the higher-order element, which is so-called one-element-per-member approach, is used to derive the higher-order element stiffness formulation that is adequate to solve the nonlinear equilibrium equation of a member by element itself. However, similarly the accurate element load solutions are resulted in at nodes only, because of no element load effects being incorporated into its stiffness formulation. C) On the other hand, the present approach extends the accurate solutions to both (discrete) nodal and (continuous) element solutions in both displacement and force fields. It heralds the element load solutions from the higher-order element formulation (generalised element load method - GELM) are commensurate with nodal solutions from the system analysis reasonably.

In summary, the present approach can possess robust capability of modelling the first- and second-order behaviour in terms of both nodal and element displacement and force solutions, which includes $\mathrm{P}-\delta$ and $\mathrm{P}-\Delta$ effect, large deformation behaviour, snap-through buckling, pre- and post-buckling and geometrical initial imperfection. In short, this paper can be therefore evolved into a unified method to yield accurate whole-domain (i.e. nodal and element) solutions of all kinds (i.e. displacement and force) under most regimes (i.e. first- and second-order elastic ranges), subjected to numerous element load scenarios. As a result, this GELM can ensure the reliable design (thanks to whole-domain accuracy under most regimes) of any civil engineering structure at the ultimate and serviceability limit states simultaneously (thanks to both fields solutions), especially indispensable to the one-element-per-member approach. 


\section{REFERENCES}

[1] Meek, J.L. and Tan, H.S., "Geometrically Nonlinear Analysis of Space Frames by An Incremental Iterative Technique", Computer Methods in Applied Mechanics and Engineering, 1984, Vol. 47, pp. 261-281.

[2] Chan, S.L. and Kitipornchai, S., "Geometric Nonlinear Analysis of Asymmetric Thin-walled Beam-columns", Engineering Structures, 1987, Vol. 9, pp. 243-254.

[3] Iu, C.K. and Bradford, M.A., "Higher-order Non-linear Analysis of Steel Structures Part I: Elastic Second-order Formulation", Advanced Steel Construction, 2012a, Vol. 8, No. 2, pp. 168-182

[4] Iu, C.K. and Bradford, M.A., "Higher-order Non-linear Analysis of Steel Structures Part II: Refined Plastic Hinge Formulation”, Advanced Steel Construction, 2012b, Vol. 8, No. 2, pp. 183-198.

[5] Chan, S.L. and Zhou, Z.H., "Pointwise Equilibrating Polynomial Element for Nonlinear Analysis of Frames", Journal of Structural Engineering, ASCE, 1994, Vol. 120, No. 6, pp. 1703-1717.

[6] Chan, S.L. and Zhou, Z.H., "Second-order Elastic Analysis of Frames Using Single Imperfect Element Per Member”, Journal of Structural Engineering, ASCE, 1995, Vol. 121 No. 6, pp. 939-945.

[7] Izzuddin, B.A., "Quartic Formulation for Elastic Beam-columns Subject to Thermal Effects", Journal of Engineering Mechanics, ASCE, 1996, Vol. 122, No. 9, pp. 861-871.

[8] Iu, C.K. and Bradford, M.A., "Second-order Elastic Finite Element Analysis of Steel Structures Using a Single Element Per Member”, Engineering Structures, 2010, Vol. 32, pp. 2606-2616.

[9] Zhou, Z.H. and Chan, S.L., "Refined Second-order Analysis of Frames with Members under Lateral and Axial Loads", Journal of Structural Engineering, ASCE, 1996, Vol. 122, No. 5, pp. 548-554.

[10] Zhou, Z.H. and Chan, S.L., "Second-order Analysis of Slender Steel Frames under Distributed Axial and Member Loads", Journal of Structural Engineering, ASCE, 1997, Vol. 123, No. 9, pp. 1187-1193.

[11] Neuenhofer, A. and Filippou, F.C., "Evaluation of Nonlinear Frame Finite-element Medels", Journal of Structural Engineering, 1997, ASCE, Vol. 123, No. 7, pp. 958-966.

[12] Neuenhofer, A. and Filippou, F.C., "Geometrically Nonlinear Flexibility-based Frame Finite Element", Journal of Structural Engineering, 1998, ASCE, Vol. 124, No. 6, pp. 704-711.

[13] Valipour, H.R. and Bradford, M.A., "Nonlinear P- $\Delta$ Analysis of Steel Frames with Semi-rigid Connections", Steel and Composite Structures, 2013, Vol. 14, No. 1, pp. 1-20.

[14] Iu, C.K. and Bradford, M.A., "Novel Non-linear Elastic Structural Analysis with Generalised Transverse Element Loads using Refined Finite element, Advanced Steel Construction, 2015, Vol. 11, No. 2, pp. 223-249.

[15] Iu, C.K., "Generalised Element Load Method for First- and Second-order Element Load Solutions", Engineering Structures, 2015, Vol. 92, pp. 101-111.

[16] Chan, S.L. and Zhou, Z.H., "On the Development of A Robust Element for Second-order "Nonlinear Integrated Design and Analysis" (NIDA), Journal of Constructional Steel Research, 1998, Vol. 47, pp. 169-190.

[17] Williams, F.W., "An Approach to the Non-linear Behaviour of Members of a Rigid Jointed Plane Framework with Finite Deflections, Quarterly Journal of Mechanics and Applied Mechanics, 1964, Vol. 17, No. 4, pp. 451-469.

[18] Eurocode 3: Design of Steel Structures - Part 1-1: General Rules and Rules for Buildings 2005. 


\section{APPENDIX I}

The terms $G_{\alpha i}(\alpha=y$ or $z, i=1$ or 2$)$ in Eq. 29 are:

$$
\begin{aligned}
& G_{\alpha 1}=\left\{\left[\frac{25600+4160 q / 7+92 q^{2} / 21+23 q^{3} / 1260}{(80+q)^{3}}\right]\left(\theta_{\alpha 1}+\theta_{\alpha 2}\right)\right. \\
&+\left[\frac{9216+1344 q / 5+132 q^{2} / 35+11 q^{3} / 420}{(48+q)^{3}}\right]\left(\theta_{\alpha 1}-\theta_{\alpha 2}\right) \\
&\left.+\left[\frac{-16 q}{35(48+q)^{3}} \bar{M}_{0}-\frac{16 q}{63(80+q)^{3}} \bar{S}_{0} L\right]\right\} \\
&=\frac{E I_{\alpha}}{L}\left\{2 b_{1}\left(\theta_{\alpha 1}+\theta_{\alpha 2}\right)+2 b_{2}\left(\theta_{\alpha 1}-\theta_{\alpha 2}\right)+b_{m 1} \bar{M}_{0}+b_{s 1} \bar{S}_{0} L\right\} \\
& G_{\alpha 2}=\left\{\left[\frac{25600+4160 q / 7+92 q^{2} / 21+23 q^{3} / 1260}{(80+q)^{3}}\right]\left(\theta_{\alpha 1}+\theta_{\alpha 2}\right)\right. \\
&-\left[\frac{9216+1344 q / 5+132 q^{2} / 35+11 q^{3} / 420}{(48+q)^{3}}\right]\left(\theta_{\alpha 1}-\theta_{\alpha 2}\right) \\
&\left.+\left[\frac{16 q}{35(48+q)^{3}} \bar{M}_{0}-\frac{16 q}{63(80+q)^{3}} \bar{S}_{0} L\right]\right\} \\
& H= \frac{I}{A L^{2}}-\sum_{\alpha=y, z}\left[b_{1}^{\prime}\left(\theta_{\alpha 1}+\theta_{\alpha 2}\right)^{2}+b_{2}^{\prime}\left(\theta_{\alpha 1}-\theta_{\alpha 2}\right)^{2}+b_{m 1}^{\prime}\left(\theta_{\alpha 1}-\theta_{\alpha 2}\right) \bar{M}_{0}\right. \\
&\left.\left.+b_{s 1}^{\prime}\left(\theta_{\alpha 1}+\theta_{\alpha 2}\right) \bar{S}_{0} L+b_{m 2}^{\prime}\right)-2 b_{2}\left(\theta_{\alpha 1}-\theta_{\alpha 2}\right)-b_{s 2}^{\prime} \bar{S}_{0}^{2} L^{2}\right]
\end{aligned}
$$

in which,

$$
\begin{aligned}
& b_{1}^{\prime}=-\left[\frac{102400 / 7+5120 q / 21}{(80+q)^{4}}\right] ; \\
& b_{2}^{\prime}=-\left[\frac{36864 / 5+3072 q / 35}{(48+q)^{4}}\right] ; \\
& b_{m 1}^{\prime}=-\left[\frac{768-32 q}{35(48+q)^{4}}\right] ; \\
& b_{m 2}^{\prime}=-\left[\frac{4 / 7+2 q / 105}{(48+q)^{4}}\right]
\end{aligned}
$$




$$
\begin{aligned}
& b_{s 1}^{\prime}=-\left[\frac{1280-32 q}{63(80+q)^{4}}\right] ; \\
& b_{s 2}^{\prime}=-\left[\frac{44 / 63+2 q / 315}{(80+q)^{4}}\right] .
\end{aligned}
$$





\title{
EXPERIMENTAL STUDY AND FINITE ELEMENT MODELLING OF PUSH-OUT TESTS ON A NEW SHEAR CONNECTOR OF I-SHAPE
}

\author{
Messaoud Titoum $^{1, *}$, Aida Mazoz ${ }^{1}$, Abdelkader Benanane $^{2}$ and Djamel Ouinas ${ }^{3}$ \\ ${ }^{1}$ Laboratory of Materials and Mechanics of Structures, University of M'sila 28000, Algeria \\ ${ }^{2}$ Laboratory of Materials and Processes of Construction, University of Mostaganem 27000, Algeria \\ ${ }^{3}$ Laboratory of numerical and experimental modelling of the mechanical phenomena, University of Mostaganem \\ 27000, Algeria \\ *(Corresponding author: E-mail: titoum65@yahoo.fr)
}

Received: 2 February 2016; Revised: 24 March 2016; Accepted: 26 March 2016

\begin{abstract}
In this paper, we present the results of experimental study and finite element modeling of the push-out tests on a new shear connector of I-shape. 24 push-out specimens with I-shape shear connectors were tested under a static loading in the Laboratory of Materials and Mechanics of Structures - LMMS at the University of M'sila, Algeria. The test specimens were designed to study the effect of the following parameters on the ultimate load capacity: the height of I-shape connector, the length of I-shape connector, the compressive strength of concrete and the number of transverse reinforcing bars. The load capacity, the ductility and the modes of failure were presented and discussed. Furthermore, a finite element modelling of the push-out tests was carried out using ANSYS software to investigate the stress distribution pattern in the area of the I-shape connector. Moreover, the finite element model was also used to simulate another type of shear connector, called channel connector in order to compare its behaviour with that of the I-shape connector. From this comparison, we suggested an equation for the prediction of the ultimate load capacity of I-shape shear connectors.
\end{abstract}

Keywords: Steel-concrete connection, I-shape shear connector, Push-out tests, F.E.M.

DOI:10.18057/IJASC.2016.12.4.7

\section{INTRODUCTION}

The shear connectors are commonly used to ensure composite action in a steel-concrete composite beam. Their main function is to resist longitudinal shear forces at the steel-concrete interface, and to prevent vertical separation between the concrete slab and the supporting steel beam. Many types of shear connectors have been developed and used in the past. The most widely used shear connector in practice is the welded stud (Figure 1(a)) with a suitable head that contributes to the shear transfer and prevents the uplift. Nevertheless, due to the small load carrying capacity of stud connectors and also due to the fatigue problems caused by live loads on composite bridges, some other alternative shear connectors are proposed such as the angle connector with anti-uplift bar (Figure 1(b)) and the channel connector (Figure 1(c)) which are frequently used in Algeria and in some other countries.

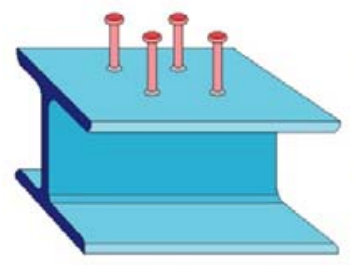

(a ) : Stud connector

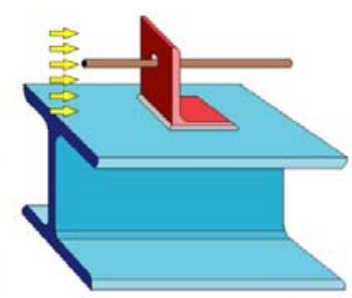

(b) : Angle connector

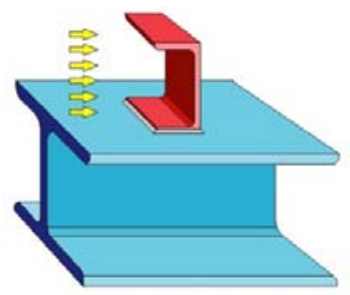

(c) : Channel connector

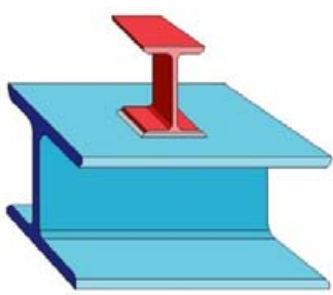

(d) I-shape connector

Figure 1. Types of Shear Connectors 
The economic considerations continue to motivate the development of new systems to ensure the load transfer between steel and concrete components in composite structures. Recently, several authors have proposed new types of shear connectors, such as Y-type perfobond rib connector [1], J-hook connector [2], Bolted connector [3], Rubber-sleeved stud [4], and V-shaped angle connector [5]. In this context, a new shear connector, called I-shape connector is proposed. As shown in Figure 1(d), the shape of this connector is appropriate to resist shear forces and prevent vertical separation between the steel beam and the concrete slab. In addition, angle and channel connectors [6] are limited to shear transfer in the recommended direction only, while the I-shape connector can resist and transfer shear in the two directions with same quantity, making it the more useful shear connector in composite beams subjected to seismic loading. Moreover, the facility of producing the I-shape connectors by their cutting from the ordinary laminated I profiles is another advantage. The welding task has the same characteristics as referred for angle and channel connectors.

A review of the literature indicates that any research work has been done to investigate the feasibility of using I-shape pieces as shear connectors. In this paper, we present the results of experimental study and finite element modelling of the push-out tests on a new shear connector of I-shape. 24 push-out specimens with I-shape shear connectors were tested under a static loading in the Laboratory of Materials and Mechanics of Structures - LMMS at the University of M'sila, Algeria. The load capacity, the ductility and the modes of failure were presented and discussed. The effect of the dimensions of I-shape connector, the effect of strength of concrete, and the effect of the number of transverse reinforcing bars have been discussed [7]. Furthermore, a finite element modelling of the push-out tests was carried out using ANSYS software [8] to investigate the stress distribution pattern in the area of the I-shape connector. Moreover, the finite element model was also used to simulate another type of shear connector, called channel connector (Figure 1(c)) in order to compare its behaviour with that of the I-shape connector. From this comparison, we suggested an equation for the prediction of the ultimate load capacity of the specific shear connector proposed in this research.

\section{EXPERIMENTAL PROGRAM}

The experimental program consisted of 24 push-out tests grouped in four series, each with three pairs. Each pair included two identical specimens. The test specimens were designed to study the effect of the following parameters on the ultimate load capacity: the height of I-shape connector, the length of I-shape connector, the compressive strength of concrete and the number of transverse reinforcing bars. Details of each push-out specimen are provided in Table1 with the dimensions of I-shape shear connector, the compressive strength of concrete slab and the number of transverse reinforcing bars. As illustration, Figure 2 shows the specimens of the series A.

Table 1. Summary of Push-out Test Specimens

\begin{tabular}{|c|c|c|c|c|c|c|c|}
\hline \multirow[t]{2}{*}{ Series } & \multirow[t]{2}{*}{ Specimen } & \multicolumn{3}{|c|}{ I-shape shear connector } & \multicolumn{2}{|c|}{ Concrete slab } & \multirow{2}{*}{$\begin{array}{c}\text { Test } \\
\text { parameter }\end{array}$} \\
\hline & & Profile & $\begin{array}{c}H_{I} \\
(\mathrm{~mm})\end{array}$ & $\begin{array}{c}L_{I} \\
(\mathrm{~mm})\end{array}$ & $\begin{array}{c}f_{c k} \\
\left(\mathrm{~N} / \mathrm{mm}^{2}\right)\end{array}$ & $\begin{array}{c}\text { Transverse } \\
\text { reinforcement }\end{array}$ & \\
\hline \multirow{6}{*}{ A } & A1-a & IEP80 & 80 & \multirow{6}{*}{60} & \multirow{6}{*}{20.11} & \multirow{6}{*}{$4 \varnothing 8$} & \multirow{6}{*}{$\begin{array}{l}\text { Height of } \\
\text { I-shape } \\
\text { connector }\end{array}$} \\
\hline & A1-b & IEF OU & oU & & & & \\
\hline & A2-a & JEP100 & 100 & & & & \\
\hline & A2-b & ILI 100 & 100 & & & & \\
\hline & A3-a & IEP120 & 120 & & & & \\
\hline & A3-b & & & & & & \\
\hline \multirow{2}{*}{ B } & B1-a & \multirow{2}{*}{ IEP80 } & \multirow{2}{*}{80} & \multirow{2}{*}{40} & \multirow{2}{*}{26.52} & \multirow{2}{*}{$4 \varnothing 8$} & \\
\hline & B1-b & & & & & & \\
\hline
\end{tabular}




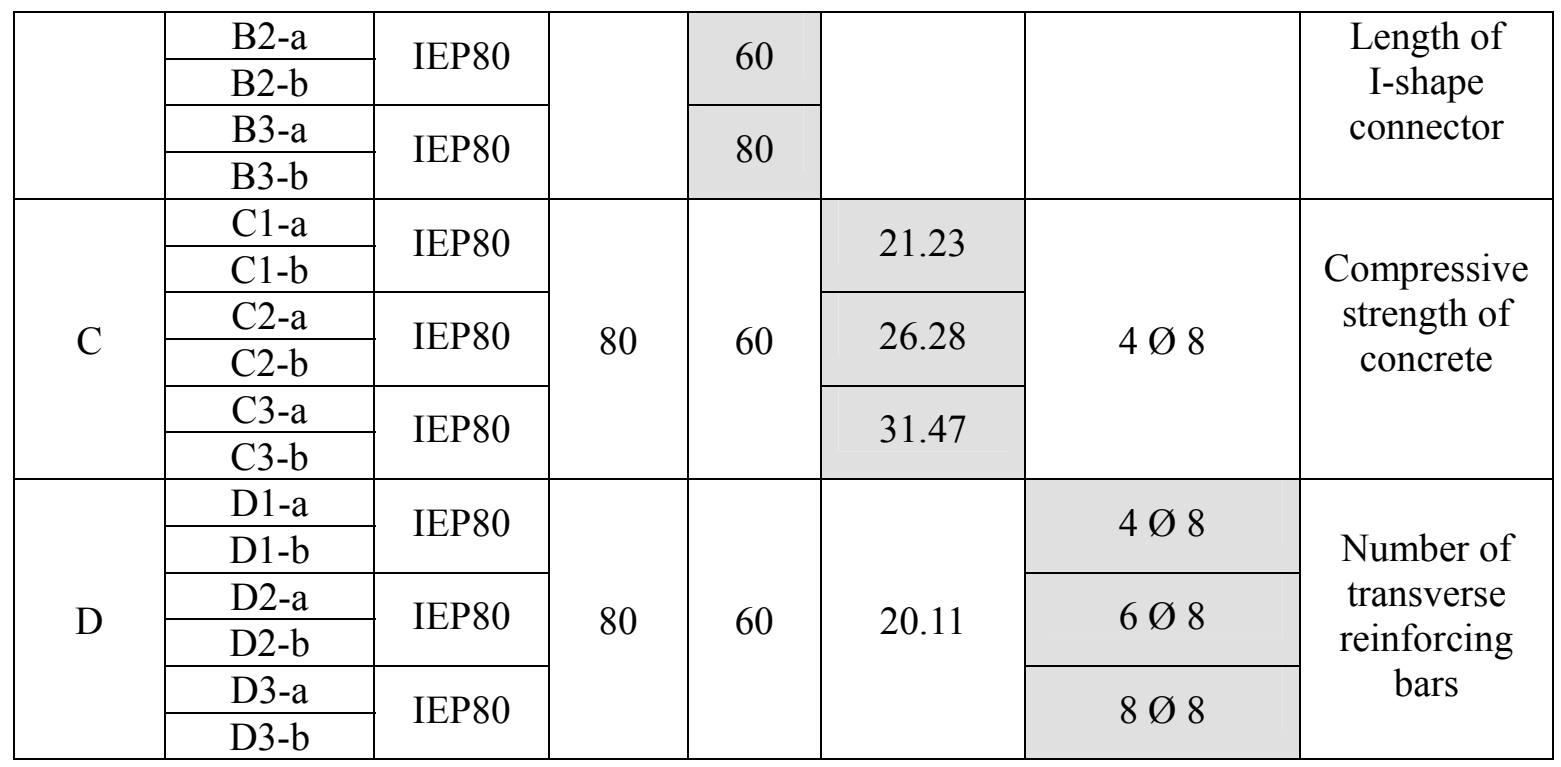

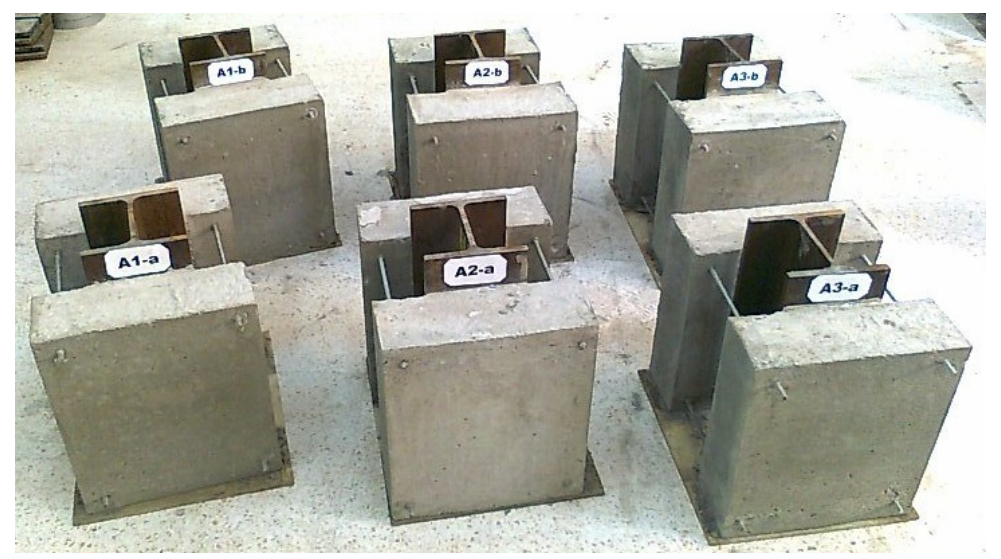

Figure 2. Push-out Specimens of the Series A

\subsection{Description of Push-out Specimens}

Due to some practical difficulties of the testing device, it was not possible to prepare the push-out specimens according to Eurocode 4 [9]. To simplify the experimental procedure, the authors have decided to follow the recommendations of British standards BS 5400-5 [10]. As shown in Figure 3, a push-out specimen consists of two small concrete slabs held in the vertical position, and attached to the flanges of a short HEB160 steel beam of $360 \mathrm{~mm}$ long, by means of welded I-shape shear connectors. The assembly was subjected to a vertical load which produced shear load along the interface between the concrete slab and the steel beam flange on both sides. A recess of $60 \mathrm{~mm}$ was provided between the bottom of the slab and the lower end of the steel beam to allow for slip during testing. The dimensions of concrete slabs were $360 \mathrm{~mm}$ long, $320 \mathrm{~mm}$ wide, and $120 \mathrm{~mm}$ thickness for each slab. For the specimens of series A, the thickness of the concrete slabs was 140 $\mathrm{mm}$ instead of $120 \mathrm{~mm}$. The distance between the web of I-shape connector and the bottom end of the concrete slab was kept constant at $210 \mathrm{~mm}$ for all specimens. These dimensions are similar to those used in other push-out tests with other types of shear connectors [11-15]. Most specimens were reinforced longitudinally and transversely with four $8 \mathrm{~mm}$ diameter bars positioned in two layers for each concrete slab, for some specimens in Series D, the number of longitudinal bars kept constant while the transverse bars were varied to six and eight bars for each concrete slab. The slabs of all push-out specimens were cast vertically, rather than horizontally, so that both slabs could be cast from the same batch of concrete to reduce the chance for variation in concrete 
strength from one slab to another. Each lift was thoroughly vibrated to eliminate air voids adjacent to the I-shape connectors. This form of casting has been successfully used by Veldanda \& Hosain [16], Studnicka et al [17], Medberry \& Shahrooz [18], Veríssimo [19], Vianna et al [20] and by Prakash et al [14]. Adoption of this procedure leads to a significant reduction of the time for execution of the test program, as well as of costs associates to the cut and the welding of the steel beams that would be necessary to execute the casting in horizontal position [21]. In addition, the casting in vertical position does not causes important modifications since the slabs have small dimensions. The chemical bond at the steel-concrete interface was eliminated by oiling the steel flanges before casting the slabs. The oiling of the steel flanges and the provision of the reinforcing bars before concrete pouring are shown in Figure 4.

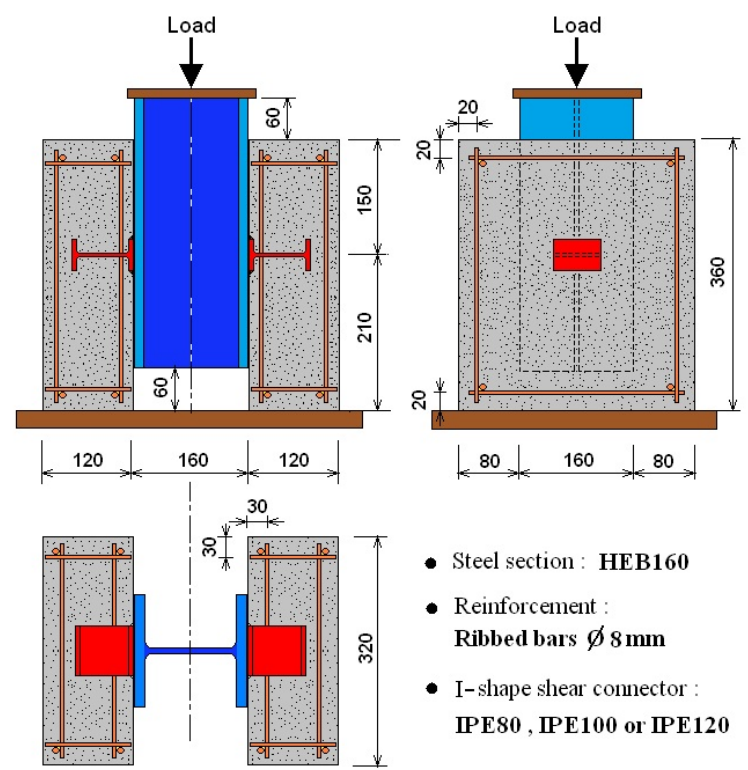

Figure 3. Push-out Specimen with I-shape Connector (Dimensions in $\mathrm{mm}$ )
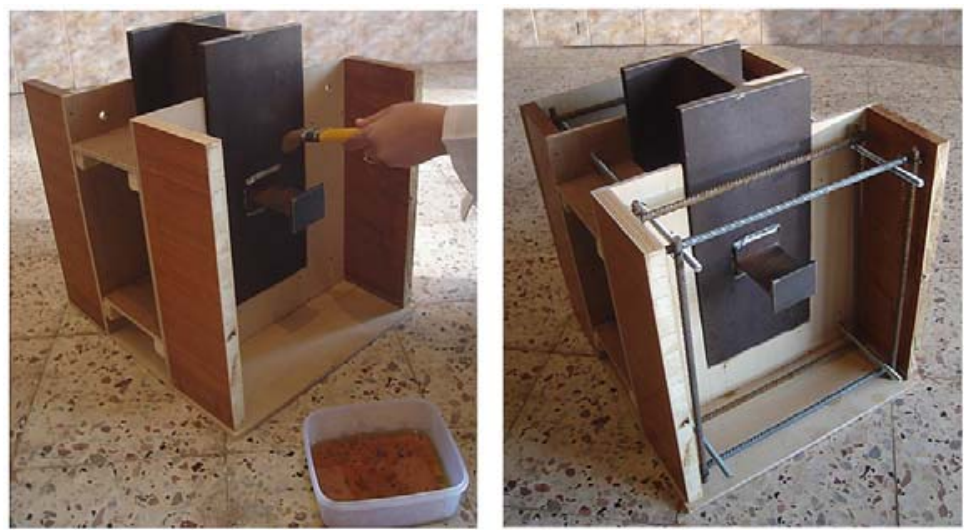

Figure 4. Oiling of the Steel Flanges and Provision of the Reinforcing Bars

\subsection{Material Properties}

After the concrete was cast for the push-out specimens, five concrete cylinders ( $160 \mathrm{~mm}$ diameter $\mathrm{x}$ $320 \mathrm{~mm}$ length) were prepared during each pouring. These concrete cylinders were tested for compressive strength on the same day of the push out tests. Table 2 shows the results of the compressive strength tests. The tensile strength and the modulus of elasticity of the concrete were calculated according to the procedure proposed by Eurocode 2 [22]. 
Table 2. Mechanical Properties of concrete material

\begin{tabular}{|c|c|c|c|c|}
\hline Specimens & $\begin{array}{c}\text { Strength } \\
\text { class of } \\
\text { concrete }\end{array}$ & $\begin{array}{c}\text { Average } \\
\text { compressive } \\
\text { strength, } f_{c k}(\mathrm{MPa})\end{array}$ & $\begin{array}{c}\text { Tensile } \\
\text { strength, } \\
f_{t}(\mathrm{MPa})\end{array}$ & $\begin{array}{c}\text { Modulus of } \\
\text { elasticity, } E_{c m} \\
(\mathrm{GPa})\end{array}$ \\
\hline $\begin{array}{c}\text { Series A } \\
\text { Series D }\end{array}$ & $\mathrm{C} 20 / 25$ & 20.11 & 2.22 & 29.997 \\
\hline Series B & $\mathrm{C} 25 / 30$ & 26.52 & 2.67 & 31.904 \\
\hline $\mathrm{C} 1-\mathrm{a}, \mathrm{C} 1-\mathrm{b}$ & $\mathrm{C} 20 / 25$ & 21.23 & 2.30 & 30.351 \\
\hline $\mathrm{C} 2-\mathrm{a}, \mathrm{C} 2-\mathrm{b}$ & $\mathrm{C} 25 / 30$ & 26.28 & 2.65 & 31.837 \\
\hline $\mathrm{C} 3-\mathrm{a}, \mathrm{C} 3-\mathrm{b}$ & $\mathrm{C} 30 / 37$ & 31.47 & 2.99 & 33.213 \\
\hline
\end{tabular}

The properties of the other materials used in this test program such as steel of I-shape shear connectors, and steel of reinforcing bars, were also determined by tension tests. Three coupon samples were cut from the web of I-shape connectors and from the reinforcing bars. The specimens' size and the tensile test procedure have been performed according to the procedure proposed by ASTM-E8-69 [23]. The results of the tension tests are summarized in Table 3. The short beam of HEB160 profile was made from S355 steel grade of nominal tensile yield strength equal to $355 \mathrm{MPa}$. No tests have been performed on this element.

Table 3. Mechanical Properties of Steel Materials

\begin{tabular}{|c|c|c|c|c|c|}
\hline Specimens & Profile & Steel grade & $\begin{array}{c}\text { Average Yield } \\
\text { Strength, } f_{y}(\mathrm{MPa})\end{array}$ & $\begin{array}{c}\text { Average ultimate } \\
\text { Strength, } f_{u}(\mathrm{MPa})\end{array}$ & $\begin{array}{c}\text { Average } \\
\text { Elongation (\%) }\end{array}$ \\
\hline \multirow{2}{*}{$\begin{array}{c}\text { Steel of } \\
\text { I-shape } \\
\text { shear } \\
\text { connectors }\end{array}$} & IPE80 & S235 & 233 & 344 & 21 \\
\cline { 2 - 6 } & IPE100 & S235 & 241 & 356 & 27 \\
\hline $\begin{array}{c}\text { Reinforcing } \\
\text { bars }\end{array}$ & $\varnothing 8$ & $\mathrm{~S} 235$ & 237 & 350 & 24 \\
\hline
\end{tabular}

\subsection{Test Setup and Instrumentation}

The push-out specimens were tested under monotonic loading using a hydraulic testing machine of $600 \mathrm{kN}$ capacity. A $30 \mathrm{~mm}$ thick steel plate was used as a base plate for the specimens, and at the top end of the specimens, a $12 \mathrm{~mm}$ thick steel plate was placed on the steel section to distribute the applied loads. Prior to initializing the test, the specimens were preloaded several times to remove any lack of fit in the test set up. The preload force was then released, and equilibrium was established in the system. Initially, the load was applied in increments of $10 \mathrm{kN}$, when the load-slip curve started to deviate from a straight line, the load increment was reduced to $5 \mathrm{kN}$ until the maximum load. The loading was continued until failure occurred. During each load increment, the slip between the steel beam and the concrete slab and the separation of the concrete slabs from the steel flanges were measured by means of four $20 \mathrm{~mm}$ dial gauges located at the level of I-shape shear connectors. Each specimen took about 45 minutes till it completely failed. Figure 5 shows a typical test setup used for the push-out specimens. 


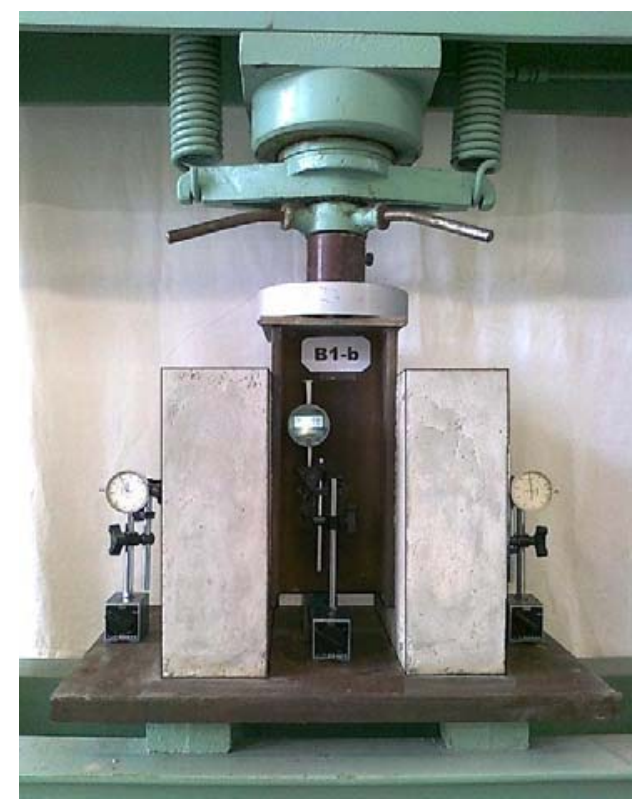

Figure 5. Test Setup and Instrumentation

\section{TEST RESULTS}

The results of the push-out tests are summarized in Table 4. The values of the load capacity and the ductility of the I-shape connector were evaluated in accordance with the specifications of Eurocode 4 [9] : The ultimate load capacity of a connector $P_{u}$ was obtained by dividing the failure load of the specimen by the number of connectors, the characteristic load $P_{R k}$ was taken as the least failure load divided by the number of connectors and reduced by $10 \%$, the slip capacity $S_{u}$ was considered as the maximum slip correspondent to the characteristic load $P_{R k}$ and the characteristic slip $S_{u k}$ was taken as $90 \%$ of the slip capacity i.e. $0.9 S_{u}$.

Table 4. Results of Push-out Tests

\begin{tabular}{|c|c|c|c|c|c|c|c|}
\hline \multirow{2}{*}{ Series } & \multirow{2}{*}{ Specimen } & \multicolumn{3}{|c|}{$\begin{array}{l}\text { Load capacity per connector } \\
(\mathrm{KN})\end{array}$} & \multicolumn{2}{|c|}{$\begin{array}{l}\text { Slip capacity } \\
(\mathrm{mm})\end{array}$} & \multirow[t]{2}{*}{ Mode of failure } \\
\hline & & $P_{\text {test }}$ & $P_{u}$ (avg.) & $P_{R k}$ & $S_{u}$ & $S_{u k}$ & \\
\hline \multirow{6}{*}{ A } & A1-a & 70.00 & \multirow{2}{*}{70.00} & \multirow{2}{*}{63.00} & \multirow{2}{*}{7.5} & \multirow{2}{*}{6.8} & \multirow{2}{*}{$\begin{array}{c}\text { Cracking }+ \\
\text { crushing } \\
\text { of concrete }\end{array}$} \\
\hline & A1-b & 70.00 & & & & & \\
\hline & A2-a & 80.00 & \multirow{2}{*}{78.75} & \multirow{2}{*}{69.75} & \multirow{2}{*}{8.2} & \multirow{2}{*}{7.4} & \multirow{2}{*}{$\begin{array}{c}\text { Cracking }+ \\
\text { crushing } \\
\text { of concrete } \\
\end{array}$} \\
\hline & $\mathrm{A} 2-\mathrm{b}$ & 77.50 & & & & & \\
\hline & A3-a & 82.50 & \multirow{2}{*}{83.75} & \multirow{2}{*}{74.25} & \multirow{2}{*}{8.8} & \multirow{2}{*}{7.9} & \multirow{2}{*}{$\begin{array}{c}\text { Cracking }+ \\
\text { crushing } \\
\text { of concrete }\end{array}$} \\
\hline & A3-b & 85.00 & & & & & \\
\hline \multirow{6}{*}{ B } & B1-a & 52.50 & \multirow{2}{*}{51.25} & \multirow{2}{*}{45.00} & \multirow{2}{*}{4.9} & \multirow{2}{*}{4.4} & \multirow{2}{*}{$\begin{array}{l}\text { Shearing } \\
\text { of connector }\end{array}$} \\
\hline & B1-b & 50.00 & & & & & \\
\hline & B2-a & 80.00 & \multirow{2}{*}{80.00} & \multirow{2}{*}{72.00} & \multirow{2}{*}{7.3} & \multirow{2}{*}{6.6} & \multirow{2}{*}{$\begin{array}{c}\text { Cracking }+ \\
\text { crushing } \\
\text { of concrete }\end{array}$} \\
\hline & B2-b & 80.00 & & & & & \\
\hline & B3-a & 107.50 & \multirow{2}{*}{108.75} & \multirow{2}{*}{96.75} & \multirow{2}{*}{9.7} & \multirow{2}{*}{8.7} & \multirow{2}{*}{$\begin{array}{l}\text { Cracking + } \\
\text { crushing } \\
\text { of concrete }\end{array}$} \\
\hline & B3-b & 110.00 & & & & & \\
\hline
\end{tabular}




\begin{tabular}{|c|c|c|c|c|c|c|c|}
\hline \multirow{6}{*}{$\mathrm{C}$} & $\mathrm{C} 1-\mathrm{a}$ & 70.00 & \multirow{2}{*}{71.25} & \multirow{2}{*}{63.00} & \multirow{2}{*}{6.9} & \multirow{2}{*}{6.2} & \multirow{2}{*}{$\begin{array}{c}\text { Cracking + } \\
\text { crushing } \\
\text { of concrete }\end{array}$} \\
\hline & $\mathrm{C} 1-\mathrm{b}$ & 72.50 & & & & & \\
\hline & $\mathrm{C} 2-\mathrm{a}$ & 80.00 & \multirow{2}{*}{80.00} & \multirow{2}{*}{72.00} & \multirow{2}{*}{7.8} & \multirow{2}{*}{7.0} & \multirow{2}{*}{$\begin{array}{c}\text { Cracking + } \\
\text { crushing } \\
\text { of concrete }\end{array}$} \\
\hline & $\mathrm{C} 2-\mathrm{b}$ & 80.00 & & & & & \\
\hline & C3-a & 82.50 & \multirow{2}{*}{82.50} & \multirow{2}{*}{74.25} & \multirow{2}{*}{5.7} & \multirow{2}{*}{5.1} & \multirow{2}{*}{$\begin{array}{l}\text { Shearing } \\
\text { of connector }\end{array}$} \\
\hline & C3-b & 82.50 & & & & & \\
\hline \multirow{6}{*}{ D } & D1-a & 67.50 & \multirow[b]{2}{*}{68.75} & \multirow[b]{2}{*}{60.75} & \multirow[b]{2}{*}{6.8} & \multirow[b]{2}{*}{6.1} & \multirow{2}{*}{$\begin{array}{c}\text { Cracking + } \\
\text { crushing } \\
\text { of concrete }\end{array}$} \\
\hline & D1-b & 70.00 & & & & & \\
\hline & D2-a & 72.50 & \multirow[b]{2}{*}{71.25} & \multirow[b]{2}{*}{63.00} & \multirow[b]{2}{*}{8.2} & \multirow[b]{2}{*}{7.4} & \multirow{2}{*}{$\begin{array}{c}\text { Cracking }+ \\
\text { crushing } \\
\text { of concrete }\end{array}$} \\
\hline & D2-b & 70.00 & & & & & \\
\hline & D3-a & 75.00 & \multirow{2}{*}{73.75} & \multirow{2}{*}{65.25} & \multirow{2}{*}{8.4} & \multirow{2}{*}{7.6} & \multirow{2}{*}{$\begin{array}{c}\text { Cracking + } \\
\text { crushing } \\
\text { of concrete }\end{array}$} \\
\hline & D3-b & 72.50 & & & & & \\
\hline
\end{tabular}

\subsection{Failure Modes}

The failure modes observed from the push-out tests can be generally classified into two types, as presented in Table 4. The first mode of failure is the shearing of connector. The characteristic feature of this failure mode was the yielding and then shearing of the web near the welded flange fillet. Figure 6(a) shows the shearing of the I-shape connector with a remarkable cracking of concrete. The second mode of failure is the cracking and crushing of concrete slab in front of the connector as illustrated in Figure 6(b). It was noticed that the shearing of connector was occurred, especially in the specimens with higher strength concrete and/or with connectors of smaller length. However, in specimens made using low and moderate strength concrete, the failure was caused by cracking and crushing of the concrete slab.

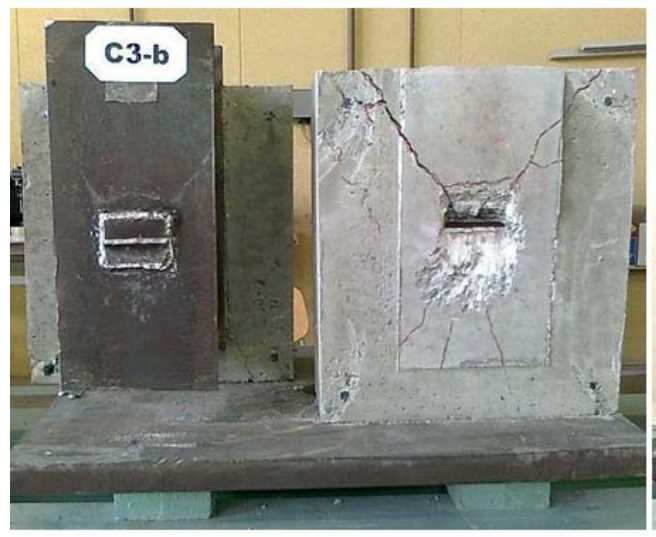

(a) Failure by shearing of connector web

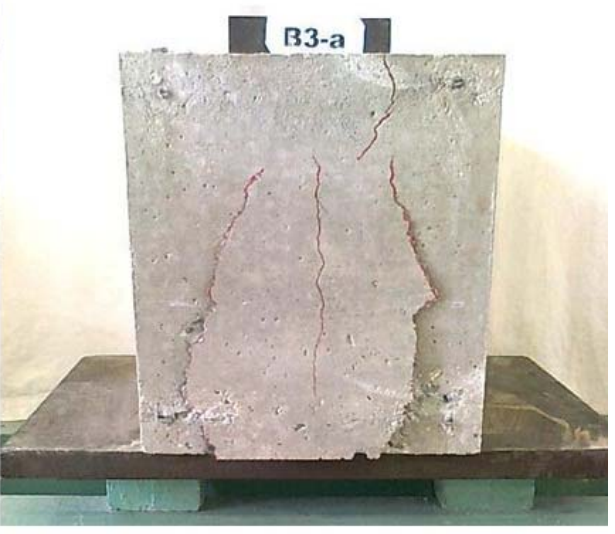

(b) Failure by cracking and crushing of concrete

Figure 6. Modes of Failure

\subsection{Load-slip Behaviour}

The load-slip curves of two specimens representing the two types of failure shown above are presented in Figure 7. Slip increased with increasing load until the specimen reached the ultimate load, and afterwards the load decreased systematically until failure. For the specimen C3-b, the 
shearing of I-shape connector was identified by a characteristic sound and load drop, and separation occurred on one side only. For the specimen B3-a, it appears that even after the cracking and crushing of concrete in front of the I-shape connector, the friction between the cracked concrete surfaces continued to provide shear resistance at large slips.

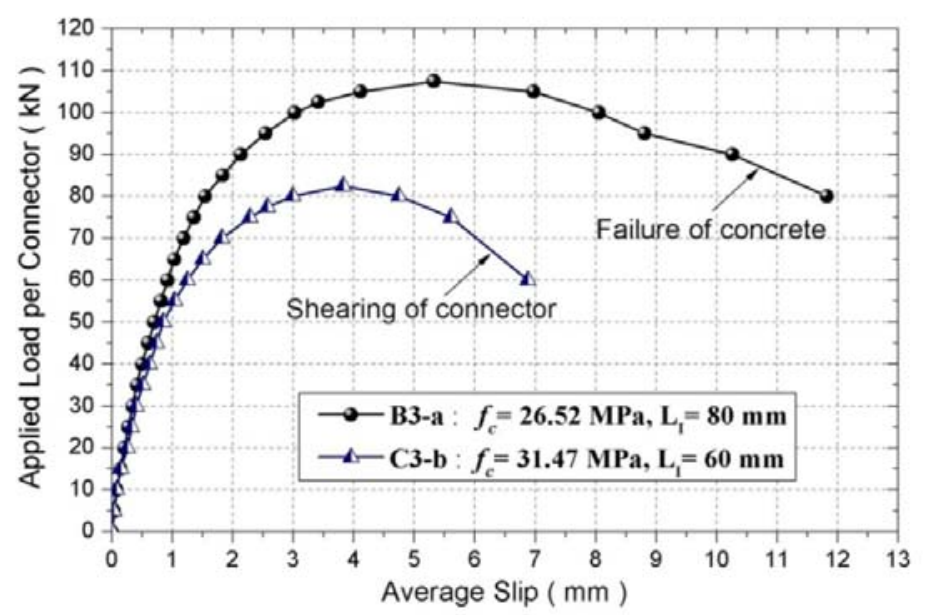

Figure 7. Typical Load-slip Curves for Specimens C3-b and B3-a

- According to Eurocode 4 [9], a connector may be taken as ductile if the characteristic slip $S_{u k}$ is at least $6 \mathrm{~mm}$. As indicated in Table 4, for the specimens that failed by cracking and crushing of concrete, the I-shape connectors are sufficiently ductile since they present a characteristic slip $S_{u k}$ greater than $6 \mathrm{~mm}$. While, for the specimens failed by shearing of connector, the characteristic slip $S_{u k}$ is slightly lower than $6 \mathrm{~mm}$ and the load-slip behaviour is less ductile. It worth noting that the push-tests were performed with load control due to some limitations of the testing machine at the time. It is possible that the values measured for slip are smaller than those that would be attained with displacement control.

- Concerning the separation of the concrete slabs, the uplift values obtained from the push-out tests with I-shape connectors, were found to be small and thus were considered to have minimal influence on the behaviour of these connectors.

\section{PARAMETRIC STUDY}

\subsection{Effect of the Height of I-shape Connector}

The load-slip curves for three pair specimens A1, A2, and A3 are shown in Figure 8. These specimens were similar in every respect except that the height of I-shape connector in specimens $\mathrm{A} 1, \mathrm{~A} 2$, and $\mathrm{A} 3$ was 80,100 , and $120 \mathrm{~mm}$, respectively. The length of I-shape connectors was 60 $\mathrm{mm}$. The compressive strength of concrete used in all three pair specimens was 20.11 MPa.

As the load-slip curves indicate, the ultimate load capacity of I-shape connector increased slightly with the increase in the height of connector. On average, the ultimate load increased by about $10 \%$ when the connector height was increased from $80 \mathrm{~mm}$ to $100 \mathrm{~mm}$. There was a further increase of $6 \%$ when the connector height was increased from $100 \mathrm{~mm}$ to $120 \mathrm{~mm}$. All three pair specimens failed due to Cracking and crushing of concrete. Since the height of I-shape connector has a small influence when failure is concrete related. However, the specimen with a higher connector showed a slightly more ductile behaviour. 


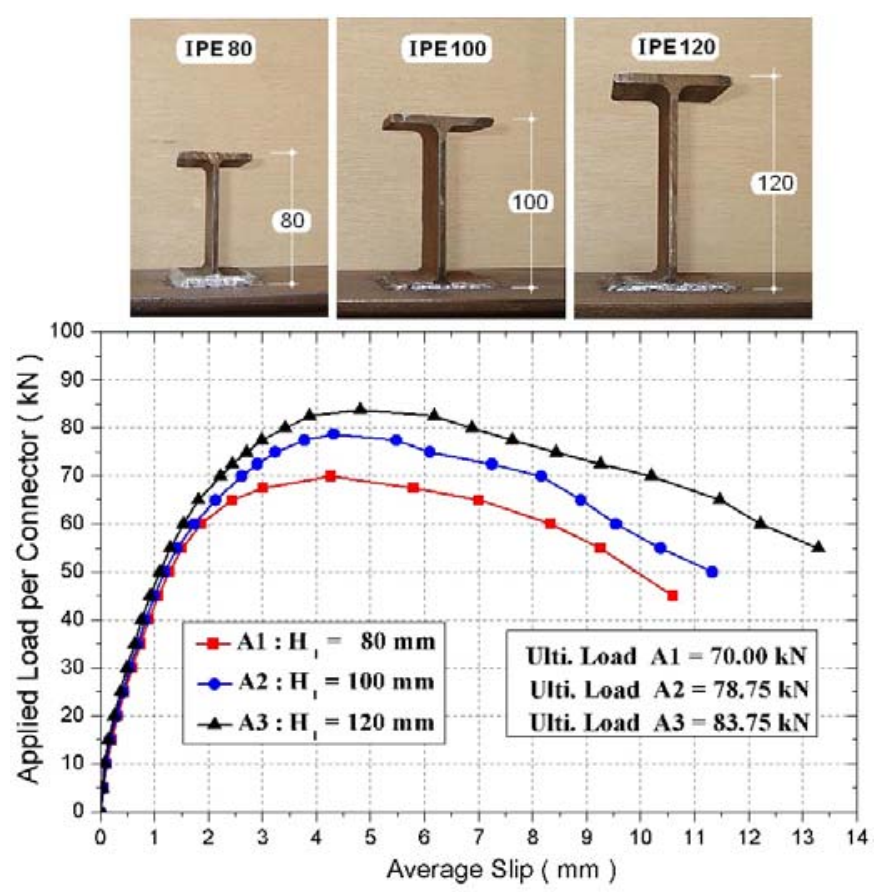

Figure 8. Effect of the Height of I-shape Connector

\subsection{Effect of the Length of I-shape Connector}

The load-slip curves for three pair of specimens B1, B2, and B3 are shown in Figure 9. These specimens were similar in every respect except that the length of I-shape connector in specimens $\mathrm{B} 1, \mathrm{~B} 2$, and B3 was 40,60 , and $80 \mathrm{~mm}$, respectively. The height of the connector used in these specimens was $80 \mathrm{~mm}$. The compressive strength of the concrete was $26.52 \mathrm{MPa}$. As the load-slip curves indicate, the ultimate load capacity is influenced significantly by the increase in connector length. On average, increasing the length of I-shape connector from $40 \mathrm{~mm}$ to $60 \mathrm{~mm}(50 \%)$ led to an increase in the ultimate load capacity of approximately $56 \%$, as well as a further increase of connector length from $60 \mathrm{~mm}$ to $80 \mathrm{~mm}(33 \%)$ led to an increase in the ultimate load capacity of approximately $27 \%$.

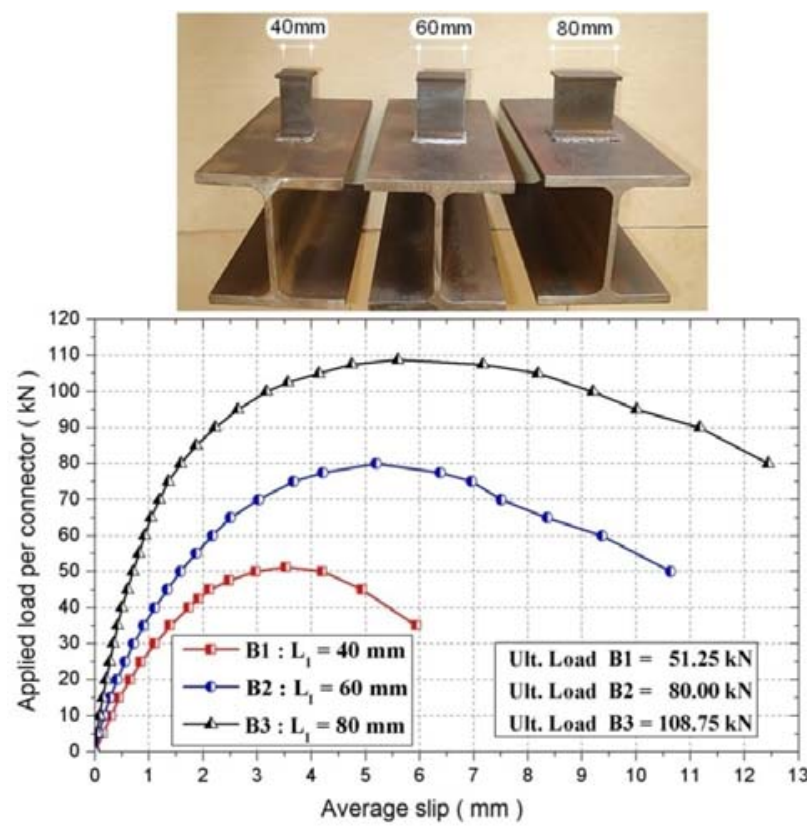

Figure 9. Effect of the Length of I-shape Connector 


\subsection{Effect of Concrete Strength}

Figure 10 presents the load-slip curves for three pair specimens $\mathrm{C} 1, \mathrm{C} 2$ and $\mathrm{C} 3$ which were identical except that the compressive strengths of concrete were $21.23,26.28$ and $31.47 \mathrm{MPa}$, respectively. As indicated in Table 4, it appears that the concrete strength governed the mode of failure. Shearing of connector was observed in the pair specimens C3 with the highest strength concrete while, in the two pair specimens $\mathrm{C} 1$ and $\mathrm{C} 2$ with lower and moderate strength concrete, respectively, failure was occurred by cracking and crushing of concrete. For an increase in the compressive strength of concrete from 21.23 to $26.28 \mathrm{MPa}(23.79 \%)$ the average increase in the ultimate load capacity of I-shape connector was approximately $12.25 \%$. However, when the concrete strength was further increased from 26.28 to $31.47 \mathrm{MPa}(19.75 \%)$, the ultimate load capacity of I-shape connector increased by only $3.13 \%$. This was expected since the failure mode at higher concrete strength was due to shearing of connector. In this case, the ultimate load capacity of I-shape connector is indirectly influenced by concrete strength.

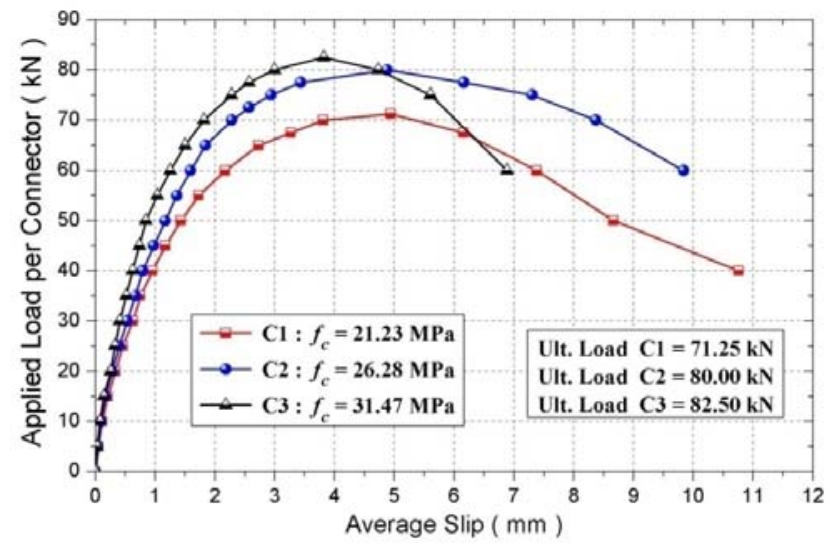

Figure 10. Effect of Concrete Strength for Specimens C1, C2 and C3

\subsection{Effect of transverse reinforcement}

The load-slip curves for three pair specimens D1, D2, and D3 are shown in Figure 11. These specimens were similar in every respect except that the number of transverse reinforcing bars in each concrete slab of specimens D1, D2, and D3 was 4Ø8, 6Ø8, and 8Ø8, respectively. The compressive strength of concrete used in all three pair specimens was $20.11 \mathrm{MPa}$. As the load-slip curves indicate, the ultimate load capacity was not significantly influenced by the increase in the number of transverse reinforcing bars. On average, increasing the number of transverse reinforcing bars from $4 \varnothing 8$ to $6 \varnothing 8$ led to an increase in the ultimate load capacity of approximately $5 \%$, while a further increasing of transverse reinforcing bars from $6 \varnothing 8$ to $8 \varnothing 8$ led to an increase in the ultimate load capacity of only approximately $2 \%$. However, the specimens with $6 \varnothing 8$ and $8 \varnothing 8$ exhibited a more ductile behaviour (i.e., larger maximum slip values) than the specimens with $4 \varnothing 8$. The reason for this difference in behaviour can be attributed to the presence of transverse reinforcing bars which limit the cracking of the concrete around the connector at the ultimate loads. 


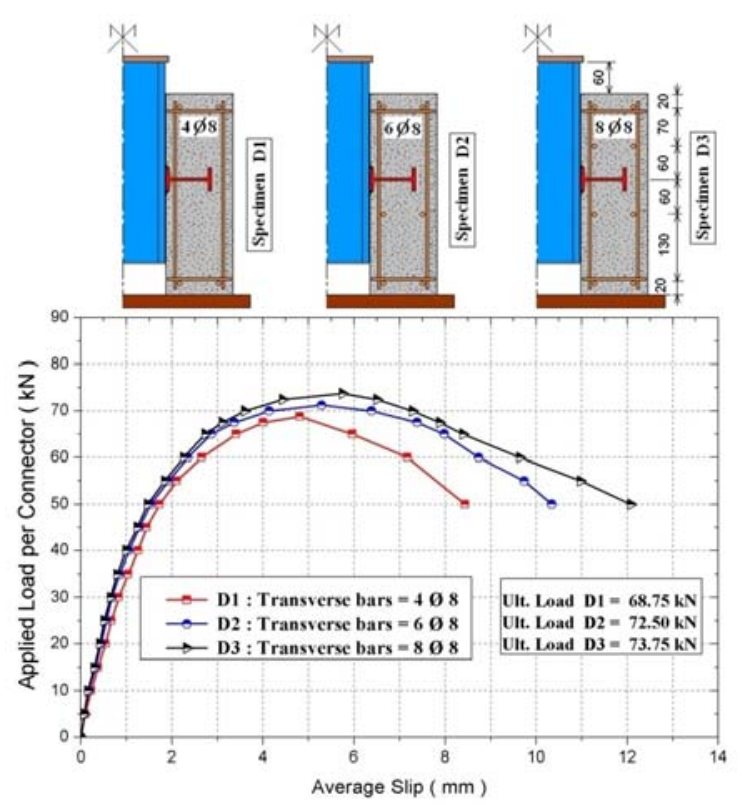

Figure 11. Effect of Transverse Reinforcement for Specimens D1, D2 and D3

\section{FINITE ELEMENT ANALYSIS}

During the preparation of the push-out specimens, we encountered difficulties in the installation of the strain gauges on the level of each I-shape connector. Therefore, to observe its local deformation, the finite element analysis serves better than that of the experimental investigation. Nevertheless, due to complexity of three-dimensional models (meshing difficulties, memory requirements, numerical convergence problems and result interpretation difficulties), a two-dimensional model was then chosen for simplicity.

Two-dimensional models with plane stress elements were used by many authors. Kim et al. [24] were one of the first researchers to employ a two-dimensional plane stress elements using LUSAS software to study the behaviour of through-deck welded shear connectors in push-out tests. The steel beam, concrete slab and stud were modelled by quadrilateral and triangular plane stress elements and the profiled steel sheeting by bar elements. Wang [25] proposed a two-dimensional model using ABAQUS software to investigate the behaviour of stud shear connectors with profiled steel sheeting in push-out tests. Quadrilateral plane stress elements were used to model the concrete slab, the steel beam and the profiled steel sheeting. Shear connectors were modelled by horizontal and vertical springs along the steel-concrete interface, and non-linear load-slippage curves representing realistic deformation characteristics were readily incorporated. Recently, Guezouli and Lachal [26] developed a new two-dimensional model to study the effect of steel-concrete contact and friction on the behaviour of stud shear connectors in push-out tests. It has been observed that the previous two-dimensional models with plane stress elements are able to predict satisfactorily the behaviour of the shear connectors both in terms of strength and ductility without any difficulty.

\subsection{Two-dimensional finite element model}

The push-out specimen shown in Figure 3 was modelled by a two-dimensional finite element model using ANSYS software [8]. Because of symmetry, only half of the specimen with one I-shape shear connector was built as shown in Figure 12. 


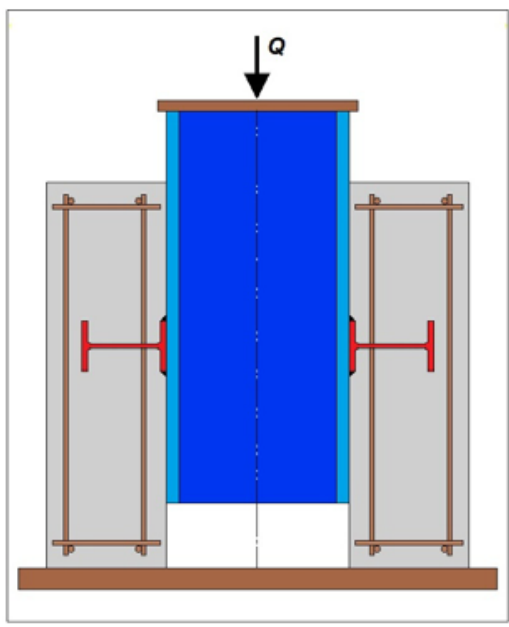

(a) Geometry of the push-out specimen

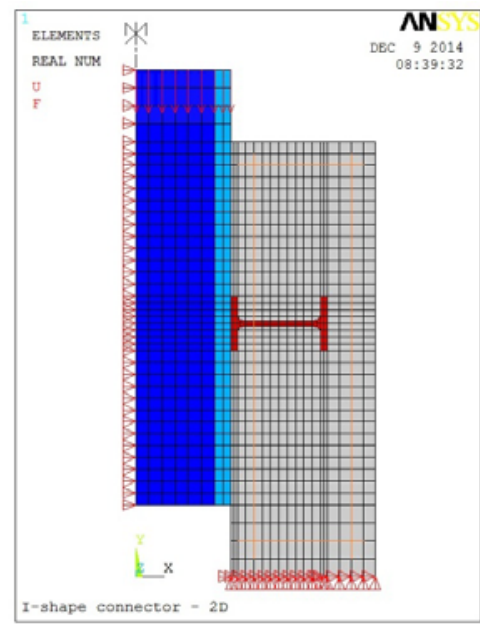

(b) Two-dimensionnel finite element model

Figure 12. Finite element modelling of push-out specimen with I-shape connector

\subsubsection{Finite element types}

The concrete slab, the steel beam and the I-shape connector were modelled using quadrilateral plane stress elements PLANE42, which have four nodes with two displacement degrees of freedom per node. The thicknesses of the plane stress elements were assigned to be equal to the effective width of the concrete slab as well as flange width and web thickness of the steel beam and the section of I-shape connector as appropriate. The reinforcing bars were modelled in a discrete manner using the two-dimensional spar element LINK1, which have two nodes with two displacement degrees of freedom per node. In this study, full bond action was assumed between the reinforcing bars and the concrete slab. Therefore, the nodes of LINK1 elements are attached to coincident nodes of PLANE42 elements of the concrete slab, so the two materials share the same nodes. The contacts along the steel-concrete interfaces between the I-shape connector and surrounding concrete and also between the flange of steel beam and concrete slab were modelled using a contact element CONTA171 associated with a target element TARGE169. These elements are able to simulate the existence of pressure between the elements when there is contact, and separation between the same ones when there is not. The contact pairs still allow the consideration of the friction between the parts. Hence, from the literature reviews, the friction coefficient developed at the interface (connector - surrounding concrete) was taken equal to 0.6 while at the interface (flange of steel beam - concrete slab) was taken equal to 0.01 because, in the push-out tests, the friction was eliminated by oiling of the steel beam flanges before the casting of concrete slabs.

\subsubsection{Material modelling of steel and concrete}

The material properties obtained from the tests were used in the finite element analyses. On one hand, the steel of I-shape connector, steel of reinforcing bars and steel beam were modelled as an isotropic elasto-plastic material in both tension and compression taking into account hardening effects. On the other hand, the behaviour of concrete was simulated by a simplified material model having different properties in tension and compression. In compression, the concrete was modelled by a multi-linear isotropic hardening relationship, which uses the von Mises yield criterion. In tension, the behaviour is linear up to the tensile strength of concrete. After this point, the softening branch remains horizontal to avoid numerical problems due to fact that the material nonlinearity in ANSYS cannot handle a negative gradient in the last stage of stress-strain curve. 


\subsubsection{Mesh and boundary conditions}

After the election of the suitable finite elements, the discretization of each part constituting the model was made by applying a coarse mesh as an overall size to reduce the time of analysis. The fine mesh was applied at the area of the I-shape connector in order to obtain more accurate results. Figure 12(b) shows the mesh and the boundary conditions adopted for the two-dimensional finite element model:

- All nodes along the middle of the steel beam web were restricted from moving in X direction due to symmetry.

- All nodes at the base of concrete slab were restricted from moving in $\mathrm{X}$ and $\mathrm{Y}$ directions to resist the compression load and to prevent the lateral spacing of the concrete slab at its base.

\subsubsection{Application of load and convergence criteria}

In this analysis, load control was applied. Loading was incrementally applied to the top line of the steel beam as shown in Figure 12(b). The slip was measured at the level of the I-shape connector. Therefore, the load-slip curve can be plotted and the ultimate load capacity can be determined. The ANSYS software [8] used the Newton-Raphson equilibrium iterations to provide convergence at the end of each load increment within tolerance limits. In this study, convergence criteria were based on force and displacement, and the convergence tolerance limits were initially selected by the ANSYS software [8]. The convergence limits for this analysis used the L2-norm (square root sum of the squares) of force tolerance equal to $0.1 \%$ and an L2-norm check on displacement with $5 \%$ tolerance.

\subsection{Calibration of the Finite Element Model}

In order to calibrate the finite element model, two push-out specimens (C3-b and B3-a) that were tested previously were simulated using the two-dimensional model described above. The dimensions of the push-out specimens and the test results were reported in the experimental part. Figure 13 presents a comparison between the (load-slip) curves recorded experimentally and those obtained numerically by the finite element method for the two specimens. There is good agreement between experimental and finite element results. Nevertheless, the numerical curves diverge from the experimental curves after the reaching of the ultimate load. This was due to the concrete material modelling used in the finite element analysis. For the specimen C3-b, the maximum load per one connector was recorded at $82.5 \mathrm{kN}$ compared with $85 \mathrm{kN}$ obtained from the finite element solution. For the specimen B3-a, the push-out test gave an ultimate load of $107.5 \mathrm{kN}$ compared with $115 \mathrm{kN}$ obtained from the finite element analysis.

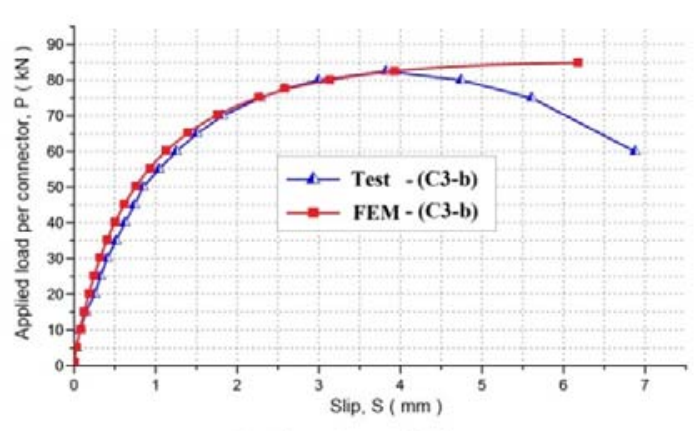

(a) Specimen C3-b

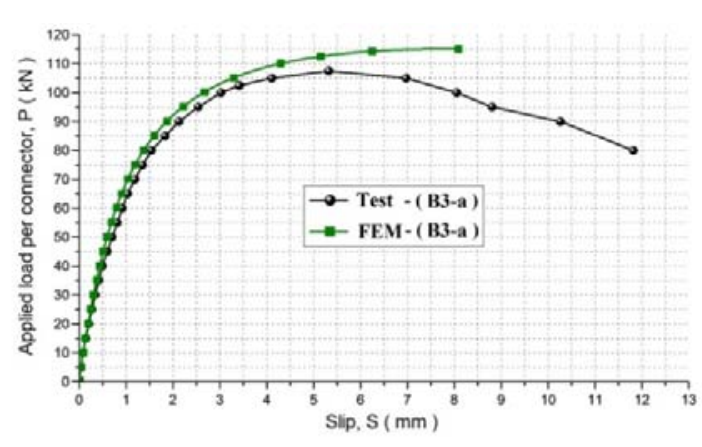

(b) Specimen B3-a

Figure 13. Load-slip Curves for Specimens C3-b and B3-a 
In the first specimen $\mathrm{C} 3-\mathrm{b}$, the failure of the shear connection was occurred by yielding and then shearing of the I-shape connector. This mode of failure was confirmed numerically by a concentration of the maximum stresses on the level of the web near the welded flange of I-shape connector as it can be seen in Figure 14(a). While, in the second specimen B3-a, the failure of shear connection was occurred by local crushing of the concrete around the I-shape connector. This mode of failure was also confirmed by the finite element analysis. As shown in Figure 14(b), a concentration of the maximum stresses was observed in the concrete at the frontal area of the connector.

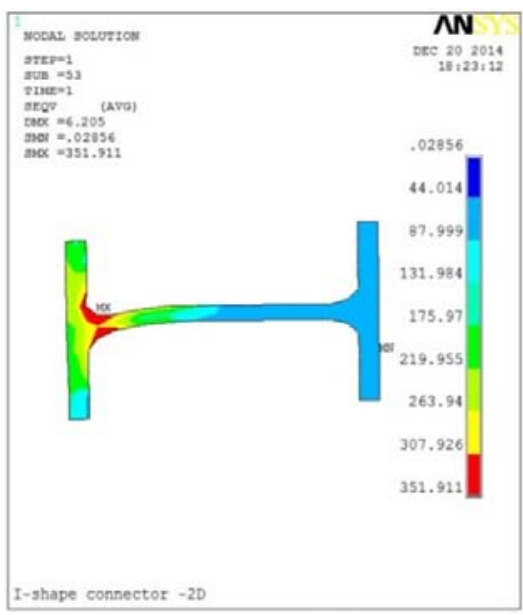

(a) Specimen C3-b

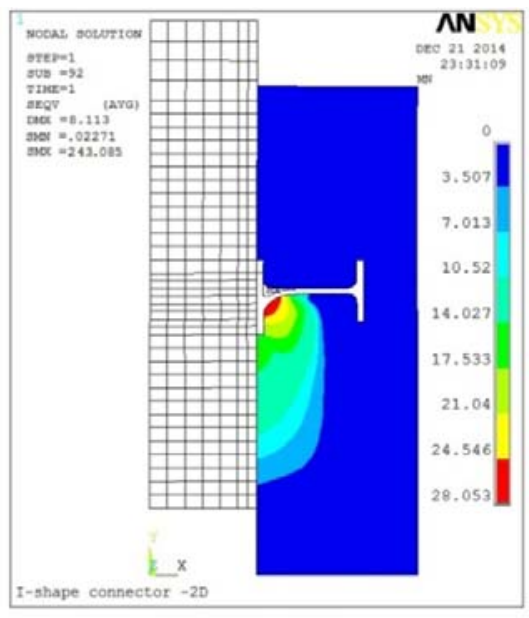

(b) Specimen B3-a

Figure 14. Stress Contour and Deformed Shape for Specimens C3-b and B3-a

The deformed shape of the connector after the failure of the specimen B3-a is compared with the finite element result. As it is shown in Figure 15, a separation of the concrete behind the connector was occurred in the push-out test. This separation was also noticed during the finite element analysis.
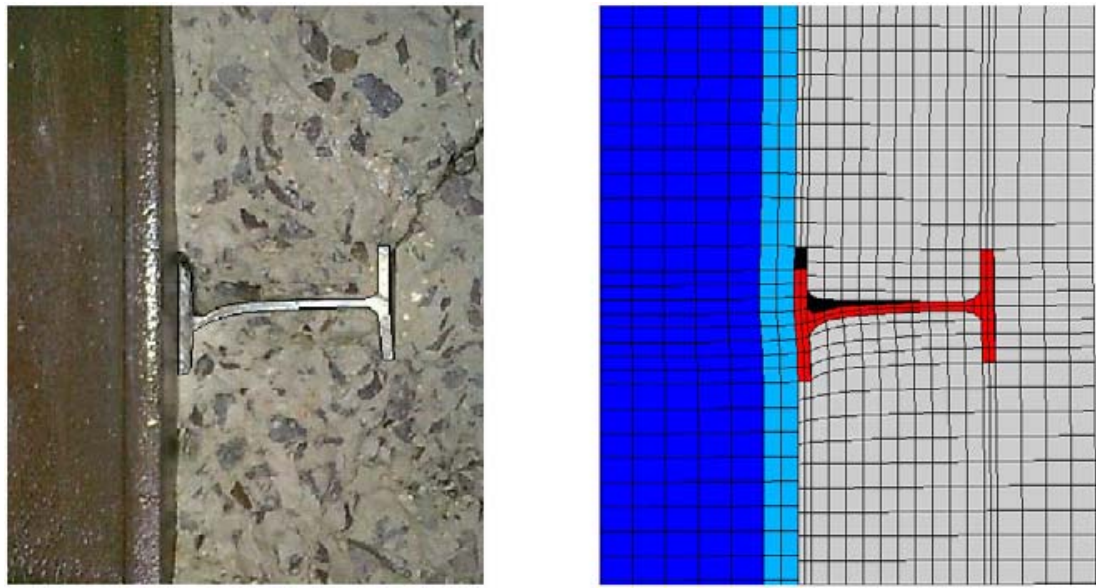

Figure 15. Typical deformed shape of the I-shape connector (specimen B3-a)

\subsection{Modelling of the Push-out Specimens with Channel Connector}

A simulation of the push-out specimens with channel shear connector of U-shape was conducted using the verified two-dimensional model in order to compare its behaviour with that of I-shape connector. Dimensions and mechanical properties of the two types of shear connectors are identical. Figure 16 shows the mesh and boundary conditions of the corresponding push-out specimens. 

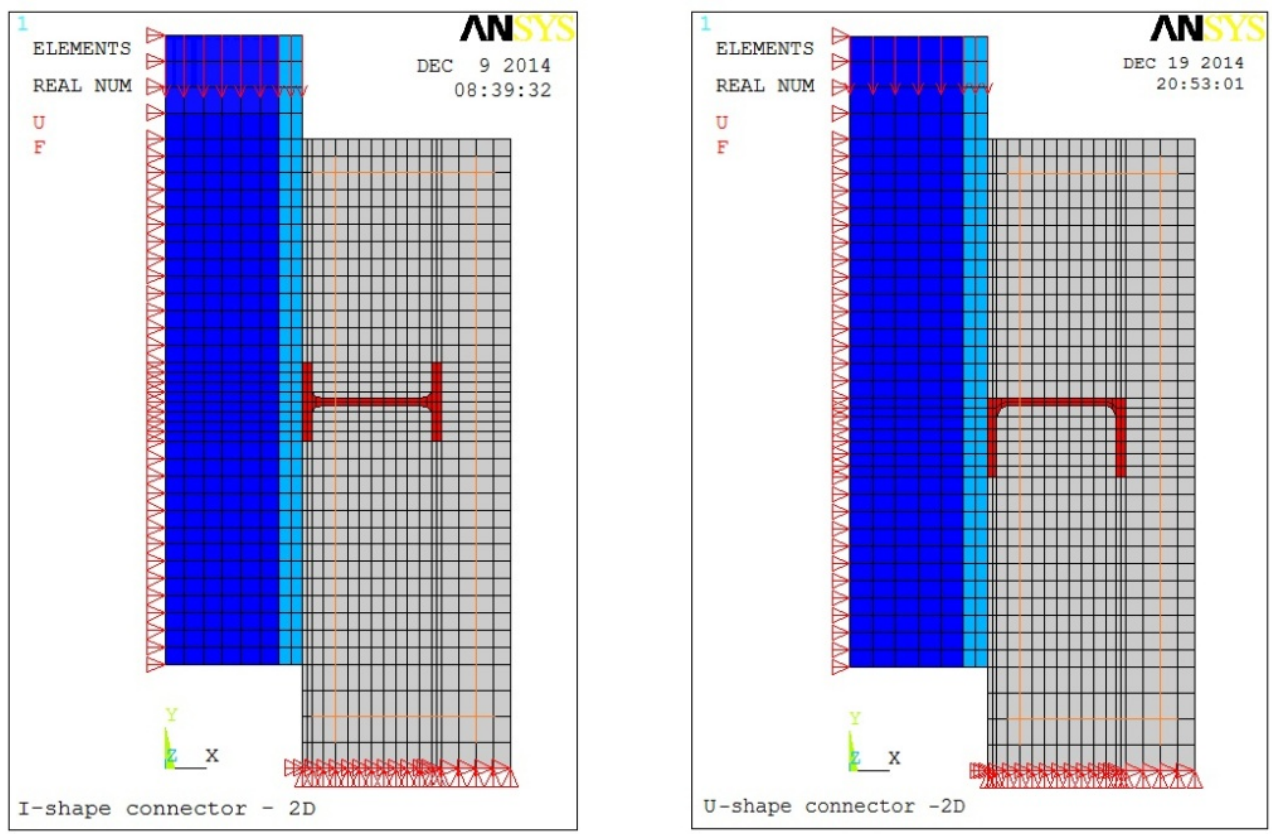

Figure 16. Mesh and Boundary Conditions for the Two Types of Shear Connectors

Figure 17 shows a comparison between the (load-slip) curves obtained from the finite element analysis for the two types of shear connectors. There is good agreement between the two curves for the two specimens C3-b and B3-a. However, the load-slip curve of channel connector appears more rigid and slightly higher than that of I-shape connector.

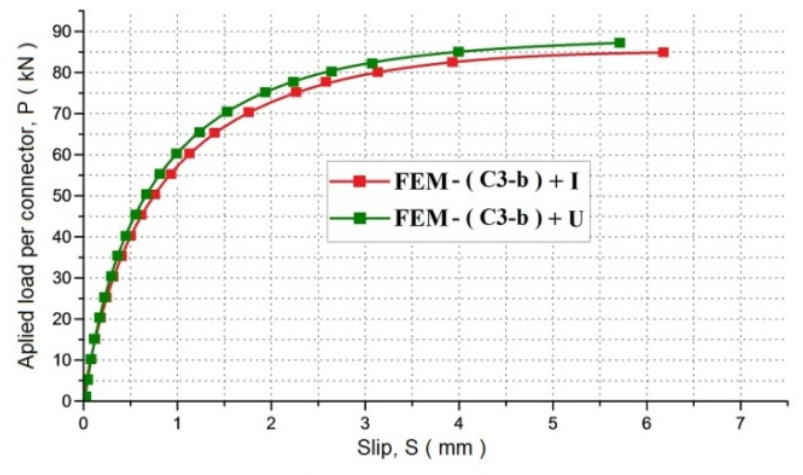

(a) Specimen C3-b

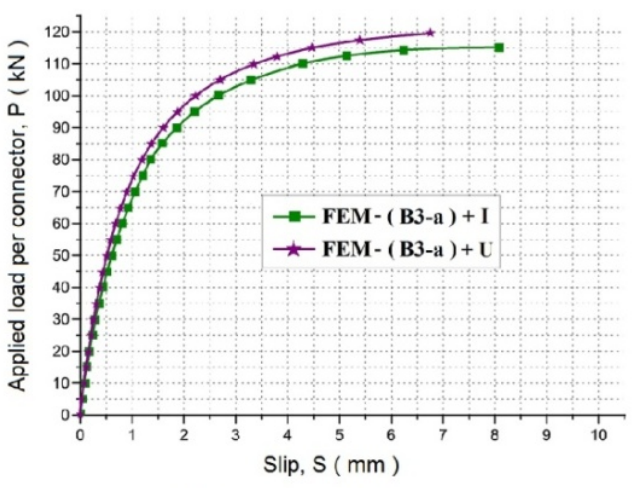

(b) Specimen B3-a

Figure 17. Comparison between the Load-slip Curves for the Two Types of Shear Connectors

As shown in Figure 18, the mode of failure by yielding and then shearing of the steel connector was confirmed numerically by a concentration of the maximum stresses at the junction of web and welded flange for the two types of shear connectors. 

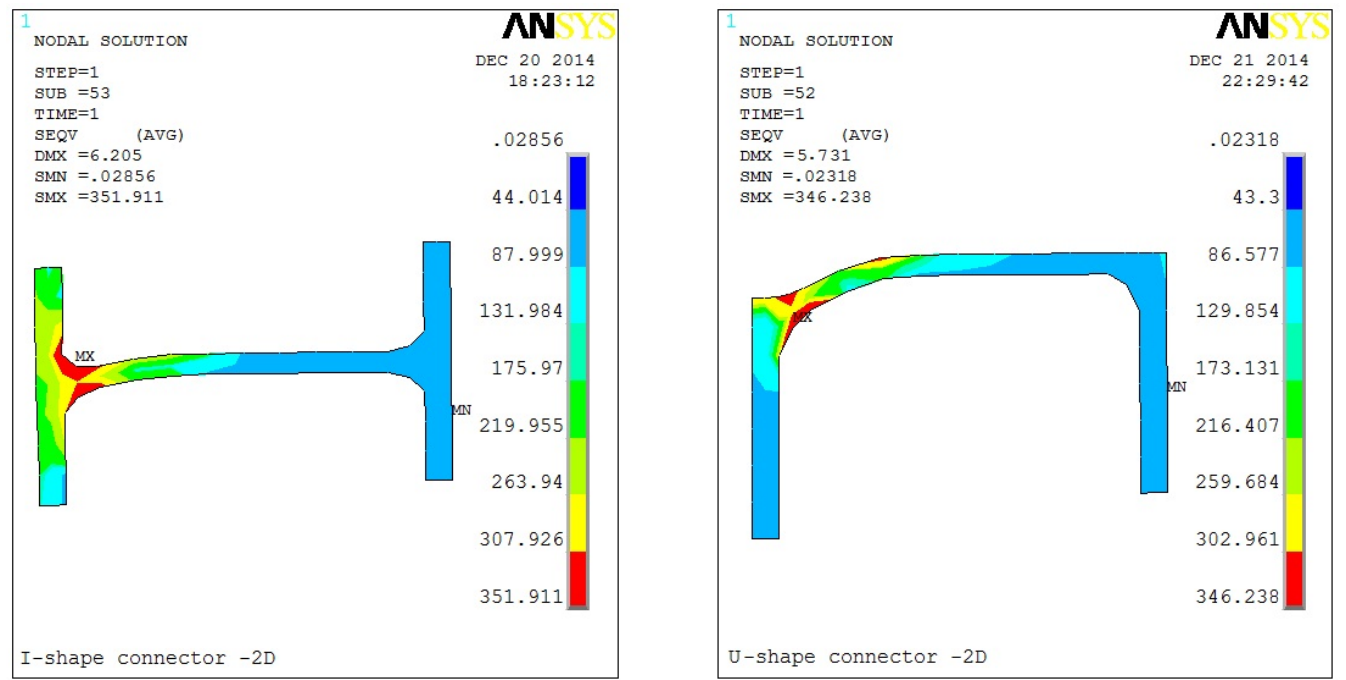

Figure 18. Stress Contour and Deformed Shape of the Two Types of Shear Connectors

The mode of failure by crushing of the concrete was also confirmed numerically for the two types of shear connectors. As shown in Figure 19, a concentration of the maximum stresses was observed in the concrete at the frontal area of the connector for the two types of shear connectors.
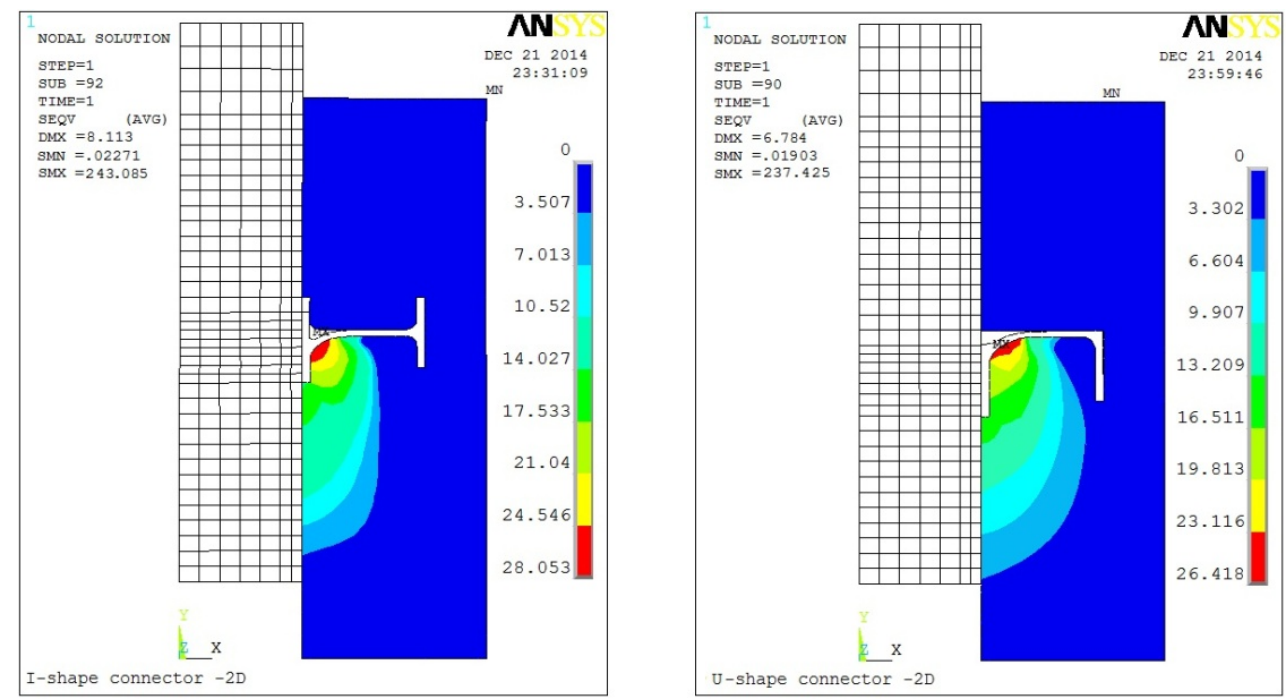

Figure 19. Stress Contour in the Concrete for the Two Types of Shear Connectors

\section{ESTIMATION OF THE ULTIMATE LOAD CAPACITY OF I-SHAPE CONNECTOR}

As mentioned above, the finite element analysis of the push-out tests on the two types of shear connectors confirms the similarity of their behaviour. Therefore, the ultimate load capacity of the I-shape connector can be estimated with the same formulas that have been developed for the channel connector.

From the literature, Slutter and Driscoll [27] suggested an empirical equation to predict the ultimate load capacity of a channel shear connector embedded in a solid concrete slab. This expression was later modified to be able to use it with light-weight concrete, and presented in the American Institute of Steel Construction specification [28] in the following form: 
$P_{u}=0.3\left(t_{f}+0.5 t_{w}\right) L_{c} \sqrt{f_{c k} E_{c m}}$

where $P_{u}$ is the ultimate load capacity of a channel shear connector $(\mathrm{N}), t_{f}$ is the flange thickness of channel shear connector $(\mathrm{mm}), t_{w}$ is the web thickness of channel shear connector $(\mathrm{mm}), L_{c}$ is length of channel shear connector $(\mathrm{mm}), f_{c k}$ is the compressive strength of concrete (MPa), and $E_{c m}$ is the modulus of elasticity of concrete (MPa).

The current Canadian standard CAN/CSA-S16-01 [29] also suggests a similar equation to predict the ultimate load capacity of channel shear connectors:

$$
P_{u}=36.5\left(t_{f}+0.5 t_{w}\right) L_{c} \sqrt{f_{c k}}
$$

Pashan and Hosain [30] concluded that the CSA equation is too conservative. By including channel height $H_{c}$ as a parameter, they developed the following empirical equation to evaluate the load capacity of channels having a height of $100 \mathrm{~mm}$ :

$$
P_{u}=\left(336 t_{w}^{2}+5.24 L_{c} H_{c}\right) \sqrt{f_{c k}}
$$

Considering the similarity of the behaviour between the two types of shear connectors, a comparison between the ultimate load values obtained from the push-out tests and those predicted by the above equations are listed in Table 5. It appears that the ultimate load capacity predicted by Eq. 2 is closer to the experimental results compared with the results obtained from Eqs. 1 and 3. The average arithmetic mean $(\mu)$ of the ratio of test to predicted values, the standard deviation $(\sigma)$, and the coefficient of variation $(v)$ for Eq. 2 are 1.003, 0.030, and 2.972\%, respectively. However, this equation was found to overestimate the ultimate load capacity when the mode of failure is shearing of connector. Therefore, another formula for ultimate load capacity of I-shape shear connector at this failure mode is necessary. Then, the final form of the adopted equation is:

$$
P_{u}=36.5\left(t_{f}+0.5 t_{w}\right) L_{I} \sqrt{f_{c k}} \leq A_{s c} f_{u}
$$

where $P_{u}$ is the predicted ultimate load of the I-shape connector $(\mathrm{N}) ; t_{f}$ is the flange thickness of the I-shape connector $(\mathrm{mm}) ; t_{w}$ is the web thickness of the I-shape connector $(\mathrm{mm}) ; L_{I}$ is the length of the I-shape connector $(\mathrm{mm}) ; f_{c k}$ is the compressive cylinder strength of concrete (MPa) ; $A_{s c}$ is the shear area of I-shape connector $\left(\mathrm{mm}^{2}\right), A_{s c}=t_{w} \cdot L_{I} ; f_{u}$ is the ultimate tensile strength of the I-shape connector steel.

The first equation refers to the concrete crushing failure, and the second corresponded to the

\begin{tabular}{|c|c|c|c|c|c|c|c|c|}
\hline \multirow{2}{*}{$\begin{array}{c}\text { Specimen } \\
\mathrm{N}^{\circ}\end{array}$} & \multicolumn{5}{|c|}{ Ultimate load per I-shape shear connector $(\mathrm{kN})$} & \multirow{2}{*}{$\frac{\text { Test }}{\text { Eq.(1) }}$} & \multirow{2}{*}{$\frac{\text { Test }}{\text { Eq.(2) }}$} & \multirow{2}{*}{$\frac{\text { Test }}{\text { Eq.(3) }}$} \\
\hline & Test & Avg. & Eq. (1) & Eq. (2) & Eq. (3) & & & \\
\hline A1-a & 70.00 & \multirow{2}{*}{70.00} & \multirow{2}{*}{97.40} & \multirow{2}{*}{69.73} & \multirow{2}{*}{134.55} & \multirow{2}{*}{0.72} & \multirow{2}{*}{1.00} & \multirow{2}{*}{0.52} \\
\hline A1-b & 70.00 & & & & & & & \\
\hline A2-a & 80.00 & \multirow{2}{*}{78.75} & \multirow{2}{*}{106.32} & \multirow{2}{*}{76.11} & \multirow{2}{*}{166.32} & \multirow{2}{*}{0.74} & \multirow{2}{*}{1.03} & \multirow{2}{*}{0.47} \\
\hline A2-b & 77.50 & & & & & & & \\
\hline A3-a & 82.50 & \multirow{2}{*}{83.75} & \multirow{2}{*}{116.61} & \multirow{2}{*}{83.48} & \multirow{2}{*}{198.36} & \multirow{2}{*}{0.72} & \multirow{2}{*}{1.00} & \multirow{2}{*}{0.42} \\
\hline A3-b & 85.00 & & & & & & & \\
\hline B1-a & 52.50 & \multirow{2}{*}{51.25} & \multirow{2}{*}{77.17} & \multirow{2}{*}{53.38} & \multirow{2}{*}{111.34} & \multirow{2}{*}{0.66} & \multirow{2}{*}{0.96} & \multirow{2}{*}{0.46} \\
\hline B1-b & 50.00 & & & & & & & \\
\hline
\end{tabular}
shearing of the connector. The lesser of the two values is used in the design.

Table 5. Comparison of Experimental and Predicted Values for Ultimate Load Capacity 


\begin{tabular}{|c|c|c|c|c|c|c|c|c|}
\hline B2-a & 80.00 & \multirow{2}{*}{80.00} & \multirow{2}{*}{115.75} & \multirow{2}{*}{80.07} & \multirow{2}{*}{154.51} & \multirow{2}{*}{0.69} & \multirow{2}{*}{1.00} & \multirow{2}{*}{0.52} \\
\hline B2-b & 80.00 & & & & & & & \\
\hline B3-a & 107.50 & \multirow{2}{*}{108.75} & \multirow{2}{*}{154.33} & \multirow{2}{*}{106.76} & \multirow{2}{*}{197.69} & \multirow{2}{*}{0.70} & \multirow{2}{*}{1.02} & \multirow{2}{*}{0.55} \\
\hline B3-b & 110.00 & & & & & & & \\
\hline $\mathrm{C} 1-\mathrm{a}$ & 70.00 & \multirow{2}{*}{71.25} & \multirow{2}{*}{100.73} & \multirow{2}{*}{71.64} & \multirow{2}{*}{138.25} & \multirow{2}{*}{0.71} & \multirow{2}{*}{0.99} & \multirow{2}{*}{0.52} \\
\hline C1-b & 72.50 & & & & & & & \\
\hline $\mathrm{C} 2-\mathrm{a}$ & 80.00 & \multirow{2}{*}{80.00} & \multirow{2}{*}{115.09} & \multirow{2}{*}{79.71} & \multirow{2}{*}{153.81} & \multirow{2}{*}{0.70} & \multirow{2}{*}{1.00} & \multirow{2}{*}{0.52} \\
\hline $\mathrm{C} 2-\mathrm{b}$ & 80.00 & & & & & & & \\
\hline C3-a & 82.50 & \multirow{2}{*}{82.50} & \multirow{2}{*}{128.94} & \multirow{2}{*}{87.23} & \multirow{2}{*}{168.32} & \multirow{2}{*}{0.64} & \multirow{2}{*}{0.95} & \multirow{2}{*}{0.49} \\
\hline C3-b & 82.50 & & & & & & & \\
\hline D1-a & 67.50 & 6875 & 9740 & 6973 & 13455 & 071 & 099 & 051 \\
\hline D1-b & 70.00 & 08.15 & 91.40 & & 134.55 & 0.11 & 0.99 & 0.51 \\
\hline D2-a & 72.50 & 7250 & 9740 & 69.73 & 134.55 & 0.74 & 1.04 & 0.54 \\
\hline D2-b & 72.50 & 12.00 & 51.40 & 09.13 & & & & \\
\hline D3-a & 75.00 & 7375 & 0740 & 6973 & 13455 & 076 & 106 & 055 \\
\hline D3-b & 72.50 & 13.15 & 91.40 & 69.15 & 134.55 & 0.10 & 1.06 & 0.55 \\
\hline & Aver & e arithr & ic mean & $(\mu)$ & & 0.708 & 1.003 & 0.506 \\
\hline & Stan & ard devi & & $(\sigma)$ & & 0.032 & $\mathbf{0 . 0 3 0}$ & 0.036 \\
\hline & Coef & cient of & riation & $(v)$ & & $4.548 \%$ & $2.972 \%$ & $7.130 \%$ \\
\hline
\end{tabular}

\section{CONCLUSION}

This paper presented the results of tests performed on 24 push-out specimens to investigate the feasibility of using I-shape pieces as shear connectors. Furthermore, a finite element modelling of the push-out tests was carried out using ANSYS software to investigate the stress distribution pattern in the area of the I-shape shear connector. Moreover, the finite element model was also used to simulate another type of shear connector, called channel connector in order to compare its behaviour with that of the I-shape shear connector. From this comparison, we suggested an equation for the prediction of the ultimate load capacity of the specific shear connector proposed in this research. From this study, the following conclusions are drawn concerning the failure modes, the ductility and the ultimate load capacity:

- The failure modes observed from the push-out tests can be generally classified into two types: Shearing of the connector and Crushing-cracking of the concrete slab. The shearing of the connector was occurred, especially in the specimens with connectors of lower steel grade and smaller length embedded in concrete slabs of higher strength. However, in specimens with I-shape connectors of higher steel grade and concrete slabs of low and moderate strength, failure was caused by cracking and crushing of the concrete surrounding the connector.

- For most push-out tests, the characteristic slip capacity was found greater than $6 \mathrm{~mm}$. Therefore, the I-shape shear connector can be considered as ductile, according to Eurocode 4.

- Concerning the separation of the concrete slabs, the uplift values obtained from the push-out tests, were found to be small and thus were considered to have minimal influence on the behaviour of I-shape shear connectors.

- The comparison between the I-shape connector and the channel connector by the finite element analysis confirms the similarity of their behaviour. Therefore, the Canadian code equation that has been adopted for the channel connectors is capable of predicting the ultimate load capacity of I-shape connectors with reasonable accuracy.

- Finally, the I-shape connectors can be effectively used in composite beams to transfer the longitudinal shear forces across the steel-concrete interface, but further experimental investigations are necessary to study their behaviour in simply supported and continuous composite beams. 


\section{ACKNOWLEDGEMENTS}

The authors would like to thank the Laboratory of Materials and Mechanics of Structures at the University of M'sila, Algeria, where the tests were conducted. The donation of steel beams by the company of BATICIC, Algeria, is gratefully acknowledged.

\section{REFERENCES}

[1] Kim, S.H., Choi, K.T., Park, S.J., Park, S.M. and Jung, C.Y., "Experimental Shear Resistance Evaluation of Y-type Perfobond Rib Shear Connector", J. Constr. Steel Res., 2013, Vol. 82, pp. 1-18.

[2] Yan, J., Liew, J.Y.R., Sohel, K.M.A. and Zhang, M.H., "Push-out Tests on J-hook Connectors in Steel-concrete-steel Sandwich Structure", Materials and Structures, RILEM, 2013, Vol. 47, No. 10, pp. 1693-1714.

[3] Pavlović, M., Marković, Z., Veljković, M. and Buđevac, D., "Bolted Shear Connectors vs. Headed Studs Behaviour in Push-out Tests", J. Construct. Steel Res., 2013, Vol. 88, pp. $134-149$.

[4] Xu, X., Liu, Y. and He, J., "Study on Mechanical Behavior of Rubber-sleeved Studs for Steel and Concrete Composite Structures", Construction and Building Materials, 2014, Vol. 53, pp. 533-546.

[5] Shariati, M., Sulong, N.H.R., Shariati, A. and Khanouki M.M.A., "Behavior of V-shaped Angle Shear Connectors: Experimental and Parametric Study", Materials and Structures, RILEM, First online: 10 December 2015, pp. 1-18.

[6] Shariati, M., Sulong, N.H.R., Suhatril, M., Shariati, A., Khanouki M.M.A. and Sinaei H., "Comparison of Behaviour between Channel and Angle Shear Connectors under Monotonic and Fully Reversed Cyclic Loading", Construction and Building Materials, 2013, Vol. 38, pp. 582 - 593.

[7] Mazoz, A., Benanane, A. and Titoum, M., "Push-out Tests on a New Shear Connector of I-shape”, Int. J. Steel Struct., 2013, Vol. 13, No. 3, pp. 519-528.

[8] Swanson Analysis Systems Inc., “ANSYS, Version 12.0 and User's Manual”, Canonsburg, Pennsylvania, 2009.

[9] EN 1994-1-1, Eurocode 4: "Design of Composite Steel and Concrete Structures - Part 1-1: General Rules and Rules for Buildings", Brussels, European Committee for Standardization, 2005.

[10] BS 5400, Steel, Concrete and Composite Bridges, Part-5: Code of Practice for Design of Composite Bridges, British Standard Institution, London, 1979.

[11] Malite, M., "Analysis of the Structural Behaviour of Steel-concrete Composite Beams Using Cold-formed Shapes", Ph.D. Thesis (text in Portuguese), University of Sao Paulo, Sao Carlos, 1993.

[12] Maleki, S. and Mahoutian, M., "Experimental and Analytical Study on Channel Shear Connectors in Fiber-reinforced Concrete", J. Construct. Steel Res., 2009, Vol. 65, pp. 1787-1793.

[13] Shariati, M., Sulong, N.H.R. and Arabnejad, M.M., "Experimental Assessment of Channel Shear Connectors under Monotonic and Fully Reversed Cyclic Loading in High Strength Concrete", Materials and Design, 2012, Vol. 34, pp. 325 - 331.

[14] Prakash, A., Anandavalli, N., Madheswaran, C.K. and Lakshmanan, N., "Modified Push-out Tests for Determining Shear Strength and Stiffness of HSS Stud Connector - Experimental Study", International Journal of Composite Materials, 2012, Vol. 2, No. 3, pp. 22-31.

[15] Han, Q., Wang, Y., Xu, J. and Xing, Y., "Static Behavior of Stud Shear Connectors in Elastic Concrete-steel Composite Beams”, J. Constr. Steel Res., 2015, Vol. 113, pp. 115-126. 
[16] Veldanda, M.R. and Hosain, M.U., "Behaviour of Perfobond Rib Shear Connectors: Push-out tests", Can. J. Civ. Eng., 1992, Vol. 19, pp. 1 - 10.

[17] Studnicka, J., Machacek, J., Krpata, A. and Svitakova, M., "Perforated Shear Connector for Composite Steel and Concrete Beams", Proceedings of the Conference Composite Construction in Steel and Concrete IV, Banff, Alberta, Canada, 2000, pp. 367 - 378.

[18] Medberry, S.B. and Shahrooz, B.M., "Perfobond Shear Connector for Composite Construction", AISC Engineering Journal, 2002, Vol. 1, pp. 2-12.

[19] Veríssimo, G.S., "Development of An Indented Steel Rib Shear Connector for Composite Steel-concrete Structures and Study of Its Structural Behaviour", PhD Thesis (Text in Portuguese), Belo Horizonte, Federal University of Minas Gerais, 2007.

[20] Vianna, J.C., Costa-Neves, L.F., Vellasco. P.C.G.S. and Andrade, S.A.L., "Experimental Assessment of Perfobond and T-perfobond Shear Connectors', Structural Response", J. Construct. Steel Res., 2009, Vol. 65, No. 2, pp. 408 - 421.

[21] Baran, E. and Topkaya, C., "An Experimental Study on Channel Type Shear Connectors", J. Constr. Steel Res., 2012, Vol. 74, pp. 108 - 117.

[22] EN 1992-1-1, Eurocode 2: "Design of Concrete Structures - Part 1-1: General Rules and Rules for Buildings", Brussels, European Committee for Standardization, 2005.

[23] American Society for Testing and Materials - ASTM: E8 -69, "Standard Methods of Tension Testing of Metallic Materials", Annual Book of Standards, Washington, 2008.

[24] Kim, B., Wright, H.D. and Cairns, R., "The Behaviour of Through-deck Welded Shear Connectors: An Experimental and Numerical Study”, J. Construct. Steel Res., 2001, Vol. 57, pp. $1359-1380$.

[25] Wang, A.J., "Advanced Finite Element Investigation into Structural Behaviour of Composite Beams”, Ph.D. Thesis, The Hong Kong Polytechnic University, 2007.

[26] Guezouli, S. and Lachal, A., "Numerical Analysis of Frictional Contact Effects in Push-out Tests", Engineering Structures, 2012, Vol. 40, pp. 39 - 50.

[27] Slutter, R.G. and Driscoll, G.C., "Flexural Strength of Steel-concrete Composite Beams", Journal of Structural Division, ASCE, 1965, Vol. 91(ST2), pp. 71 - 99.

[28] American Institute of Steel Construction, AISC-360-05: "Specification for Structural Steel Buildings", Chicago, 2005.

[29] Canadian Standards Association, CSA-S16-01: "Limit States Design of Steel Structures", Toronto, Ontario, Canada, 2001.

[30] Pashan, A. and Hosain M.U., "New Design Equations for Channel Shear Connectors in Composite Beams”, Can. J. Civil Eng., 2009, Vol. 36, pp. 1435 - 43. 


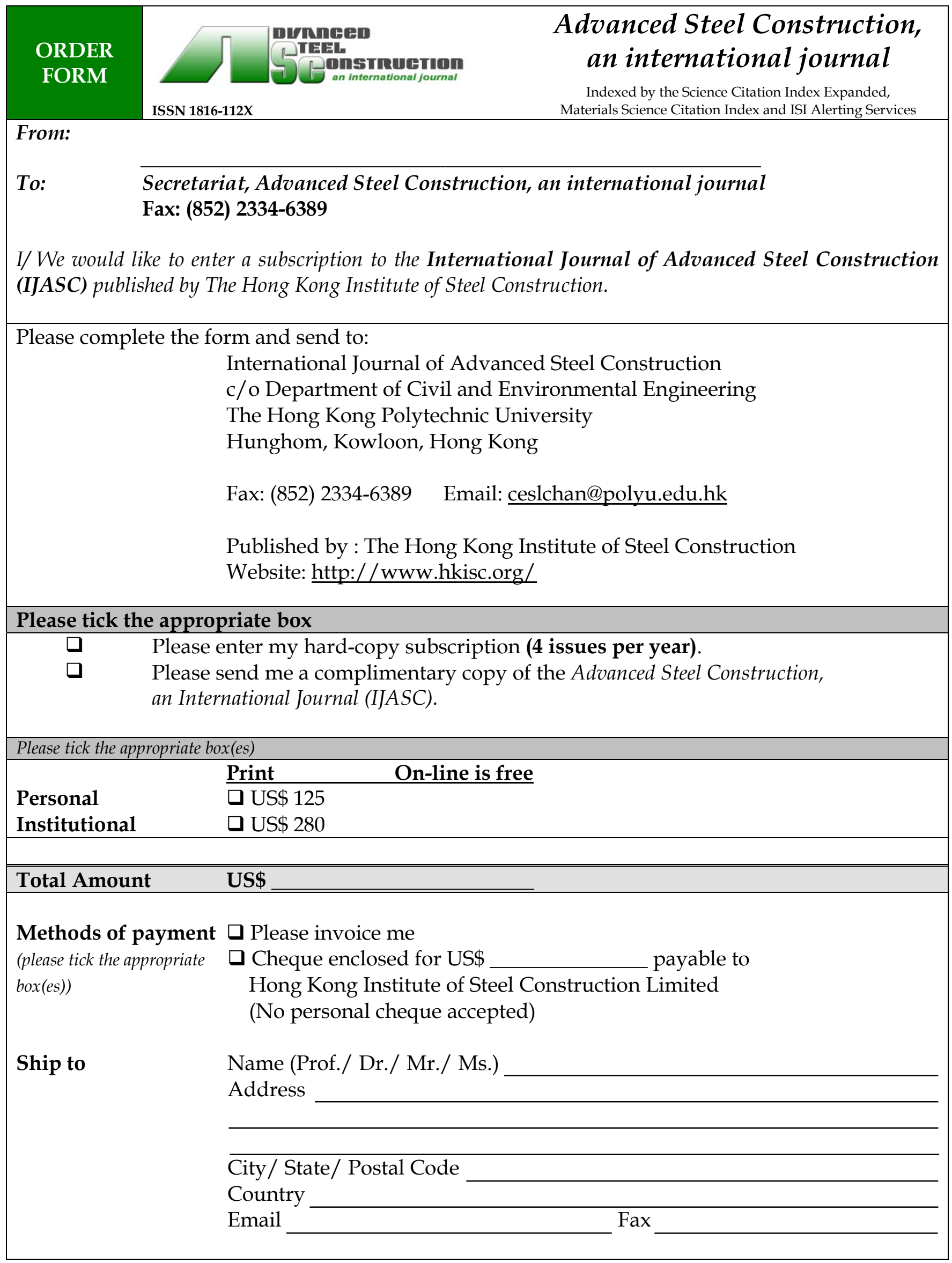

